Final Report

FHWA/IN/JTRP-2004/15

\title{
CONSTRUCTABILITY, MAINTAINABILITY, AND OPERABILITY OF FIBER REINFORCED POL YMER (FRP) BRIDGE DECK PANELS
}

\author{
By \\ Makarand (Mark) Hastak, Ph.D., CCE \\ Assistant Professor \\ Daniel W. Halpin, Ph. D. \\ Professor \\ TaeHoon Hong \\ Graduate Research Assistant \\ School of Civil Engineering \\ Purdue University \\ Joint Transportation Research Program \\ Project No. C-36-56NNN \\ File No. 7-4-65 \\ SPR-2778 \\ In Cooperation with the \\ Indiana Department of Transportation \\ and the \\ U.S Department of Transportation \\ Federal Highway Administration
}

The contents of this report reflect the views of the authors who are responsible for the facts and the accuracy of the data represented herein. The contents do not necessarily reflect the official views or policies of the Federal Highway Administration and the Indiana Department of Transportation. The report does not constitute a standard, specification or regulation.

Purdue University

West Lafayette, Indiana 47907

November 2004 


\section{TECHNICAL Summary}

INDOT Research

Technology Transfer and Project Implementation Information

TRB Subject Code: 25-1 Bridges

Publication No.: FHWA/IN/JTRP-2004/15, SPR-2778

November 2004

Final Report

\section{Constructability, Maintainability, and Operability of Fiber-Reinforced Polymer (FRP ) Bridge Deck Panels}

\section{Introduction}

Recent advances in composite materials for civil engineering have created interesting possibilities for replacing conventional structural forms with components made out of fiber reinforced composite materials. Composite materials offer several advantages over conventional materials such as a superior strength/weight ratio, a better stiffness/weight ratio, a high degree of chemical inertness, and flexible custom design characteristics. In a recent article in the Engineering News Record, James Roberts of the California Department of Transportation was quoted as follows: "Quick-setting concrete, nighttime work, composite materials for both decks and whole structures, and large incentives for contractors will be tools for faster construction..." (ENR, June 11, 2001).

Some of the potential down-stream benefits include lower life-cycle costs, lighter members, high corrosion and fatigue resistance, and higher live load capacity (Seible and Karbhari 1996). The mass production capabilities of composite members offer possibilities for schedule compression, productivity and quality improvement, savings in labor and material costs, enhanced durability, and performance reliability (Mirmiran 1995, Kelly 1989, Gall 1986). Weight reduction and modular properties of composite members also lend to improved transportability, ease of installation, and less need for heavy equipment. Although initial investment for the production of composite members may be higher than conventional materials, it is likely to fall as the demand for composites increases (Goldstein 1996, Partridge 1989).

Composite materials are clearly having a major impact on how facilities are designed, constructed, and maintained. In order to enhance the application of fiber-reinforced composites in infrastructure renewal, it will be important to understand the constructability, maintainability and operability issues related to the use of Fiber Reinforced Polymer (FRP) structural components. This research report evaluates the constructability, maintainability and operability issues related to FRP bridge decks as compared to conventional deck construction.

Comprehensive literature review was conducted to understand FRP composite materials for bridge application, composite manufacturing processes, composite manufacturers, installation procedure of FRP bridge deck panels, etc.

Questionnaire survey-I was used to identify data on (i) standard techniques and material for FRP deck construction, (ii) man-hour requirement, cost, duration, productivity required for individual projects as well as any barriers encountered in installing FRP decks and (iii) constructability, operability, and maintainability of FRP decks. Questionnaire-II assisted research team in collecting information from the manufacturers with respect to the constructability, maintainability, operability, and life cycle cost issues related to their products and the manufacturing process.

In addition to the questionnaires, five case studies were conducted for candidate projects in Ohio that have used FRP bridge deck panels. Also, construction simulation study was performed to determine the productivity, manhour requirement and system bottlenecks that were important for understanding the construction process in both FRP bridge deck panels and Conventional bridge deck panels. The detailed data required for the simulation study were collected through questionnaire-III and interviews. 


\section{Findings}

In terms of challenges and technical issues in the application of FRP bridge deck panels, more efficient manufacturing and effective production methods should be explored and developed to enhance their application in civil infrastructure.

Constructability issues of FRP bridge deck panels:

(a) Based on results of questionnaire survey-I sent to bridge engineers of each State DOT, concrete cast-in-place and wood or timber were ranked as the deck structure types that have been frequently replaced by FRP bridge deck panels. Most manufacturers have developed their own technology to provide the connection between decks and between deck and girder. Until now, the FRP bridge deck panels produced by Martin Marietta Composites, called DuraSpan ${ }^{T M}$, have been ranked as the most popular product. The products of Hardcore Composites, Kansas Structural Composites, and Creative Pultrusion have been used by several State DOTs. Bridge engineers indicated that Bituminous and Polymer concrete are the most preferred materials. Latex Modified Concrete was the least preferred by the State DOTs. Pultrusion has been ranked as the most used manufacturing process. Hand Layup and Vacuum Assisted Resin Transfer Modeling (VARTM) processes are also used by many manufacturers. Five respondents indicated construction and design barriers encountered while installing FRP bridge deck panels whereas, three indicated vendor as the barrier and one of them mentioned labor barriers. Usually, flat bed trucks were used to delivery the FRP panels from factory to the job site and their maximum deliverable sizes were variable depending on project requirements. It took usually a few days to deliver the panels.

(b) Questionnaire survey-I was also sent to county engineers of candidate projects identified in this research. Based on their responses, mostly concrete cast-in-place decks have been replaced by FRP decks. Only one of the candidate projects' deck structure type was wood or timber. Three out of five candidate projects used Hardcore composites' product using VARTM manufacturing process whereas, the remaining two candidate projects utilized Martine Marietta Composites' product (DuraSpan ${ }^{T M}$ ). Bituminous has been ranked as the most important wearing surface material. Only one candidate project employed polymer modified asphalt. In terms of the method for guardrail installation, most of the respondents preferred the 'Guardrail attached to the deck'. Design barriers encountered in installing FRP decks were the most important problem.

Operability and Maintainability of FRP bridge deck panels:

(a) The results of questionnaire survey-I that was sent to bridge engineers of each State DOT indicated that in terms of maintainability issues, deteriorated conventional bridge decks have been mostly replaced by FRP bridge deck panels when their condition rating reached 4 whereas condition rating 6 or 7 for bridge substructure. The durability of wearing surface particularly delamination has been indicated as the highest maintenance problem. Most respondents expected 75 years as service life of FRP bridge deck panels while they mentioned $25-50$ years as average service life of a concrete bridge deck.

(b) The results of questionnaire survey-I sent to county engineers of candidate projects indicated that in terms of condition rating of existing bridge structures, deteriorated conventional bridge decks have been replaced by FRP bridge deck panels when the condition rating for decks reached 2 to 4 and that for a bridge substructure reached 7 . Two counties have not established a specific analysis procedure or method to inspect, maintain and repair the FRP bridge deck panels. One county has performed visual inspection three to four times per year. The county engineer for this county indicated that any repairs to the panels would be undertaken based on discussion with the manufacture. Another county has performed visual inspection only once every year. Three counties did not have any plan to monitor the service of FRP bridge deck panels. One of the counties has performed tap test once every year. Clark county engineers indicated that there were no problems with regard to maintenance and operation after FRP bridge deck panels were installed. However, fire damage was found on the bottom of panels in 
this county as a probable cause of vandalism. The maintenance problems commonly generated in other counties were delamination, debonding, and cracking of wearing surface and some minor gaps between the bottom of FRP deck and the concrete beams.

Future research direction:

(i) Innovative modular systems to reduce high initial cost. If the material cost of FRP bridges will not decrease, their application may be limited to bridges of low volume rural types

(ii) Research on failure of the wearing surface (iii) Integration of FRP bridge design, i.e., efficient design and characterization of panel-to-panel joints and attachment of deck-togirder is required

(iv) Development of design standards and guidelines

(v) Benefit-Cost analysis for economical engineering

(vi) Develop an analytical model to predict the FRP bridge deterioration over time.

(vii) Develop an analytical model to assess life cycle cost of FRP bridge deck panels.

\section{Implementation}

This research provides construction guidelines for FRP bridge deck panels that could be effectively used by INDOT. These guidelines identify (i) construction sequence, (ii) constructability issues, (iii) maintainability issues, (iv) operability issues, and (v) construction cost issues. Also this research provides information on the state of the art and manufacturing processes currently in use.
The productivity, man-hour requirement, and system bottlenecks for FRP bridge deck construction are determined by construction simulation study. The results obtained from this study could be used by INDOT to improve the productivity of FRP bridge deck construction in the future.

\section{Contacts}

For more information:

Prof. Makarand (Mark) Hastak
Principal Investigator
School of Civil Engineering
Purdue University
West Lafayette IN 47907
Phone: (765) 494-0641
Fax: (765) 494-0644
E-mail: hastak@ecn.purdue.edu

\author{
Indiana Department of Transportation \\ Division of Research \\ 1205 Montgomery Street \\ P.O. Box 2279 \\ West Lafayette, IN 47906 \\ Phone: (765) 463-1521 \\ Fax: (765) 497-1665
}

\section{Purdue University}

Joint Transportation Research Program

School of Civil Engineering

West Lafayette, IN 47907-1284

Phone: (765) 494-9310

Fax: (765) 496-7996

E-mail: jtrp@ecn.purdue.edu

http://www.purdue.edu/jtrp 


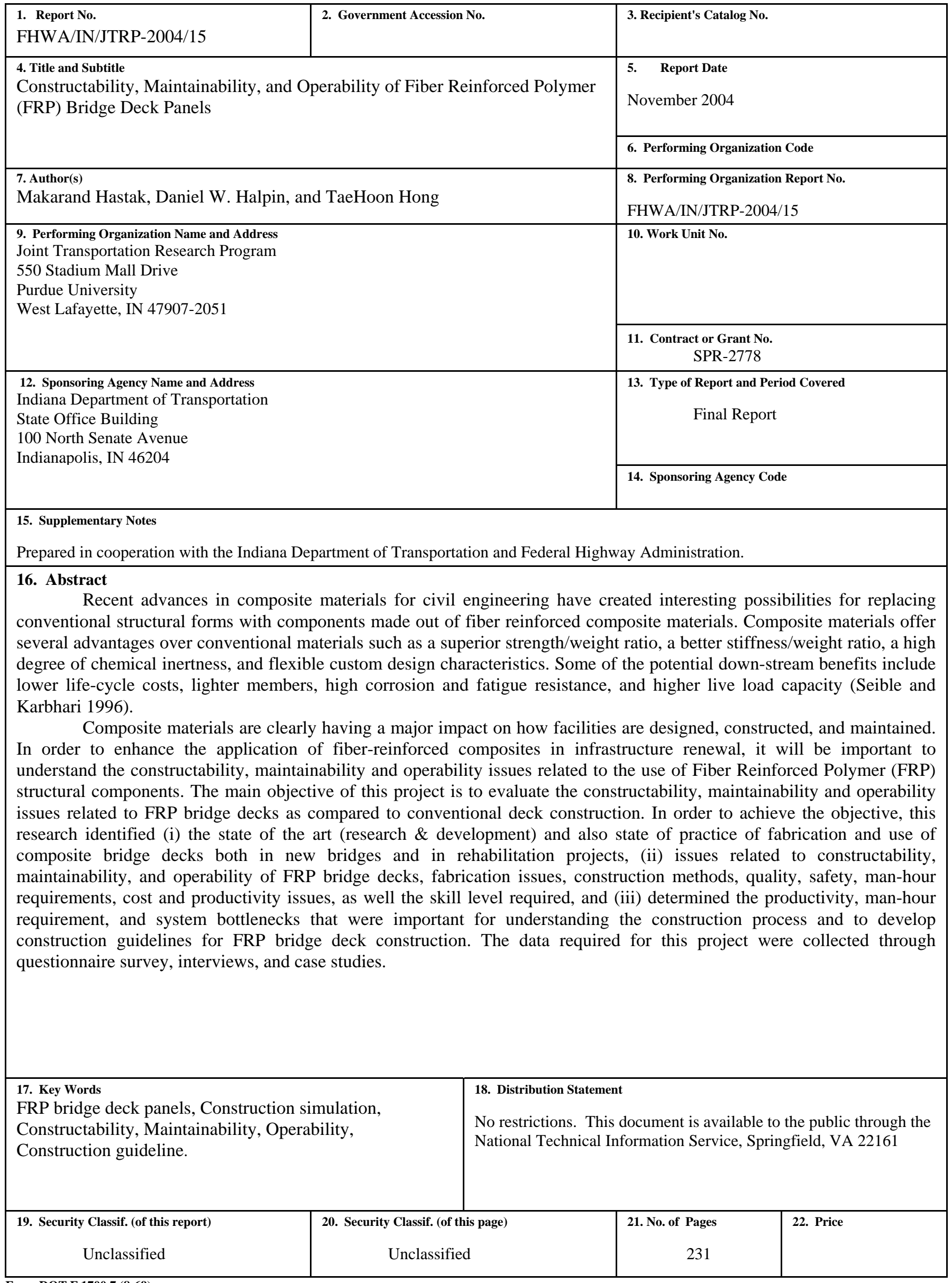




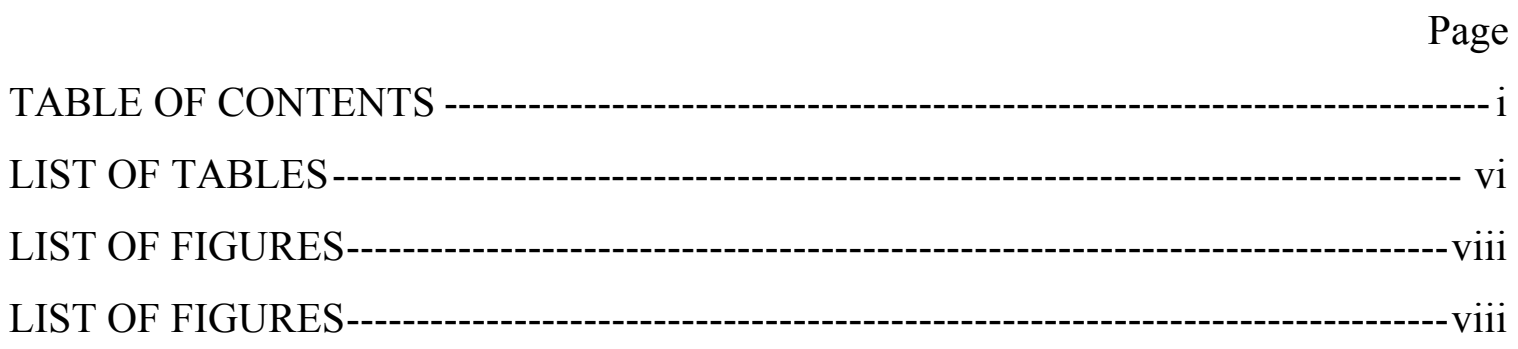

CHAPTER 1: INTRODUCTION---- 1

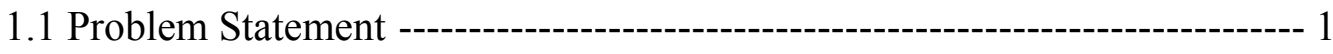

1.2 Objective and Scope of Research---------------------------------------------- 2

1.3 Research Framework and Methodology ---------------------------------- 3

1.3.1 Task-1: Literature Review--------------------------------------- 3

1.3.2 Task-2: Preliminary Data Collection -------------------------------------- 4

1.3.3 Task-3: Identification of Candidate Projects---------------------------- 5

1.3.4 Task-4: Detailed Data Collection, Analysis, and Process Modeling---- 5

1.3.5 Task-5: Development of Construction guideline------------------------- 6

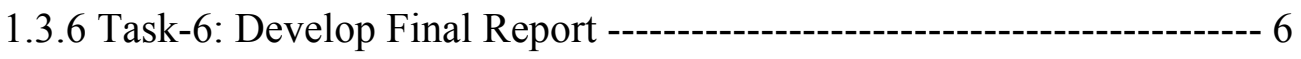

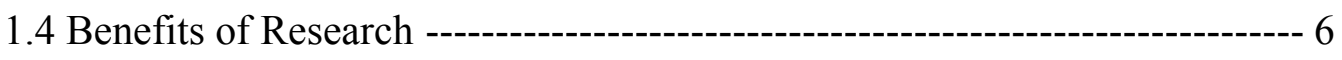

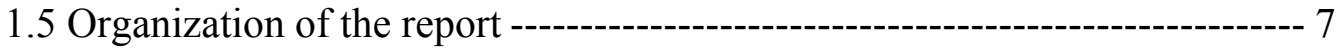

CHAPTER 2: Literature Review--- 9

2.1 FRP composite materials for bridge applications ---------------------- 9

2.2 Advantage and Disadvantage of FRP Composite Materials ---------------- 10

2.2.1 Advantage ------------------------------------------------------------10

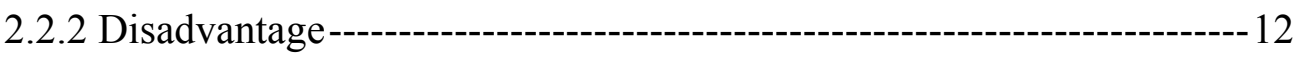

2.3 Composites Manufacturing Processes --------------------------------- 13

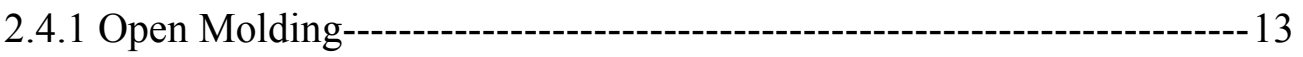

2.4.2 Closed Molding-------------------------------------------------------------16

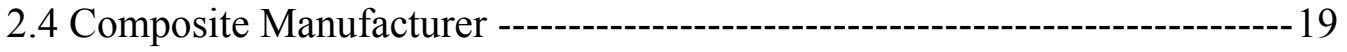


2.4.1 Creative Pultrusions, Inc.------------------------------------------19

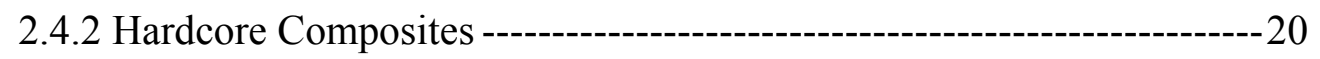

2.4.3 Kansas Structural Composites, Inc. ---

2.4.4 Strongwell ---------------------------------------------------------22

2.4.5 Martin Marietta Composites --------------------------------------23

2.5 Previous analytical and experimental works on FRP bridge deck panels --25

2.6 Installation procedure of FRP bridge deck panels by manufacturers --------26

2.5.1 HCI (Hardcore Composites Inc.) --------------------------------27

2.5.2 MMC (Martin Marietta Composites) ---------------------------------30

2.5.3 CPI (Creative Pultrusion Inc.) -----_---31

2.5.4 KSCI (Kansas Structural Composites Inc.) ---------------------------34

2.6 Challenges and Technical Issues in their application ---------------------36

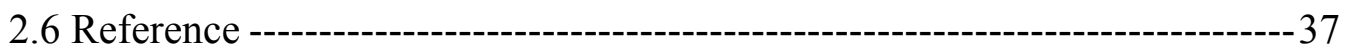

CHAPTER 3: PRELIMINARY DATA COLLECTION AND DATA ANALYSIS

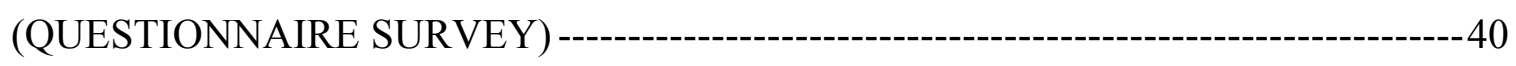

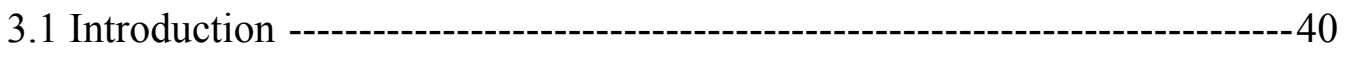

3.2 Questionnaire Survey ---

3.1.1 General information of FRP bridge deck panels --------------------41

3.1.1.1 Reasons for not using FRP bridge deck panels to date---------------46

3.1.1.2 The schedule for future application-------------------------48

3.1.1.3 Advantages of FRP bridge deck panels ---------------------------49

3.1.1.4 The Application of FRP bridge deck panels --------------------50

3.1.2 Construability issues of FRP bridge deck panels-----------------------51

3.1.2.1 Deck structure types replaced -----------------------------------52

3.1.2.2 Construction sequence/method for connection--------------------53

3.1.2.3 Wearing surface ------------------------------------------59

3.1.2.4 Specific installation method ---------------------------------60

3.1.2.5 Manufacturing processes --------------------------------------------60 
3.1.2.6 FRP bridge deck cross-section types --------------------------62

3.1.2.7 Construction specifications --------------------------------65

3.1.2.8 Detailed information on completed projects---------------------66

3.1.2.9 Barriers encountered in installing FRP bride deck panels ----------71

3.1.2.10 Delivery issues ----------------------------------------------- 73

3.1.3 Maintainability and Operability issues of FRP bridge deck panels -------74

3.1.4. Construction cost of FRP bridge deck panels ------------------------- 77

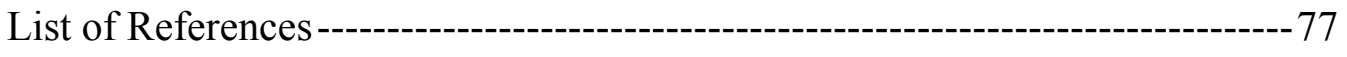

CHAPTER 4: PRELIMINARY DATA COLLECTION AND DATA ANALYSIS------ 79

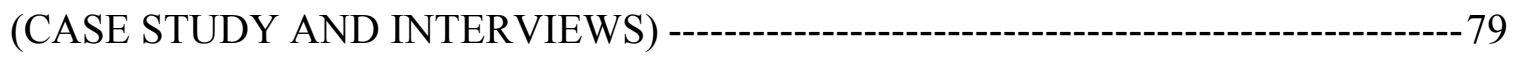

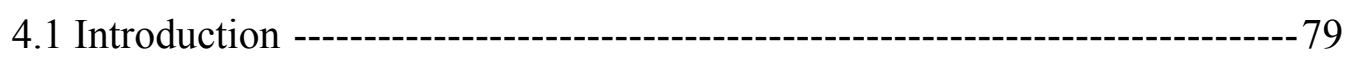

4.2. Project 100 in Ohio ------o- 80

4.2.1 Project 100 --- 80

4.2.2 Composites for Infrastructure (C4I) Initiative -------------------------- 83

4.3 Case Studies about FRP bridge deck construction -------------------------84

4.3.1 General Information and Interview Results ----------------------------- 85

4.3.2 Clark County, $\mathrm{OH}$----_-

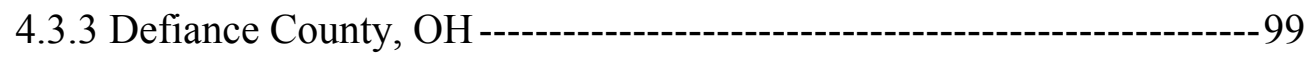

4.3.4 Greene County, $\mathrm{OH}$------------------------------------------------- 102

4.3.5 Hamilton County, OH ------------------------------------------ 106

4.4 Result analysis of questionnaire survey ----------------------------- 111

4.5. Manufacturer for FRP bridge deck panels --------------------------- 118

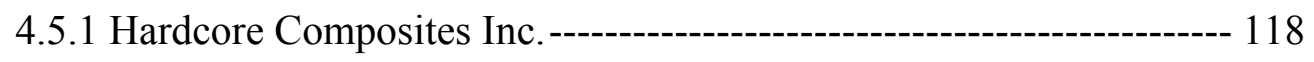

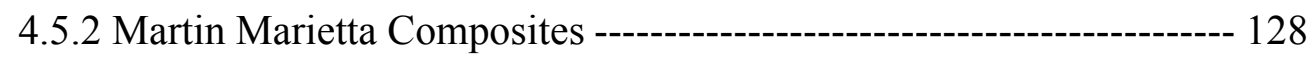

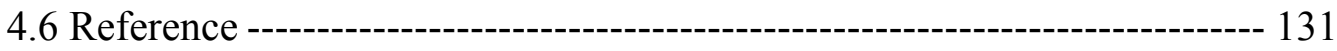

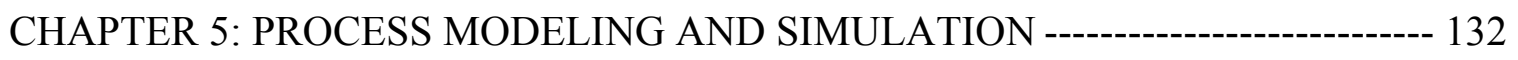

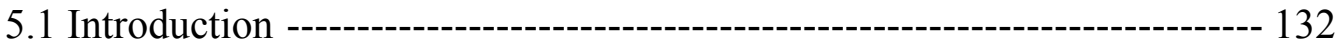




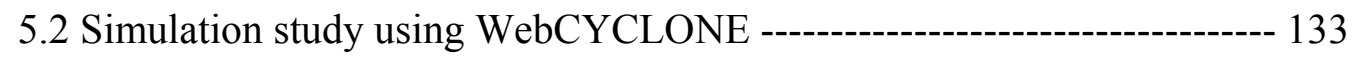

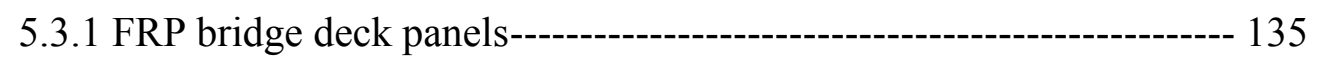

5.3.2 Precast prestressed concrete deck panels -------------------------------- 145

5.4 Data collection --------------------------------------------------------------------- 148

5.4.1 Data for simulation of FRP bridge deck panel construction ----------- 148

5.4.2 Data for simulation of Precast Concrete Panels ------------------------ 150

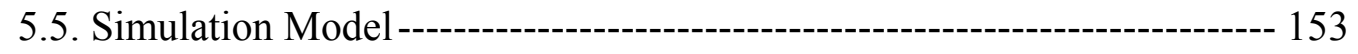

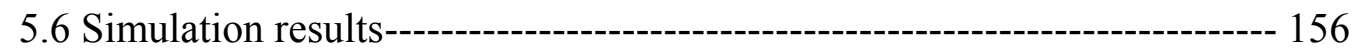

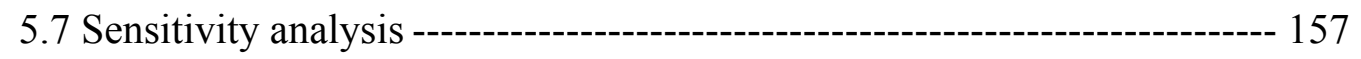

5.7.1 FRP bridge deck panels----------------------------------------------------- 157

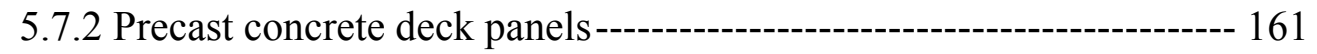

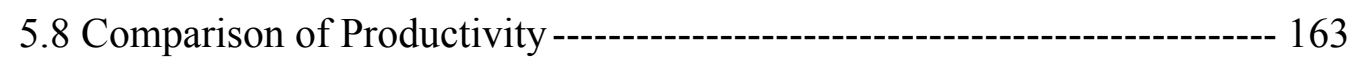

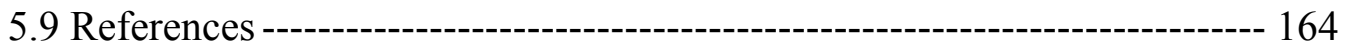

CHAPTER 6 Conclusion and Construction Guidelines-------------------------------------- 165

6.1 Summary of research------------------------------------------------------------- 165

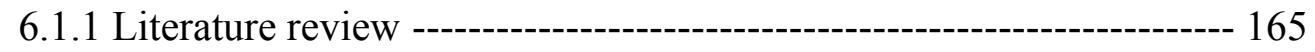

6.1.2 Preliminary Data Collection and Identification of Candidate Projects 166

6.1.3 Detailed Data Collection, Analysis and Process modeling ----------- 171

6.2 Research Conclusions ----------------------------------------------------------- 172

6.2.1 Constructability of FRP bridge deck panels ---------------------------- 172

6.2.2 Operability and Maintainability of FRP bridge deck panels---------- 174

6.3 Construction guidelines for FRP bridge deck panels ----------------------- 175

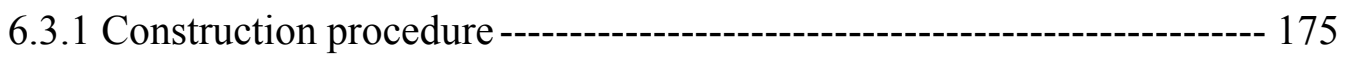

6.3.2 Installation methods-------------------------------------------------------- 176

6.3.2.1 Connection of deck panels ---------------------------------------- 177

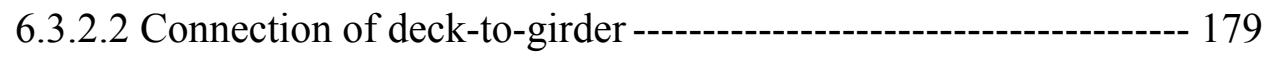

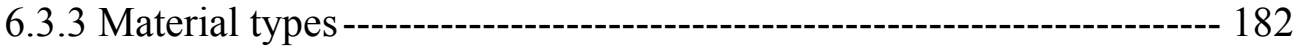


Page

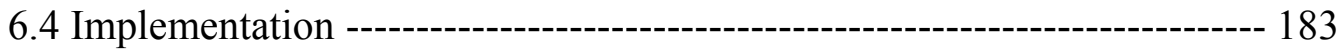

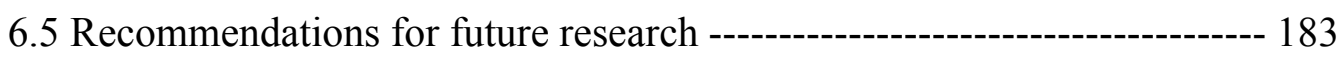

Appendix

Appendix A: Questionnaire Survey-I------------------------------------------- 185

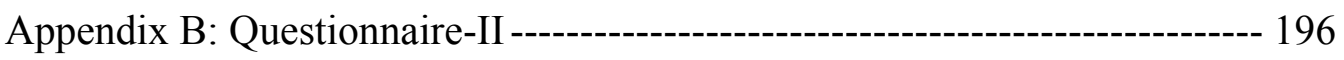

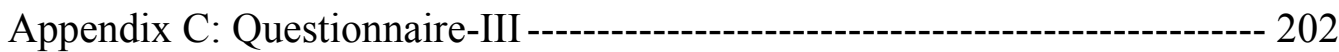

Appendix D: Hardcore Composites Bridge Inspection and Repair Manual-- 207

Appendix E: Input Files for FRP Bridge Deck Panels ----------------------- 210

Appendix F: Input Files for Precast Concrete Deck Panels ------------------ 212

Appendix G: Simulation Results based on varied resources in Precast Concrete

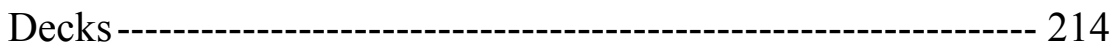

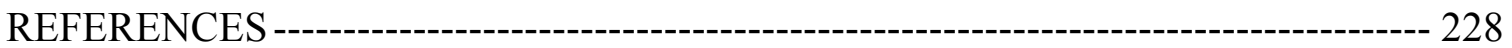




\section{LIST OF TABLES}

Page

Table 2-1 Typical Advantages of FRP Bridge Deck (O'Connor 2003) ............................. 11

Table 2-2 Typical Disadvantages of FRP Bridge Deck (O’Connor 2003) ...................... 12

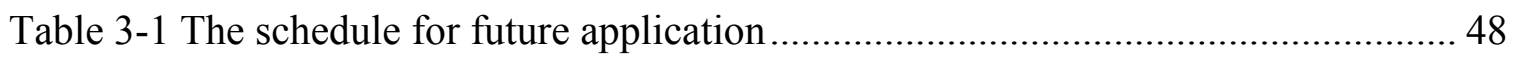

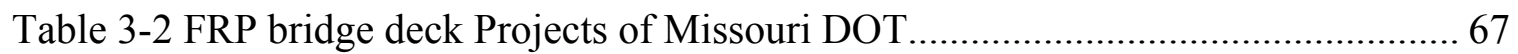

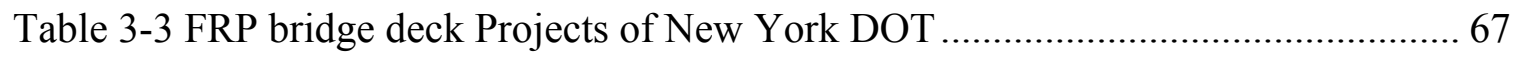

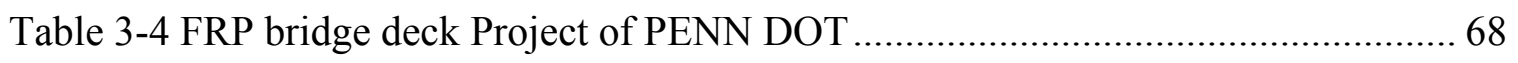

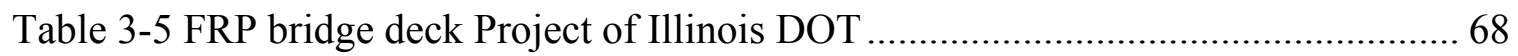

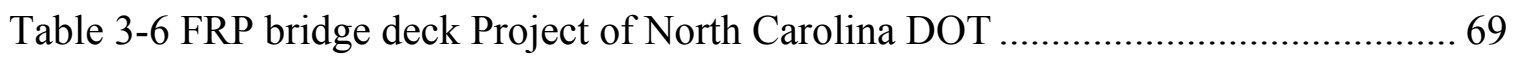

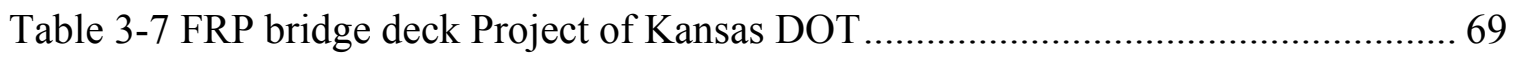

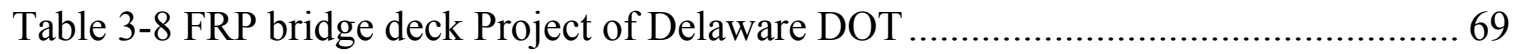

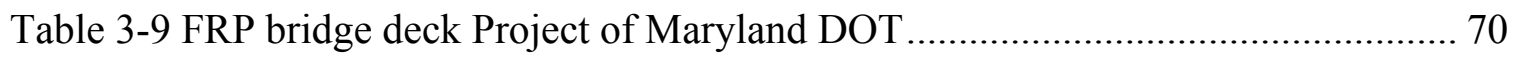

Table 3-10 FRP bridge deck Project of Oregon DOT ….......................................... 70

Table 3-11 Expected service life of Concrete versus FRP bridge deck panels ............... 76

Table 5-1 Basic modeling elements of the CYCLONE ............................................ 134

Table 5-2 Duration input data of FRP bridge deck panels......................................... 149

Table 5-3 Resource input data of FRP bridge deck panels (Labors and equipment) ..... 149

Table 5-4 Equipment costs of FRP bridge deck panels' construction .......................... 150

Table 5-5 Duration input data of Precast concrete deck panels .................................. 151

Table 5-6 Resource input data of Precast concrete deck panels (Labors and equipment)

Table 5-7 Equipment costs of Precast concrete deck panels ..................................... 152

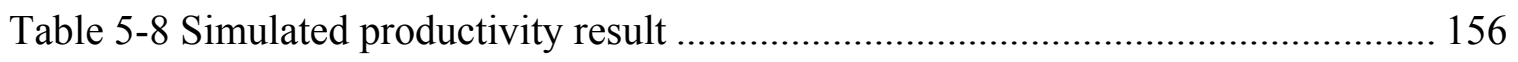

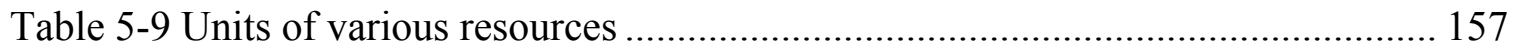

Table 5-10 Simulation results based on varied resources in FRP bridge deck panels.... 159

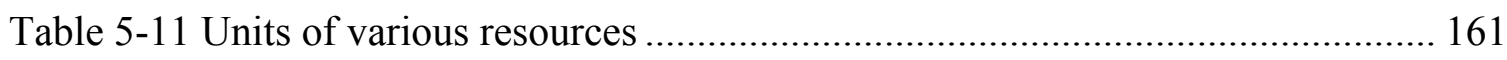

Table 5-12 Comparison of productivity in both systems......................................... 163 


\section{LIST OF FIGURES}

Page

Figure 3-1 Number of DOTs responding to the questionnaire survey.......................... 41

Figure 3-2 DOT currently using or not using FRP bridge deck panels ........................ 42

Figure 3-3 Advantage of FRP bridge deck panels ................................................. 50

Figure 3-4 Road type of application for FRP bridge deck panels................................ 51

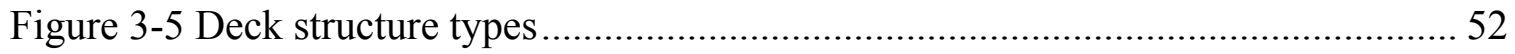

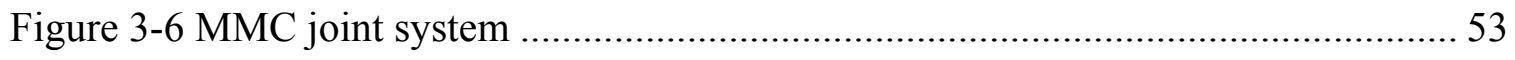

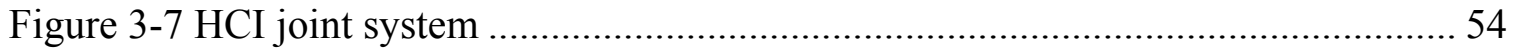

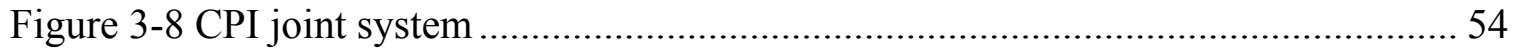

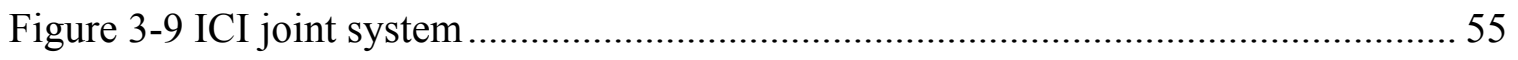

Figure 3-10 Construction method for deck connection ............................................ 56

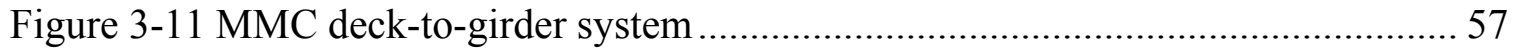

Figure 3-12 MMC deck-to-girder system's pictures ............................................. 57

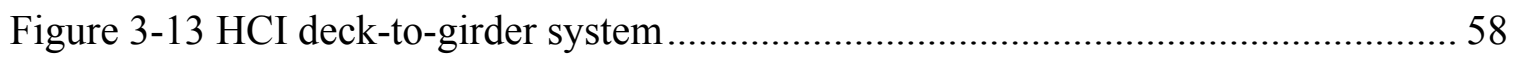

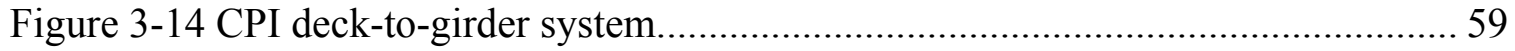

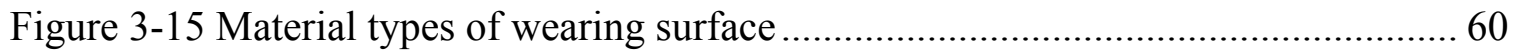

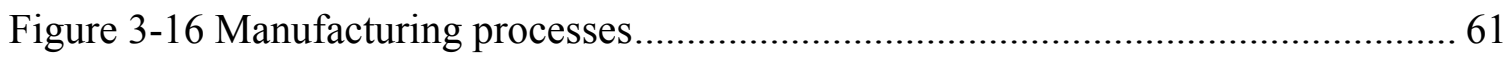

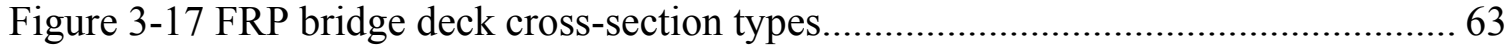

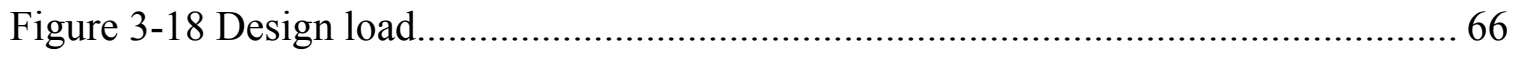

Figure 3-19 Barriers encountered in stalling FRP bride deck panels ........................... 71

Figure 3-20 Condition rating of existing bridge structures....................................... 74

Figure 4- 1 FRP Composites Decks installed in Project 100 .................................... 81

Figure 4-2 Composite decks installed under C4I initiative ...................................... 84

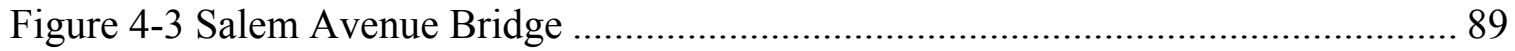

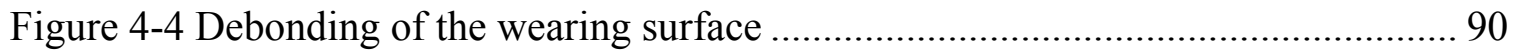

Figure 4- 5 Wearing surface cracking at a deck joint ............................................. 90

Figure 4-6 Concrete Cracks in CDS deck system.................................................. 91

Figure 4-7 Westbrook Road Bridge over Dry Run Creek .......................................... 92 
Figure 4-8 Sintz Road over Rock Run Bridge .......................................................... 93

Figure 4-9 Steel S-Clip attached to studs along bottom of panels ................................ 95

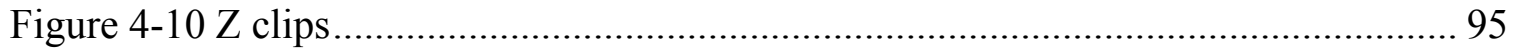

Figure 4- 11 Sample of wearing surface used in Sintz Road over Rock Run Bridge....... 96

Figure 4-12 Guardrail cantilevered from girders ...................................................... 96

Figure 4-13 Fire damage found in the bottom of panels........................................... 98

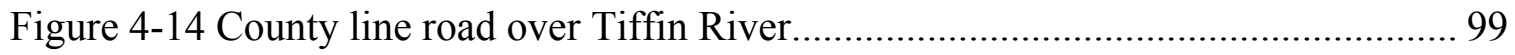

Figure 4-15 Sample of FRP bridge deck panels (Manufacturer: MMC) ...................... 100

Figure 4-16 Guardrail cantilevered from girders ................................................... 101

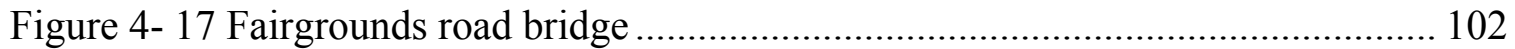

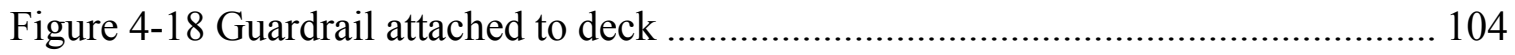

Figure 4-19 De-bonding, and cracking of Wearing surface ...................................... 105

Figure 4- 20 Keeping tolerance around deck edge with guardrail straight.................... 106

Figure 4-21 Five Mile Road Bridge \# 0171 ............................................................ 106

Figure 4-22 Five Mile Road Bridge \#0087 ............................................................... 107

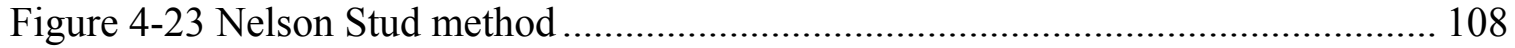

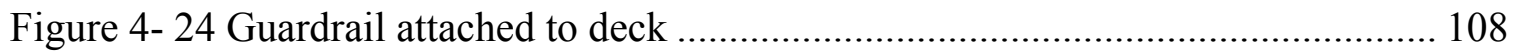

Figure 4-25 Honeycomb cells of sandwiched panels ............................................ 109

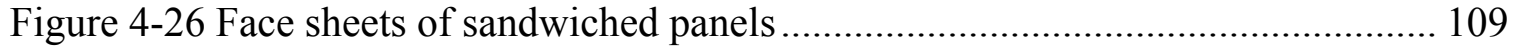

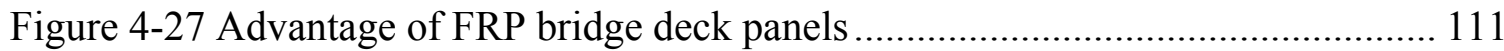

Figure 4-28 Road type of application for FRP bridge deck panels............................. 113

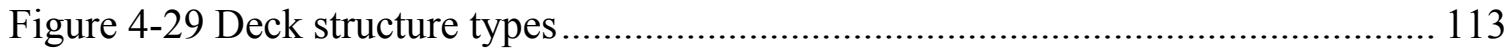

Figure 4-30 Manufacturer and manufacturing method............................................ 114

Figure 4-31 Material types of wearing surface .................................................... 115

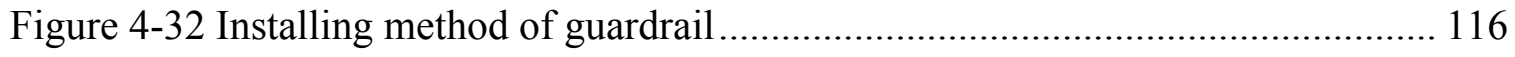

Figure 4-33 Barriers encountered in stalling FRP bride deck panels .......................... 116

Figure 4-34 Condition rating of existing bridge structures....................................... 117

Figure 4-35 Number of bridges for DOTs using HCI's FRP bridge deck panels.......... 119 
Figure 4-36 Number of bridges versus installed Year of HCI's FRP bridge deck panels

Figure 4-37 Number of vehicle and pedestrian bridges ........................................... 120

Figure 4-38 Number of bridges based on total square footage .................................. 120

Figure 4-39 Number of bridges according to wearing surface ................................. 121

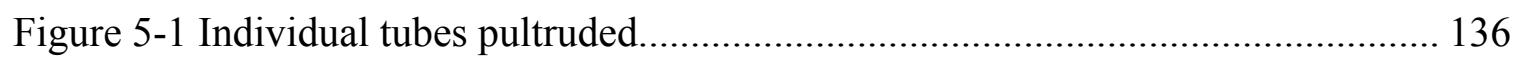

Figure 5-2 Panels assembled with a polyurethane adhesive ..................................... 136

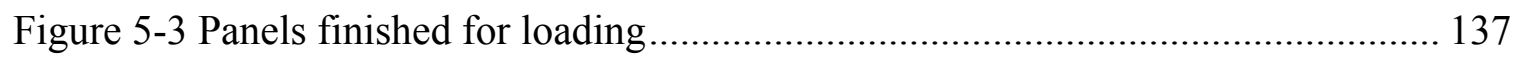

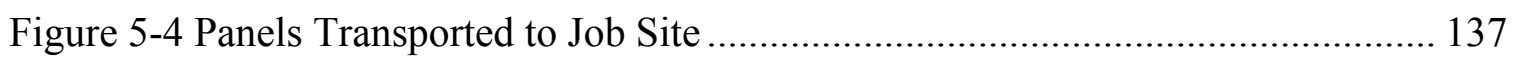

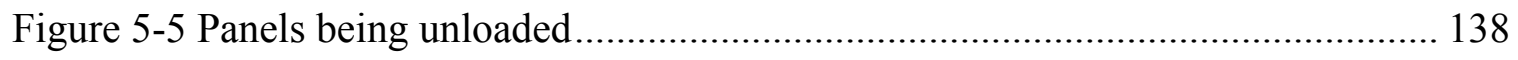

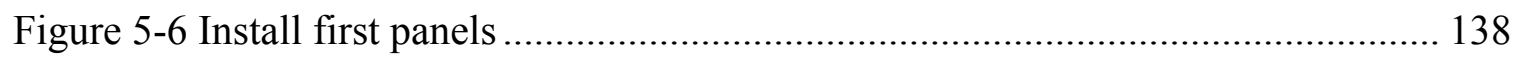

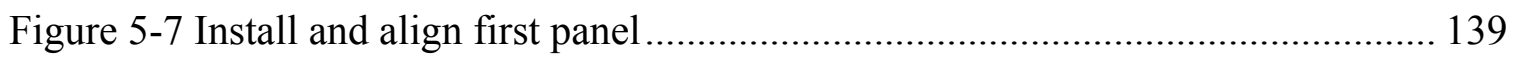

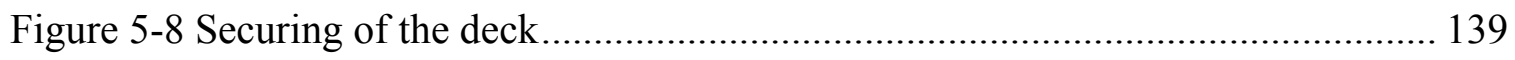

Figure 5-9 Liquid primer and epoxy paste applied to field joints............................... 140

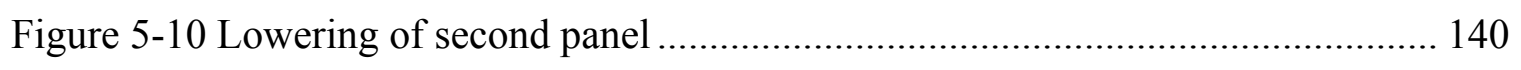

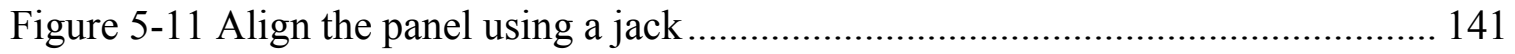

Figure 5-12 Place FRP splice strips over field joints............................................. 141

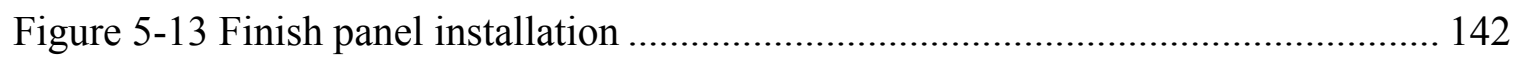

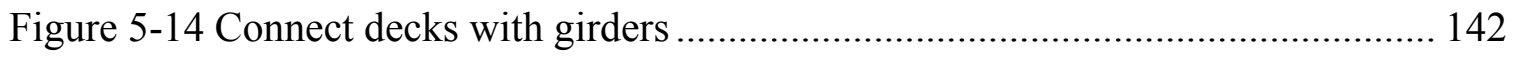

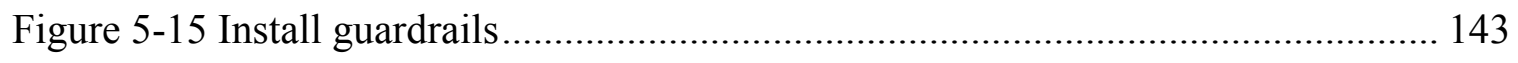

Figure 5- 17 Cape Girardeau Bridge, Cape Girardeau, Missouri ................................ 145

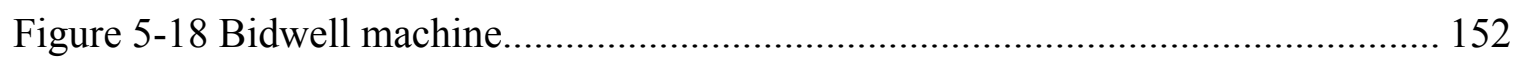

Figure 5-19 Simulation model for FRP bridge deck panels ..................................... 154

Figure 5-20 Simulation model for Precast concrete deck panels................................ 155

Figure 5-21 Cost per unit (hours) versus scenarios number in FRP bridge decks.......... 160

Figure 5-22 Cost per unit (hours) versus scenarios number in FRP bridge decks.......... 160

Figure 5-23 Cost per unit versus scenario number in Precast concrete decks ............... 162

Figure 5-24 Cost per productivity unit versus scenario number in Precast concrete decks 
Figure 6-1 MMC joint system 177

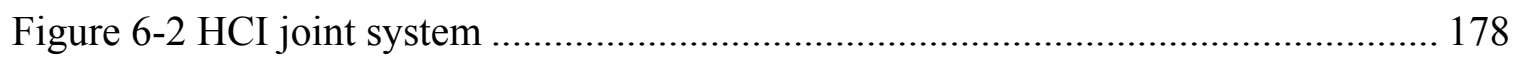

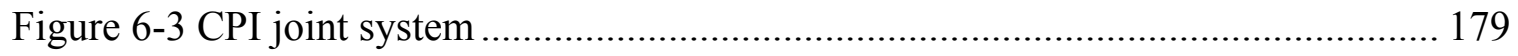

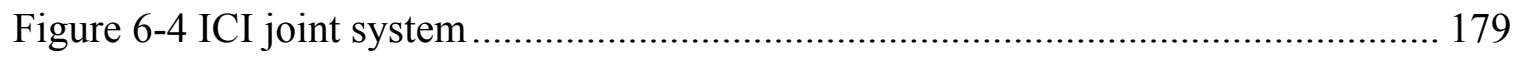

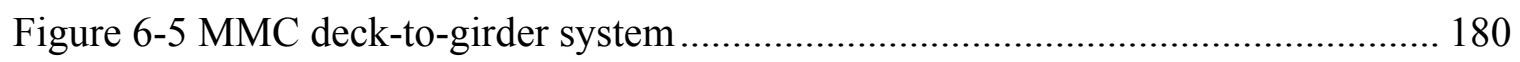

Figure 6-6 MMC deck-to-girder system's pictures ................................................ 180

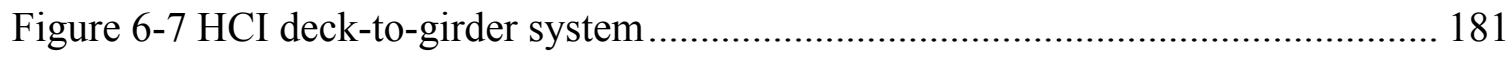

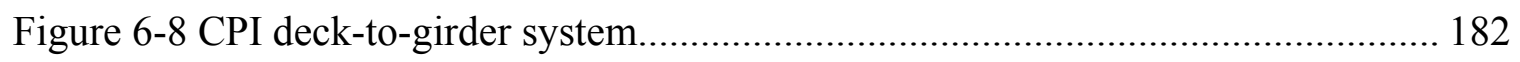




\section{CHAPTER 1: INTRODUCTION}

\section{$\underline{1.1 \text { Problem Statement }}$}

Recent advances in composite materials for civil engineering have created interesting possibilities for replacing conventional structural forms with components made out of fiber reinforced composite materials. Composite materials offer several advantages over conventional materials such as a superior strength/weight ratio, a better stiffness/weight ratio, a high degree of chemical inertness, and flexible custom design characteristics. In a recent article in the Engineering News Record, James Roberts of the California Department of Transportation was quoted as follows: "Quick-setting concrete, nighttime work, composite materials for both decks and whole structures, and large incentives for contractors will be tools for faster construction..." (ENR, June 11, 2001).

Some of the potential down-stream benefits include lower life-cycle costs, lighter members, high corrosion and fatigue resistance, and higher live load capacity (Seible and Karbhari 1996). The mass production capabilities of composite members offer possibilities for schedule compression, productivity and quality improvement, savings in labor and material costs, enhanced durability, and performance reliability (Mirmiran 1995, Kelly 1989, Gall 1986). Weight reduction and modular properties of composite members 
also lend to improved transportability, ease of installation, and less need for heavy equipment. Although initial investment for the production of composite members may be higher than conventional materials, it is likely to fall as the demand for composites increases (Goldstein 1996, Partridge 1989).

Composite materials are clearly having a major impact on how facilities are designed, constructed, and maintained. In order to enhance the application of fiberreinforced composites in infrastructure renewal, it is important to understand the constructability, maintainability and operability issues related to the use of Fiber Reinforced Polymer (FRP) structural components. This research evaluates the constructability, maintainability and operability issues related to FRP bridge decks as compared to conventional deck construction.

\subsection{Objective and Scope of Research}

It is the objective of this research to develop construction guideline for FRP bridge deck. Some of the specific objectives of the study include:

- To identify state of the art (research and development) and also state of practice of fabrication and use of composite bridge decks both in new bridges and in rehabilitation projects.

- To identify issues related to constructability, maintainability, and operability of FRP bridge decks, fabrication issues, construction methods, quality, safety, manhour requirements, cost and productivity issues, as well the skill level required. 
- To determine the productivity, man-hour requirement, and system bottlenecks that were important for understanding the construction process and to develop construction guidelines for FRP bridge deck construction.

- Research report that documents the research process and the results obtained.

To achieve these objectives, the data related to the proposed process modeling and simulation were collected through a questionnaire survey, interviews, and case studies.

\section{$\underline{1.3 \text { Research Framework and Methodology }}$}

\subsubsection{Task-1: Literature Review}

An extensive literature review was conducted to identify state of the art (research and development) and state of practice of fabrication and use of composite bridge decks both in new bridges and in rehab projects. The literature review also assists in identifying the constructability issues as well as the variables that differentiate between conventional deck construction and that using composite and/or FRP bridge deck panels. Additionally, a questionnaire survey was conducted. The questionnaire addressed issues such as constructability, maintainability, and operability of FRP bridge decks, fabrication issues, construction methods, man-hour requirements, cost and productivity issues, as well the skill level required. The questionnaire was sent to all the State DOTs. 


\subsubsection{Task-2: Preliminary Data Collection}

The prime data requirements for achieving the stated objectives included:

- Data on standard techniques and materials used for conventional as well as FRP deck construction.

- Data on man-hour requirement, cost, duration, productivity and efficiency, as well as any limitations and barriers to the construction of FRP decks as compared to conventional deck construction.

- Identification of issues that would impact the design, construction, quality, cost, safety as well as constructability, operability, and maintainability of FRP decks when compared to conventional deck construction.

The data required for this research were collected through questionnaires, case studies, personnel interviews, and existing literature. Additionally, information was solicited from various research institutions, fabricators of FRP decks, as well as state and private agencies that have developed and utilized composite material applications for bridge deck application. Three questionnaire studies were conducted during the course of the research (i) questionnaire survey-I was sent to all DOTs as well as to State and county engineers of the case study candidate projects, (ii) questionnaire-II was sent to the two manufacturers, Hardcore Composites, and Martin Marietta, to gather specific data after conducting personal interviews with their representatives, (iii) questionnaire-III was used to collect project specific information with respect to productivity, process, and resource requirements in order to develop process simulation models. 


\subsubsection{Task-3: Identification of Candidate Projects}

Seven candidate projects for FRP bride deck construction were identified for onsite data collection and study. Field studies allowed the observation and analyses of the installation of advanced modular deck systems to evaluate benefits due to speed and ease of installation. The candidate projects were located in Ohio.

To perform a comparative analysis of conventional versus FRP bridge deck construction, additional data were collected from conventional bridge deck projects that utilized precast concrete deck panels.

\subsubsection{Task-4: Detailed Data Collection, Analysis, and Process Modeling}

Process modeling and simulation were used to determine the productivity, manhour requirement, and system bottlenecks that were important for understanding the construction process and to develop standard construction guidelines for FRP bridge deck construction. Initial process modeling was done based on the data collected through available literature and questionnaire survey. Additional data required for comparing the conventional versus FRP deck construction were collected through case studies and personnel interviews and included cost, skilled/unskilled man-hour requirement, limitations, and barriers such as technological barrier or skill requirement. Technical barriers typically included the lack of professional experience in the use of composite materials and manufacturing challenges associated with innovative design. On the other hand, economic barriers usually included the high initial cost of production and lack of data on life cycle cost/benefits of new materials. 


\subsubsection{Task-5: Development of Construction guideline}

In order to develop construction guidelines for FRP bridge deck construction, different types of modular deck systems were evaluated to understand the issues that would impact design, construction, quality, cost, safety, as well as constructability, operability, and maintainability of FRP bridge decks. The data required for this analysis were collected through available literature, questionnaire survey, and field data collection. Based on the results of the previous tasks, standard construction guidelines were developed for INDOT.

\subsubsection{Task-6: Develop Final Report}

INDOT personnel were kept informed of the outcome of this study and their suggestions and comments were actively solicited. The work performed in this study was documented in a draft report and submitted to INDOT for review and comments four months prior to the scheduled completion date of the project. The comments provided by INDOT were incorporated and a final report was delivered to INDOT by the completion date of the project.

\subsection{Benefits of Research}

The proposed research has a strong potential to make definite impact on the application of composites in bridge deck construction. Recent advances in the use of composite materials have started to show real benefits for the construction industry, but there are significant barriers to widespread use in the industry. This research has focused 
on identifying the constructability, operability, and maintainability issues with respect to FRP bridge deck construction. Additionally, this research has developed construction guidelines for the use of FRP bridge deck construction that incorporates issues that impact construction, quality, cost, safety, as well as constructability, operability, and maintainability of FRP bridge decks.

\subsection{Organization of the report}

This report is composed of six chapters. Chapter 1 provides a general overview of the current practices and obstacles on the application of FRP bridge deck panels. This section also highlights the objectives and scope of this research, and provides a brief overview of methodologies used in realizing the stated objectives. An extensive literature review introduced in Chapter 2 includes: (i) FRP composite materials for bridge applications, (ii) challenges and technical issues in their application, (iii) advantages and disadvantages of FRP composite materials, (iv) manufacturing processes for composites, (v) composite manufacturers, (vi) previous analytical and experimental works on FRP bridge deck panels, (vii) construction procedure for FRP bridge deck panels as recommended by manufacturers, and (viii) challenges and technical issues in their application.

Preliminary data collection through questionnaire survey-I that was sent to all State DOTs and the data analyses are discussed in Chapter 3. Additional preliminary data collection and analyses through case studies, interviews, and the questionnaire survey-I that was sent to county engineers are discussed in Chapter 4. 
Chapter 5 illustrates process modeling and simulation study of the construction process for the conventional versus FRP bridge deck panels. Chapter 6 describes the standard construction guidelines developed for the FRP bridge deck panels. Finally, the summary of research, main finding, and recommendation for future research are also introduced in Chapter 6. 
CHAPTER 2: Literature Review

\section{$\underline{2.1 \text { FRP composite materials for bridge applications }}$}

Developed 30 years ago for the aerospace industry, fiber-reinforced polymer (FRP) materials have been used in various applications. In particular, recent advances in composite materials for civil engineering have created interesting possibilities for replacing conventional structural forms with components made out of fiber reinforced composite materials. More and more civil engineers are beginning to gain confidence and experience in applying composite materials to civil structures. There are more than 80 bridge projects worldwide using FRP composites materials and about 30 projects in the U.S., 26 of which were built within the last 4 years (SPI 1998).

Fiber-Reinforced Polymer (FRP) composites is defined as a polymer matrix that is reinforced with a fiber or other reinforcing material with a sufficient aspect ratio to provide a reinforcing function in one or more directions. Composite materials are clearly having a major impact on how facilities are designed, constructed, and maintained. In order to enhance the application of fiber-reinforced composites in infrastructure, it will be important to understand the constructability, maintainability and operability issues related to the use of FRP structural components. These new materials are applicable to both 
construction of new structures and maintenance and rehabilitation of existing bridges. In particular, bridge decks have received the greatest amount of attention in the past few years, due to their inherent advantages in strength and stiffness as compared to traditional steel reinforced concrete decks. Reducing the weight of replacement decks in rehabilitation projects also presents the opportunity for rapid placement and reduction in dead load, thus raising the live load rating of the structure (Alampalli et al. 1999).

\section{$\underline{2.2 \text { Advantage and Disadvantage of FRP Composite Materials }}$}

Composite materials of FRP bridge decks are typically made with vinyl ester or polyester resin reinforced with E-glass fiber. They are engineered and fabricated in a controlled factory then assembled and installed at a bridge site where a wearing surface is added. These characteristics of composite materials offer several advantages over conventional materials providing large incentives for contractors as a tool for faster construction. Other significant advantages include a superior strength/weight ratio, a better stiffness/weight ratio, a high degree of chemical inertness, and flexible custom design characteristics. However, there are still some unfavorable characteristics of FRP composites materials such as high initial cost, design restriction, and limited experiences that prevent their wide application in civil infrastructure.

\subsubsection{Advantage}

Composite materials have many advantages over conventional materials such as lower life-cycle costs, lighter members, high corrosion and fatigue resistance, and higher 
live load capacity (Seible and Karbhari 1996). The mass production capabilities of composite materials also offer possibilities for schedule compression, productivity and quality improvement, savings in labor and material costs, enhanced durability, and performance reliability (Mirmiran 1995, Kelly 1989, Gall 1986). Weight reduction and modular properties of composite materials also provides improved transportability, ease of installation, and less need for heavy equipment. Although initial investment for the production of composite materials may be higher than conventional materials, it is likely to fall if the demand for composites increases (Goldstein 1996, Partridge 1989).

Table 2-1 Typical Advantages of FRP Bridge Deck (O'Connor 2003)

\begin{tabular}{c|l}
\hline \hline No. & \multicolumn{1}{|c}{ Advantages } \\
\hline \hline 1 & Light weight. \\
\hline 2 & Resistance to de-icing salts and other chemicals \\
\hline 3 & Fast installation \\
\hline 4 & Good durability \\
\hline 5 & $\begin{array}{l}\text { Lower user costs, less expense for maintenance and protection of traffic, and better } \\
\text { public relations due to reduced traffic delay }\end{array}$ \\
\hline 6 & Long service life. \\
\hline 7 & Fatigue resistance \\
\hline 8 & Good quality due to fabrication in a controlled environment \\
\hline 9 & Ease of installation. \\
\hline 10 & Cost savings \\
\hline
\end{tabular}

As seen in Table 2-1, its lightweight material and ease of construction provide significant labor and traffic control cost savings to offset a higher initial cost of FRP application. An FRP deck could reduce the weight of conventional construction by 70 to 80 percent. In addition, the modular panel construction of bridge deck enables fast project delivery. A bridge built of composite materials can be constructed and put in service in a relatively short duration. This technology has demonstrated that a bridge structure can be 
replaced and put into service in a matter of hours rather than days or months compared to conventional materials (Tang and Podolny 1998).

\subsubsection{Disadvantage}

In spite of many advantages over the conventional materials, FRP bridge deck has many drawbacks to resolve such as high initial cost, restricted design, limited experiences, and so on. Its higher initial cost is the most concern for application of FRP bridge deck. Even though the added expense is offset by other savings such as maintenance and protection of traffic, the unit cost of FRP materials is often more expensive than conventional materials. The other concern is related to the FRP material properties due to inexperience within the construction industry. There are few FRP bridges that have been in service for any substantial length of time. This resulted in lack of long term performance data, lack of design standards as addressed in Table 2-2.

Table 2-2 Typical Disadvantages of FRP Bridge Deck (O’Connor 2003)

\begin{tabular}{c|l}
\hline \hline No. & \multicolumn{1}{|c}{ Advantages } \\
\hline \hline 1 & High initial cost \\
\hline 2 & Deflection driven design due to FRP's low modulus of elasticity \\
\hline 3 & No standard manufacturing process. \\
\hline 4 & Sensitive response to thermal change than concrete and steel \\
\hline 5 & Some failure of the wearing surface (i.e. cracking, debonding) \\
\hline 7 & The resultant tendency to creep over time \\
\hline 8 & Limited FRP experience within the construction industry \\
\hline 9 & Lack of long term performance data \\
\hline 10 & Lack of design standards \\
\hline
\end{tabular}

As seen in Table 2-1, higher initial cost compared to a conventional concrete deck is the most significant problem to resolve. In addition, FRP's low modulus of elasticity leads to a deflection driven design which does not allow a designer to fully capitalize on 
the FRP's strength. Also, currently available designs are proprietary so that there is no standard manufacturing process. In particular, response to thermal change is slightly different than for concrete and steel so that it requires special consideration when an FRP deck is used on a concrete or steel superstructure.

FRP material properties like strength and stiffness naturally degrade over time. The resultant tendency to creep is another disadvantage. Some past projects have experienced a failure of the wearing surface (i.e. cracking and/or debonding). Appropriate strength reduction factors need to be used to insure adequate stiffness over the entire service life of the structure.

\subsection{Composites Manufacturing Processes}

In this section, typical manufacturing processes used by FRP composite bridge deck manufacturers are addressed. There are many different manufacturing processes available to the composites manufacturer. Each fabrication process has its own characteristics that define the type of products that can be produced. Is spite of this, generic manufacturing processes can be divided into two types: open molding and closed molding.

\subsubsection{Open Molding}

Open molding is a common process for making fiberglass composite materials employed in the industry. Once the product has cured, then it is removed from the mold and the mold is used for the next product. Therefore, companies can inexpensively make 
a wide variety of products. The raw materials are applied by hand or by spray into the open mold. Usually, the mold is left open while the materials react and harden, or "cure". It is typically used for making boat hulls and decks, RV components, truck cabs and fenders, spas, bathtubs, shower stalls and other relatively large, non-complex shapes. The open molding involves either spray-up or hand lay-up. Both methods are often used together to reduce labor.

\section{(1) Hand Lay-up (Wet Lay-up) Process}

Hand lay-up is an open molding method for making various composites products such as boats, bath-ware, housing, auto components, and many other products. Though the production volume per mold is low, it is feasible to produce substantial product quantities using multiple molds. In a particular hand lay-up process, high solubility resin

is sprayed, poured, or brushed into a mold where the reinforcement is placed. Depending upon the thickness or density of the reinforcement, it may receive additional resin to improve saturation and allow better draping into the mold surface. The reinforcement is then rolled, brushed, or applied using a squeegee to remove entrapped air and to compact it against the mold surface (Busel and Lockwood 2002).

(2) Spray-up (Chopped Laminate) Process

Spry-up or chopping process is an open mold method similar to hand lay-up in its suitability. In the spray-up process, the mold is first treated with mold release. If a gel coat is used, it is typically sprayed into the mold after the mold release has been applied. The gel coat is then moved to be cured in a heated oven at about $120^{\circ} \mathrm{F}$ and then, the 
mold is ready for fabrication. In the spray-up process, catalyzed resin and glass fiber are sprayed into the mold using a chopper gun that blows the short fibers directly into a sprayed resin stream so that both materials are applied at the same time.

Finally, the laminate is compacted by hand with rollers. Wood, foam or other core material may be added, and a second spray-up layer is applied to embed the core between the laminate skins. The part is then cured, cooled and removed from the reusable mold (Composite World 2003)

(3) Filament Winding

The filament winding process is used for tubular composite parts such as composite pipe, electrical conduit, and composite tanks. Fiberglass roving strands are impregnated with a liquid thermosetting resin and wrapped onto a rotating mandrel in a specific pattern (Busel and Lockwood 2002). After the winding operation, the resin is cured or polymerized and the composite part is removed from the mandrel.

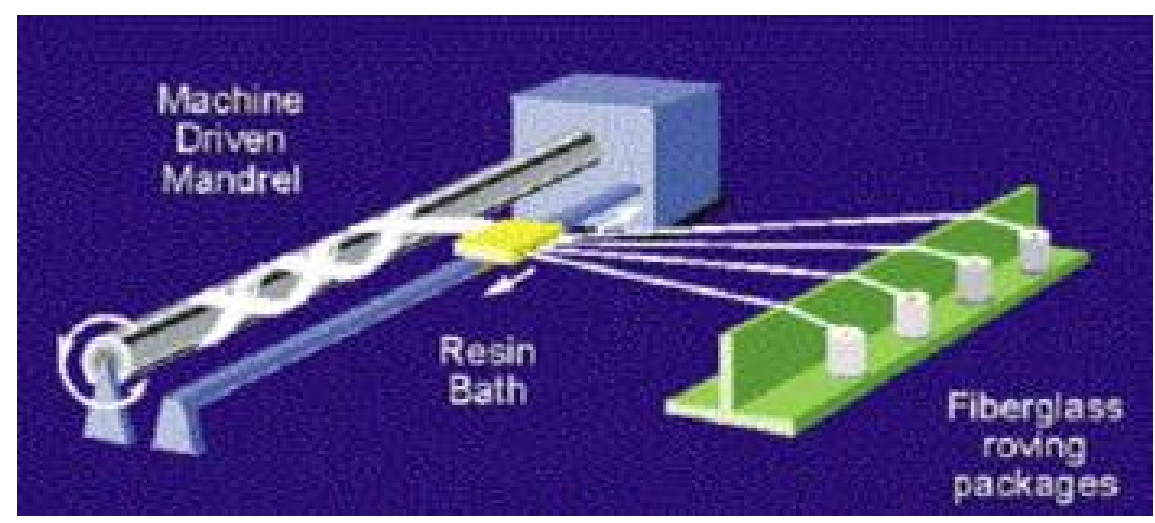

Figure 2-1 Diagram of Filament Winding Process (Busel and Lockwood 2002)

Figure 2-1 shows typical diagram of filament winding process. However, initial capital investment is relatively higher compared to other open mold processes. The 
primary portion of largest expense for an existing filament winder is the cost of the winding mandrel (Busel and Lockwood 2002).

\subsubsection{Closed Molding}

With advancements in FRP composite materials in recent years, closed molding has become a viable technology reducing emissions and optimizing the glass-resin ratio. It produces a higher quality laminate and allows both sides of the part to have a finished appearance. In the closed molding, liquid resin is not exposed to the air. However, this process is much more expensive than open molding. Closed Molding is only used where the higher product quality is needed. There are several types of closed molding processes as follows

(1) Resin Transfer Molding (RTM)

Resin Transfer Molding (RTM) is one of lowest cost manufacturing process that has received a lot of attention in recent years. As shown in Figure 2-2, the dry fiber reinforcement is arranged into a pre-form placed in a mold. The mold is closed and resin is injected into the mold under relatively low pressures until the entire cavity is filled. After the resin is cured, the finished part is removed from the mold.

RTM produces parts that do not need to be autoclaved. A part designed for a hightemperature application usually undergoes post-cure. Most RTM applications use a twopart epoxy formulation. Vacuum is sometimes used to enhance the resin flow and reduce void formation. The part is typically cured with heat (Composite World 2003). 


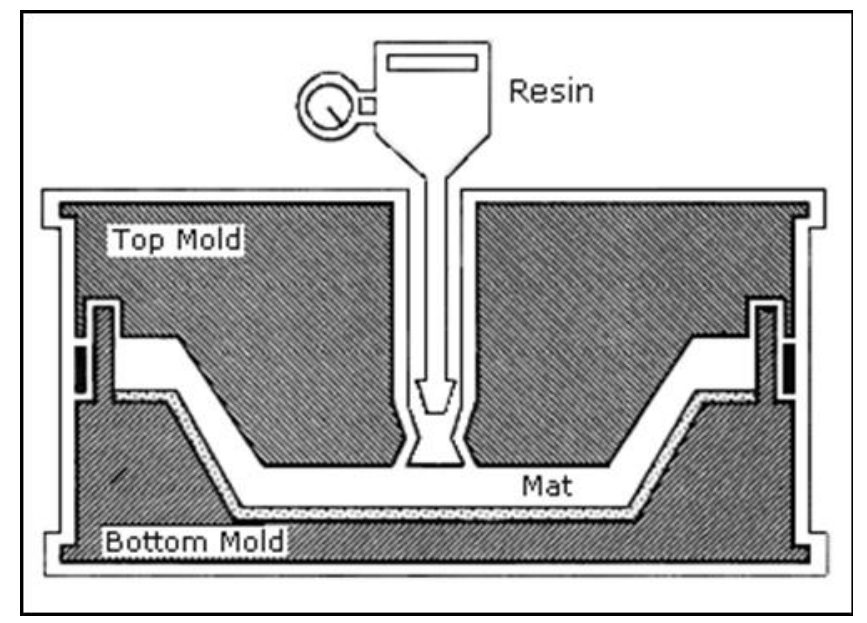

Figure 2-2 Matched Molds Used in RTM (Busel and Lockwood 2003)

The benefits of RTM are that the mold surface can produce a high quality finish and it can produce parts as much as 5 20 times faster than open molding method. In addition, complex mold shapes are possible and emissions are lower than open mold process (Busel and Lockwood 2002).

(2) Resin Infusion Molding (RIM)

Resin Infusion Molding (RIM) shares many characteristics of vacuum bag molding and resin transfer molding (RTM). Like RTM, infusion reduces styrene emissions by wetting out and curing the laminate in a closed system. With a single shot, the infusion process creates a high performance laminate eliminating potential bonding problems. This process is possible to attain fiber to resin ratios as high as 70:30 along with the virtual elimination of air entrapment and voids. This process necessitate a mold similar to that of any open molding process and a unitary vacuum. 


\section{(3) Injection Molding}

Injection molding is one of the oldest processes for plastics and the most closed process. A compound is pumped into a steel mold and the melted plastic is injected into a heated mold where the part is formed. This process is often fully automated (Busel et a. 2000).

(4) Pultrusion

Pultrusion is an automated manufacturing process for the production fiber reinforced composites with constant cross-section. The properties of the composite produced with this process can compete with traditional steel and aluminum for strength and weight. The polymer reinforced matrix can be formulated to meet the most demanding chemical, flame retardant, electrical and environmental conditions (EPTA 2003).

The process involves pulling raw materials rather than pushing, as is the case in extrusion through a heated steel forming die using a continuous pulling device. The reinforcement materials are in continuous forms such as rolls of fiberglass mat and doffs of fiberglass roving. As the reinforcements are saturated with the resin mixture in the resin bath and pulled through the die, hardening of the resin is initiated by the heat from the die forming corresponding shape of the die (Strongwell 2003). While pultrusion machine design varies with part geometry, the basic pultrusion process concept is described in Figure 2-3.

Pultrusion can produce both simple and complex profiles eliminating the need for extensive post-production assembly of components. This process allows for optimized 
fiber architectures with uniform color eliminating the need for many painting requirements (Busel and Lockwood 2003).

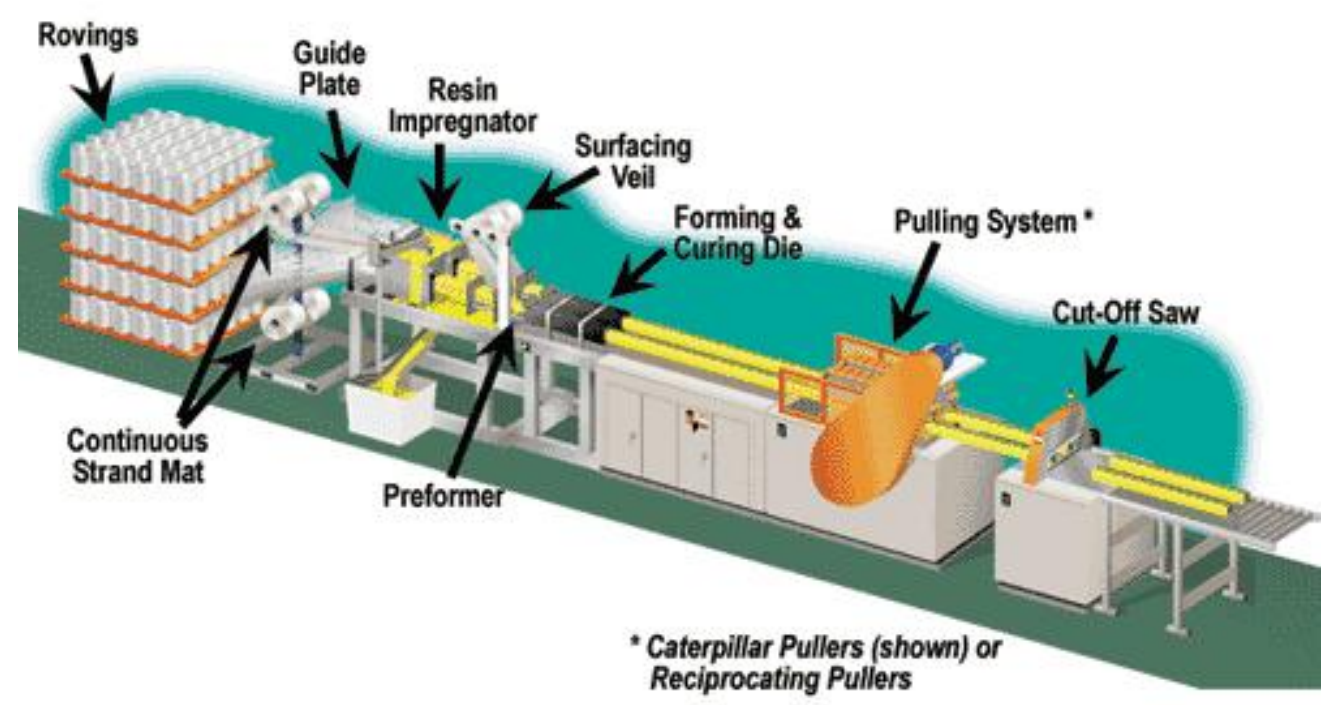

Figure 2-3 The Pultrusion Process (Source: Strongwell 2003)

\section{$\underline{2.4 \text { Composite Manufacturer }}$}

The cost competitiveness of an FRP deck is typically project dependent and each FRP composite bridge deck manufacturer has its own system for the application. Following is the brief summary of characteristics of several leading FRP composite bridge deck manufacturers.

\subsubsection{Creative Pultrusions, Inc.}

Creative Pultrusions, Inc. (CP) was established in 1973. The company operates in two manufacturing locations: Alum Bank, Pennsylvania (Corporate Headquarters) and Roswell, New Mexico (CP 2003). 
Superdeck of Creative Pultrusion (Figure 2-4) is a pre-engineered FRP composite bridge deck manufactured by the pultrusion process. Two profiles - double trapezoid (DT) hexagonal section (HX) is pultruded and bonded together to form bridge deck modules. The fiber architecture is composed of E-glass fibers in the form of multi-axial stitched fabrics, continuous roving and continuous fiber mats. The resin matrix is a weatherresistant vinyl ester resin.

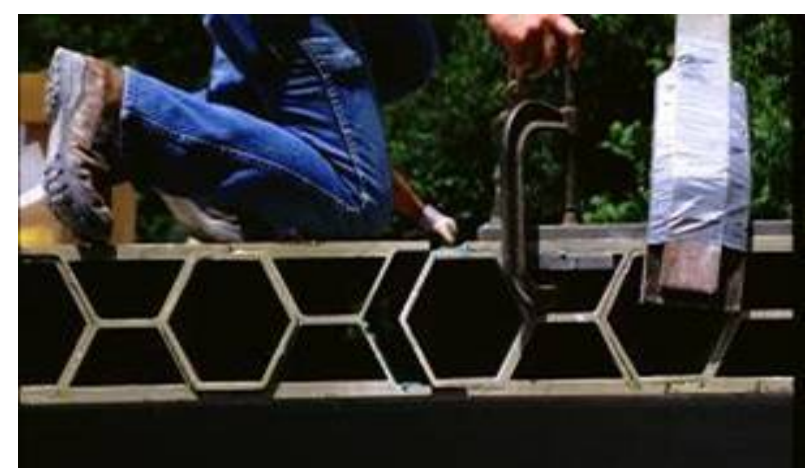

Figure 2-4 Superdeck FRP Composite Panel (Source: FHWA)

\subsubsection{Hardcore Composites}

Hardcore Composites, founded in 1984, is the leading manufacturer of large-scale fiber reinforced polymer (FRP) composite materials for infrastructure applications. Its products, systems, and components include bridges and walkways, marine fender systems, and specialty composite stay-in-place concrete forms. Hardcore is famous for their specialty in the composite marine structures. Their customers include many state departments of transportation, port authorities, highway and marine contractors and specialty concrete repair contractors (Hardcore 2003).

In particular, Vacuum Assisted Resin Transfer Molding (VARTM) is used for the manufacturing process as seen in Figure 2-5. Hardcore has refined this process and 
developed an orthotropic honeycomb structural core to obtain the required structural properties and cost competitiveness. Hardcore currently operates out of a 108,000 sq. ft. facility in New Castle, Delaware.

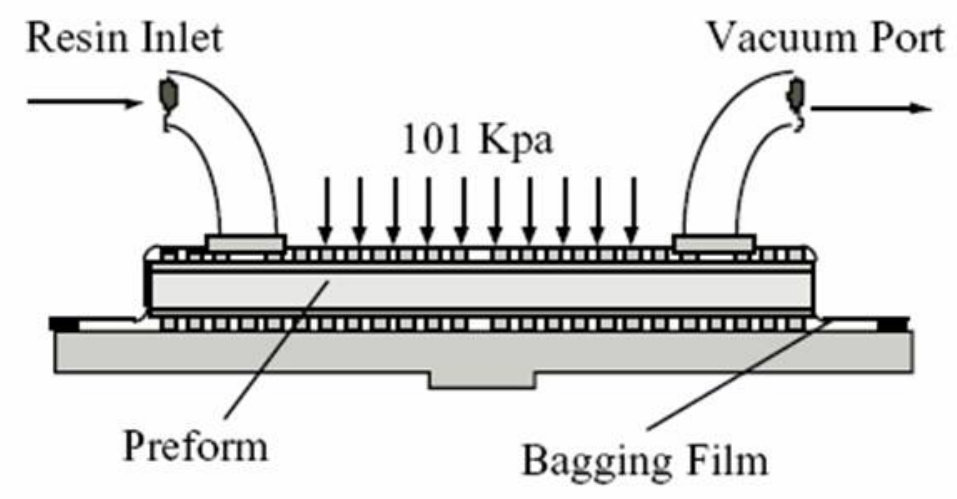

Figure 2-5 Vacuum Assisted Resin Transfer Molding (VARTM)

(Source: Smith et al. 2000)

\subsubsection{Kansas Structural Composites, Inc.}

Kansas Structural Composites, Inc. was formed in 1995 and they manufacture the fiber-reinforced polymer honeycomb (FRPH) sandwich panels. The company concentrates on applications for heavy-duty structural panels for the deteriorating highway infrastructure. KSCI built all fiber reinforced polymer (FRP) bridge on a public road on November 8, 1996 for the first time in U.S. over No-Name Creek, just three miles west of Russell, Kansas (KSCI 2003).

The use of fiberglass in FRPH sandwich construction produces a lightweight, corrosion-resistant panel that is relatively low in cost when compared to aerospace composite constructions. Even more, when considering the reduced costs of installation and public inconvenience, the cost of these panels can be favorably compared to more 
conventional construction materials. Prototypes can be built at costs of between $\$ 3$ and \$5 per pound (KSCI 2003).

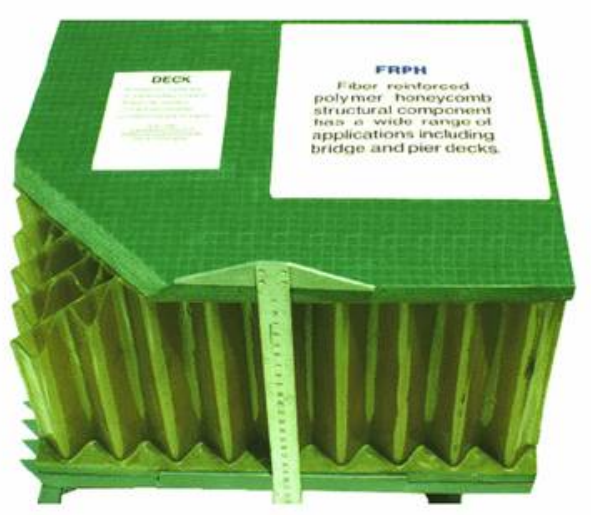

Figure 2-6 Cross-Section of FRPH Deck Panel (Source: Busel and Lockwood 2003)

The fabrication for the most components of KSCI's bridge decks is completed by hand lay-up process method. Figure 2-6 shows cross-section of FRPH deck panel which is constructed by $\mathrm{KSCI}$.

\subsubsection{Strongwell}

Strongwell claims to be both the world's largest pultruder of fiber reinforced polymer composites and North America's largest polymer concrete precaster. Strongwell has worldwide customer bases which include large industrial and commercial firms, major A\&E's, leading contractors and distributors, and hundreds of other companies in a wide variety of markets. The company has three pultrusion manufacturing facilities in Bristol, Virginia, Washington County, Virginia and Chatfield, Minnesota.

Strongwell is actively involved in the advancement of FRP technology for civil infrastructure applications. Emerging applications for Strongwell's pultruded FRP 
products are pedestrian bridges and AASHTO HS-25 bridge superstructure, decks and guard rails. Strongwell manufactures a vehicular bridge deck (Figure 2-7) by combining pultruded square tubes and pultruded plate. The deck system can be designed for optimum performance depending upon design loads and stringer spacing. Tube sizes are typically 4 " $\times 1 / 4$ " or 6 " $\times 3 / 8$ " and plate thickness is typically $3 / 8$ " thick. The deck systems come complete with fastening hardware to allow positive attachment to steel, concrete of FRP bridge stringers (Strongwell 2003).

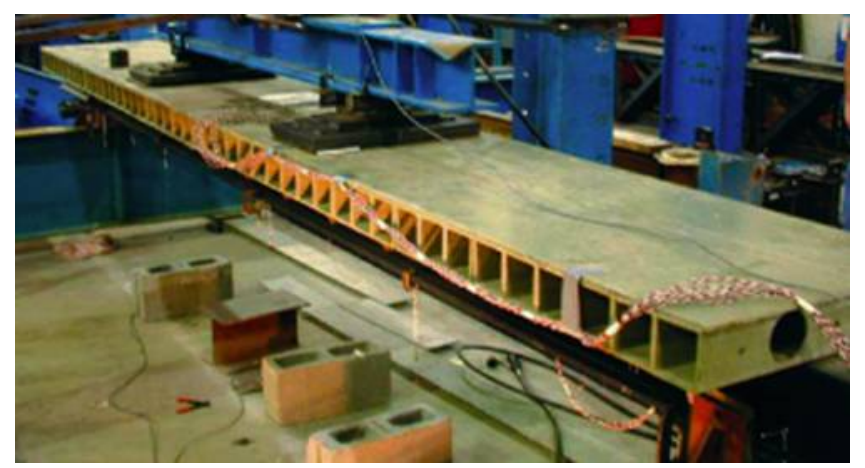

Figure 2-7 Strongwells' FRP bridge deck (Strongwell 2003)

\subsubsection{Martin Marietta Composites}

Martin Marietta Composites (MMC) is one of the subsidiaries of Martin Marietta Materials (MMM), a national leader in the construction materials industry. MMC was founded by Martin Marietta Materials for the purpose of pursuing advanced material applications in bridges and infrastructures. The company's customers include federal agencies, state and local transportation departments in approximately two dozen states (MMC 2003). 
Martin Marietta Composites is located in Raleigh, North Carolina. The main product, DuraSpan ${ }^{\circledR}$ bridge decks, along with other structural composite products are manufactured in Sparta, North Carolina.

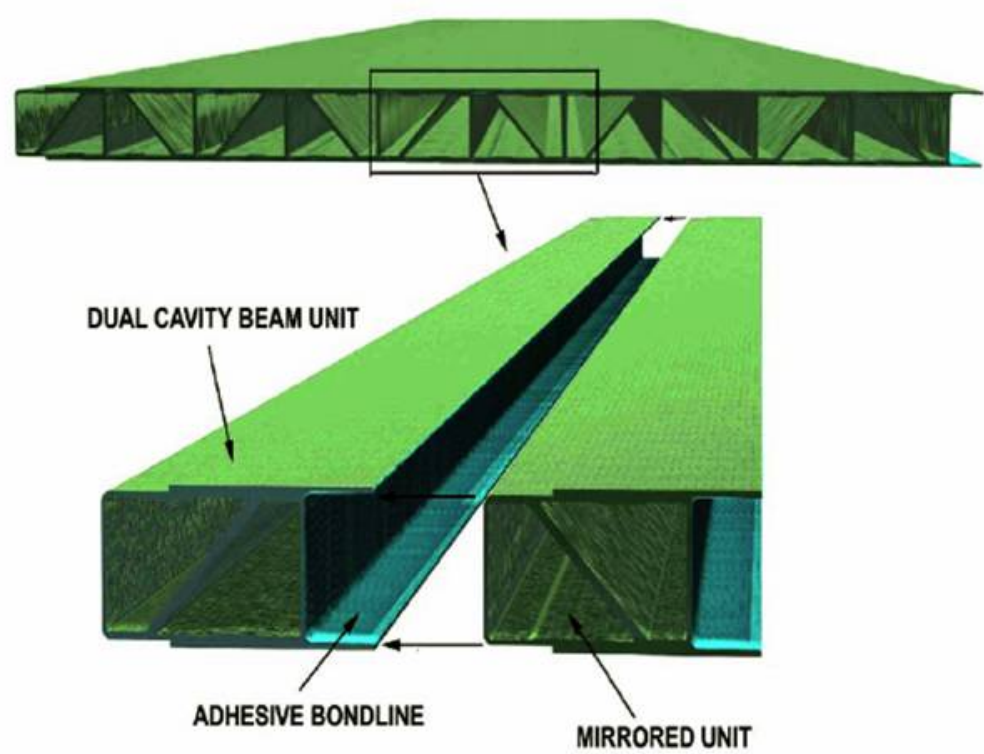

Figure 2-8 Schematic of MMC's DuraSpan FRP Deck Panel (Source: FHWA)

Martin Marietta Composites' FRP bridge deck is made of composite materials consisting of continuous fiber reinforcement of E-glass. The deck elements are formed through pultrusion in which fibers are wetted with the polymer resin and then pulled through heated metal dies, which at controlled temperatures and speeds causes the resin to cure (Busel and Lockwood 2003). Figure 2-8 shows Schematic of MMC's DuraSpan FRP Deck Panel. Panels are typically 8 to $10 \mathrm{ft}$. in width. The bonded panels are sent to finish shop, where all secondary work such as hole cutting and sealing, installation of closeouts, surface finishing and so on is performed. Panels are then shipped directly to the job site for installation (MMC 2003). 


\subsection{Previous analytical and experimental works on FRP bridge deck panels}

FRP composite materials have been used successfully in other fields like aerospace, defense, and automobile industries. Even though there are a lot of database for their application, they may not directly be used for civil engineering applications. The reason is that there are critical differences in terms of load cycling, exposure to different environment, different service life and scale structure, and even the type of fiber and resin used as compared to FRP composites for civil infrastructure. Zureick et al. (1995) has emphasized such difference in operating conditions and configuration between bridge deck structure and aerospace application (Zureick et al. 1995).

- Exposure to moisture and ultraviolet

- Exposure to organic growths

- Continuous load cycling

- Long durations between inspection and maintenance

- Long service lives

- Large-scale structure

- Field joints and attachments

- Field assembly

Thus, it is increasingly becoming critical issues to convince their long-term durability in civil infrastructure after exposure to various environmental conditions during the expected service life of FRP composites. In this light, several studies have indicated the importance of their durability issues in civil infrastructure to enhance their 
application by structural designers and civil engineers (Stechkel et al. 1999; Karbhari 2003; Karbhari et al. 2003; Karbhari and Zhang 2003). Karbhari et al. (2003) identified seven specific environmental conditions (damage modes) leading to damage to FRP composites as an indicator of need for further collection, validation, and dissemination of data related to durability of FRP composites. The durability of a material or structure was defined as its ability to resist cracking, oxidation, chemical degradation, delamination, wear, and/or the effects of foreign object damage for a specified period of time, under the appropriate load conditions, under specified environmental conditions (Karbhari et al. 2003).

- Moisture/Solution effects

- Alkali effects

- Thermal effects

- Creep/relaxation effects

- Fatigue effects

- Ultraviolet (UV) effects

- Effect of fire

\subsection{Installation procedure of FRP bridge deck panels by manufacturers}

Construction procedure of FRP bridge deck panels by manufacturer varies from each other. In general, there are no uniform standards for installation and the manufacturer's own specification is used for installation. The following describes some similarities and differences in installation process between the manufactures. 


\subsubsection{HCI (Hardcore Composites Inc.)}

Typical panels are shipped flat on standard semi-truck trailers. Panels are fabricated in as large as possible dimensions to reduce the number of field connections. Standard 1"-8 UNC lifting elements are molded into the panels to provide convenient picking. The picking weight and field orientation of each panel is provided with shipment of the panel (Hardcore 2003). Figure 2-9 shows overview of typical installation of a Single $20 \mathrm{ft}$ x $26 \mathrm{ft}$. Bridge Panel manufactured by Hardcore.

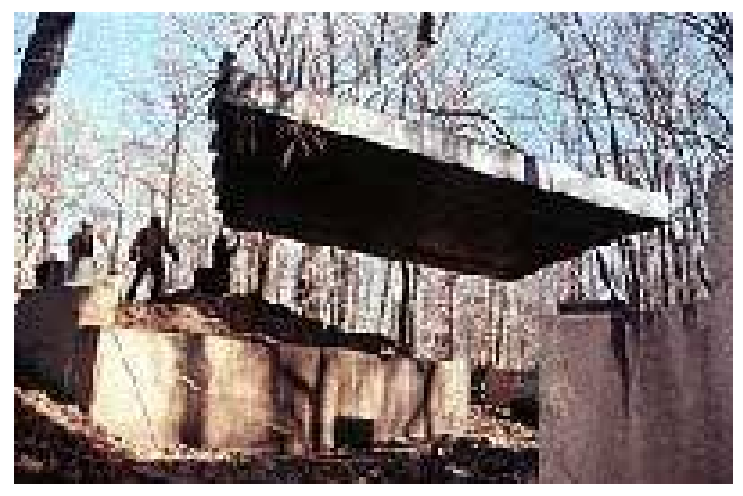

Figure 2-9 Installation of a Single 20 ft. x 26 ft. Bridge Panel (Source: Hardcore 2003)

Regardless of the type of construction, one-piece or multiple panels, each Hardcore structure is shipped with the specified embedment (Figure 2-10). These include lifting elements, guardrail attachments, attachments to the abutments and polymer concrete wearing surface and so on (Hardcore 2003). 


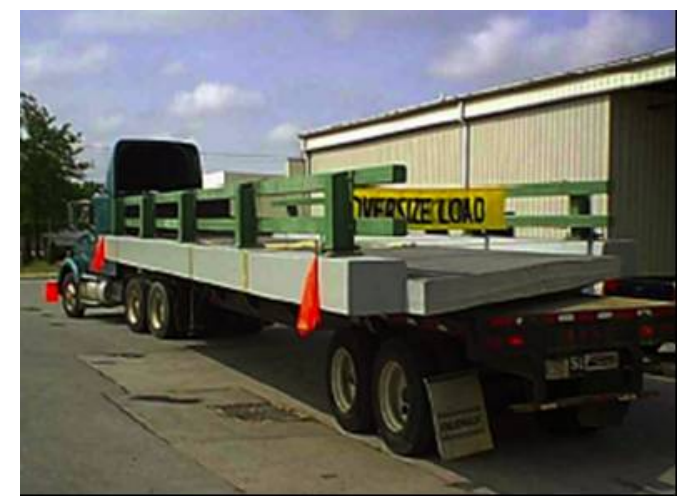

Figure 2-10 Shipping of a Complete 39ft. x $17 \mathrm{ft}$. Panel (Source: Hardcore 2003)

Hardcore Composites has three types of design for deck connections. These are panel-to-abutment connections, panel-to-panel connections and panel-to-beam connections. When the FRP deck is self-supporting, the panels are connected to the abutments (see Figure 2-11). Connections are based on economically available anchor bolts. Match drilled holes through the panel to the abutment are typically specified at the fixed end. Slotted holes with a traditional expansion joint or a semi-integral approach slab can be detailed at the free end. In all cases, the anchorage is designed for factored loads and uplift forces in case of flooding.

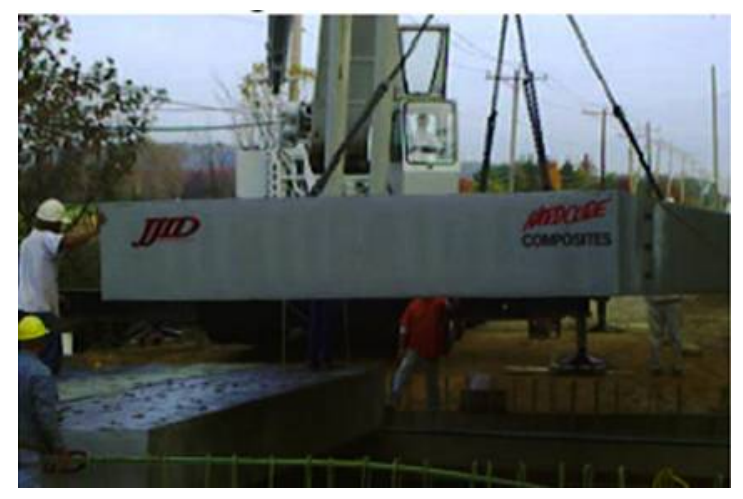

Figure 2-11 Installation of $32 \mathrm{ft}$. x $13 \mathrm{ft}$. Longitudinal Panels on Abutments (Source: Hardcore 2003) 
For example, in the case of panel-to-panel connections, typical connections are designed using adhesively bonded butt joints or lap-splices (Hardcore 2003). The space between panels is completely filled with adhesive. Typically construction grade epoxy or marine grade methacrylate is used.

In particular, cellular core technology developed by Hardcore enables virtually unlimited three-dimensional fiber architecture. Curbs can be molded monolithically with the deck panel as a separate structure. For continuous curbs, scuppers are typically molded into the panel to provide drainage in the gutter (Hardcore 2003). Figure 2-12 shows typical installation of splice plates and bonded FRP Curbs.

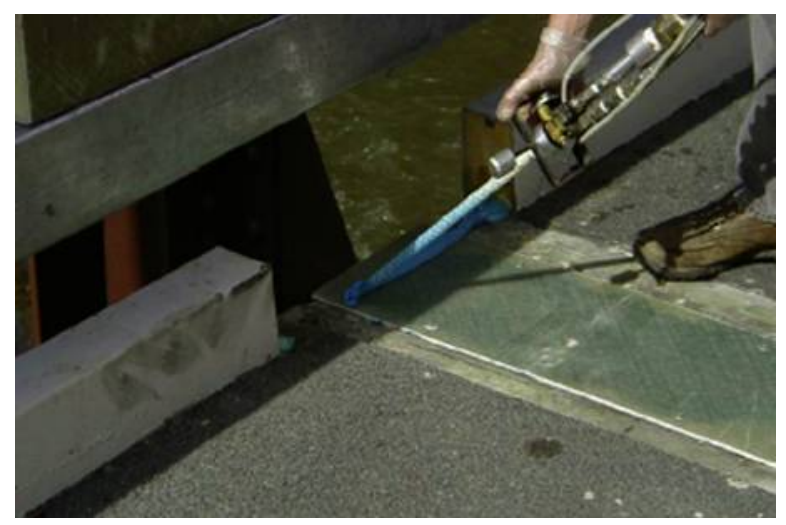

Figure 2-12 Installation of Splice Plates and Bonded FRP Curbs (Source: Hardcore 2003)

In the case of guardrail connection (see Figure 2-13), guardrails are attached by either top-mounted or side mounted systems. For panels with a section depth of at least 8 inches, top mounted guardrails use embedded studs with adequate development length. For panels less than 8 -inches thick, guardrails are attached by bolting through the deck and using a galvanized or stainless steel plate at the bottom face of the panel to distribute forces (Hardcore 2003). 


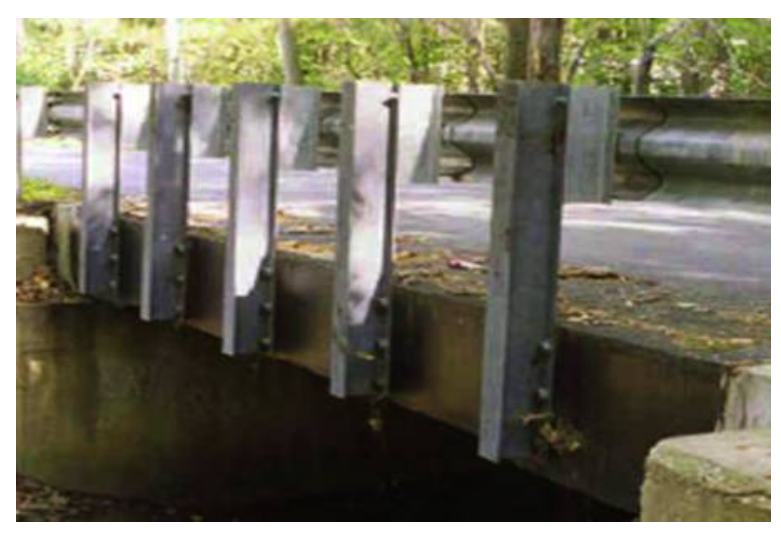

Figure 2-13 Side-Mounted Guardrail on Vehicle Bridge (Source: Hardcore 2003)

\subsubsection{MMC (Martin Marietta Composites)}

Once the individual tubes have been pultruded, they are assembled into panels using a polyurethane adhesive. The width of panels are typically 8 to $10 \mathrm{ft}$. The bonded panels are sent to finish shop, where all secondary work such as hole cutting and sealing, installation of closeouts, surface finishing and so on is performed. Panels are then shipped directly to the bridge construction site for installation.

All MMC decks make use of composite bending-action with the girder using conventional shear studs and stirrups. Holes at the desired spacing for the connections are cut into the deck and foam inserts are placed inside the tubes to provide closed cavity. After that, shear studs are field welded when the deck panels are installed in place. Finally, grout is poured in the cavity of the deck. MMC has several methods of forming and pouring the haunches that are similar to conventional methods and have been accepted by various contractors and DOTs. Pouring of the haunches also needs to be performed after the panels are in place to ensure a uniform bearing surface (MMC 2003). Figure 2-14 shows typical liquid primer and epoxy paste being applied to the field joint. 


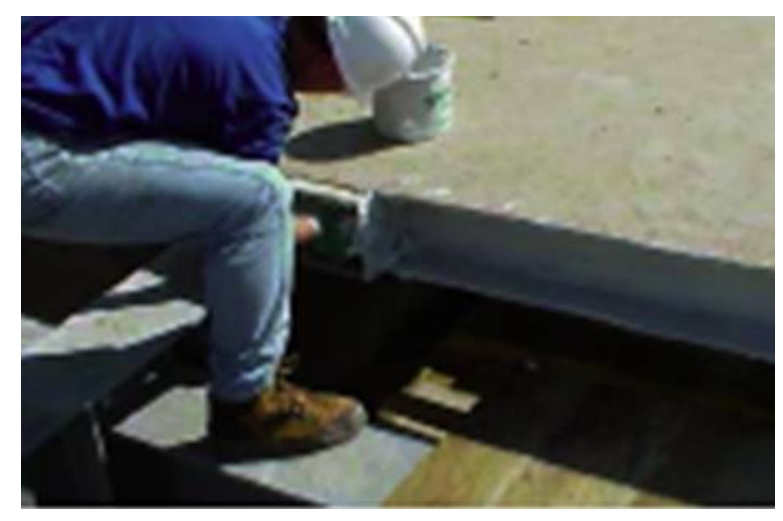

Figure 2-14 Liquid Primer and Epoxy Paste to being applied the Field Joint (Source: MMC 2003)

In the case of concrete barriers, the same method used for the deck-to-girder connections can be used to connect the deck to the reinforcing steel in the barriers. For steel guardrails (Figure 2-15), base plates for the rail posts are bolted through the deck or the guardrail may be cantilevered from the girders.

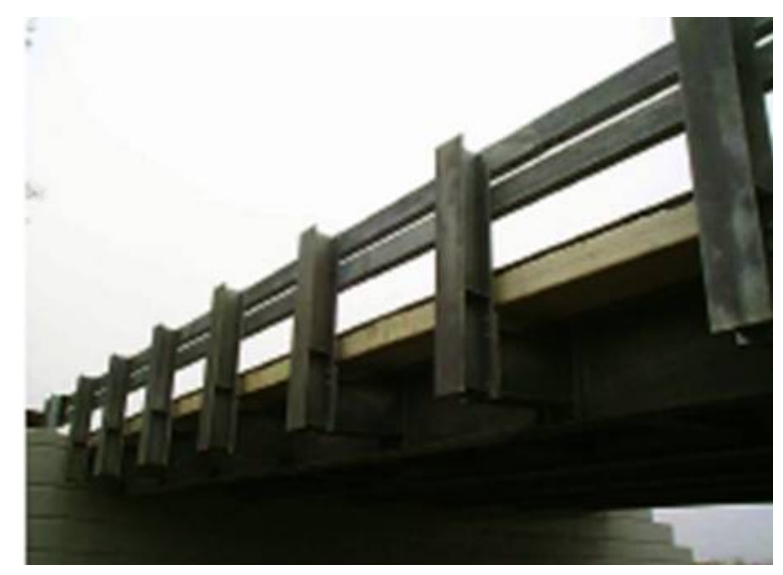

Figure 2-15 Steel Guardrail Cantilevered from Girders (Source: MMC 2003)

\subsubsection{CPI (Creative Pultrusion Inc.)}

The bridge deck arrives at the construction site in assembled modules approximately $8 \mathrm{ft}$. in width with the desired length. The modules weighs approximately 
$25 \mathrm{lbs} / \mathrm{ft}^{2}$, including the polymer concrete wearing surface or $22 \mathrm{lbs} / \mathrm{ft}^{2}$ without polymer concrete (CPI 2003). The bridge deck modules are usually lifted with nylon straps (Figure 2-16), four 3.5 in. x 6.25 in x $10 \mathrm{ft}$. long wood beams can be inserted into the hexagonal end sections for lifting the deck modules into position (CPI 2003).

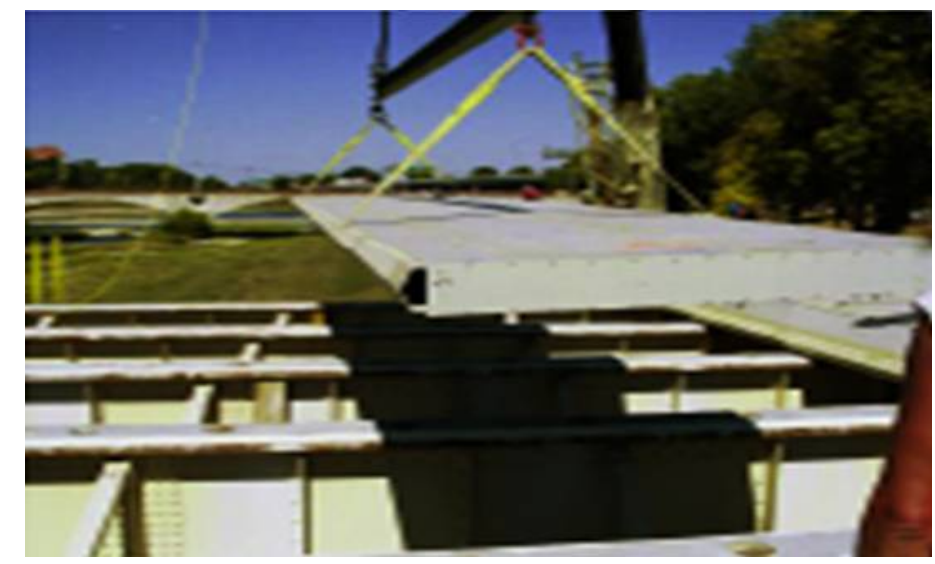

Figure 2-16 Lifting Deck Panel Using Nylon Strap (Source: CPI 2003)

The deck modules are adhered with high-performance two-component polyurethane adhesive or equivalent. The components are applied from a bulk dispensing system. The mix ratios by volume of the adhesive are 3.5 resin to 1-part curative. Figure 2-17 shows typical application of adhesive to the connecting sections.

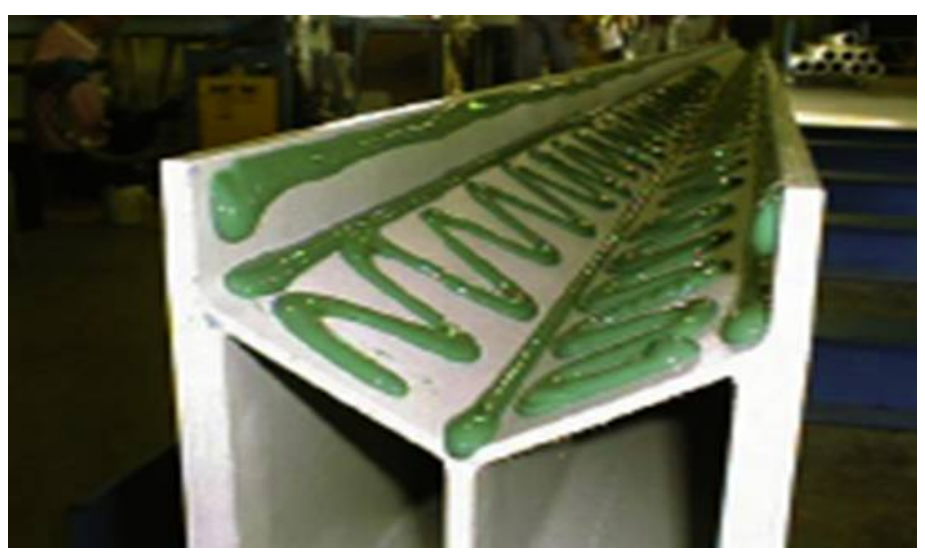

Figure 2-17 Application of Adhesive to the Connecting Sections 
The deck modulus need to be positioned or moved within 50 minutes after the adhesive has been applied before it starts hardening. The working time will decrease with a rise in temperature and increase in lower temperatures. Typical duration of the installation for CPI's 6660 series deck panel is approximately 50 minutes. at $70^{\circ} \mathrm{F}$ (CPI 2003).

The following procedure summarize the proper application of adhesive to the connecting sections (Busel and Lockwood 2003).

- First of all, apply a large bead of adhesive in the two radii sections of the bridge module truss.

- Second, apply a lard bead of adhesive at the edge of the truss flange. Third, apply a large bead of adhesive to the flat wall of the truss section in a sinusoidal pattern as shown in Figure 2-17. The horizontal distance between the peaks of the sinusoidal pattern shall not exceed 3 in.

- Finally, repeat the pattern applied on the bottom half of the truss section to the top half of the hexagonal component on the second deck module.

In addition, the following procedure outlines the proper installation of the deck modules at the construction site (Busel and Lockwood 2003).

- After applying the adhesive, locate the deck modules properly on the support beams.

- Position a minimum of two 6-ton hydraulic jacks per every 8 to $9 \mathrm{ft}$. of deck on the steel girders as shown in Figure 2-18.

- Apply even pressure in the plan of the deck by simultaneously jacking the deck module into the connected module. 
- Jack the deck module into the receiving module until a gap is no longer visible between the two modules. For example, adhesive should flow from the ends of interface.

- Allow adhesive to set to the consistency of a rubber eraser and remove the excess with a putty knife.

- Repeat steps 1-4 until all deck modules are in place.

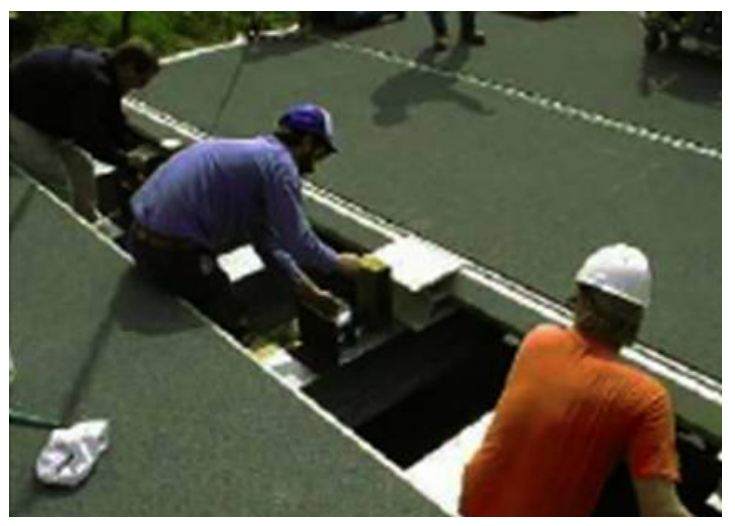

Figure 2-18 Joining Panels Together with Hydraulic Jacks (Source: CPI 2003)

\subsubsection{KSCI (Kansas Structural Composites Inc.)}

Many elements of the bridges are assembled at the factory to reduce the amount of field work required at the time of installation. Figure 2-19 shows a general overview of FRP composite bridge deck installation. The guardrail posts are inserted into the sockets of the edge closeouts and retained with one-inch solid pultruded dowels through the walls of each socket and the web of the post. The dowels are then protected with a vinyl ester resin. The posts, the synthetic wood standoff blocks, and FRP W-rail were drilled to accept one-inch FRP thread studs, which were secured with FRP nuts. This procedure eliminated the need to install railing at the site (KSCI 2003). 


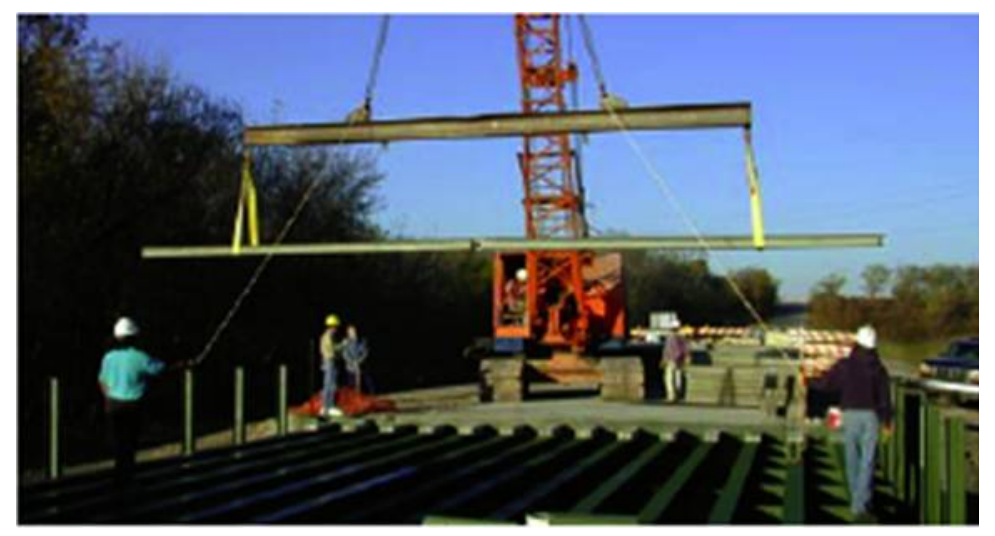

Figure 2-19 Installation of the KSCI's FRP Composite Deck (Source: KSCI 2003)

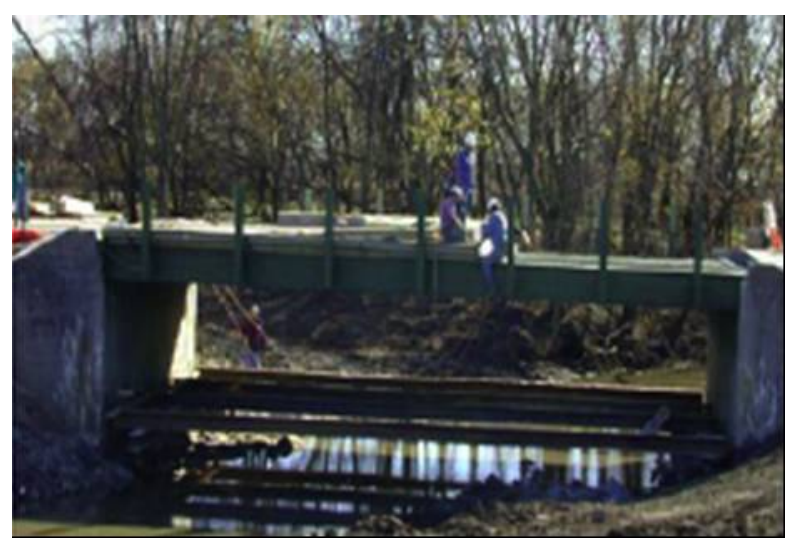

Figure 2-20 Bolting Down FRP Composite Deck (Source: KSCI 2003)

A primary bond is achieved by applying a wet laminate and vinyl ester resin to the lap joint flange on the bottom of the center section. The panel is then lifted and the joint is pulled together. To avoid scraping the wet laminate from the lap joint flange, the panel is suspended to hang with a five degree list. Chains are strung between the lift eyes of the center panel and the exterior panel. The panel is pulled into place until the joint is firm. Finally, the panel is lowered onto the header. In order to produce a optimal laminate thickness, upper side of the joint is overlaid with alternating layers of CSM and stitched roving. After this laminate had cured, the joint is filled with polymer concrete to match 
the level of the wear surface (KSCI 2003). Figure 2-20 shows bolting down FRP Composite Deck at the construction site.

\subsection{Challenges and Technical Issues in their application}

There are many challenges in the application of FRP composite materials. Those challenges should be considered as an opportunity to improve the materials to ensure that the final product will be durable and reliable.

First of all, the main concern with FRP composite materials is the long-term durability since the sufficient historical performance data are not available in bridge applications. For example, there is a concern among bridge engineers for the long-term integrity of bonded joints and components under cyclic fatigue loading. There are also concerns with improper curing of the resins and moisture absorption and/or ultraviolet light exposure of composites that may affect the strength and stiffness of the structural system. Certain resin systems are found ineffective in the presence of moisture. In the case of a glass fiber composite, moisture absorption may affect the resin and allow the alkali to degrade the fibers. Therefore, there is much work to be done in developing welldesigned anchorages, connection details, and bonded joints in composites for long-term durability (Tang and Podolny 1998).

Secondly, even though FRP composites have a higher tensile strength over conventional materials, the design has been focused on the stiffness requirement rather than strength. There is still much room for improvement and advancement of the composite deck systems in order to capitalize on its material strength. The key to 
successful application of the deck superstructure system is to optimize its geometric cross section and to establish well-defined load paths (Tang and Podolny 1998).

Finally, in order to maintain and take advantage of favorable characteristics of FRP composite bridge deck, more desirable and practical research is needed to increase demand and application. More efficient manufacturing and effective production methods should be explored and developed in terms of cost efficiency. Moreover, marketability, constructability, maintainability, and operability of FRP bridge deck panels should be supported by the continuous future research works.

In a summary, the following technical needs and concerns should be address: (i) development of design standards and guidelines; (ii) efficient design and characterization of panel-to panel joints and attachment of decks to stringers; and (iii) economical engineering of cost analysis.

\subsection{Reference}

Alampalli, S., O'Connor, J., Yannotti, A. P., and Luu, K. T. (1999). "Fiber-reinforced plastics for bridge construction and rehabilitation in New York." Materials and Construction: Exploring the connection, Proc., $5^{\text {th }}$ Materials Engineering Congress, L. C. Bank, ed., ASCE, Reston, Va., 344-350.

Busel, P. John and Lockwood, D. James (2002). "Product selection guide: FRP composite products for Bridge applications." The Market Development Alliance of the FRP Composites Industry, Harrison, NY.

Composite World (2003). "Composite Industry Overview." Ray Publishing Inc., $<\mathrm{http}$ ://www.compositesworld.com/sb/ov-introduction> (Nov. 6, 2003).

Creative Pultrusions (CP) (2003). "Corporate Information." Creative Pultrusions, Inc., $<$ http://www.creativepultrusions.com/corporate.html $>$ (Nov. 12, 2003).

European Pultrusion Technology Association (EPTA) (2003). "What is pultrusion?" $<$ http://www.pultruders.com $>$ (Oct. 5, 2003). 
Gall, T. L. (1986). Engineers' Guide to Composite Materials. American Society for Metals.

Goldstein, H. (1996). "Catching up on Composites." Civil Engineering, ASCE, March, pp. 47-49.

Hardcore Composites (2003). "About Hardcore." Hardcore Composites Inc., $<$ http://www.hardcorecomposites.com/about.html $>$ (Jul. 23, 2003).

Infrastructure Composites International (ICI) (2003). "Who are we?" Infrastructure Composites International Inc., < http://www.infracomp.com/index.html $>$ (Jul.22, 2003).

Kansas Structural Composites Inc. (KSCI) (2003). "Company profile.” Kansas Structural Composites, Inc. <http://www.ksci.com/> (Jun. 12, 2003).

Kelly, A. (Ed.). (1989). Concise Encyclopedia of Composite Materials, Pergamon Press plc, Oxford, England.

Kelton, W. D., Sadowski, R. P., and Sadowski, D. A. (2002). "Simulation with ARENA," $2^{\text {nd }}$ edition, McGraw-Hill, New York, NY, 3-15.

Martin Marietta Composites (MMC). (2003). "Composite Materials Overview." Martin Marietta Composites Inc., <http://www.martinmarietta.com/Products/composites. asp > (Oct. 12, 2003).

Mirmiran, A. (1995). "Concrete Composite Construction for Durability and Strength." Proceedings of the Symposium on Extending Life Span of Structures, International Association for Bridge and Structural Engineering, San Francisco, CA, pp. 11551160.

O'Connor, Jerry (2003). "FRP Decks and Superstructures: Current Practice." FHA, < http://www.fhwa.dot.gov/bridge/frp/deckprac.htm> (Dec. 4, 2003).

Partridge, I. (Ed.). (1989). Advanced Composites. New York, Elsevier Applied Science.

Tang, Benjamin and Podolny, Walter Jr. (1998). "A Successful Beginning for Fiber Reinforced Polymer (FRP) Composite Materials in Bridge Applications." Proc., Int. Conf. on Corrosion and Rehabilitation of Reinforced Concrete Structures, December 7-11, 1998, Orlando, FL.

Sieble, F. and Karbhari, V. (1996). "Advanced Composites for Civil Engineering Applications in the United States." University of California, San Diego, CA.

Seible, F. and Karbhari, V. (1996). "Advanced Composites Build on Success," Civil Engineering, ASCE, August, Vol.66, No. 8, pp. 44-47. 
Smith, S.A., Emmanwori, L.L., Sadler, R.L., and Shivakumar, K.N. (2000). "Evaluation of Composite sandwich panels fabricated using vacuum assisted resin transfer molding." Center for Composite Materials Research, North Carolina A\&T State University, Greensboro, NC.

SPI Composites Institute (1998). "A Look at the World's FRP Composites Bridges." A publication of the Market Development Alliance, New York, 1998.

Strongwell (2003). "Bridge superstructure and deck system components and applications." Strongwell, Inc., $<$ http://www.strongwell.com/specialproducts/bridgesdecks.htm \#decks> (Oct.13, 2003).

Tang, B. and Podolny, W. (1998). "A successful beginning for fiber reinforced polymer (FRP) composite materials in bridge applications." FHWA Proceeding, International Conference on corrosion and rehabilitation of reinforced concrete structures, Orlando, FL. 


\section{CHAPTER 3: PRELIMINARY DATA COLLECTION AND DATA ANALYSIS (QUESTIONNAIRE SURVEY)}

\section{$\underline{3.1 \text { Introduction }}$}

As mentioned in Chapter-1, preliminary data for this research were collected through a series of questionnaire, case studies, and personal interviews. The purpose of this survey was to collect subjective and objective data with regard to constructability, maintainability, operability of FRP (Fiber Reinforced Polymer) bridge deck panels. Also, information was collected with respect to the fabrication, construction methods, quality, safety, man-hour requirements, cost and productivity issues, as well as the skill level required in order to develop standard construction guidelines for FRP bridge deck construction. Questionnaire-I assisted the research team in identifying a set of criteria that were important to establish the state of the art (research and development) and also state of practice of fabrication and use of composite bridge decks both in new bridge and in rehabilitation projects. This chapter illustrates the analysis of the data obtained from questionnaire survey-I. 


\subsection{Questionnaire Survey}

The questionnaire survey was sent to the bridge engineers of 52 State Departments of Transportation (DOTs) using regular mail or e-mail. As shown in Figure $3-1,47$ out of 52 DOTs $(90 \%)$ responded to the questionnaire. The questionnaire is composed of four parts: (1) General information of FRP bridge deck panels, (2) Constructability of FRP bridge deck panels, (3) Maintainability and operability of FRP bridge deck panels, and (4) Life cycle cost (LCC) of FRP bridge deck panels. A copy of the questionnaire survey is attached in appendix A.

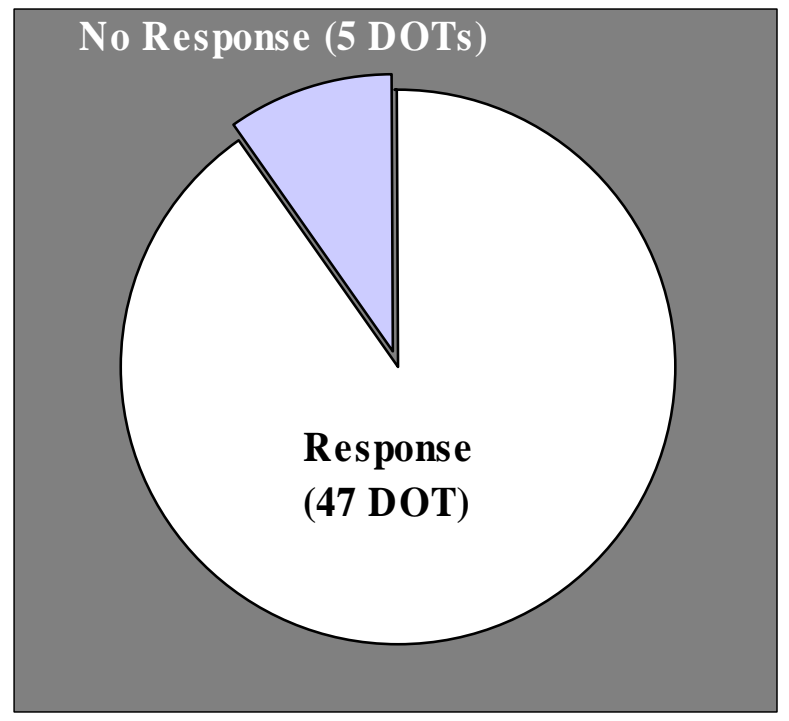

Figure 3-1 Number of DOTs responding to the questionnaire survey

\subsubsection{General information of FRP bridge deck panels}

According to the results of the questionnaire survey, a total of 9 DOTs have currently used FRP bridge deck panels among 47 DOTs responding to the questionnaire 
survey (Figure 3-2). In Figure 3-2, sections marked 1 and 2 along $X$ axis represent DOT currently using FRP bridge deck panels and DOT currently not using FRP bridge deck panels, respectively. The information posted by FHWA helped a research team in identifying DOTs currently using FRP bridge deck panels among DOTs not resending to questionnaire survey.

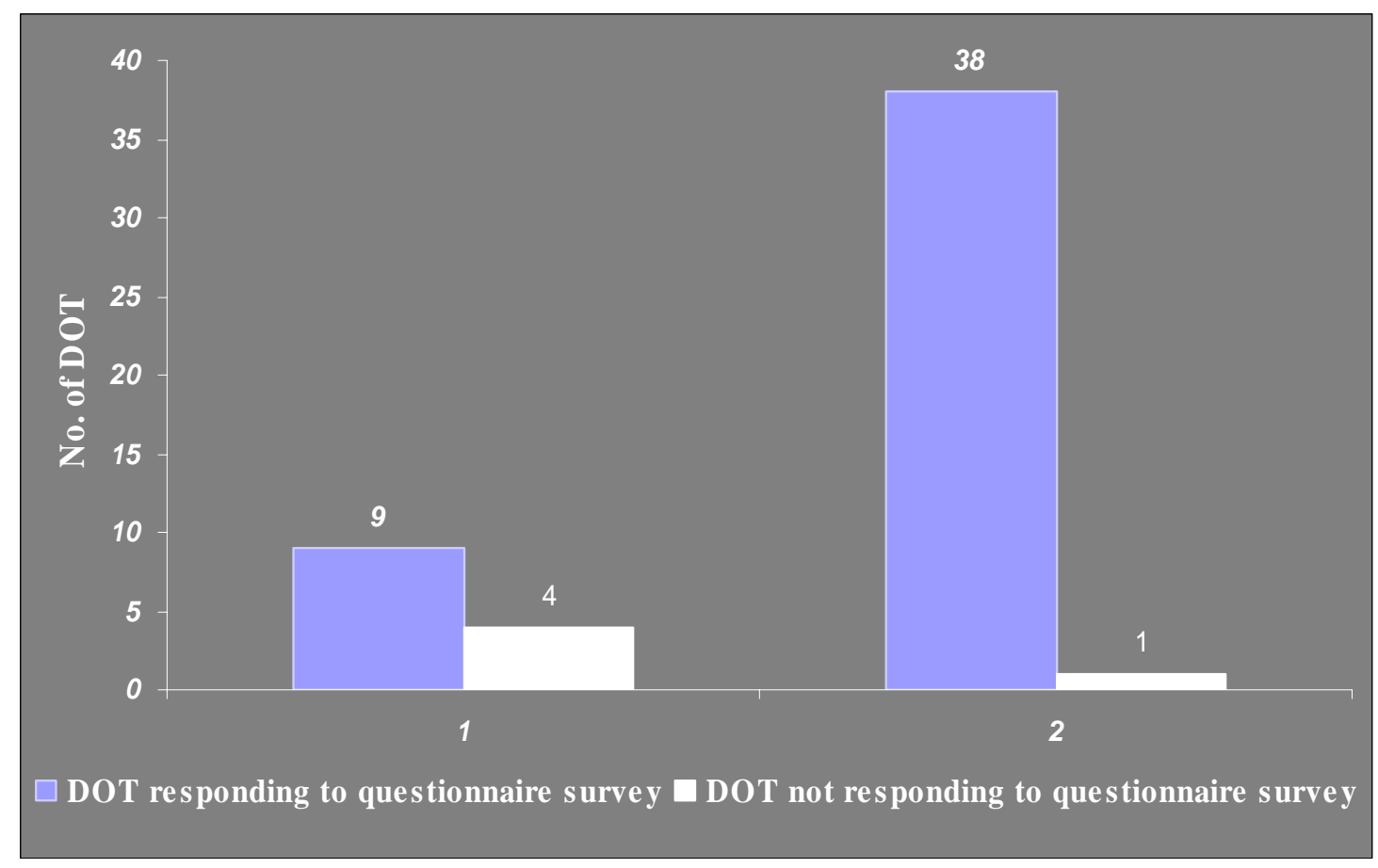

Figure 3-2 DOT currently using or not using FRP bridge deck panels

However, according to the information posted by FHWA on "Current practices in FRP composite technology" several FRP bridge deck construction projects have been completed by 17 DOTs (Current 2003). The 17 DOTs are as follows
ㅁ California
口 Delaware*
口 Idaho
口 Illinois* 


$\begin{array}{ll}\square & \text { Iowa** } \\ \square & \text { Kansas* } \\ \square & \text { Maryland* } \\ \square & \text { Missouri** } \\ \square & \text { New York* } \\ \square & \text { North Carolina* } \\ \square & \text { Ohio* } \\ \square & \text { Oregon* } \\ \square & \text { Pennsylvania* } \\ \square & \text { South Carolina } \\ \square & \text { Virginia** } \\ \square & \text { West Virginia } \\ \square & \text { Wisconsin** }\end{array}$

It was interesting to note the difference between the FHWA information and that obtained through the questionnaire. Based on the results of the questionnaire survey, the 9 DOTs listed among group-1 in Figure 3-2 are marked with an (*), whereas, the 4 DOTs marked with $(* *)$ responded to the questionnaire survey as "They currently do not use FRP bridge deck panels". The differences in response are listed below:

\section{Iowa DOT}

- FHWA web-info.

o The ' $53^{\text {rd }}$ Avenue over Crow Creek' project located in Bettendorf, Iowa was completely finished in 2001 by Martin Marietta 
Composites (MMC), one of the manufacturers producing FRP bridge deck panels.

- Questionnaire Survey

o The design of the first FRP deck is underway. One bridge deck has been scheduled for installing FRP bridge deck panels within 5 years.

o The criteria for selecting FRP bridge deck panel application include: (1) ease of installation (2) ease of transportation, and (3) less sensitive to environmental conditions.

\section{Missouri DOT:}

- FHWA web-info.

o The 'City of St. James' project was completely finished by Kansas Structural Composites Inc.,(KSCI), one of the manufacturers producing FRP bridge deck panels.

- Questionnaire survey

o The Missouri Department of Transportation has not installed any FRP decks on state maintained routes. The city of St. James Missouri has used FRP deck panels on three structures. Dr. Antonio Nanni of the University of Missouri - Rolla can provide additional details.

o Three structures were installed in the local jurisdiction of the city of St. James, Missouri. The installation of these structures was part of an 
experimental program to determine the viability of FRP bridge deck panels

\section{Virginia DOT:}

- FHWA web-info.

o Troutville Weigh Station (Strongwell)

o Tom's Creek Bridge, Blacksburg, VA (Strongwell)

o Icky Cr, Sugar Grove, VA (Strongwell beams, timber deck)

- Questionnaire survey

o Troutville weigh station: This project was completed by Strongwell Corp. VDOT allowed the FRP deck system to be placed into the ramp at the weight station. The project was monitored by Professor Tommy Cousins from Virginia Tech University for Strongwell. VDOT also provided Richard T. Brown from Atlantic Research Corporation the same access to do FRP research.

o Tom's Creek Bridge, Blacksburg, VA and Icky Cr, Sugar Grove, VA: The two projects involved FRP beams but with a timber deck and asphalt riding surface.

o Within 1 year, FRP bridge deck panels will be scheduled for installation as part of an Innovative Bridge Research and Construction (IBRC) project.

o The criteria for selecting a bridge for FRP bridge deck panel application for the Innovative Bridge Research and Construction (IBRC) program 
noted above was to increase the posted weight limit. Funds are allocated for the program by the FHWA annually. State DOT's submit their projects for consideration. One of the projects put forward by VaDOT that will receive funds is to replace the existing deck on a truss span with an FRP deck so that the posting limit could be raised.

\section{Wisconsin DOT}

- FHWA web-info.

o US-151 / Hwy 25 (Composite Deck Solution (CDS) hybrid deck system)

- Questionnaire survey

o The design of the first FRP deck is underway.

o The CDS system is similar to one method of conventional concrete bridge deck construction, except that FRP is used to replace steel.

\subsubsection{Reasons for not using FRP bridge deck panels to date}

Even though the FRP bridge deck panels have a lot of advantage over conventional bridge deck, the acceptance of FRP bridge deck panels has been conspicuously slow. The bridge engineers were asked why their DOT has not used FRP bridge deck panels. The summary of their opinion is as follows:

Want to see more reliable performance data before using them. Too expensive, unproved durability, lack of detail 
Not familiar with design criteria. Once installed, what condition inspection criteria and repair procedures would be used?

a There is no specification for their design or acceptance by AASHTO.

Not comfortable with this technology. No research associated with that.

L Lack of supplier and installers in the area.

口 Washington DOT: They don't view FRP deck panels as economically viable alternatives to conventional reinforced concrete decks for standard bridge applications.

Based on the questionnaire responses, most of the respondents currently considered high initial cost to be the main disadvantage of FRP bridge deck panel application. A few respondents were concerned of the maintenance issues after their installation. Another obstacle for the application of FRP bridge deck panels was lack of reliable performance data to prove their long service life. The respondents from Hawaii, Georgia, and Washington DOT indicated that the application of FRP bridge deck panels was not yet cost effective and appropriate for their requirements. The respondents from Texas DOT indicated lack of crash tested railing attachments for FRP bridge deck panels as a hindrance to their application. Whereas, Arkansas DOT indicated that they have not been asked to use the panels but they may be receptive if a contractor would make a request or there is an otherwise clear advantage to use them for a particular application. 


\subsubsection{The schedule for future application}

Among the State DOTs responding to the questionnaire survey, only three out of thirty eight State DOTs currently not using FRP bridge deck panels have plans for installing FRP bridge deck panels within five years.

Table 3-1 The schedule for future application

\begin{tabular}{|c|c|c|c|}
\hline & DOT & Plan & No Plan \\
\hline \multirow{3}{*}{$\begin{array}{l}\text { DOTs currently } \\
\text { not using FRP } \\
\text { bridge deck panel }\end{array}$} & $\overline{\text { Iowa }}$ & $\overline{11}$ & \\
\hline & Virginia & * & \\
\hline & Vermont & 1 & \\
\hline \multirow{9}{*}{$\begin{array}{l}\text { DOTs currently } \\
\text { using FRP bridge } \\
\text { deck panel }\end{array}$} & New York & $5-10$ & \\
\hline & Ohio & 2 & \\
\hline & Pennsylvania & 1 & \\
\hline & Illinois & 1 & \\
\hline & North Carolina & & $\sqrt{ }$ \\
\hline & Kansas & 3 & \\
\hline & Delaware & N/A & \\
\hline & Maryland & & $\sqrt{ }$ \\
\hline & Oregon & 1 & \\
\hline
\end{tabular}

Note: * Within 1 year, FRP bridge deck panels will be scheduled for installation as part of an IBRC project.

As presented in Table 3-1, Delaware State DOT does not know yet whether they can use them in the near future or not and only two State DOTs have no plan to use them within five years. The number of projects scheduled in the rest of the State DOTs range from one to ten. Especially, in case of New York DOT, five to ten projects using those panels will be scheduled and Kansas State DOT has three scheduled projects within next 5 years. One of the important finding of the questionnaire was that only eight percent of the State DOTs that do not currently use FRP bridge deck panels would like to use them. 


\subsubsection{Advantages of FRP bridge deck panels}

In the questionnaire the respondents were asked to prioritize the advantages of FRP bridge deck panels using a scale of $1-5$, where 1 represented "least priority" and 5 represented "top priority" (Figure 3-3). The advantages of FRP bridge deck panels are marked A-E on the horizontal axis in Figure 3-3, where (A) Increased capacity for live load with possible elimination of weight restrictions, (B) Good durability, fatigue resistance, long service life, resistance to de-icing salts, (C) Fast installation due to modular, prefabricated nature, and reduced traffic delay, (D) Cost saving, less expense for maintenance than total replacement, and (E) Less environmental impact and fewer permits required than replacement.

According to several previous studies, FRP composite materials can not only extend service life but also reduce maintenance costs thereby improving life cycle cost efficiency (Zhou et al. 2001, Ehlen 1999, Ehlen 1997, Yost and Schmeckpeper 2001). However, as shown in Figure 3-3, bridge engineers responding to the questionnaire survey doubted somewhat that FRP bridge deck panels could offer cost saving in terms of less expense for maintenance than total replacement. Nystrom et. al. (2003) identified in their study that FRP bridge technology would not be cost competitive, even in the standard short-span bridges, if the cost of component materials does not reduce significantly. Therefore, it is imperative to reduce cost of FRP components in the application of FRP bridge deck panels. 


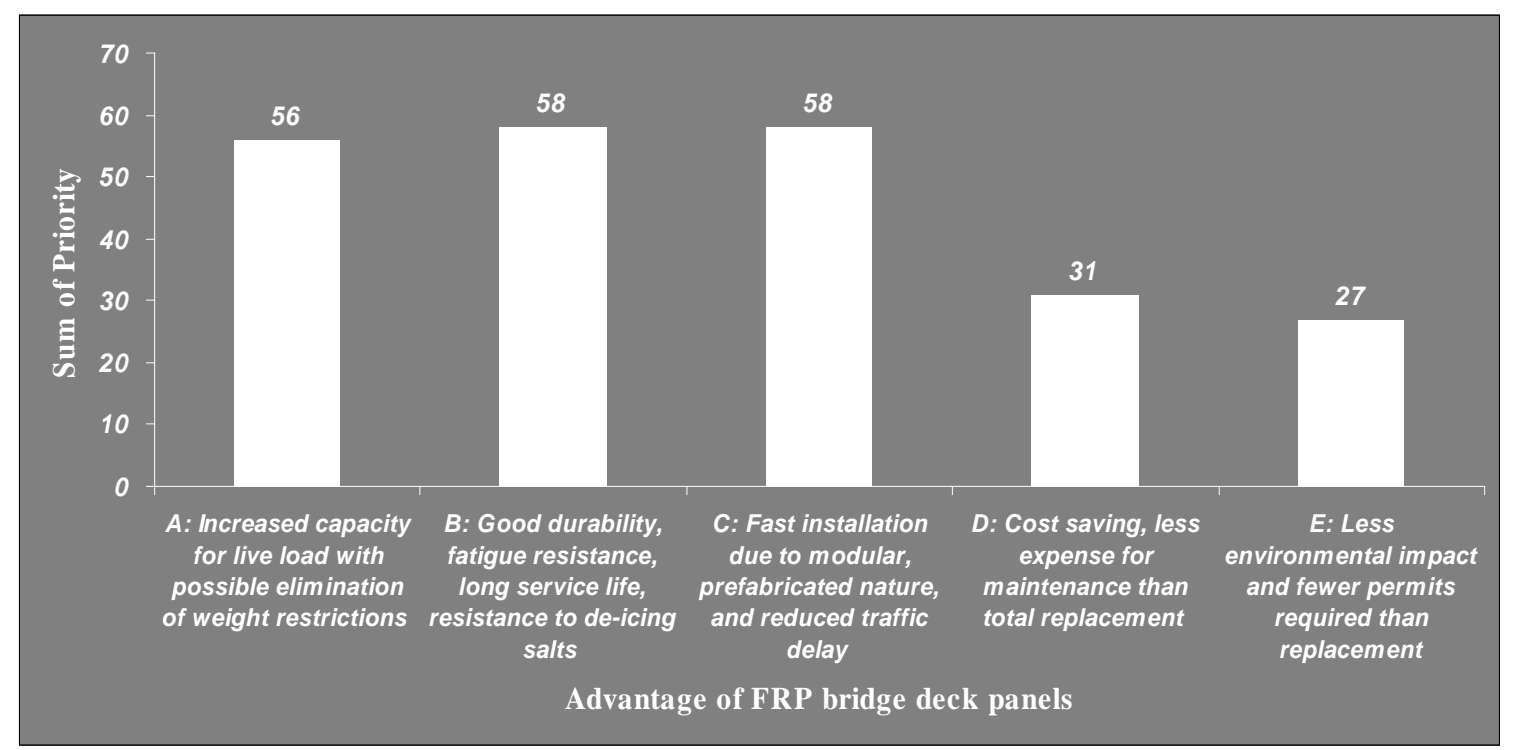

Figure 3-3 Advantage of FRP bridge deck panels

\subsubsection{The Application of FRP bridge deck panels}

As shown in Figure 3-4, 8 out of 9 DOTs currently using FRP bridge deck panels have used them in low-volume-rural roadways. Delaware and Ohio DOT have also used them on high-volume-rural roadways. FRP bridge deck panels have also been installed on lift span (movable bridge) by Martin Marietta Composites, Inc., at Astoria, Oregon. It is the first application of its kind in the United Sates where the existing wood or timber decking on a movable bridge was replaced by FRP bridge deck panels. 


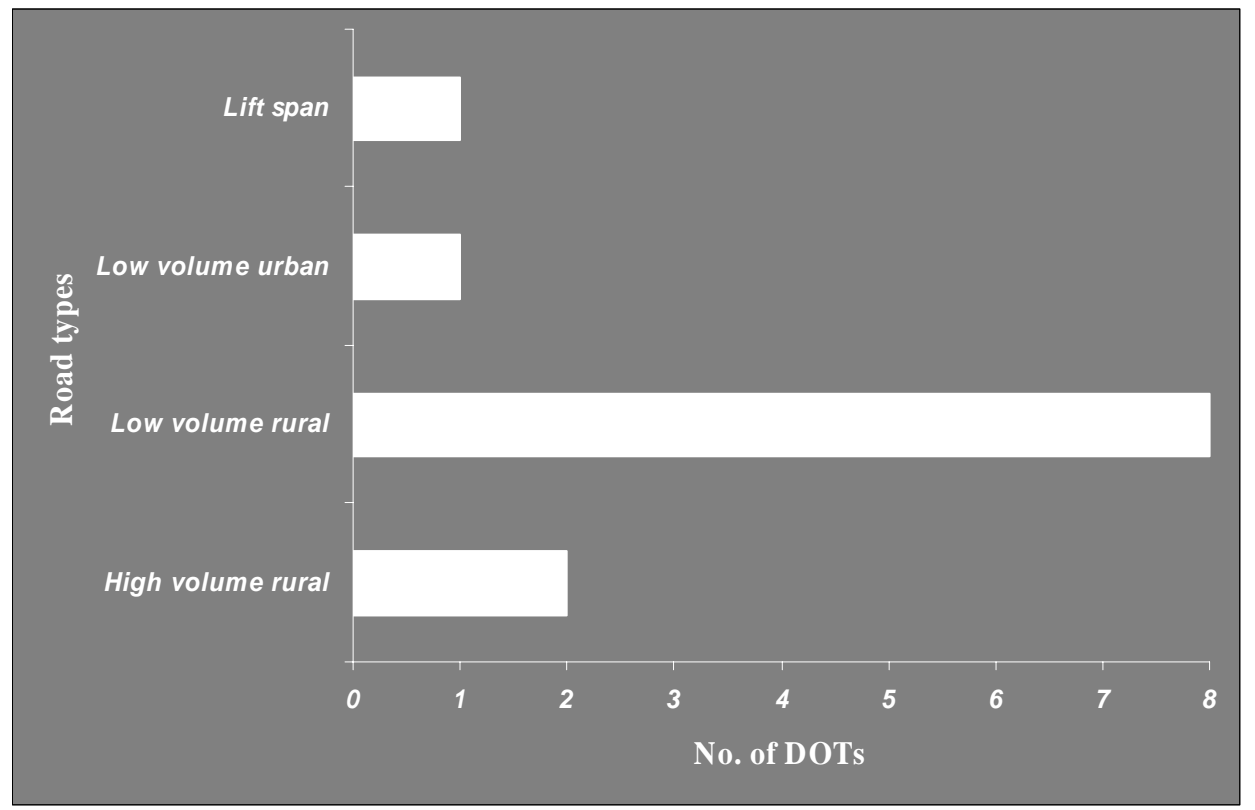

Figure 3-4 Road type of application for FRP bridge deck panels

3.1.2 Construability issues of FRP bridge deck panels

In this section, the following issues with regard to construability of FRP bridge deck panels are introduced.

$\square \quad$ Deck structure types

$\square \quad$ Construction sequence/method

- For connection of FRP bridge deck panels

- For connection of deck-to-girder,

$\square \quad$ Wearing surface

$\square \quad$ Specific installation method

口 Manufacturing processes

$\square \quad$ FRP bridge deck cross-section types

口 Construction specifications 
$\square$ Detailed information on completed project (i.e., project name, location, date installed, etc.)

$\square \quad$ Barriers encountered in installing

$\square \quad$ Delivery issues

\subsubsection{Deck structure types replaced}

FRP bridge deck panels have been predominantly used to replace 'Concrete Castin-place' and 'Wood or Timber' deck structures as shown in Figure 3-5. According to the results of the questionnaire survey, FRP bridge deck panels could be used to replace various types of deck structure.

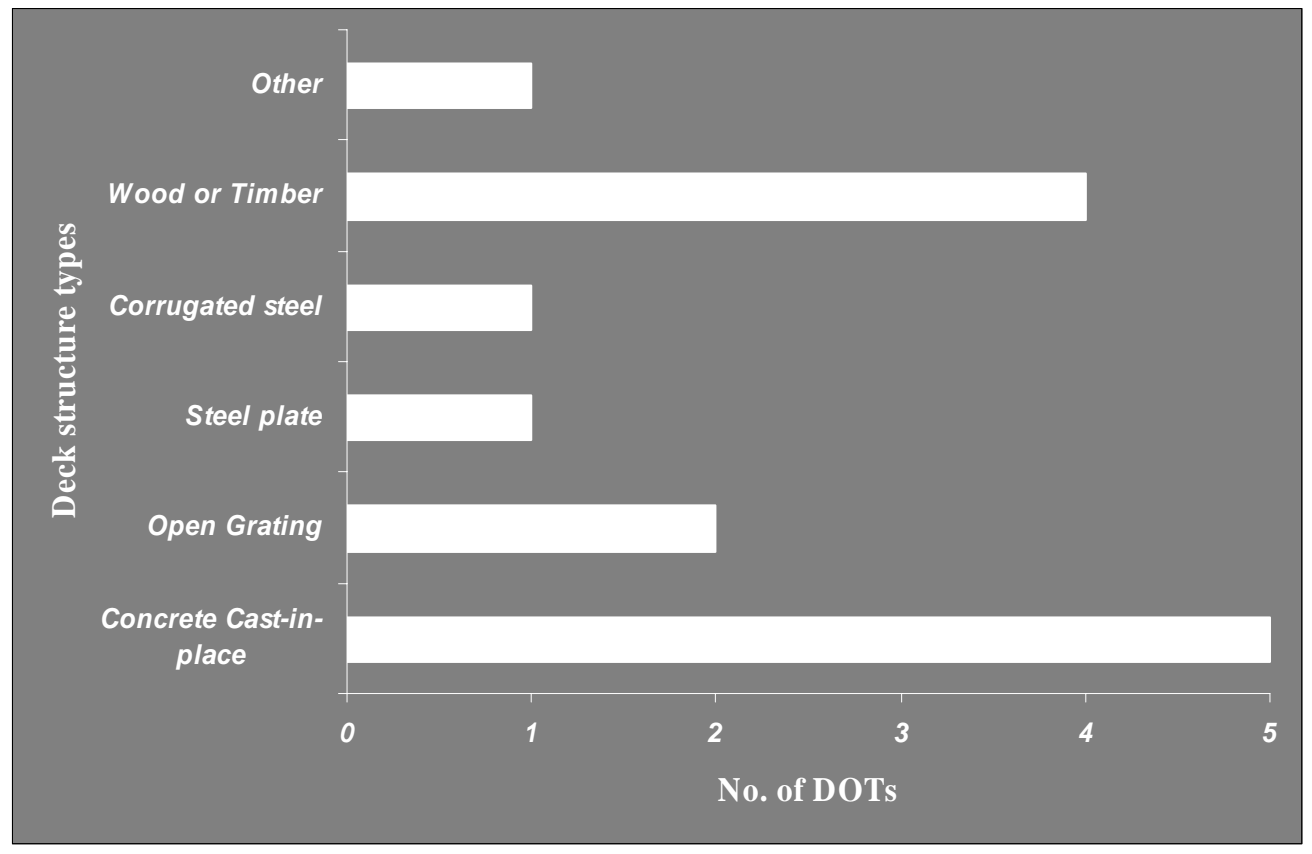

Figure 3-5 Deck structure types 


\subsubsection{Construction sequence/method for connection}

Based on the results of the questionnaire survey, a total of 5 manufacturers' FRP bridge deck panels have been installed. In this section, the information on construction sequence/method to connect those panels and decks to girders is discussed. However, the sequence might change a little according to the project requirements.

(1) For connection of FRP bridge deck panels

Martine Marietta Composites (MMC): Typical panel-to-panel connections are made by applying epoxy adhesive in the tongue-and-groove and then holes are drilled through both sections and FRP dowel bars are placed in the hole. The dowel bars are installed to protect the joint while the epoxy adhesive cures. As a last step, FRP splice strips are installed over the field joints for additional durability (Refer to Figure 3-6).

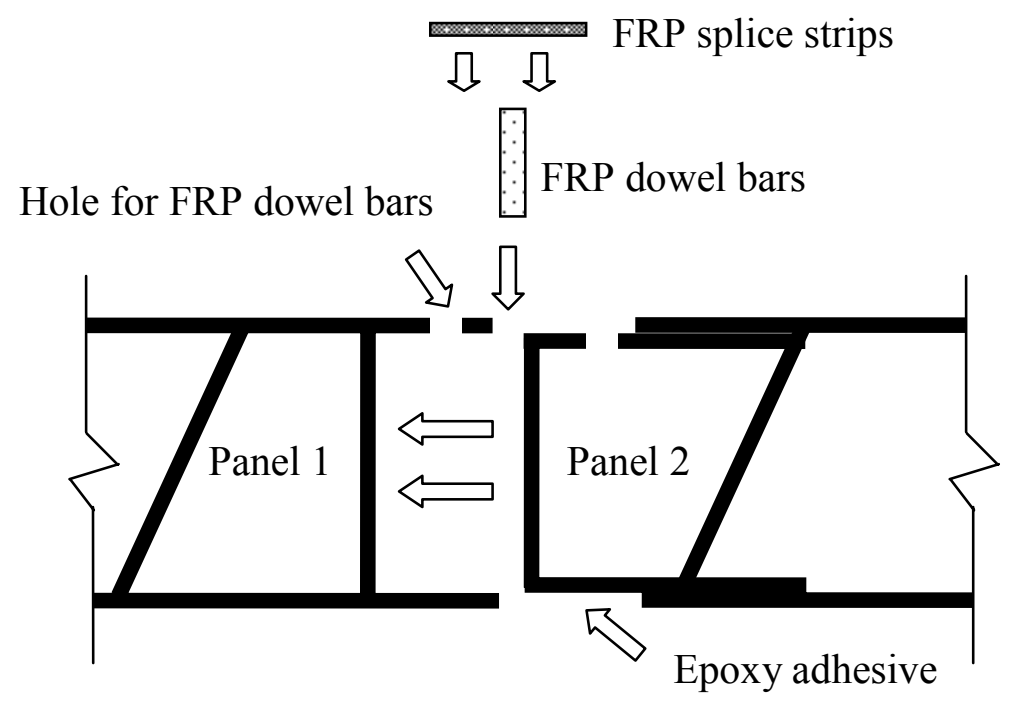

Figure 3-6 MMC joint system 
Hardcore Composite Inc.,(HCI): The panels are connected by using epoxy adhesive in the tongue-and-groove and FRP splice plate are installed over the filed joints for additional durability (Refer to Figure 3-7).

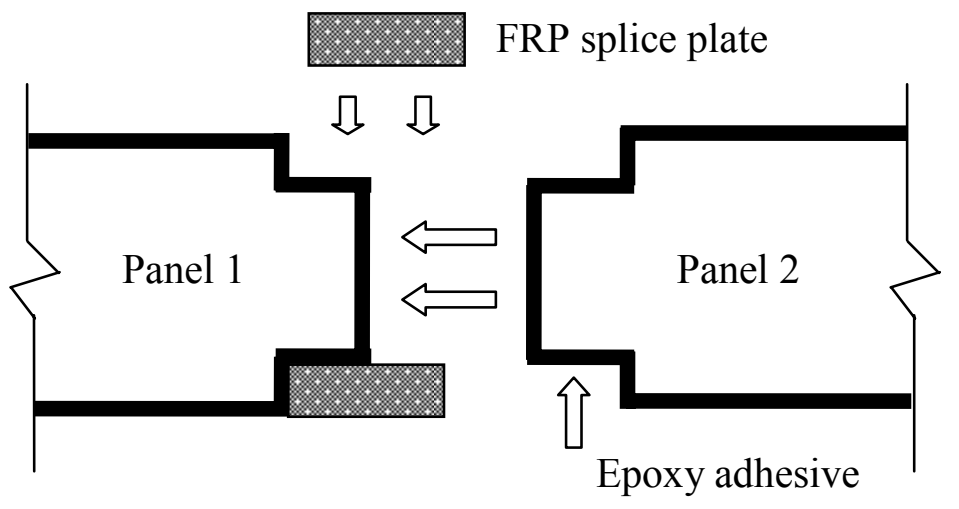

Figure 3-7 HCI joint system

G Kansas Structural Composites Inc., (KSCI): The panel-to-panel connection method is somewhat similar to that of $\mathrm{HCI}$ except for using bolts and nuts instead of FRP splice plates.

Creative Pultrusion Inc., (CPI): The deck modules are connected with polyurethane adhesive in the tongue-and-groove (Refer to Figure 3-8).

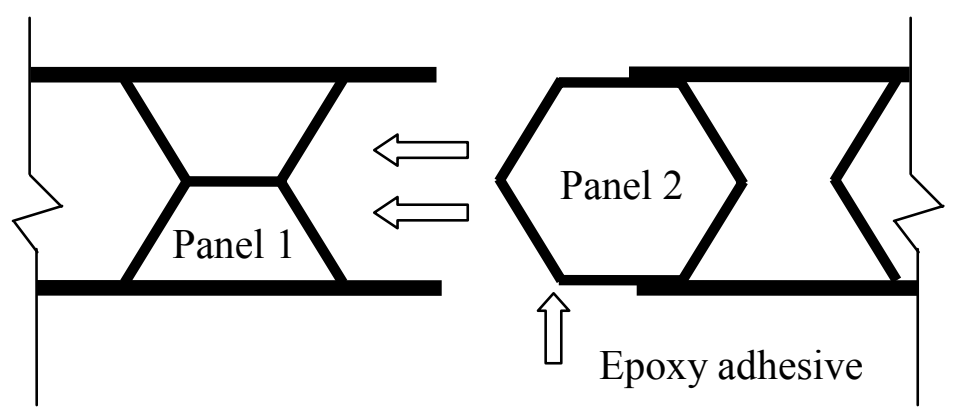

Figure 3-8 CPI joint system

Infrastructure Composites International (ICI): Pilogrip adhesive is used to connect the male and female ends of adjacent panels together (Refer to Figure 3-9) 


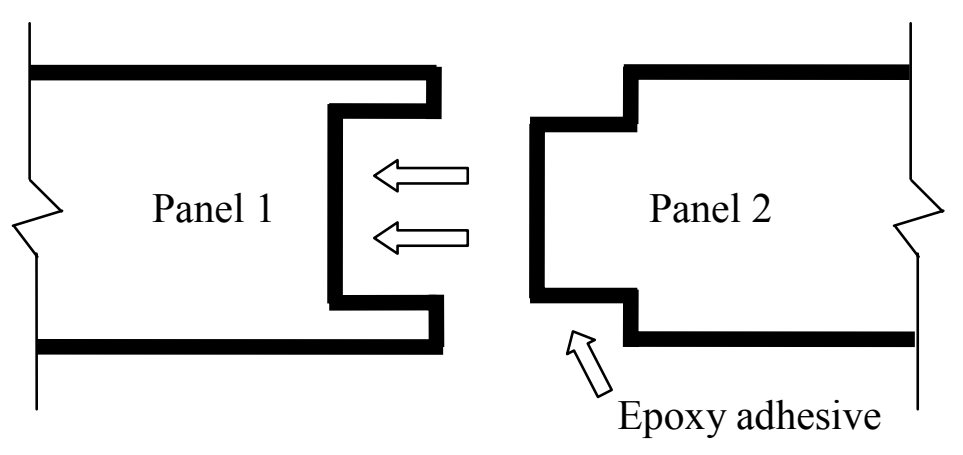

Figure 3-9 ICI joint system

The questionnaire survey indicated that cracks were generated in the field joints of FRP bridge panels for all the manufacturers. It is apparent that manufacturers should improve the construction method for applying field joints to prevent these cracks. As shown in Figure 3-10, the deck connection of MMC has been used most up to now.

$\begin{array}{ll}\square & \text { Missouri DOT: KSCI } \\ \square & \text { New York DOT : MMC and HCI } \\ \square & \text { Ohio DOT: HCI, MMC, ICI, and CPI } \\ \square & \text { Oregon DOT: MMC } \\ \square & \text { Pennsylvania DOT: MMC, HCI, and CPI } \\ \square & \text { Illinois DOT: MMC } \\ \square & \text { North Carolina DOT: MMC } \\ \square & \text { Kansas DOT: KSCI } \\ \square & \text { Delaware DOT: HCI } \\ \square & \text { Maryland DOT: MMC }\end{array}$




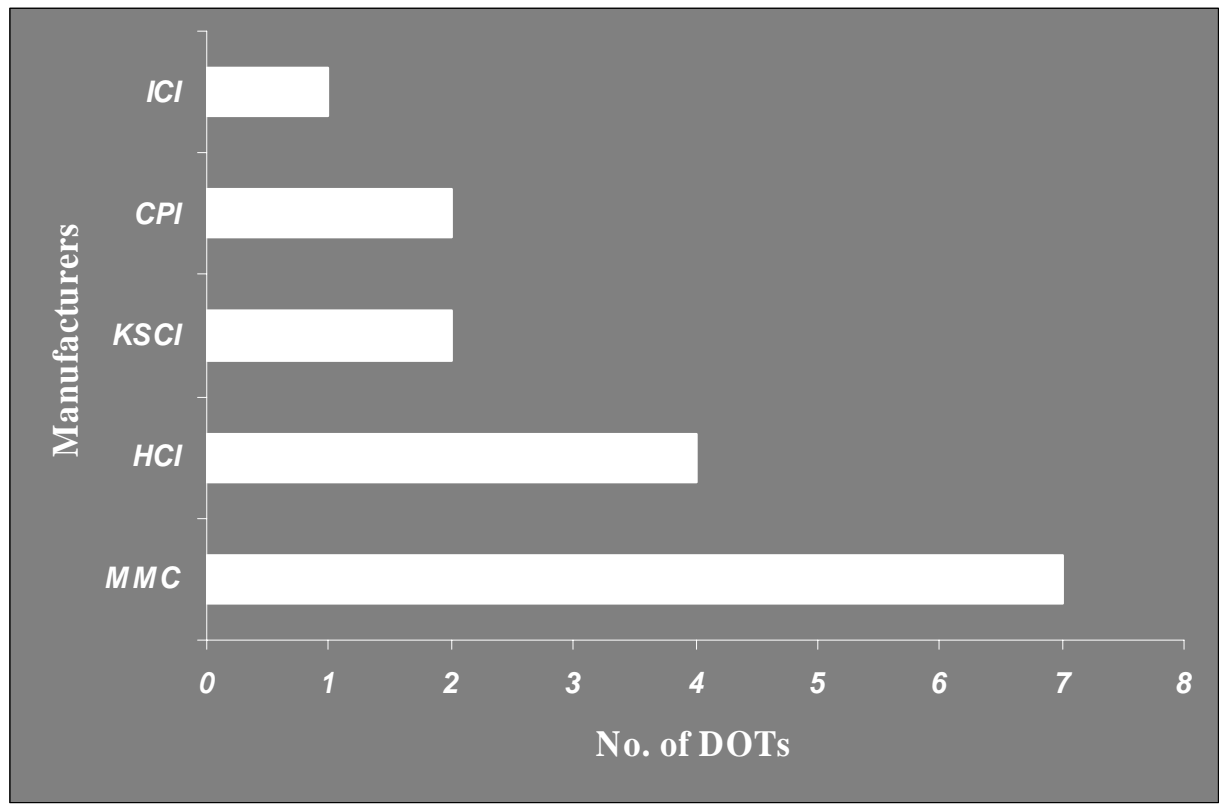

Figure 3-10 Construction method for deck connection

(2) For connection of deck-to-girder (Busel and Lockwood 2000)

$\square$ MMC: After the decks of MMC are in place, they are connected with the girders by using shear studs (Figure 3-12 (a)) Holes are cut into the deck for connection in the factory. As shown in Figure 3-12 (c), the shear studs are welded into the girders using a shear stud gun and then non-shrink grout is poured in the cavity as shown in Figure 3-12 (d). 


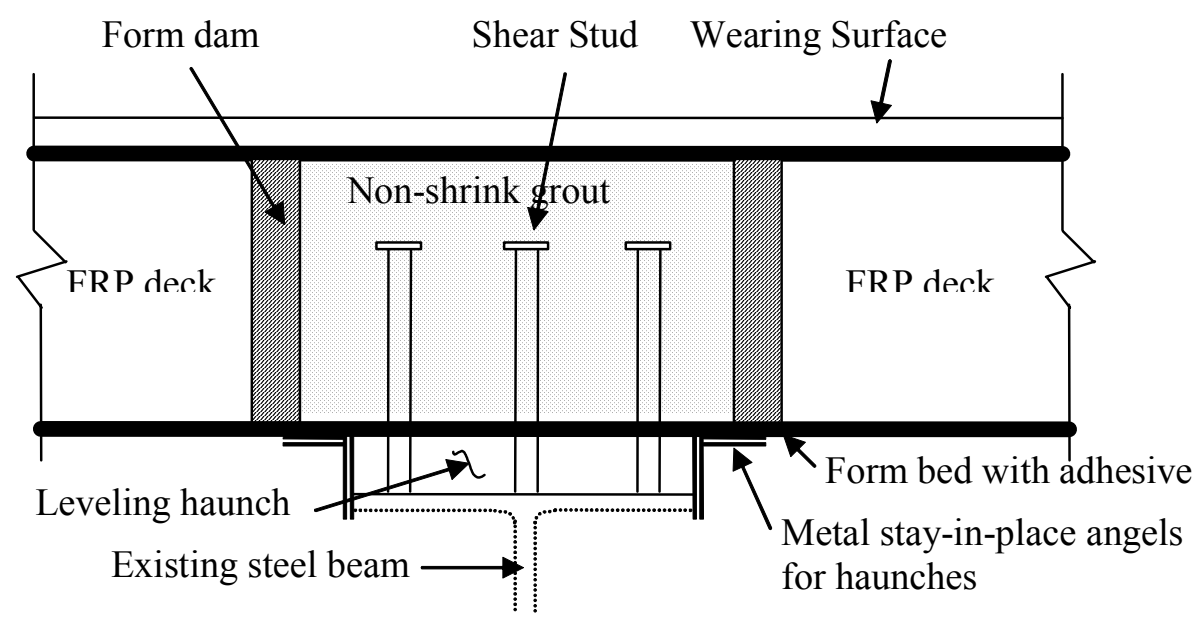

Figure 3-11 MMC deck-to-girder system

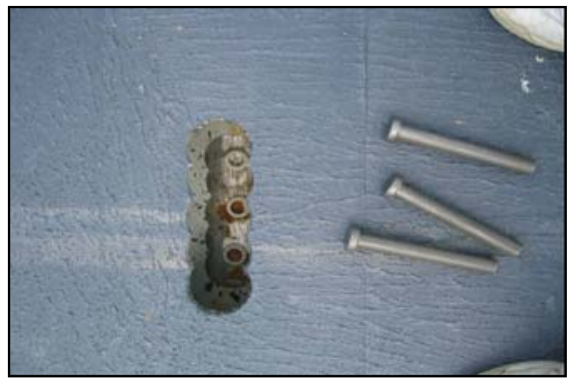

(a) Ready to use shear studs

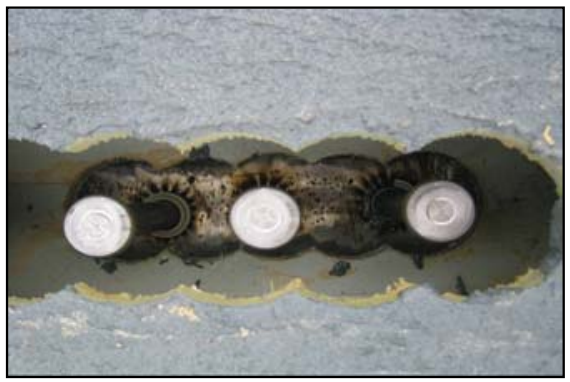

(b) After welding shear studs

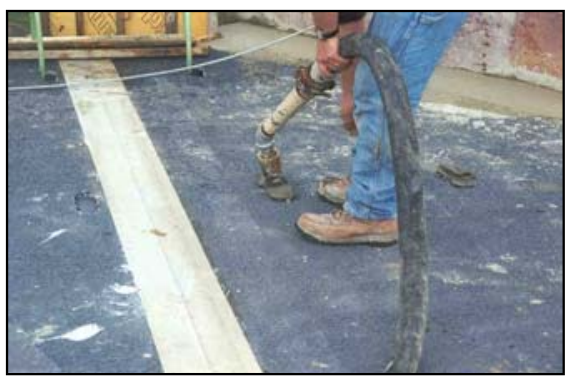

(d) Non-shrink grouting

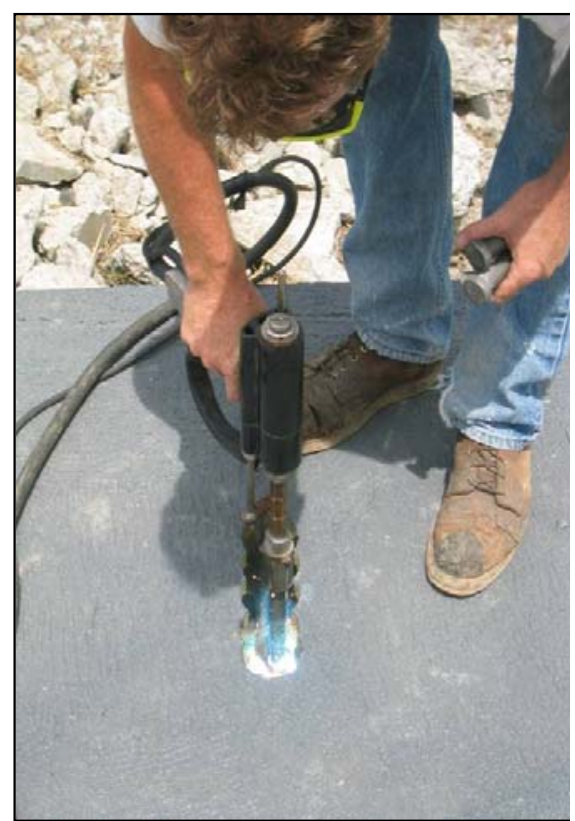

(c) Shear stud gun

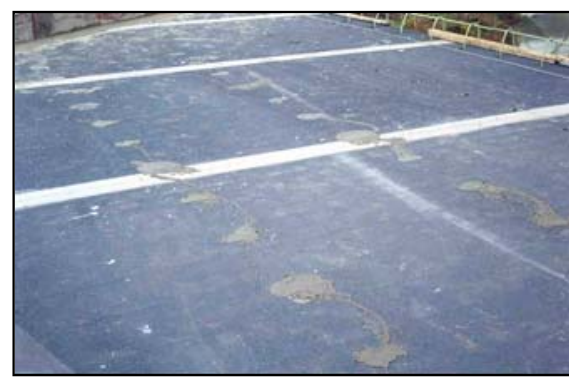

(e) After non-shrink grouting

Figure 3-12 MMC deck-to-girder system's pictures 
HCI: As shown in Figure 3-13, in the deck-to-girder connection, studs are welded into the concrete beams through predrilled stud-holes in each of the panels. The studs are welded to the steel embedded in the deck and to the steel plates embedded in the concrete beam. Finally, non-shrink grout is poured in the cavity

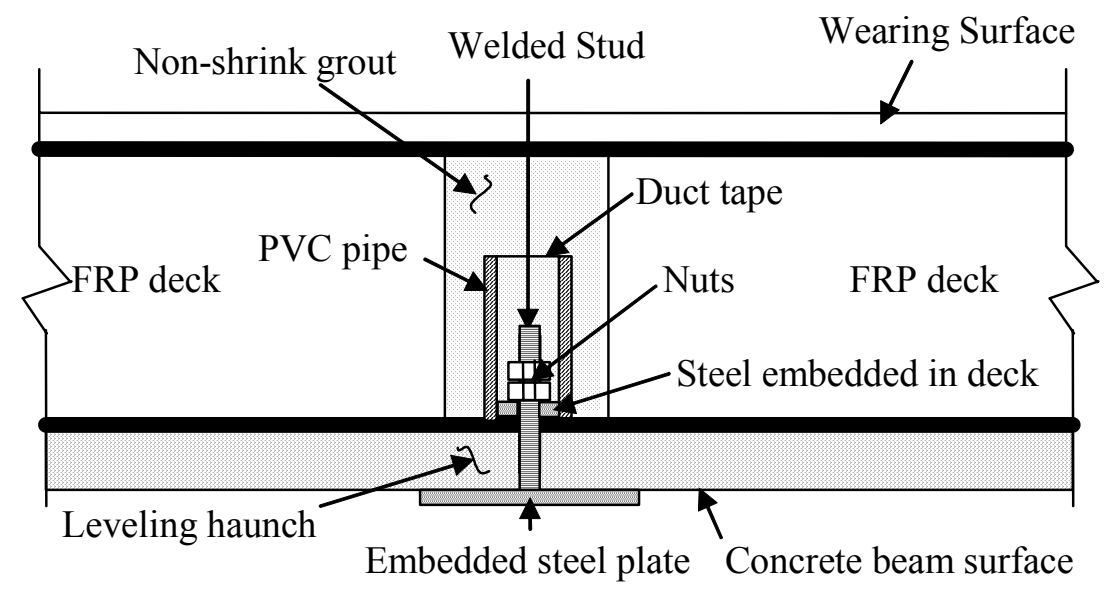

Figure 3-13 HCI deck-to-girder system

KSCI: To connect deck-to-girder, blind fasteners are used at the joints.

Blind fasteners require access from only one side of the work piece when they are installed. Polymer concrete is poured to fill the joints.

CPI: Unlike other manufacturers, CPI uses spacer wedges instead of a haunch in order to achieve the desired cross slope. The FRP bridge deck panels are placed on top of the spacer wedges and the shear studs are welded into the existing steel girders through predrilled stud-holes in each of the panels. Two cardboard bulkheads are inserted into the deck section in order to make cavity to grout and then non-shrink grout is poured in the cavity (Refer to Figure 3-14) 


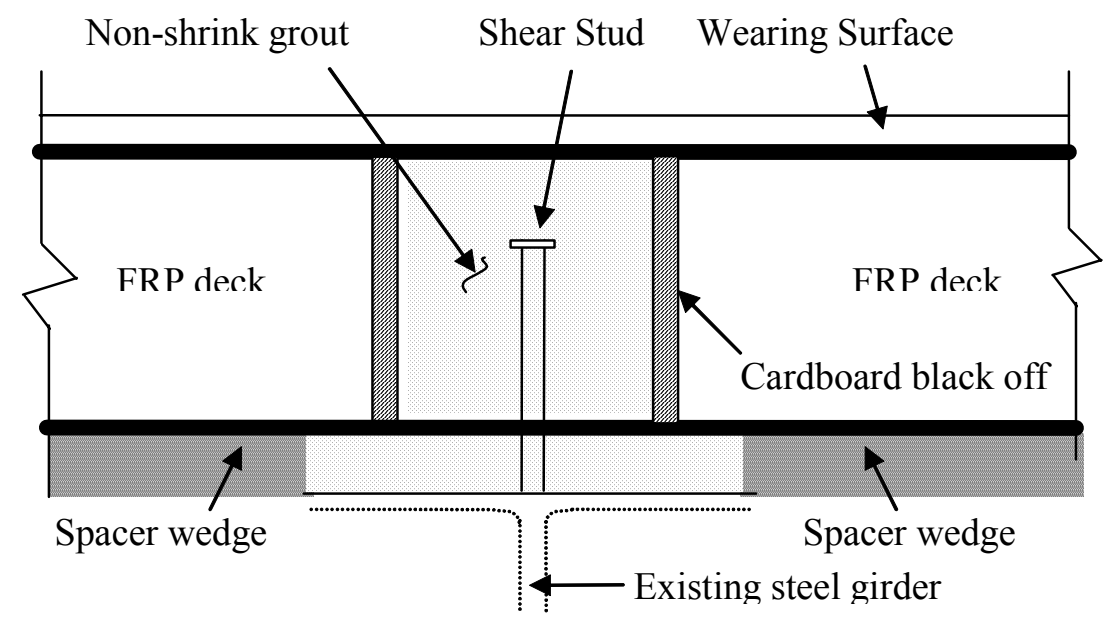

Figure 3-14 CPI deck-to-girder system

$\square \quad$ ICI: Once the panels are in place, shear studs are welded into the girder flanges through predrilled holes in each of the panels. A plastic cylinder is inserted into the holes in order to make cavity for the grout and then nonshrink grout is poured into the cavity.

\section{$\underline{3.1 .2 .3 \text { Wearing surface }}$}

Bituminous material was predominantly used as the material for the wearing surface for FRP bridge deck panels followed by polymer concrete, epoxy overlay, and latex modified concrete (Figure 3-15). For example, 'HOT Bituminous asphalt' and 'Basalt aggregate' was used in Pennsylvania DOT. The wearing surface product applied by Pennsylvania DOT was 'T-48' made by Transpo Industries Inc. 


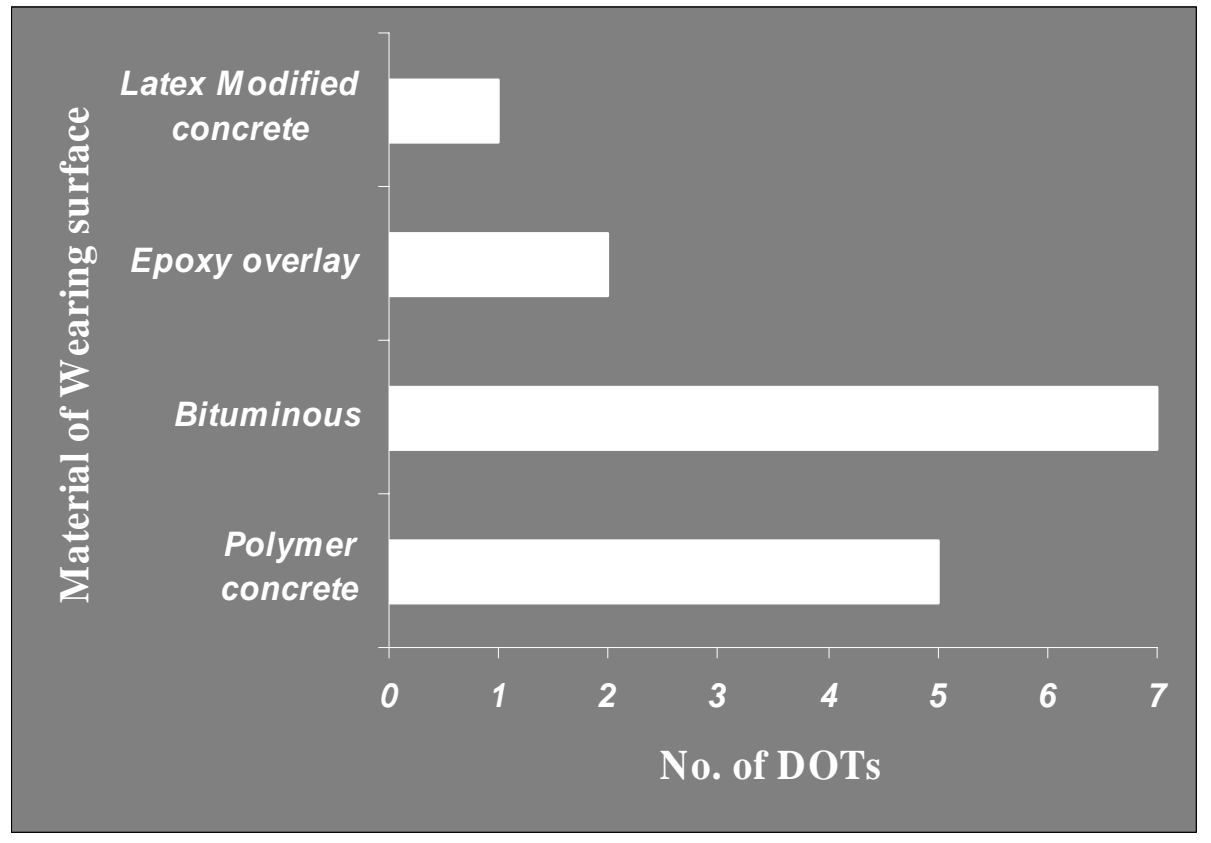

Figure 3-15 Material types of wearing surface

\subsubsection{Specific installation method}

The DOTs that responded to the questionnaire indicated that they do not have a specific method of FRP bridge deck panel installation but they followed the installation method recommended by the manufacturer selected for their projects.

\subsubsection{Manufacturing processes}

The following is a summary of manufacturing methods used by different DOTs for FRP bridge deck panels

Missouri DOT: Open molding (Hand Lay-up)

NY DOT: Open Molding (Hand Lay-up), Closed Molding (Pultrusion and Vacuum Assisted Resin Transfer Molding) 
Ohio DOT: Open Molding (Hand Lay-up), Closed Molding (Pultrusion and Vacuum Assisted Resin Transfer Molding: VARTM)

․ Pennsylvania DOT; Open Molding (Hand Lay-up), Closed Molding

(Pultrusion and Vacuum Assisted Resin Transfer Molding)

IIllinois: Closed Molding (Pultrusion)

North Carolina DOT: Closed Molding (Pultrusion)

ㅁ Kansas DOT: Open Molding (Hand Lay-up)

D Delaware DOT: Close Molding (Vacuum Assisted Resin Transfer

Molding: VARTM)

口 Maryland DOT: Close Molding (Pultrusion)

Oregon DOT: Close Molding (Pultrusion)

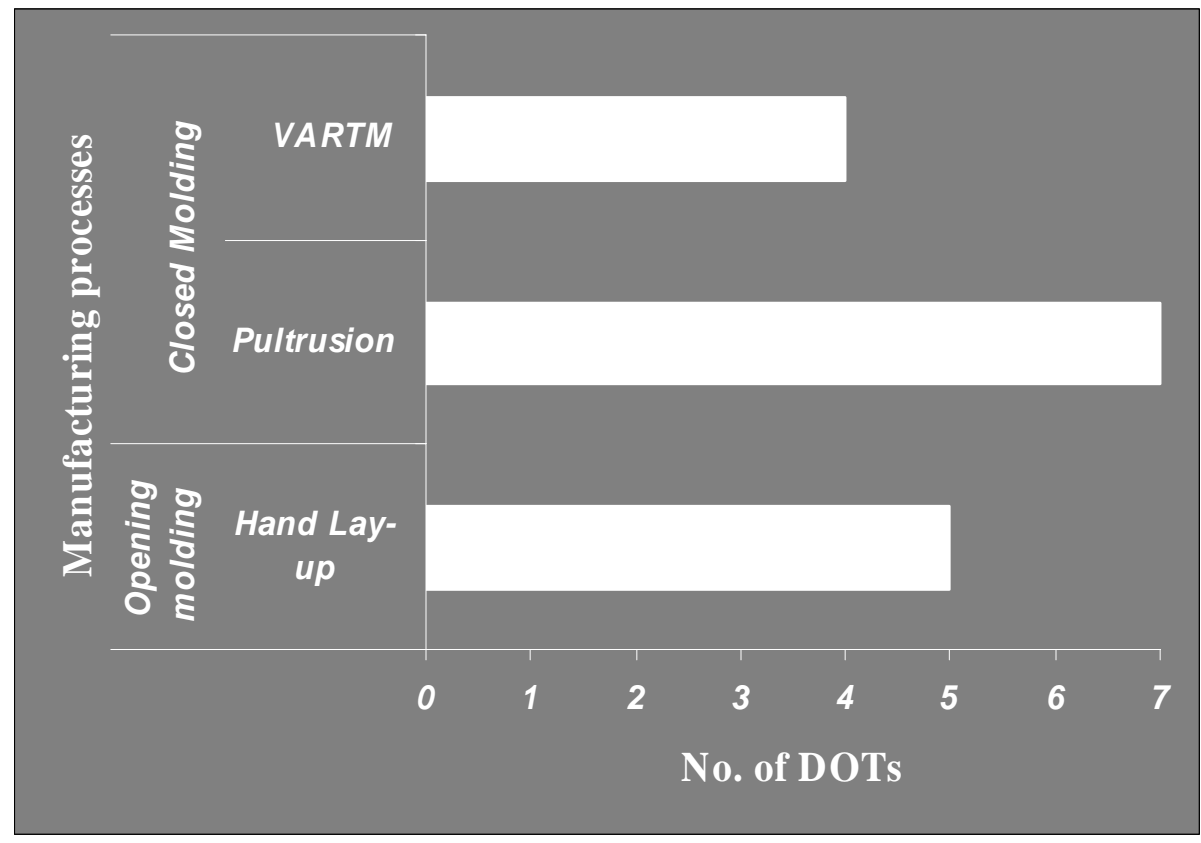

Figure 3-16 Manufacturing processes

The 'Pultrusion' processing method was used by 7 DOTs and is directly related to the manufacturing process used by the selected manufacturer (also refer to Figure 3-10). 
As explained in Chapter 2, Martin Marietta Composites (MMC) and Creative Pultrusion Inc., (CPI) use 'Pultrusion' method whereas Hand lay-up method is used by Hardcore Composites Inc., (HCI) and Kansas Structural Composites Inc., (KSCI). Vacuum Assisted Resin Transfer Molding (VARTM) method has also been used by HCI.

\subsubsection{FRP bridge deck cross-section types}

According to a study by Zureick et al. (1995), the performance of several FRP bridge deck panel configurations was tested using a general-purpose finite-element code, Structural Analysis software (SAP) IV in the preliminary studies (Henry 1985, Ahmad and Plecnik 1989, Plecnik and Azar 1991). The SAP utilizes the finite element method to calculate the response of a structure such as displacement, stress, strain, moment, etc. The finite element method is one of the most popular structural analysis methods using computers. From the preliminary studies it was found that the design was always controlled by the deflection limit state rather than the strength limit state.

The results of these preliminary studies indicated that type 'A' of Figure 3-17 had the lowest deflection limit as compared to other cross-section types. According to the studies by Henry (1985) and Ahmad and Plecnik (1989), deflection limit (stringer spacing/800) was satisfied when the thickness of top, bottom, and diagonal member were 5/8 in., 1/2 in., 3/8 in., respectively with a height of 9 in. as shown in Figure 3-17 (Zureick et. al. 1995). 

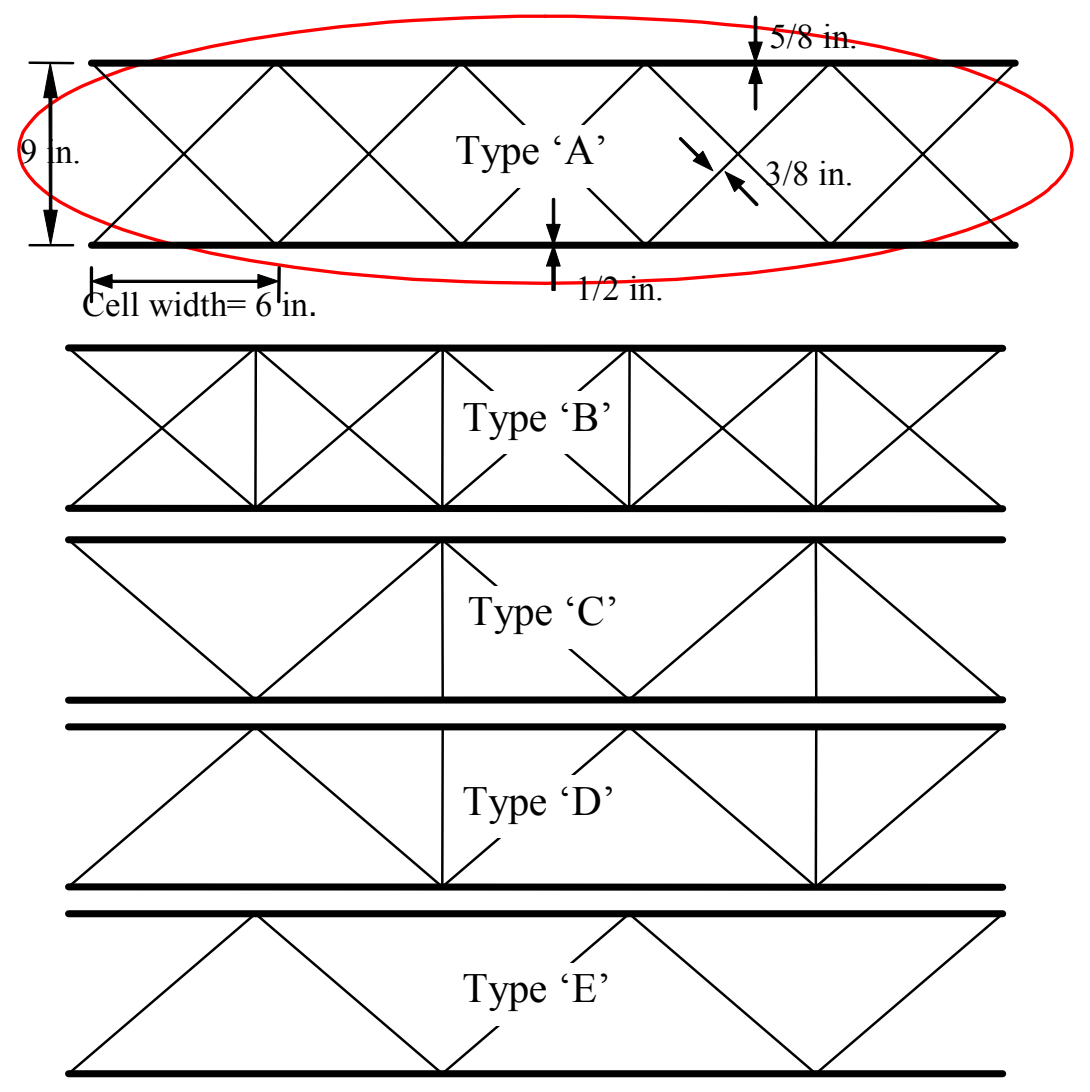

Figure 3-17 FRP bridge deck cross-section types

In order to identify the cross-section types and the thickness used by different states the following questions were asked in the questionnaire: (i) What is the thickness of top, bottom, and diagonal plates of the FRP bridge cross-section types used in your state? (ii) Please indicate the cross-section types used in your state? The summary of the responses is as follows:

$\square \quad$ Missouri DOT: Honeycomb or Vertical sine-wave type

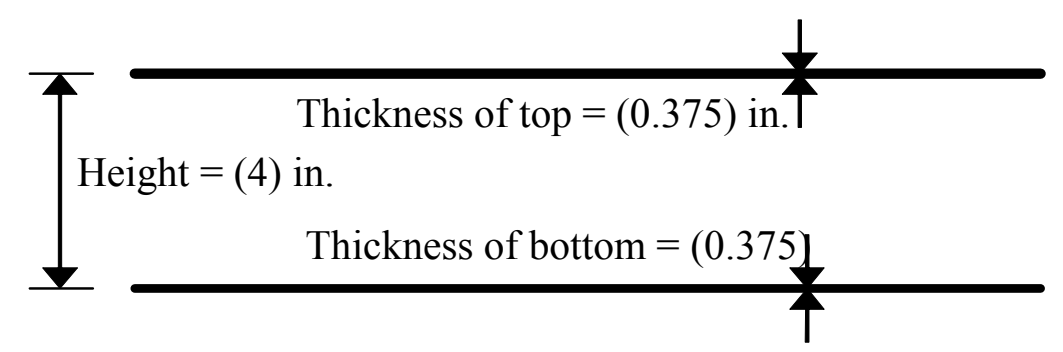


- Pennsylvania DOT: Honeycomb or Vertical sine-wave type (Bridge 1),

Box-type, and Hexagon-type

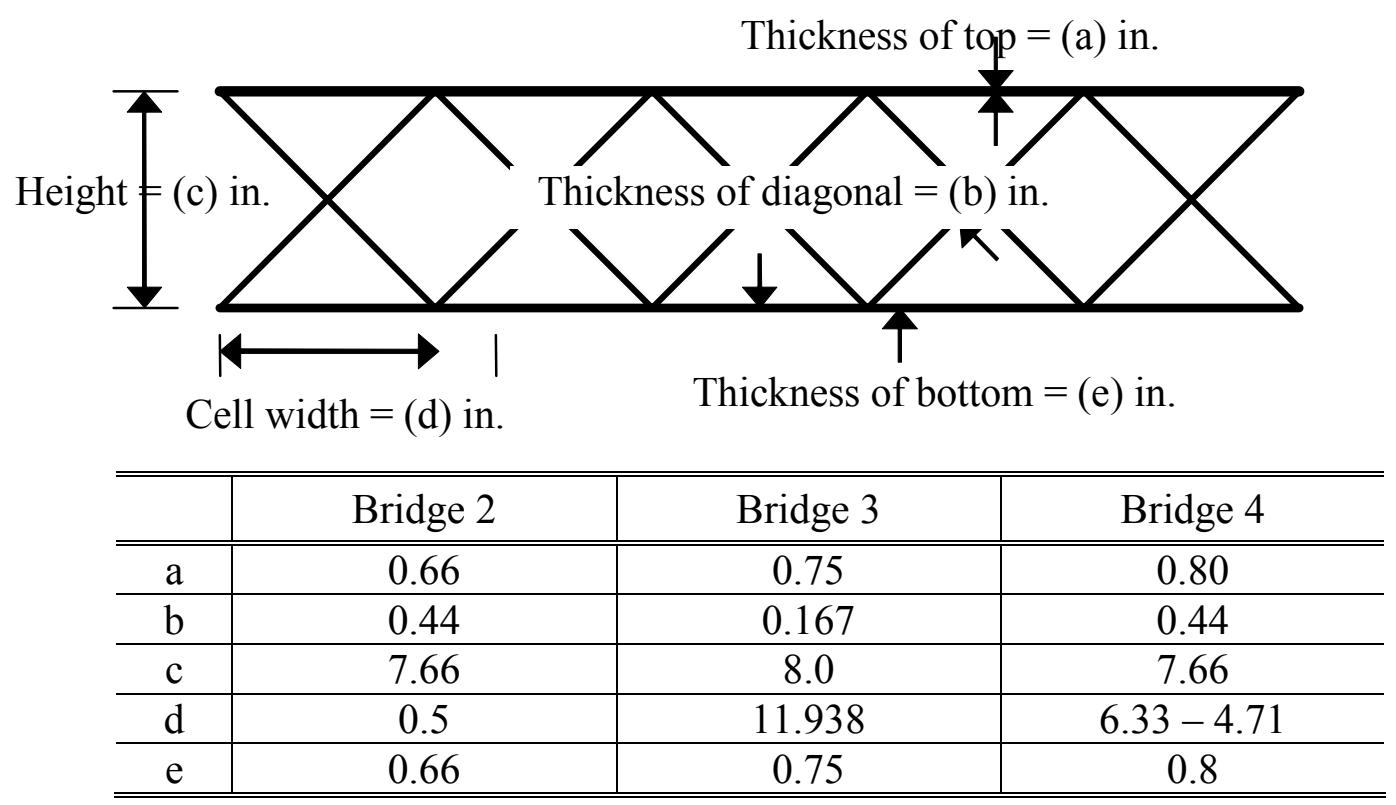

Dorth Carolina DOT: Box-types

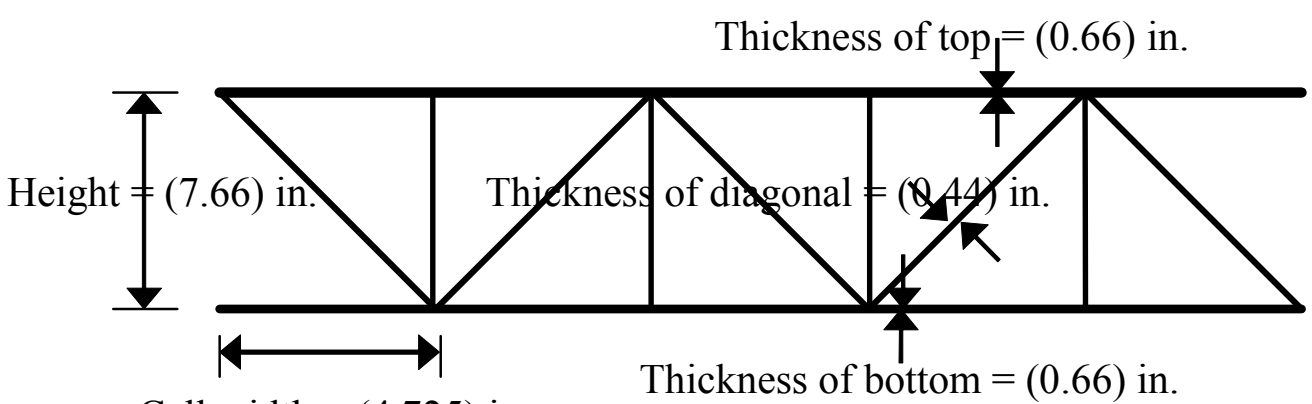

Cell width $=(4.725)$ in.

Kansas DOT: Vertical sine-wave type (*:4 3/4 in. -22.5 in.)

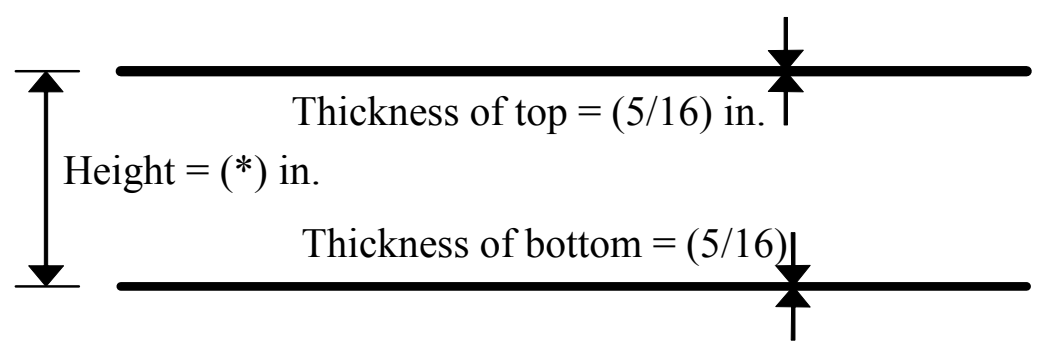




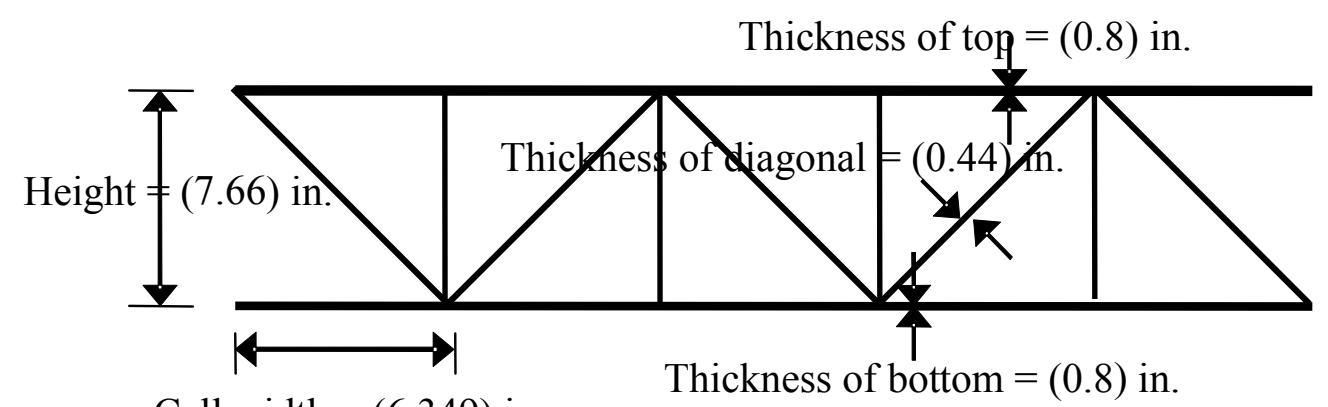

Cell width $=(6.349)$ in.

O Oregon: Box-types
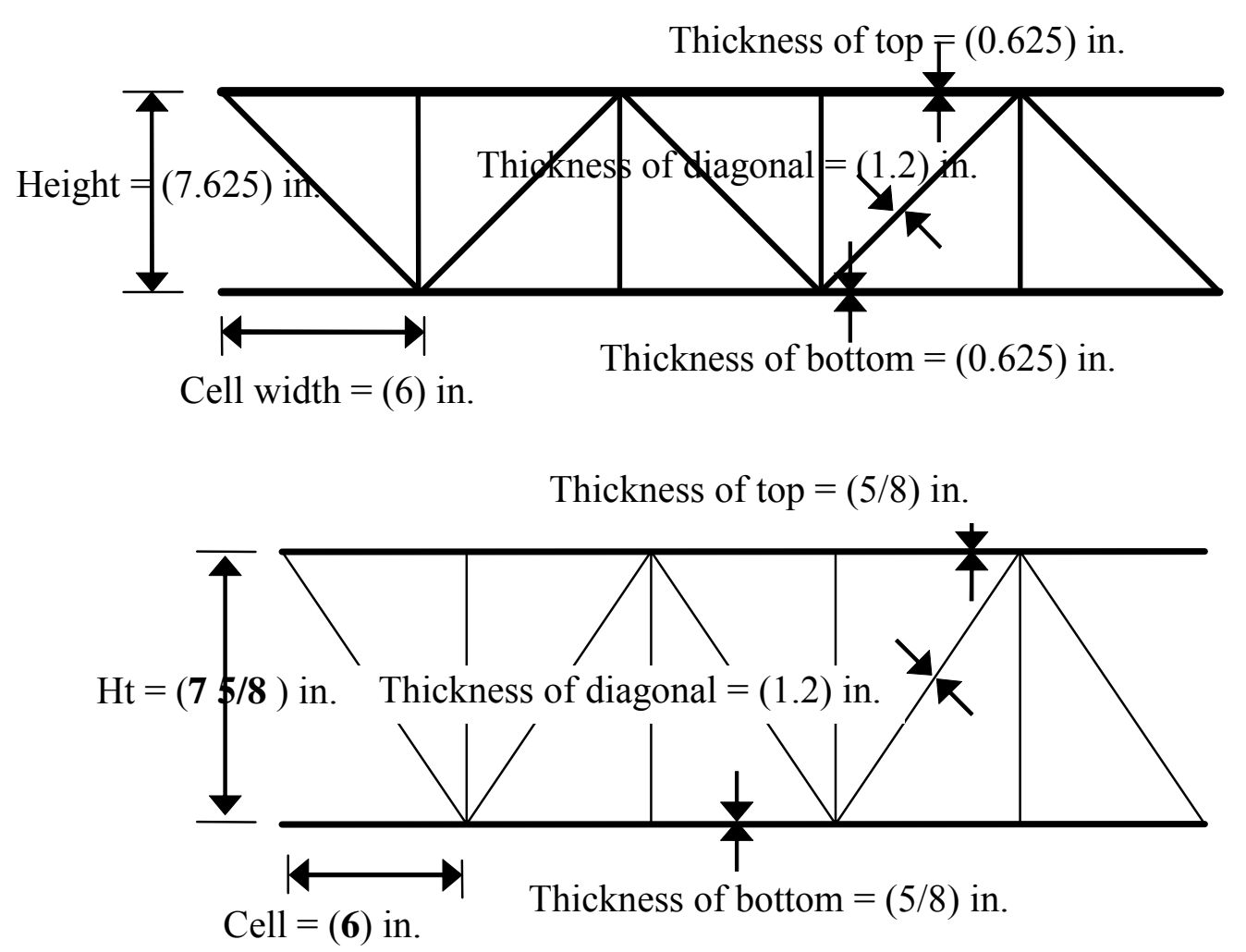

\subsubsection{Construction specifications}

Respondents were asked to indicate the construction specifications of FRP bridge deck panels such as standard specification, warranty issues from manufactures and 
FHWA, deflection limit, design load, etc. None of the responding DOTs had a standard construction specification for FRP bridge deck panels. Only job specific specifications were used. Two respondents indicated that they had a warranty from the suppliers.

ㅁ Pennsylvania DOT: 2 years warranty on FRP superstructure from Hardcore Composite Inc.

D Delaware DOT: Warranty of FRP bridge deck panels

Six respondents answered to the question with regard to design load. As shown in Figure 3-18, New York and Pennsylvania DOT had a design load HS 25 as compared to HS 20 in four DOTs and the deflection limit ranged from L/500 to L/800 (L: Stringers spacing).

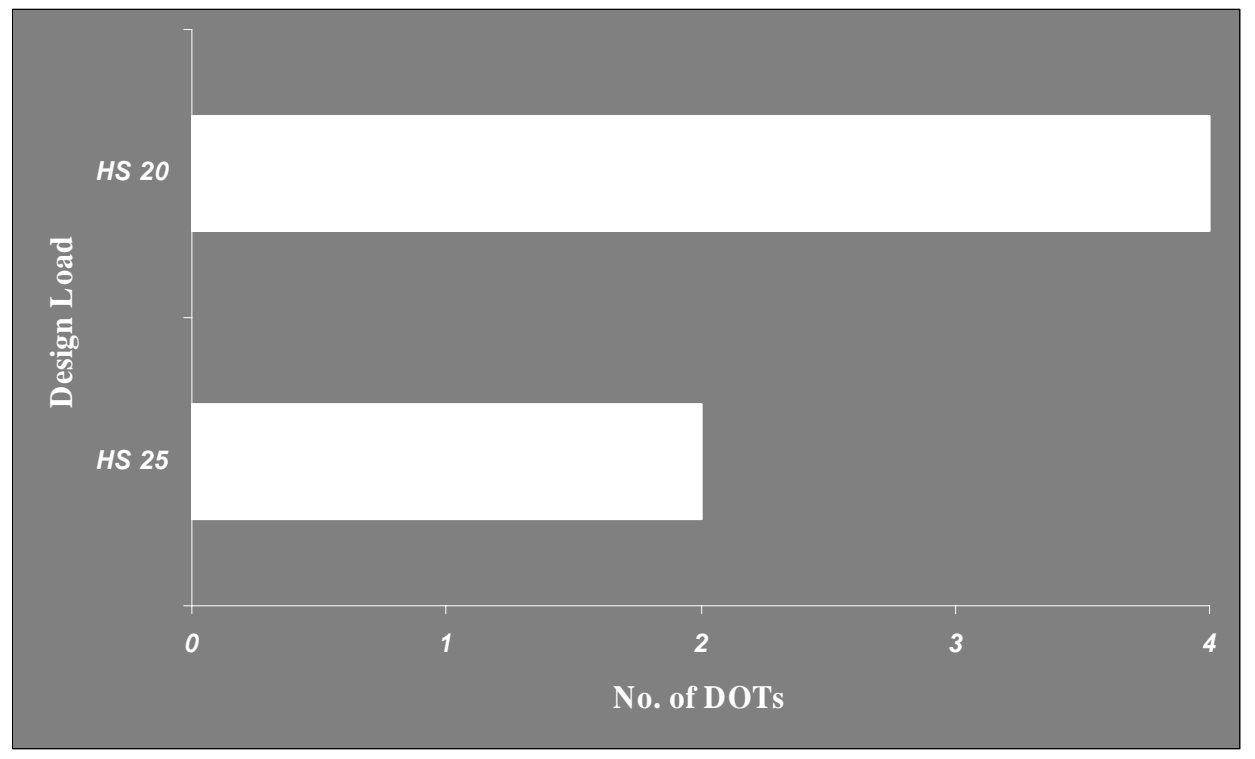

Figure 3-18 Design load

\subsubsection{Detailed information on completed projects}

The following tables illustrate the details with respect to the projects completed by various DOTs. 
Table 3-2 FRP bridge deck Projects of Missouri DOT

\begin{tabular}{|c|c|c|c|c|c|c|c|c|}
\hline \multirow{2}{*}{$\begin{array}{c}\text { Project/Bridge } \\
\text { Name }\end{array}$} & \multirow{2}{*}{ Location } & \multirow{2}{*}{$\begin{array}{c}\text { Date } \\
\text { Installed }\end{array}$} & \multirow{2}{*}{$\begin{array}{c}\text { Duration } \\
\text { (Day) }\end{array}$} & \multirow{2}{*}{$\begin{array}{l}\text { Manufacturer } \\
\text { (Supplier) }\end{array}$} & \multirow{2}{*}{$\begin{array}{l}\text { \# of } \\
\text { spans }\end{array}$} & \multicolumn{2}{|c|}{ Size of FPR bridge deck panels (Feet) } & \multirow{2}{*}{$\begin{array}{l}\text { No. of FRP bridge deck } \\
\text { panels used per span }\end{array}$} \\
\hline & & & & & & Length of panel & Width of panel & \\
\hline St. Johns St. & St. James & $\underline{\underline{9} / 2000}$ & 10 & KSCI & 1 & $8.86 \mathrm{ft}$. & $12.75 \mathrm{ft}$. & $6-4 "$ thick \\
\hline Jay St. & St. James & $\underline{9} / 2000$ & 10 & KSCI & 1 & $26.92 \mathrm{ft}$. & $2-4.92 \mathrm{ft} ., 2-7.83 \mathrm{ft}$. & $4-5.5$ " thick \\
\hline St. Francis St. & St. James & $\underline{11 / 2000}$ & 5 & KSCI & 1 & $26.25 \mathrm{ft}$. & $6.83 \mathrm{ft}$. & $4-22$ " thick \\
\hline
\end{tabular}

Table 3-3 FRP bridge deck Projects of New York DOT

\begin{tabular}{|c|c|c|c|c|c|c|c|c|c|c|c|}
\hline \multirow{2}{*}{$\begin{array}{c}\text { Project/ } \\
\text { Bridge Name }\end{array}$} & \multirow{2}{*}{ Location } & \multirow{2}{*}{$\begin{array}{c}\text { Date } \\
\text { Installed }\end{array}$} & \multirow{2}{*}{$\begin{array}{l}\text { Duration } \\
\text { (Day) }\end{array}$} & \multirow{2}{*}{$\begin{array}{c}\text { \# of } \\
\text { person }\end{array}$} & \multirow{2}{*}{$\begin{array}{l}\text { Hours/ } \\
\text { person }\end{array}$} & \multirow{2}{*}{$\begin{array}{l}\text { Manufacturer } \\
\text { (Supplier) }\end{array}$} & \multirow{2}{*}{ Contractor } & \multirow{2}{*}{$\begin{array}{l}\text { \# of } \\
\text { spans }\end{array}$} & \multirow{2}{*}{$\begin{array}{l}\text { No. of FRP } \\
\text { bridge deck } \\
\text { panels used } \\
\text { per span }\end{array}$} & \multicolumn{2}{|c|}{$\begin{array}{c}\text { Size of FPR } \\
\text { bridge deck } \\
\text { panels (Feet) }\end{array}$} \\
\hline & & & & & & & & & & $\begin{array}{c}\text { Lengt } \\
\mathrm{h} \text { of } \\
\text { panel } \\
\end{array}$ & $\begin{array}{c}\text { Width } \\
\text { of } \\
\text { panel } \\
\end{array}$ \\
\hline $\begin{array}{c}\text { Rte } \\
\text { 248/Bennetts } \\
\text { Creek }\end{array}$ & $\begin{array}{l}\text { Steuben } \\
\text { County }\end{array}$ & $10 / 98$ & 2 & 8 & 16 & Hardcore & State Forces & 1 & 2 & 25 & 16 \\
\hline $\begin{array}{c}\text { Rte 367/ } \\
\text { Bentley Creek }\end{array}$ & $\begin{array}{l}\text { Chemung } \\
\text { County }\end{array}$ & $10 / 99$ & 5 & 6 & 40 & Hardcore & State Forces & 1 & 6 & 14.5 & 43 \\
\hline $\begin{array}{c}\text { Rte 223/Cayuta } \\
\text { Creek }\end{array}$ & $\begin{array}{l}\text { Chemung } \\
\text { County }\end{array}$ & $10 / 00$ & 5 & 6 & 40 & Hardcore & State Forces & 1 & 6 & 14.5 & 43 \\
\hline $\begin{array}{c}\text { Rte 418/ } \\
\text { Schroon River }\end{array}$ & $\begin{array}{l}\text { Warren } \\
\text { County }\end{array}$ & $11 / 00$ & 5 & 8 & 50 & $\begin{array}{c}\text { Martin } \\
\text { Marietta }\end{array}$ & $\begin{array}{c}\text { Reale } \\
\text { Construction }\end{array}$ & 1 & 21 & 8 & 25 \\
\hline $\begin{array}{c}\text { CR 52/Conesus } \\
\text { Lake Outlet }\end{array}$ & $\begin{array}{l}\text { Livingston } \\
\text { County }\end{array}$ & $12 / 01$ & $\mathrm{~N} / \mathrm{A}$ & $\mathrm{N} / \mathrm{A}$ & $\mathrm{N} / \mathrm{A}$ & Hardcore & $\begin{array}{l}\text { County } \\
\text { Forces }\end{array}$ & 1 & 2 & 42 & 16 \\
\hline $\begin{array}{c}\text { S Broad St/Dyke } \\
\text { Creek }\end{array}$ & $\begin{array}{c}\text { Alleghany } \\
\text { County }\end{array}$ & $10 / 00$ & $\mathrm{~N} / \mathrm{A}$ & $\mathrm{N} / \mathrm{A}$ & $\mathrm{N} / \mathrm{A}$ & $\begin{array}{c}\text { Hardcore } \\
\text { Composites }\end{array}$ & $\begin{array}{l}\text { County } \\
\text { Forces }\end{array}$ & 2 & 8 & 7.75 & 24 \\
\hline \multirow[t]{2}{*}{$\begin{array}{c}\text { CR 46/E Branch } \\
\text { Salmon River }\end{array}$} & $\begin{array}{l}\text { Lewis } \\
\text { County }\end{array}$ & $10 / 01$ & $\mathrm{~N} / \mathrm{A}$ & $\mathrm{N} / \mathrm{A}$ & $\mathrm{N} / \mathrm{A}$ & $\begin{array}{c}\text { Martin } \\
\text { Marietta }\end{array}$ & $\begin{array}{l}\text { County } \\
\text { Forces }\end{array}$ & 1 & 5 & 8 & 26 \\
\hline & $\begin{array}{c}\text { Washington } \\
\text { County }\end{array}$ & $12 / 02$ & $\mathrm{~N} / \mathrm{A}$ & $\mathrm{N} / \mathrm{A}$ & $\mathrm{N} / \mathrm{A}$ & $\begin{array}{c}\text { Martin } \\
\text { Marietta } \\
\end{array}$ & $\begin{array}{l}\text { County } \\
\text { Forces }\end{array}$ & $\mathrm{N} / \mathrm{A}$ & $\mathrm{N} / \mathrm{A}$ & N/A & $\mathrm{N} / \mathrm{A}$ \\
\hline
\end{tabular}


Table 3-4 FRP bridge deck Project of PENN DOT

\begin{tabular}{|c|c|c|c|c|c|c|c|c|c|c|c|}
\hline \multirow{2}{*}{$\begin{array}{c}\text { Project/ } \\
\text { Bridge Name }\end{array}$} & \multirow{2}{*}{ Location } & \multirow{2}{*}{$\begin{array}{c}\text { Date } \\
\text { Installed }\end{array}$} & \multirow{2}{*}{$\begin{array}{l}\text { Duration } \\
\text { (Day) }\end{array}$} & \multirow{2}{*}{$\begin{array}{c}\text { \# of } \\
\text { person }\end{array}$} & \multirow{2}{*}{$\begin{array}{l}\text { Hours/ } \\
\text { person }\end{array}$} & \multirow{2}{*}{$\begin{array}{l}\text { Manufacturer } \\
\text { (Supplier) }\end{array}$} & \multirow{2}{*}{ Contractor } & \multirow{2}{*}{$\begin{array}{l}\text { \# of } \\
\text { spans }\end{array}$} & \multirow{2}{*}{$\begin{array}{l}\text { No. of FRP } \\
\text { bridge deck } \\
\text { panels used } \\
\text { per span }\end{array}$} & \multicolumn{2}{|c|}{$\begin{array}{l}\text { Size of FPR bridge } \\
\text { deck panels (Feet) }\end{array}$} \\
\hline & & & & & & & & & & $\begin{array}{l}\text { Length } \\
\text { of panel }\end{array}$ & $\begin{array}{l}\text { Width } \\
\text { of panel }\end{array}$ \\
\hline $\begin{array}{l}\text { SR1037-570 } \\
\text { Dubois Creek }\end{array}$ & $\begin{array}{l}\text { Susayehanns } \\
\text { County }\end{array}$ & $12-01$ & 1 & & & Hardcore & $\begin{array}{l}\text { Fahs- } \\
\text { raston }\end{array}$ & 1 & 2 & $22^{\prime}-3^{\prime \prime}$ & $16^{\prime}-5^{1 / 4}$ \\
\hline $\begin{array}{c}\text { County } \\
\text { Bridge II }\end{array}$ & $\begin{array}{l}\text { Bedford } \\
\text { County }\end{array}$ & 09-02 & 1 & 8 & 8 & $\begin{array}{l}\text { Martin } \\
\text { Marietta }\end{array}$ & $\begin{array}{c}\text { New } \\
\text { Enterprise }\end{array}$ & 2 & 7 & $8^{\prime}$ & $22^{\prime}$ \\
\hline $\begin{array}{l}4003-0050- \\
0000\end{array}$ & $\begin{array}{l}\text { Somerset } \\
\text { County }\end{array}$ & $\begin{array}{c}10-06- \\
1998\end{array}$ & 2 & 9 & 8 & $\begin{array}{c}\text { Creative } \\
\text { Pultrusions }\end{array}$ & $\begin{array}{c}\text { Somerset } \\
\text { Co. } \\
\text { PENNDO } \\
\text { T Bridge } \\
\text { Crew } \\
\end{array}$ & 1 & 3 & $?$ & $?$ \\
\hline Boyer Bridge & Butler Co. & $\begin{array}{c}10-18- \\
01\end{array}$ & 1 & 6 & 7.5 & $\begin{array}{c}\text { Martin } \\
\text { Marietta } \\
\text { (Creative } \\
\text { Pultrusion) }\end{array}$ & $\begin{array}{l}\text { PENNDO } \\
\text { T Forces }\end{array}$ & 1 & $?$ & $?$ & $?$ \\
\hline
\end{tabular}

Table 3-5 FRP bridge deck Project of Illinois DOT

\begin{tabular}{|c|c|c|c|c|c|c|c|c|c|c|}
\hline \multirow{2}{*}{$\begin{array}{c}\text { Project/ } \\
\text { Bridge Name }\end{array}$} & \multirow{2}{*}{ Location } & \multirow{2}{*}{$\begin{array}{c}\text { Date } \\
\text { Installed }\end{array}$} & \multirow{2}{*}{$\begin{array}{l}\text { Duration } \\
\text { (Day) }\end{array}$} & \multirow{2}{*}{$\begin{array}{c}\text { \# of } \\
\text { person }\end{array}$} & \multirow{2}{*}{$\begin{array}{l}\text { Hours/ } \\
\text { person }\end{array}$} & \multirow{2}{*}{$\begin{array}{l}\text { Manufacturer } \\
\text { (Supplier) }\end{array}$} & \multirow{2}{*}{$\begin{array}{l}\text { \# of } \\
\text { spans }\end{array}$} & \multirow{2}{*}{$\begin{array}{c}\text { No. of FRP } \\
\text { bridge deck } \\
\text { panels used per } \\
\text { span }\end{array}$} & \multicolumn{2}{|c|}{$\begin{array}{l}\text { Size of FPR bridge } \\
\text { deck panels (Feet) }\end{array}$} \\
\hline & & & & & & & & & $\begin{array}{l}\text { Length } \\
\text { of panel }\end{array}$ & $\begin{array}{l}\text { Width } \\
\text { of panel }\end{array}$ \\
\hline $\begin{array}{l}\text { Fayette ST } \\
\text { Bridge }\end{array}$ & $\begin{array}{c}\text { City of } \\
\text { Jacksonville South } \\
\text { Fayette street } \\
\end{array}$ & $06 / 15 / 01$ & 1 & 8 & 5 & $\begin{array}{l}\text { Martin } \\
\text { Marietta }\end{array}$ & 3 & 3 & 10 & 36 \\
\hline
\end{tabular}


Table 3-6 FRP bridge deck Project of North Carolina DOT

\begin{tabular}{|c|c|c|c|c|c|c|c|c|}
\hline \multirow{2}{*}{$\begin{array}{l}\text { Project/ } \\
\text { Bridge } \\
\text { Name }\end{array}$} & \multirow{2}{*}{ Location } & \multirow{2}{*}{$\begin{array}{c}\text { Date } \\
\text { Installed }\end{array}$} & \multirow{2}{*}{$\begin{array}{l}\text { Manufacturer } \\
\text { (Supplier) }\end{array}$} & \multirow{2}{*}{ Contractor } & \multirow{2}{*}{ \# of spans } & \multirow{2}{*}{$\begin{array}{c}\text { No. of FRP } \\
\text { bridge deck } \\
\text { panels used per } \\
\text { span }\end{array}$} & \multicolumn{2}{|c|}{$\begin{array}{l}\text { Size of FPR bridge } \\
\text { deck panels (Feet) }\end{array}$} \\
\hline & & & & & & & $\begin{array}{l}\text { Length } \\
\text { of panel }\end{array}$ & $\begin{array}{l}\text { Width of } \\
\text { panel }\end{array}$ \\
\hline $\begin{array}{l}\text { GFRP } \\
\text { Br\#22 }\end{array}$ & Union County & $-\frac{9}{20} \frac{1}{1}$ & $\begin{array}{l}\text { Martin } \\
\text { Marietta }\end{array}$ & $\begin{array}{c}\text { NCDOT } \\
\text { Bridge } \\
\text { Maintenance }\end{array}$ & 4 & 4 & 10 & $24^{\prime}$ \\
\hline
\end{tabular}

Table 3-7 FRP bridge deck Project of Kansas DOT

\begin{tabular}{|c|c|c|c|c|c|c|c|c|}
\hline \multirow{2}{*}{$\begin{array}{l}\text { Project/ } \\
\text { Bridge Name }\end{array}$} & \multirow{2}{*}{ Location } & \multirow{2}{*}{$\begin{array}{c}\text { Date } \\
\text { Installed }\end{array}$} & \multirow{2}{*}{$\begin{array}{l}\text { Manufacturer } \\
\text { (Supplier) }\end{array}$} & \multirow{2}{*}{ Contractor } & \multirow{2}{*}{$\begin{array}{l}\text { \# of } \\
\text { spans }\end{array}$} & \multirow{2}{*}{$\begin{array}{c}\text { No. of FRP } \\
\text { bridge deck } \\
\text { panels used per } \\
\text { span } \\
\end{array}$} & \multicolumn{2}{|c|}{$\begin{array}{l}\text { Size of FPR bridge deck panels } \\
\text { (Feet) }\end{array}$} \\
\hline & & & & & & & Length of panel & Width of panel \\
\hline$\underset{*}{\text { No Name Creek }}$ & $\begin{array}{l}\text { Russell } \\
\text { Co. }\end{array}$ & $11 / 95$ & $\begin{array}{c}\text { Kansas } \\
\text { Structural } \\
\text { Composites }\end{array}$ & $\begin{array}{l}\text { Russell Co. } \\
\text { Hwy Dept. }\end{array}$ & 1 & 3 & $23.25^{\prime}$ & $9.25^{\prime}$ \\
\hline $\begin{array}{c}126-19 \\
\text { K-6895-02 (031) } \\
\text { Lightening Cr }\end{array}$ & $\begin{array}{l}\text { Crawford } \\
\text { Co. }\end{array}$ & $10 / 15 / 99$ & $\begin{array}{c}\text { Kansas } \\
\text { Structural } \\
\text { Composites }\end{array}$ & $\begin{array}{c}\text { Beachner } \\
\text { Construction } \\
\text { Co. } \\
\end{array}$ & 1 & 6 & 8 ' & $31^{\prime}$ \\
\hline $\begin{array}{c}126-19 \\
\text { K-6895-02 (035) } \\
\text { Limestone Cr } \\
\end{array}$ & $\begin{array}{l}\text { Crawford } \\
\text { Co. }\end{array}$ & $10 / 15 / 99$ & $\begin{array}{c}\text { Kansas } \\
\text { Structural } \\
\text { Composites } \\
\end{array}$ & $\begin{array}{c}\text { Beachner } \\
\text { Construction } \\
\text { Co. } \\
\end{array}$ & 1 & 6 & 8 & $31 '$ \\
\hline
\end{tabular}

Table 3-8 FRP bridge deck Project of Delaware DOT

\begin{tabular}{|c|c|c|c|c|c|c|c|c|}
\hline \multirow{2}{*}{$\begin{array}{c}\text { Project/ } \\
\text { Bridge } \\
\text { Name }\end{array}$} & \multirow[b]{2}{*}{ Location } & \multirow[b]{2}{*}{$\begin{array}{c}\text { Date } \\
\text { Installed }\end{array}$} & \multirow[b]{2}{*}{$\begin{array}{c}\text { Manufacturer } \\
\text { (Supplier) }\end{array}$} & \multirow[b]{2}{*}{ Contractor } & \multirow[b]{2}{*}{$\begin{array}{c}\text { \# of } \\
\text { spans }\end{array}$} & \multirow{2}{*}{$\begin{array}{c}\text { No. of FRP } \\
\text { bridge deck } \\
\text { panels used per } \\
\text { span } \\
\end{array}$} & \multicolumn{2}{|c|}{ Size of FPR bridge deck panels (Feet) } \\
\hline & & & & & & & Length of panel & Width of panel \\
\hline BR 351 & Glasgow & Nov. 98 & Hardcore & JJIDM Inc. & 1 & 2 & 30 & 15 \\
\hline BR 192 & Pick Creek & 99 & Hardcore & JJIDM Inc. & 1 & 1 & 42 & 16.5 \\
\hline
\end{tabular}


Table 3-9 FRP bridge deck Project of Maryland DOT

\begin{tabular}{|c|c|c|c|c|c|c|c|c|c|c|c|}
\hline \multirow{2}{*}{$\begin{array}{c}\text { Project/ } \\
\text { Bridge } \\
\text { Name }\end{array}$} & \multirow{2}{*}{ Location } & \multirow{2}{*}{$\begin{array}{c}\text { Date } \\
\text { Installed }\end{array}$} & \multirow{2}{*}{$\begin{array}{l}\text { Duration } \\
\text { (Day) }\end{array}$} & \multirow{2}{*}{$\begin{array}{c}\text { \# of } \\
\text { person }\end{array}$} & \multirow{2}{*}{$\begin{array}{l}\text { Hours/ } \\
\text { person }\end{array}$} & \multirow{2}{*}{$\begin{array}{l}\text { Manufacturer } \\
\text { (Supplier) }\end{array}$} & \multirow{2}{*}{ Contractor } & \multirow{2}{*}{$\begin{array}{c}\text { \# of } \\
\text { spans }\end{array}$} & \multirow{2}{*}{$\begin{array}{l}\text { No. of FRP } \\
\text { bridge deck } \\
\text { panels used } \\
\text { per span } \\
\end{array}$} & \multicolumn{2}{|c|}{$\begin{array}{l}\text { Size of FPR bridge } \\
\text { deck panels (Feet) }\end{array}$} \\
\hline & & & & & & & & & & $\begin{array}{l}\text { Length } \\
\text { of panel }\end{array}$ & $\begin{array}{l}\text { Width of } \\
\text { panel }\end{array}$ \\
\hline $\begin{array}{c}\text { MD } \\
\text { 24/Deer } \\
\text { Creek }\end{array}$ & $\begin{array}{c}\text { Harford } \\
\text { Country, } \\
\text { MD }\end{array}$ & $\begin{array}{c}6 / 25 / 01 \\
- \\
9 / 15 / 01 \\
\end{array}$ & 75 day & 8 & 9 & $\begin{array}{l}\text { Martin } \\
\text { Marietta }\end{array}$ & $\begin{array}{l}\text { JJIDM } \\
\text { Inc. }\end{array}$ & 1 & 3 & $\begin{array}{c}10 \text { ' and } \\
8\end{array}$ & $\begin{array}{c}17 '-91 / 2 " \\
\text { and } \\
13 '-81 / 2 "\end{array}$ \\
\hline
\end{tabular}

Table 3-10 FRP bridge deck Project of Oregon DOT

\begin{tabular}{|c|c|c|c|c|c|c|c|c|c|c|c|}
\hline \multirow{2}{*}{$\begin{array}{c}\text { Project/ } \\
\text { Bridge } \\
\text { Name }\end{array}$} & \multirow{2}{*}{ Location } & \multirow{2}{*}{$\begin{array}{c}\text { Date } \\
\text { Installed }\end{array}$} & \multirow{2}{*}{$\begin{array}{l}\text { Duration } \\
\text { (Day) }\end{array}$} & \multirow{2}{*}{$\begin{array}{c}\text { \# of } \\
\text { person }\end{array}$} & \multirow{2}{*}{$\begin{array}{l}\text { Hours/ } \\
\text { person }\end{array}$} & \multirow{2}{*}{$\begin{array}{l}\text { Manufacturer } \\
\text { (Supplier) }\end{array}$} & \multirow{2}{*}{ Contractor } & \multirow{2}{*}{$\begin{array}{l}\text { \# of } \\
\text { spans }\end{array}$} & \multirow{2}{*}{$\begin{array}{l}\text { No. of FRP } \\
\text { bridge deck } \\
\text { panels used } \\
\text { per span }\end{array}$} & \multicolumn{2}{|c|}{$\begin{array}{l}\text { Size of FPR bridge } \\
\text { deck panels (Feet) }\end{array}$} \\
\hline & & & & & & & & & & $\begin{array}{l}\text { Length } \\
\text { of panel }\end{array}$ & $\begin{array}{c}\text { Width of } \\
\text { panel }\end{array}$ \\
\hline $\begin{array}{c}\text { Lewis \& } \\
\text { Clark Bridge }\end{array}$ & $\begin{array}{l}\text { Astoria, } \\
\text { Clastsop } \\
\text { Co., OR }\end{array}$ & 2001 & 15 & $\begin{array}{l}5-6 \\
\operatorname{Max} .\end{array}$ & & $\begin{array}{l}\text { Martin } \\
\text { Marietta }\end{array}$ & $\begin{array}{l}\text { Hamilton } \\
\text { Constr. }\end{array}$ & 1 & $\begin{array}{l}12 \text { for } \mathrm{L}= \\
113^{\prime}-8^{\prime}\end{array}$ & $\begin{array}{l}\text { Typ. } \\
10\end{array}$ & $\begin{array}{c} \pm 20^{\prime} \\
\text { (full } \\
\text { bridge) }\end{array}$ \\
\hline $\begin{array}{l}\text { Old Youngs } \\
\text { Bay Bridges }\end{array}$ & $\begin{array}{l}\text { Astoria, } \\
\text { Clastsop } \\
\text { Co., OR }\end{array}$ & 2002 & 22 & $\begin{array}{l}5-6 \\
\operatorname{Max} .\end{array}$ & 8 & $\begin{array}{l}\text { Martin } \\
\text { Marietta }\end{array}$ & $\begin{array}{l}\text { Hamilton } \\
\text { Constr. }\end{array}$ & 1 & $\begin{array}{c}17 \text { for } \mathrm{L}= \\
166^{\prime}\end{array}$ & $\begin{array}{l}\text { Typ. } \\
10\end{array}$ & $\begin{array}{c} \pm 21 \\
\text { (full } \\
\text { bridge) }\end{array}$ \\
\hline
\end{tabular}




\subsubsection{Barriers encountered in installing FRP bride deck panels}

Except for two DOTs (North Carolina and Oregon DOT) all other respondents currently using FRP bridge deck panels, experienced at least one barrier during installation of the panels. Especially, the design and construction barrier was listed among the top barriers by 5 DOTs and vendor barrier was listed as being limited to only one or two suppliers.

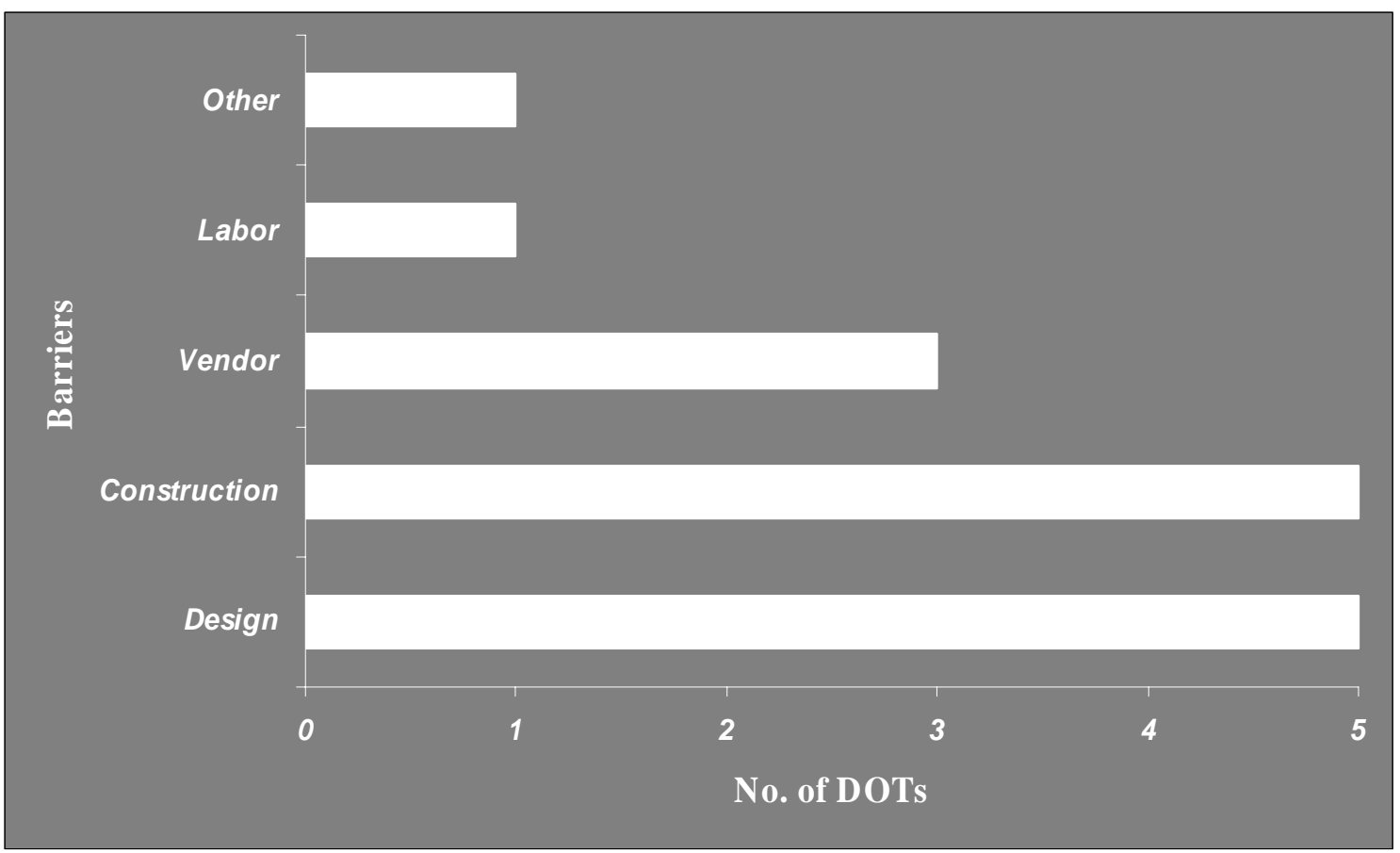

Figure 3-19 Barriers encountered in stalling FRP bride deck panels

The following is a summary of barriers encountered in installing FRP bridge deck panels:

$\square$ Design barriers:

o Lack of specifications

o Must rely on manufacturer design 
o Parapet connection (No design specification for all bridges)

o New concepts for connections

o Unknown design parameters

Construction barriers:

o Contractor Unfamiliarity

o Lack of knowledge of system

o Too much field modification without design review

o Unknown installation and handling methods

o Tolerance issues that lead to saw cuts having to be made. The tolerance issues were due to fabrication and panel connection tolerances. Due to these tolerances, the panels ended up being slightly longer than anticipated. When the last panel was set, it overhung the bridge by a few inches. To correct this and allow the panel to fit, the extra was cut off and the panels were inserted without any further problems.

口 Labor barriers:

o Unskilled labor

V Vendor barriers

o Only one FRP manufacturer bid for the job

o Limited to Kansas Fabricator

$\square$ Other barriers:

o Who is responsible for girder/panel connection 


\subsubsection{Delivery issues}

It is one of the important issues to reduce construction duration. With regard to delivery issues, three questions were asked: (i) the method of delivery of FRP bride deck panels, (ii) the maximum size of FRP bridge deck panels transported and the cost of transportation, and (iii) the required delivery time. All respondents indicated that a Flatbed truck was used to deliver the panels from the factory to the job site. Their maximum size was a variable depending on the project requirements. The summary of the responses with respect to the panel size is as follows:

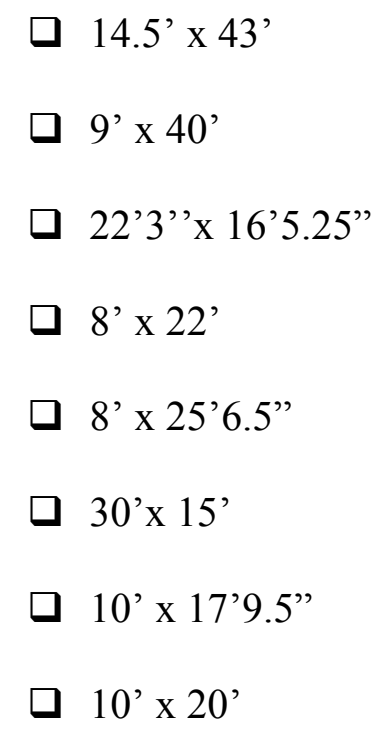

As for the delivery time, if the fabrication facility was located near a particular project and the FRP bridge deck panels were fabricated ahead of time, they could be shipped by the flat bed truck when they were needed. Therefore, in this particular case, it took a few hours to deliver them to the project site (i.e., 1.5 to 3 hours). However, otherwise, it took about one week. A few days were usually required to deliver the panels (i.e., 1 or 2 days) 


\subsubsection{Maintainability and Operability issues of FRP bridge deck panels}

Respondents were asked about the condition rate of the bridge decks and substructure when FRP bridge deck panels were considered for replacing deteriorated bridge decks. As shown in Figure 3-20, the deteriorated bridge decks were mostly replaced when their $\mathrm{CR}$ was 4 and whereas $\mathrm{CR}$ of 6 or 7 was considered for the deteriorated bridge substructures. Most of the DOTs use a scale of 0-9 (0: Failed Condition- 9: Excellent Condition) to measure the condition rate. Whereas, New York uses a scale from 0-7 (0: Failed Condition- 7: Excellent Condition) for the measurement of condition rate (CR) of bridge structures. For New York DOT, the bridge decks and substructure are replaced when their $\mathrm{CR}$ is 4 and 3 respectively.

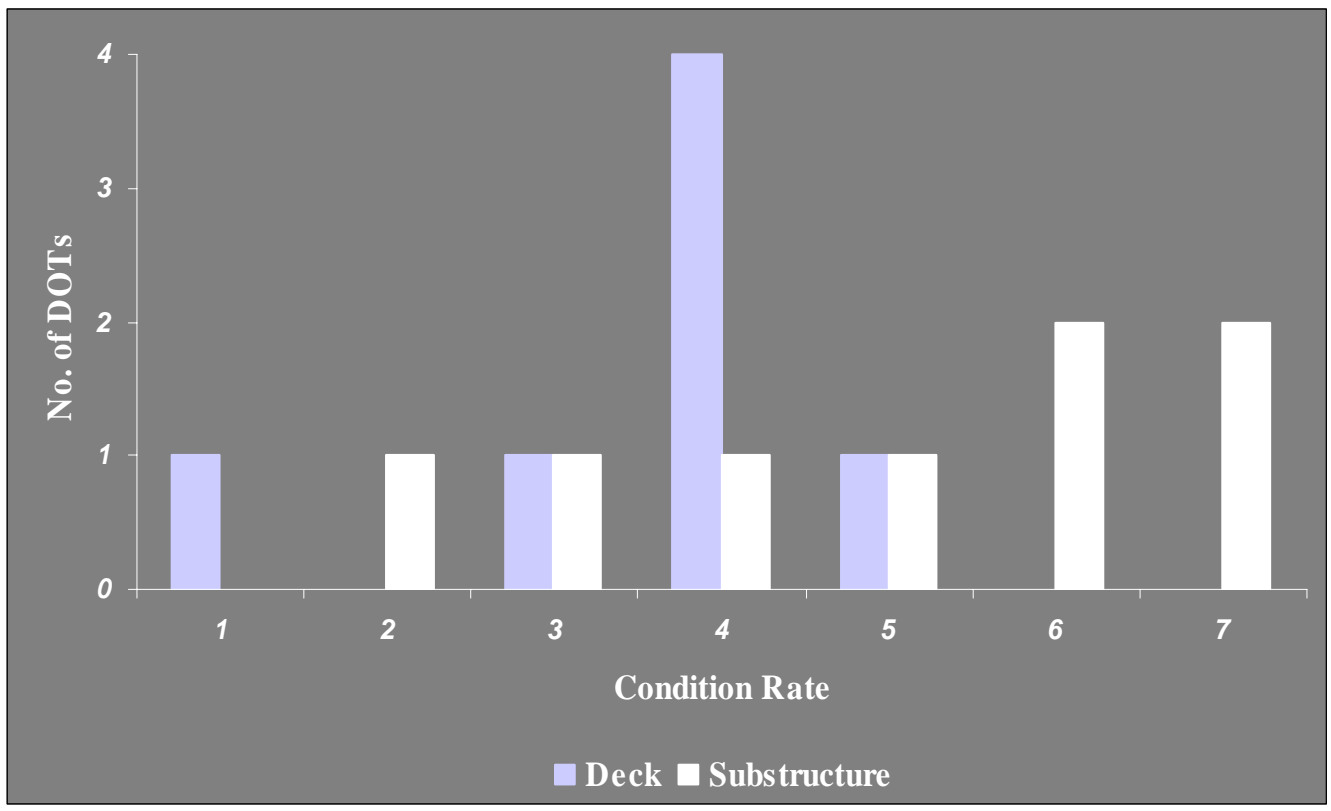

Figure 3-20 Condition rating of existing bridge structures

Since the FRP bridge deck panels have been applied for highway bridge structures over the last few decades, most of the DOTs currently using them do not have a lot of 
experience in their maintenance. Therefore, it is impossible to collect their performance data including maintenance records which is one of obstacles in the application of new material in construction area. Therefore, this research identified various issues or problem with regards to maintenances and operation after they were installed. Based on the results of the questionnaire survey, Delaware, Maryland, and North Carolina DOTs have not experienced any maintenance problems. The following is a summary of other DOTs with regard to maintenance and operability issues.

New York DOT: Durability of wearing surface. On three bridges there has been delamination of the polymer concrete wearing surface from the FRP deck. It has since been corrected by better surface preparation of the FRP deck (Sandblasting). Also there has been some localized delamination in the deck between the skin and the core. This can be repaired by epoxy injection.

口 Ohio DOT:

o Delamination and unbonded areas in panel skins

o Deck-to-girder connection at haunches

o Field and shop joint problems

o Polymer wearing surface deficiencies

o Cracks in concrete wearing surface

o Joints between different deck systems

o Water intrusions

$0 \quad$ Existing fire damage

口 Kansas DOT

o Field modifications of connection to girders 
o Deck surface problems (wearing surface)

$\square$ Oregon DOT:

o Wearing surface problem

$\square$ Pennsylvania DOT

o Epoxy overlay delamination

Except for Delaware, 8 DOTs don't have specific analysis procedure or method established in order to inspect, maintain, and repair the FRP bridge deck panels. In Delaware DOT, Sensors and gauges are installed for regular inspection. In terms of inspection and monitoring the service of FRP bridge deck panels, biannual inspection has been performed by Maryland and Oregon DOT.

In case of Pennsylvania DOT, the first and second projects have been monitored for 3 years and load test was performed for all four projects. Especially, the fourth project has been monitored as part of FHWA IBRC contract to determine composite action between steel stringer and FRP panels (refer to Table 3-4)

Table 3-11 Expected service life of Concrete versus FRP bridge deck panels

\begin{tabular}{l|c|c}
\hline \multicolumn{1}{c|}{ DOT } & $\begin{array}{c}\text { Average service life of Concrete } \\
\text { Bridge Deck (Year) }\end{array}$ & $\begin{array}{c}\text { Expected service life of FRP } \\
\text { Composite Bridge Deck (Year) }\end{array}$ \\
\hline \hline New York & 25 & 75 \\
\hline Ohio & 30 & 75 \\
\hline Pennsylvania & $\begin{array}{c}\text { 40:Epoxy coated rebar } \\
\text { 30: Black rebar }\end{array}$ & $40-75$ \\
\hline Illinois & 25 & Unknown \\
\hline Kansas & 30 & Unknown, maybe 10 to 20 years \\
\hline Delaware & Unknown & 75 \\
\hline Maryland & 50 & Over 100 \\
\hline Oregon & 15 & 75 \\
\hline \hline
\end{tabular}


Respondents were also asked what the expected service life of FRP bride deck panels was as compared to average service life of concrete bridge decks. A total of 8 DOTs responded to the question and the responses are summarized in Table 3-11.

\subsubsection{Construction cost of FRP bridge deck panels}

\begin{tabular}{|c|c|}
\hline DOT & Initial construction cost \\
\hline New York & $\$ 65-75 / \mathrm{SF}$ \\
\hline Pennsylvania & $\begin{array}{l}\text { (1) SR1037-570 Dubois Creek } \\
\text { - Initial construction: Unit cost: 465/sf, total:341,500 } \\
\text { (2) County Bridge II } \\
\text { - Initial construction cost: } 485,000 \text { (lump sum bid) } \\
\text { - Engineering and fabrication cost } 60,000 \\
\text { - testing -171,000 } \\
\text { (3) 4003-0050-0000 } \\
\text { - Initial construction cost: } 125,000 \text { (material only) } \\
\text { - Engineering and fabrication cost: } 39,000 \\
\text {-Maintenance cost: } 25,000 \\
\text { (4) Boyer Bridge } \\
\text {-Initial construction cost: } 129.60 / \text { sf Total:138,802.77 }\end{array}$ \\
\hline Delaware & $\begin{array}{ll}\text { (1) BR } 351 \text { Project } \\
- & \text { Initial construction cost : } 220,000(244.44 / \mathrm{sf}) \\
- & \text { Engineering and Fabrication cost: } 760,000(844.44 / \mathrm{sf}) \\
\text { (2) BR } 192 \text { Project: } \\
-\quad \text { Initial construction } \operatorname{cost}=250,000(360.75 / \mathrm{sf})\end{array}$ \\
\hline Maryland & $\begin{array}{l}\text { Initial construction Cost: } \$ 911,057.70 \\
\text { Engineering and Fabrication Cost: } \approx \$ 91,108\end{array}$ \\
\hline
\end{tabular}

\section{List of References}

Ahmad, S. H., and Plecnik, J. M. (1989). "Transfer of composite technology to design and construction of bridges," U.S. DOT Report, Sep. 1989.

Busel, J. P. and Lockwood, J. D., eds. (2000). Production selection guide: FRP composite products for bridge applications, Market development Alliance (MDA) of the FRP composites industry, Harrison, NY. 
Current Practices in FRP Composites Technology FRP Bridge Decks and Superstructures. (2003). <http://www.fhwa.dot.gov/bridge/frp/deckproj.htm> (Oct.04.2003)

Ehlen, Mark A. (1999). "Life Cycle Costs of Fiber-Reinforced-Polymer Bridge Decks." Journal of Materials in Civil Engineering, ASCE, 11(3), 224-230

Ehlen, Mark A. (1997). "Life Cycle Costs of New Construction Materials." Journal of Infrastructure Systems, ASCE, Vol. 3, No. 4, pp. 129-133.

Henry, J.A. (1985). "Deck girders system for highway bridges using fiber reinforced plastics." M.S. Thesis, North Carolina State University, NC.

Nystrom, H. E., Watkins, S. E., Nanni, A., and Murray, S. (2003). "Financial viability of fiber-reinforced polymer (FRP) bridges." Journal of Management Engineering, 19(1), 2-8.

Plecnik, J. M., and Azar, W. A. (1991). "Structural components, highway bridge deck applications." International Encyclopedia of composites, I. Lee and M. Stuart (eds), Vol. 6, pp.430-445.

Yost, J. R. and Schmeckpeper, E. R. (2001). "Strength and serviceability of FRP grid reinforced bridge decks." Journal of Bridge Engineering, ASCE, Vol. 6, No. 6, pp. 605-612.

Zhou, A., Lesko, J. J., and Davalos, J. F. (2001). "Fiber reinforced polymer decks for bridge systems." COMPOSITES 2001, Convention and Trade Show, Composite Fabrications Association (CFS), Tampa, FL, Oct. 2001.

Zureick, A, Shin, B., and Munley, E. (1995). "Fiber-reinforced polymeric bridge decks." Structural Engineering Review, 7(3), Aug. 1995, pp. 257-266. 


\title{
CHAPTER 4: PRELIMINARY DATA COLLECTION AND DATA ANALYSIS (CASE STUDY AND INTERVIEWS)
}

\begin{abstract}
$\underline{4.1 \text { Introduction }}$
In addition to the questionnaire survey, case studies and interviews were conducted to collect preliminary data on constructability, operability, and maintainability of FRP bridge deck panels. This chapter illustrates the results of the case studies and interviews. Seven candidate projects were selected for the case studies. Five out of seven candidate projects (Sintz Road over Rock Run Bridge in Clark County, Five mile Road Bridge \#0171, 0087, and 0071 in Hamilton County, and Westbrook Road Bridges in Montgomery County) were under Project 100 in Ohio and two candidate projects (Fairgrounds Road Bridges in Greene County and County Line Road over Tiffin River in Defiance County) were part of a new program called 'Composites For Infrastructure' (C4I). The county engineers of the candidate projects were interviewed during the case studies. This chapter elaborates upon the finding of the case studies and interviews including detailed information about C4I and Project 100 in Ohio. In order to collect additional data on constructability, operability, and maintainability of FRP bridge deck panels from a manufacturer point of view, the research team visited two manufacturing
\end{abstract}


facilities, Hardcore Composites Inc. (HCI), and Martin Marietta Composites (MMC). This chapter also elaborates upon the results of interviews with their engineers.

\subsection{Project 100 in Ohio}

\subsubsection{Project 100}

'Project 100'was initiated by the state of Ohio to encourage and enhance commercial growth of FRP composites bridge decks. The main objective of this program was to design, manufacture and install a composites bridge decks in each of Ohio's 88 counties and 12 Department of Transportation districts between 2000-2005 (Reeve 2000). Another goal of 'Project 100' was economic development in Ohio by establishing an industry that would develop and supply composite bridge decks to the eastern United States (Project 2003)

Under this program, the Ohio Department of Development (ODOD) assisted the counties and districts by subsidizing the high initial installation cost of FRP bridge decks. The National Composites Center (NCC) helped counties and districts in selecting a project and working with FRP deck manufacturers as well as the Ohio Department of Transportation (ODOT). 


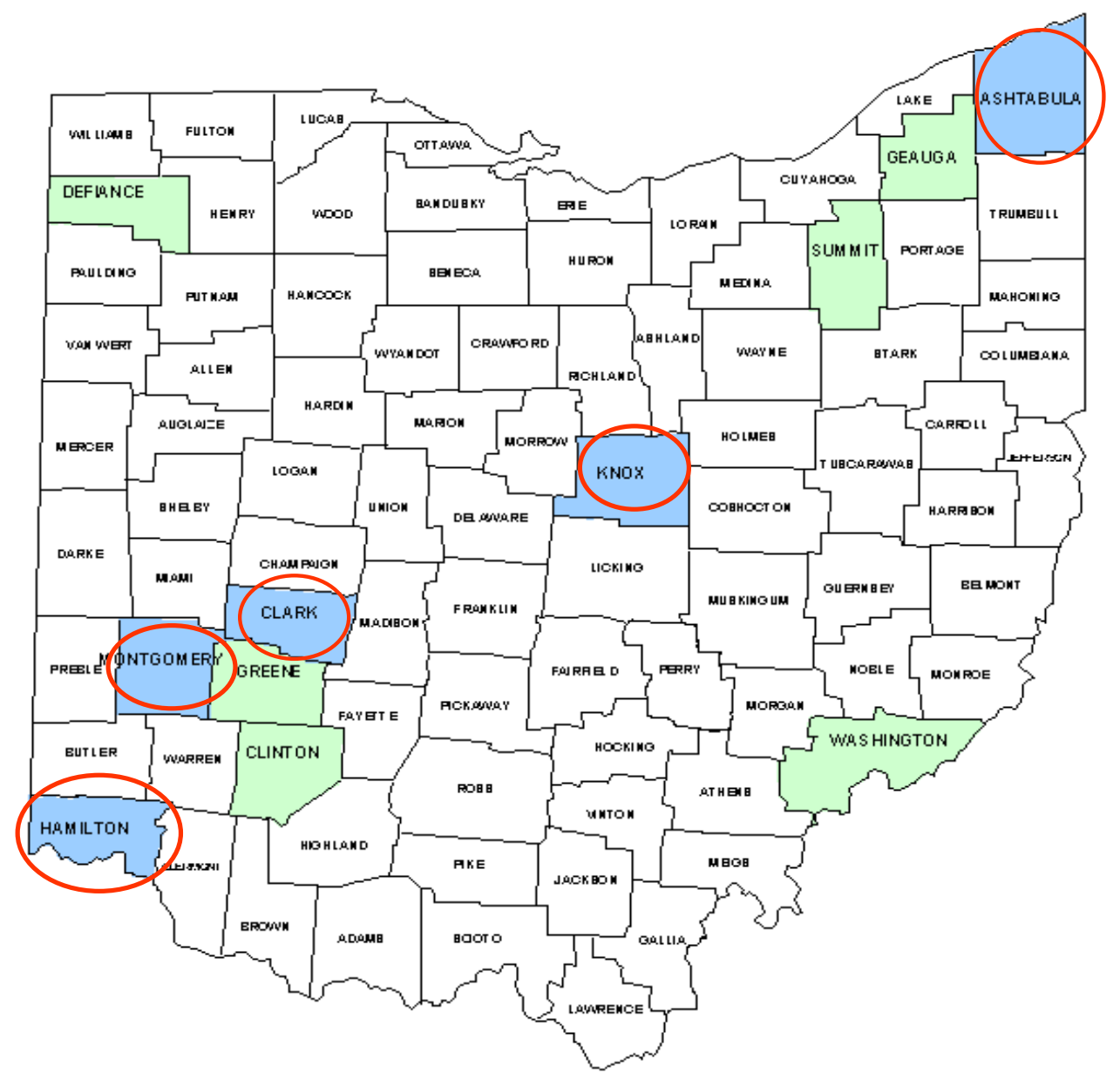

Figure 4- 1 FRP Composites Decks installed in Project 100

- During Phase-I of Project 100 (Project

$\square$ NCC selected Hardcore Composites of New Castle, Delaware to supply the deck panels.

$\square$ Hardcore Composites agreed to invest in local facilities to manufacture the panels, thereby creating a new industry in Ohio (Project 2003 and Reeve 2000).

- Composite decks installed under Project 100 by the end of Phase I

$\square$ Ashtabula County: Shaffer Road Bridge 
Clark County: Sintz Road over Rock Run Bridge

口 Hamilton County: Five mile Road Bridge \# 0171, 0087, and 0071 bridges

․ Knox County: Elliot Run Bridge

Montgomery County: Spaulding Road and Westbrook Road bridges

Wright Patterson AFB: Hebble Creek bridges

- Two conditions were required to accomplish the Project 100

a A single supplier would have to be "guaranteed" a significant share of the market to justify investment in an Ohio plant

- State funding would be required to subsidize bridge owners for more costly FRP decks in the near term until costs were reduced to a point at which FRP decks became competitive with conventional materials (Project 2003 and Reeve 2000)

During the first 18 months of the project 100, the two conditions were satisfied, however, the two conditions were not satisfied for the full planned duration of the project 100. The lack of state funding for Phase II of Project 100 lead NCC to redefine the program since the Ohio biennial budget for FY 2002 - 2003 did not include funds for Phase II of Project 100. Another factor forcing the program was procurement regulations, which make it impossible to direct a sufficiently high enough volume of business to a specific supplier (Hardcore Composites) to set up an adequate economic presence in Ohio. Therefore, NCC took into account other ways to achieve the economic development objective of the program (Project 2003 and Reeve 2000). 


\subsubsection{Composites for Infrastructure (C4I) Initiative}

Under a new program called Composites for Infrastructure (C4I), NCC signed an agreement with MMC in Aug. 2001. The initiative focuses on facilitating FRP bridge deck installations without state subsidy and examining other infrastructure related applications for composite materials. Under the C4I, the first composite bridge deck was Greene County Fairgrounds Road and the largest to date to be successfully installed

- Composite decks installed under C4I initiative

Greene County: Fairgrounds road bridge

口 Summit County: Hudson road/wolf creek Bridge

Geauga County: Hotchkiss road bridge

․ Washington County: Cats creek bridge

Clinton County: Hales branch road bridges

Defiance County: County line road over Tiffin River 


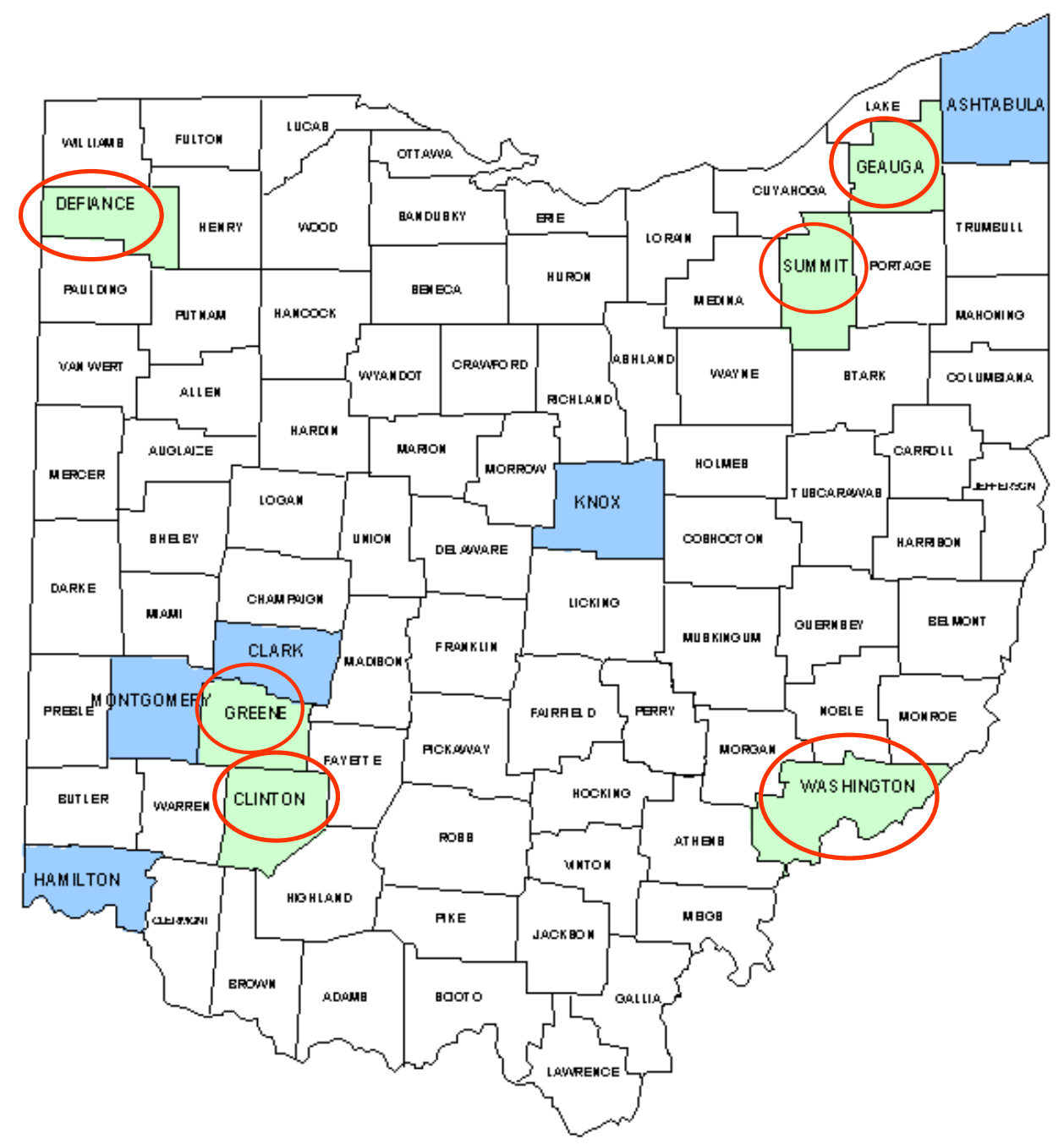

Figure 4-2 Composite decks installed under C4I initiative

\section{$\underline{4.3 \text { Case Studies about FRP bridge deck construction }}$}

Five counties in Ohio were visited by the research team to collect data on constructability, maintainability, and operability of FRP bridge deck panels. In addition to the interview with county engineers, questionnaire survey was used to establish state of 
practice of fabrication and use of composite bridge decks. This section illustrates the data obtained from four out of five counties (except for Montgomery County).

\subsubsection{General Information and Interview Results}

\section{CASE STUDY-1: Sintz Road over Rock Run Bridge, Clark County}

Personnel Interviewed: Bruce Smith, County Engineer

Doug Frank, County Bridge Superintendent

Paul W. Debuty, Bridge Designer

- ,Clark County does not have any plans within next 5 years for installation of new FRP bridge deck panels

- Unlike some other counties, Sintz Road over Rock Run Bridge located in Clark County used $50 \mathrm{Z}$ clips instead of a haunch.

- The ADT of the bridge was 1600 (10\% truck) - Low volume rural.

- The project was the third out of Project 100.

- County engineers were mostly not satisfied by the work done by Hardcore Composites because they did not provide any technical help at the job site for installation.

- The speed limit for the bridge is $55 \mathrm{MPH}$.

- On time delivery and better quality control of decks was considered as an important issue for future projects utilizing FRP bridge deck panels.

- The criteria used for selecting a bridge for FRP bridge deck panel application included:

o Low ADT, No skew, No Super-elevation, Low ADTT.

- Any preference in the supplier of FRP bridge deck panels 
o The first and only bridge was supplied by Hardcore Composites. But the county would likely use another supplier due to the poor quality of the panels on future projects.

\section{CASE STUDY-2: County line road over Tiffin River, Clark County}

Personnel Interviewed: Warren Schlatter, Chief Deputy Engineers.

- Within 5 years, a new project has been scheduled for installation of FRP bridge deck panels

- The FRP composite bridge deck panels were used in $\underline{\text { High volume rural. }}$

\section{CASE STUDY-3: Fairgrounds road bridge, Greene County}

Personnel Interviewed: Bob Geyer, County Engineer

- No new bridge deck panels have not been scheduled for installation in the near future (within 5 years)

- The FRP composite bridge deck panels were used in $\underline{\text { High volume rural. }}$

- 15,200 car traffic volumes in a day is not heavy traffic for this bridge.

- The reason for selecting Martin Marietta:

o Warranty from Martin Marietta Composite: 30 years for their material

o Recommendation by consultant

- The criteria of your state for selecting a bridge for FRP bridge deck panel application

o Need a grant for the construction because of high initial cost.

- The project started in March 2001 and finished on June 2, 2002.

- Miscalculated amount of grout that lead to change order. 
- Contractor: AHERN associate, in Springfield, $\mathrm{OH}$

- Engineer: LJB, in Dayton. (Mark Handerson)

- NCC is supposed to monitor the bridge but they are not sure whether NCC is doing or not because they have not seen any results.

- 3 spans, 2 abutments, and 2 piers

- Problem issues: keeping tolerance around deck edge with guardrail straight

- The price of the whole project is twice as compared to a conventional project.

- One of the future concerns is that if the epoxy is delaminated from the deck, how to get the deck off, how to get the fiber glass for replacement, and how to patch it back in place.

- In terms of monitoring system

o Dead load and temperature is always monitored, also visual inspection of under and over the surface is done by NCC. They check the color of the surface and any change of color brings attention.

o Live Load Tests: Conducted every six months for Greene County FRP deck for 2 years and data on load transfer and deflection is collected.

o Continuous monitoring of temperature: data is collected continuously and analyzed every month

o Monitor: Temperature effects, Shear load transfer at field joints, Shear load transfer at deck-to-girder connection, and Deflection

o Monitoring for Greene and Clinton Counties was funded by Innovative Bridge Research and Construction (IBRC) program 
CASE STUDY-4: Five Mile Road Bridge \# 0071, \# 0087, and \#0171, Hamilton

\section{County}

Personnel Interviewed: Steve Mary, County Engineer

- No new bridge deck panels have been scheduled for installation in the near future (within 5 years)

- The criteria for selecting a bridge for application of FRP bridge deck panels

o Existing substructure in good shape and existing concrete beam in good shape.

- The first bridge took 2 and half day to set up the FRP bridge deck panel and one day for second and third bridge. There is a learning curve. However, it took two years to finish the three projects (Five mile road bridge \# 0171, 0087, and 0071) because a lot of time was required for pre-engineering including the selection of FRP deck manufacturer.

- Project engineer: LJB, in Dayton. (Mark Handerson)

- Contractor: Forth Defiance County (No choice in selecting contractor)

- One year warranty on material from Hardcore Composites

- There was no competitive bid in the selection of supplier for the FRP bridge deck panels

CASE STUDY-5: Salem Avenue Bridge, Westbrook Road Bridge over Dry Run Creek, and Spaulding Road Bridge, Montgomery County

Personnel Interviewed: Roberts S. Hoag, Chief Deputy Engineer 
A. Salem Avenue Bridge
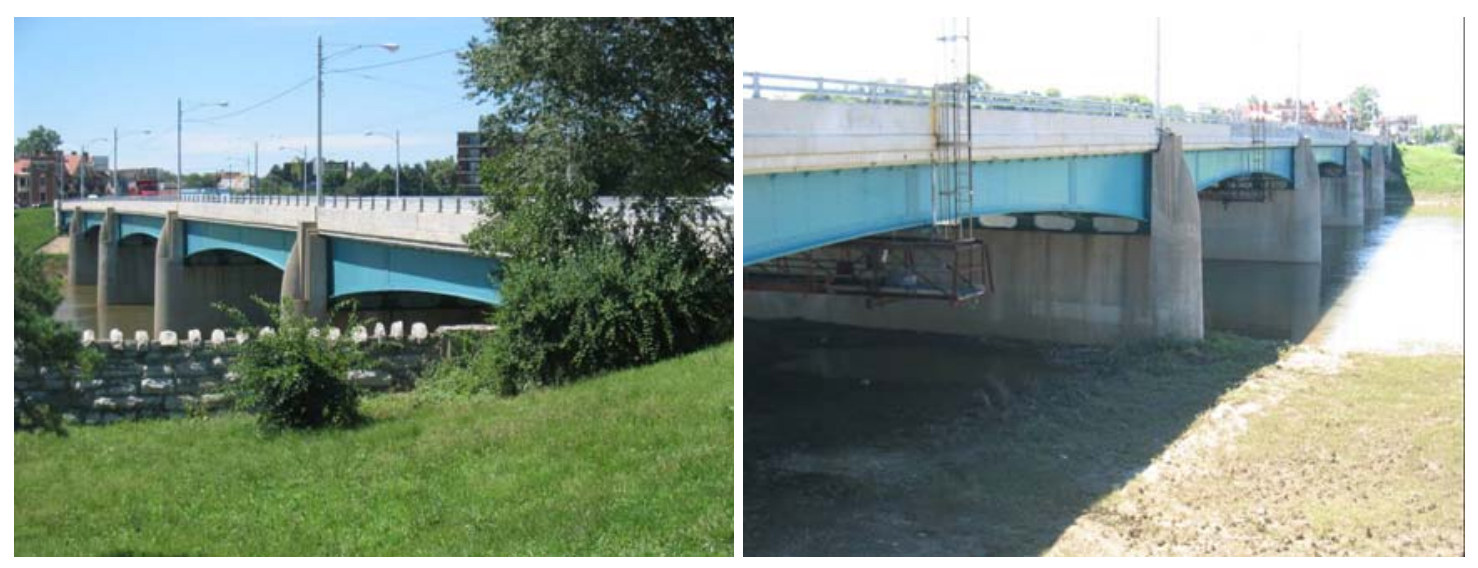

Figure 4-3 Salem Avenue Bridge

- A five span continuous haunched steel plate girder structure

- Six lanes of traffic over the Great Miami River on SR 49 in Dayton, Ohio.

- Consisted of six girders spaced at about 8 feet 9 inches.

- Ohio Department of Transportation (ODOT) decided on an innovative replacement strategy

o Replace the concrete bridge deck of this bridge

o Develop added field experience to support the transportation industry's ongoing search.

o Used four different FRP composite deck systems

- Composite Deck Solution (CDS), Dayton, Ohio

- Creative Pultrusions, Inc. (CPI), Alum Bank, Pennsylvania

- Hardcore Composites, Inc. (HCI), Newcastle, Delaware

- Infrastructure Composites, Inc. (ICI), San Diego, California 
- $80 \%$ funds provided by the Federal Highway Administration (FHWA) and $20 \%$ by ODOT

- Contractor: National Engineering, Cleveland, Ohio

- Wearing surface: Poly-Carb, Inc., Cleveland Ohio

- Montgomery County engineers have responsibility on long-term maintenance.

- Maintenance problems identified by the evaluation team

o Delamination and unbonded areas in panel skins
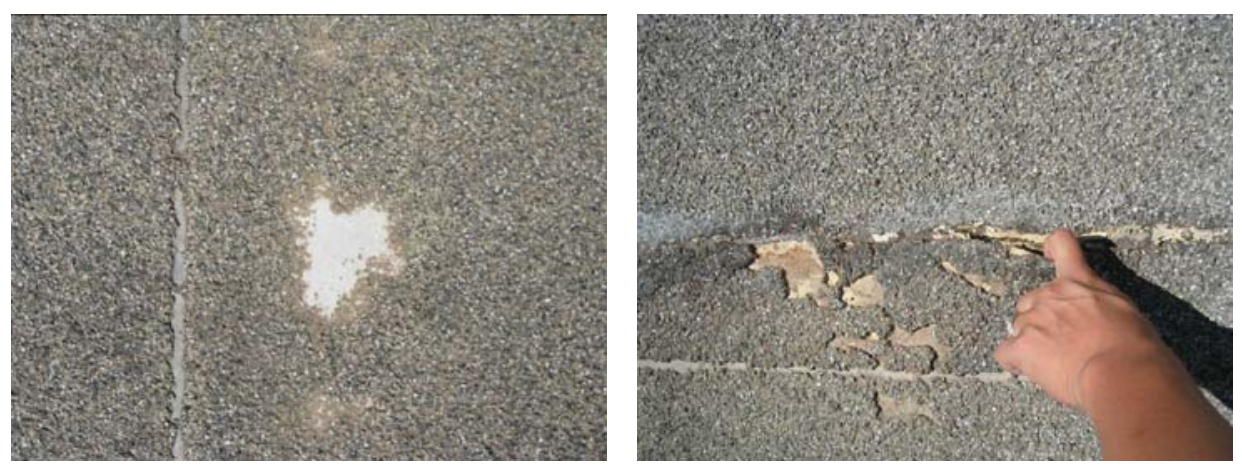

Figure 4-4 Debonding of the wearing surface

o Deck-to girder connection at haunches: Some of the CPI, HCI, and ICI panels were observed to be lifted off the haunch as much as $1 / 16$ inch.

o Field and shop joint problems
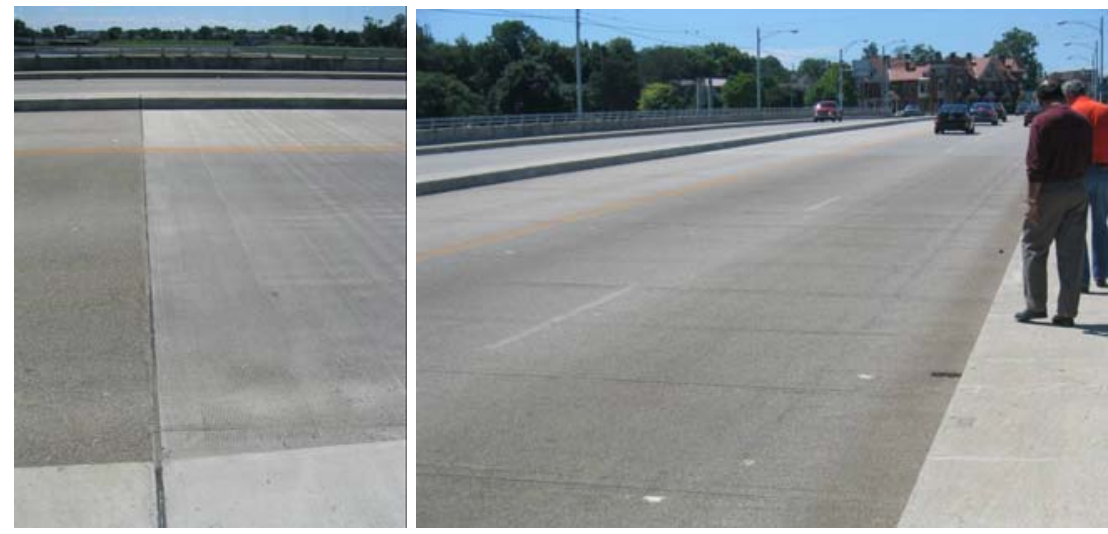

Figure 4- 5 Wearing surface cracking at a deck joint 
o Polymer wearing surface deficiencies

o Cracks in concrete wearing surface

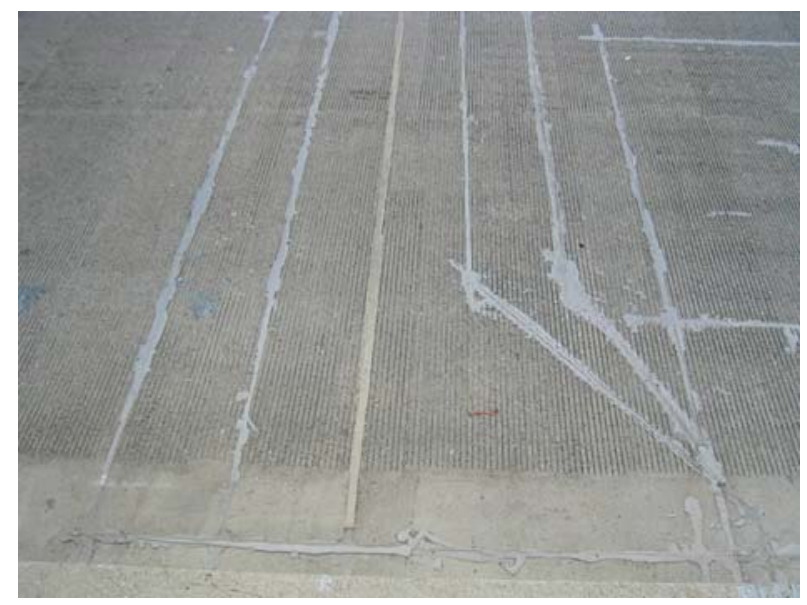

Figure 4-6 Concrete Cracks in CDS deck system

o Joints between different deck systems

o Water intrusion: Water was found within the HCI panel

o Existing fire damage: fire damage was found alongside an in-service $\mathrm{HCI}$ deck panel (Panel No. 7). No obvious structural damage occurred. 
B. Westbrook Road Bridge over Dry Run Creek

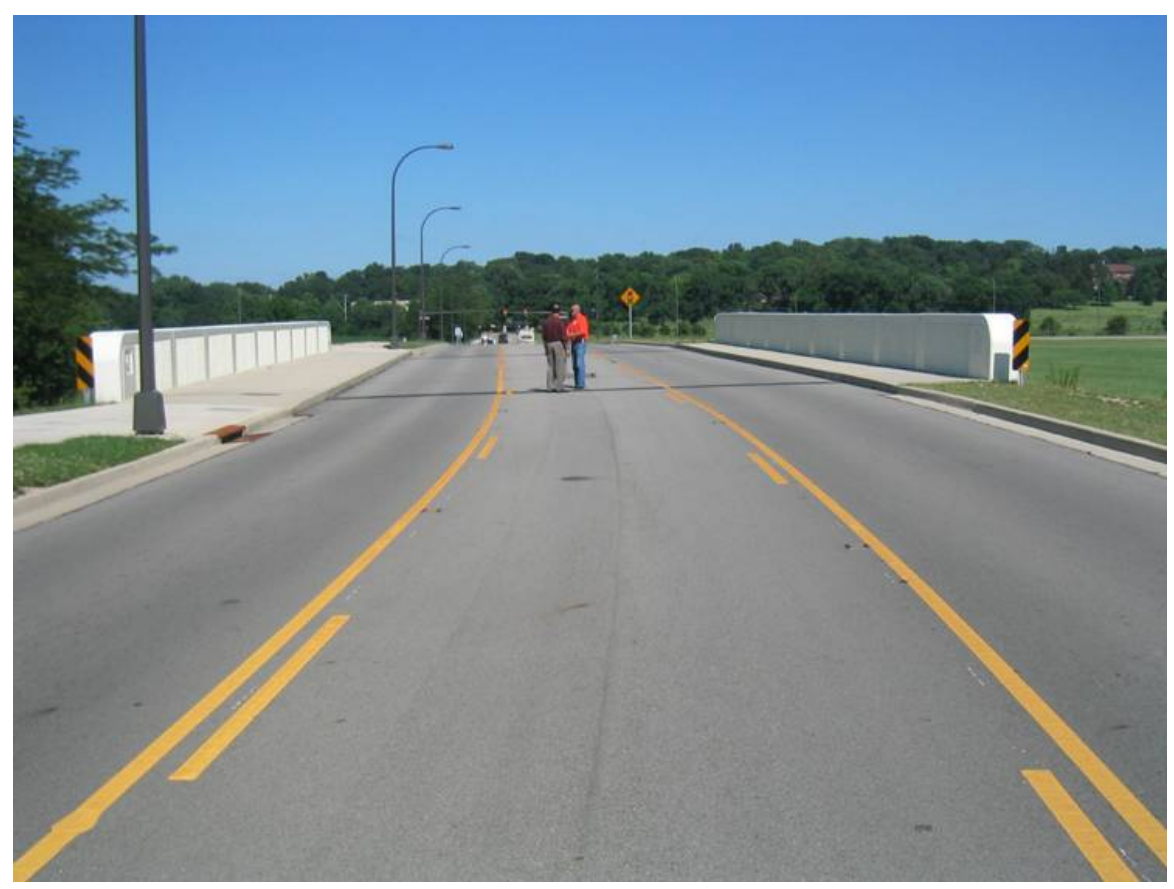

Figure 4-7 Westbrook Road Bridge over Dry Run Creek

- Deck Dimensions: 34 feet 3 inch $* 32$ feet 8 inch

- Total square footage: 975

- Design load: HS 20

- Single span

- Wearing surface: asphalt

- Guardrail attached to deck

- Manufacturer and manufacturing method: HCI and VARTM

C. Spaulding Road Bridge

- Deck Dimensions: 83 feet 1 inch * 56 feet

- Total square footage: 4,653

- Design load: HS 20 
- Single span

- Wearing surface: asphalt

- Guardrail: Concrete

- Manufacturer and manufacturing method: HCI and VARTM

4.3.2 Clark County, $\mathrm{OH}$

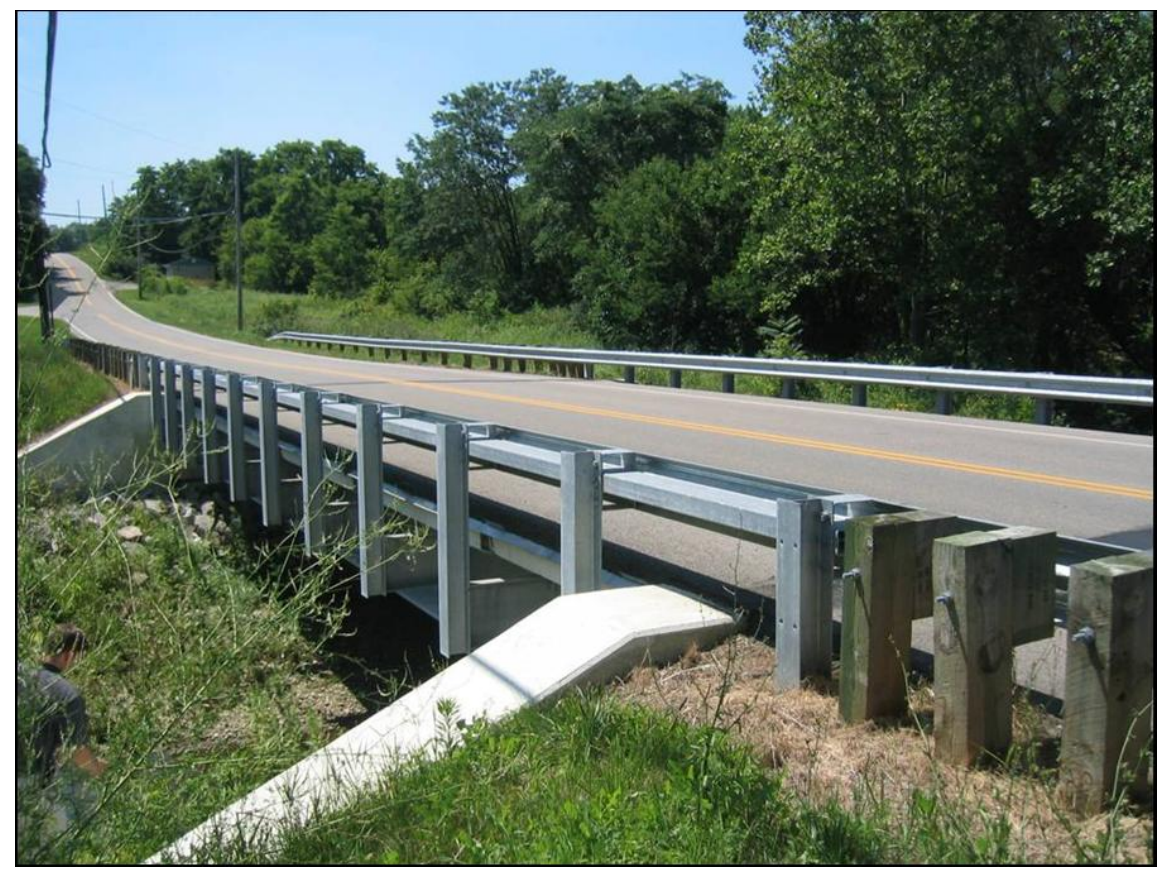

Figure 4-8 Sintz Road over Rock Run Bridge

- Project or bridge name: CLA-TR-231

- Location: Sintz Road

- Date installed: October 2000

- Project Duration(Day): About 60

- Number of person: About 4 
- Hours/person: 8

- Deck dimension: 62 feet $* 30$ feet

- Total square footage: 1,860

- Manufacturer: HCI

- Contractor: Pitoenix bridge

- Number of span: 1

- Number of FRP bridge deck panels used per span: 6

- Size of FRP bridge deck panels: 30 feet long and 10 feet wide

\section{$\underline{\text { 4.3.2.1 Construability issues of FRP bridge deck panels }}$}

- Wood or Timber among deck structure types has been replaced by FRP bridge deck panels.

- Epoxy adhesive is employed for the connection of FRP bridge deck panels. ('Glued' with a product called 'Plexus')

- Method employed for the connection between the FRP bridge deck panels and girder or stringer: Steel S-Clips attached to studs along bottom of panels 


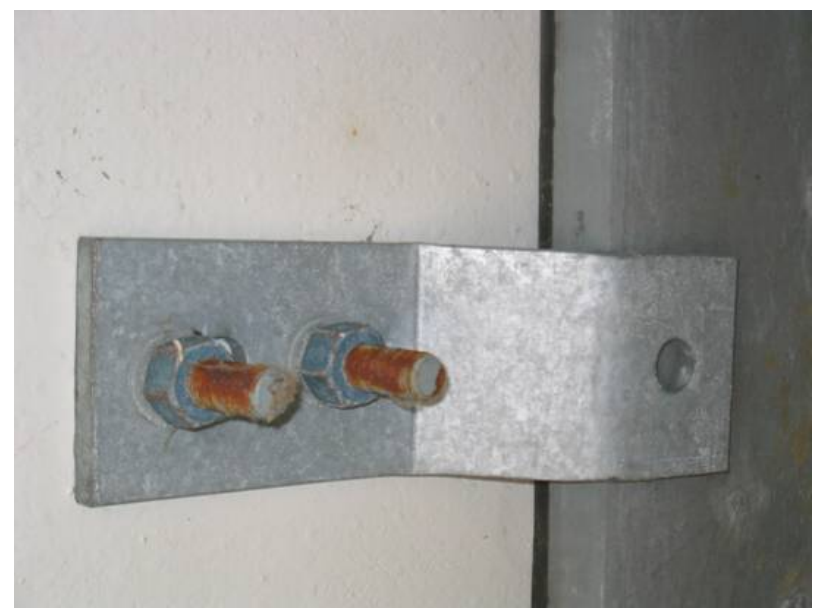

Figure 4-9 Steel S-Clip attached to studs along bottom of panels

- Use of Z clips instead of grout haunch

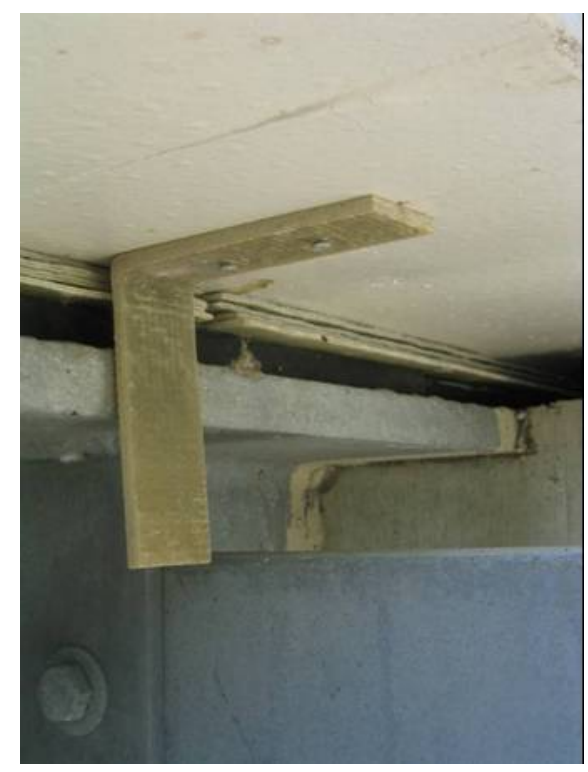

Figure 4-10 Z clips

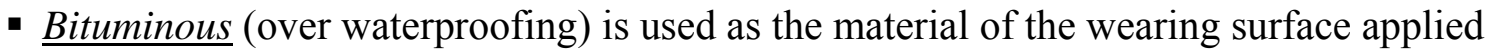
for FRP bridge deck panels.

- Wearing surface aggregate: ODOT specification 404, asphalt concrete 


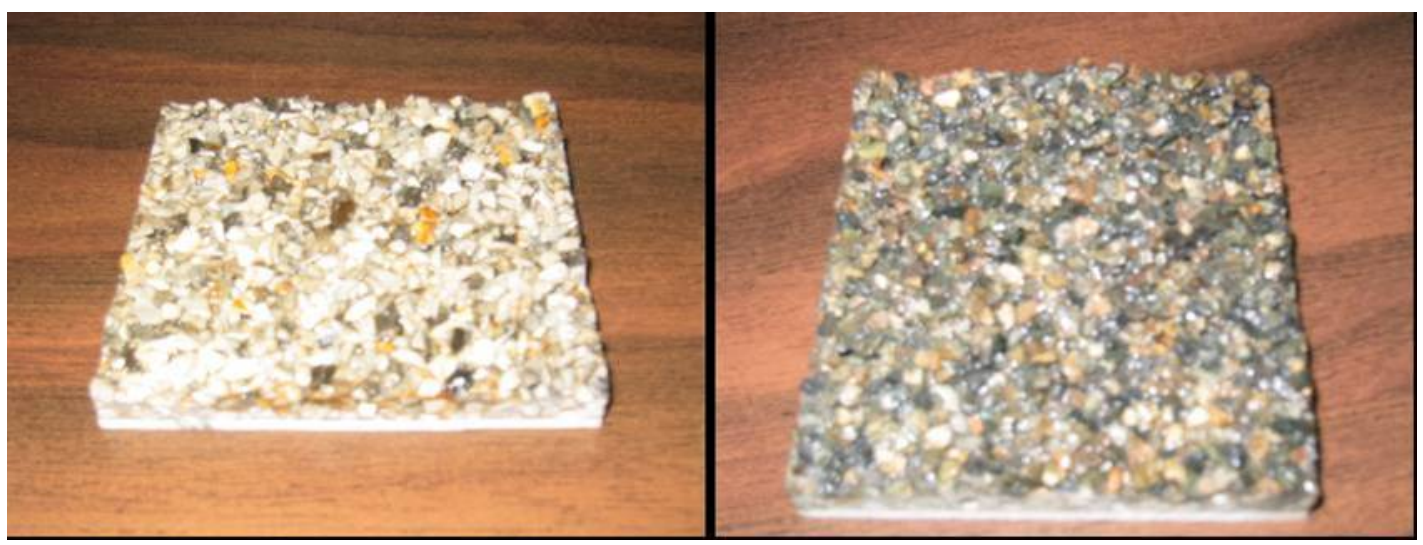

Figure 4- 11 Sample of wearing surface used in Sintz Road over Rock Run Bridge

- Manufacturing process: Closed Molding (Vacuum Assisted Resin Transfer Molding:

VARTM)

- No construction specification of FRP bridge deck panels

o No warranty issues and experimental Features

- Design Load and deflection limitation: HS-20

- Guardrail is connected to the outside beam connection between panels

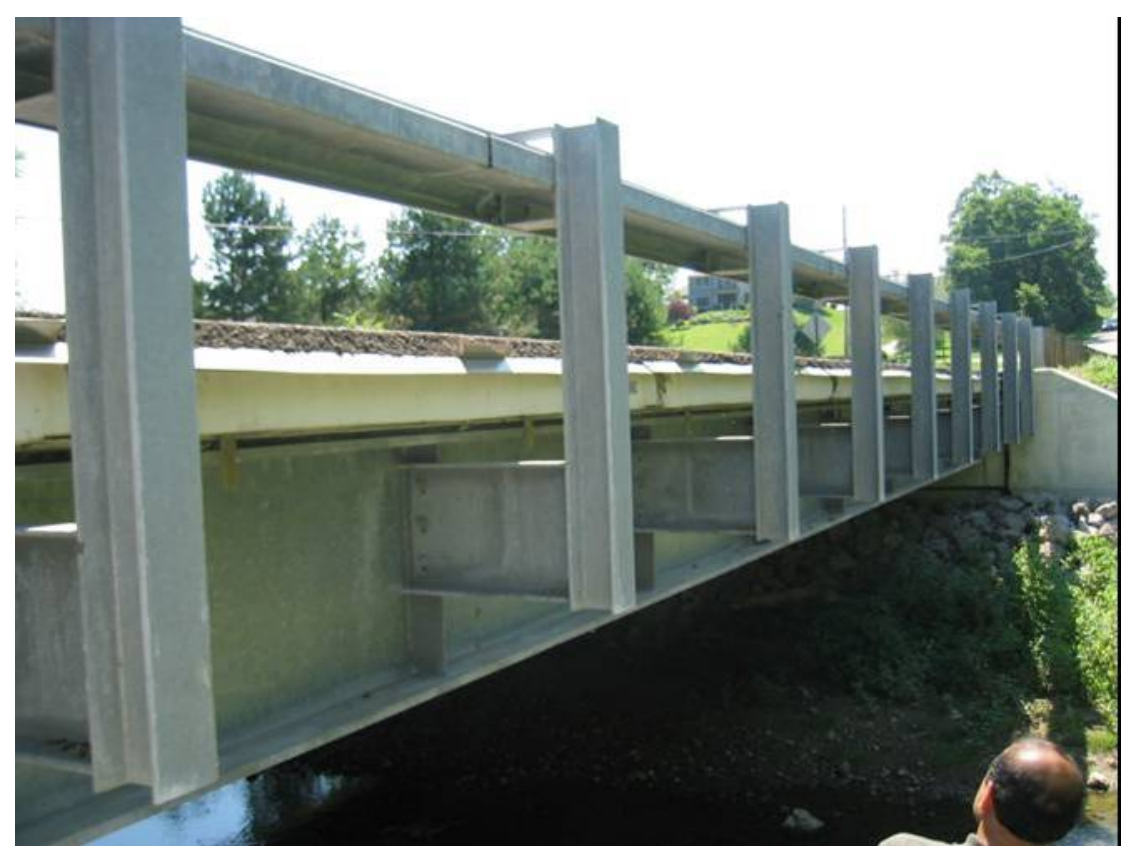

Figure 4-12 Guardrail cantilevered from girders 
- Barriers

o Construction barriers: FRP panel dimensions varied

o Vendor barrier: Epoxy machine was not working correctly.

- The cross-section type

o Hardcore composites: Sandwiched panel

- Flatbed Truck is used for delivery of FRP bridge deck panels from factory to job site.

- The maximum size of FRP bridge deck panels transported: N/A

- Delivery time of FRP bridge deck panels from factory to job site: N/A

\subsubsection{Maintainability and Operability issues of FRP bridge deck panels}

- When the condition rate of bridge decks was 4, FRP bridge deck panels were considered for replacing deteriorated bridge decks.

- When the condition rate of the substructure was 3, FRP bridge deck panels were selected.

- Specific analysis procedure or method established in order to inspect, maintain, and repair the FRP bridge deck panels

o Visual inspection 3-4 times per years. Any repairs to the panels will be based on discussion with the manufacturer.

- In terms of inspection and monitoring the service of FRP bridge deck panels

o Tap test is performed every year.

- Issues/problems with maintenance and operation after the FRP bridge deck panels were installed: No. 

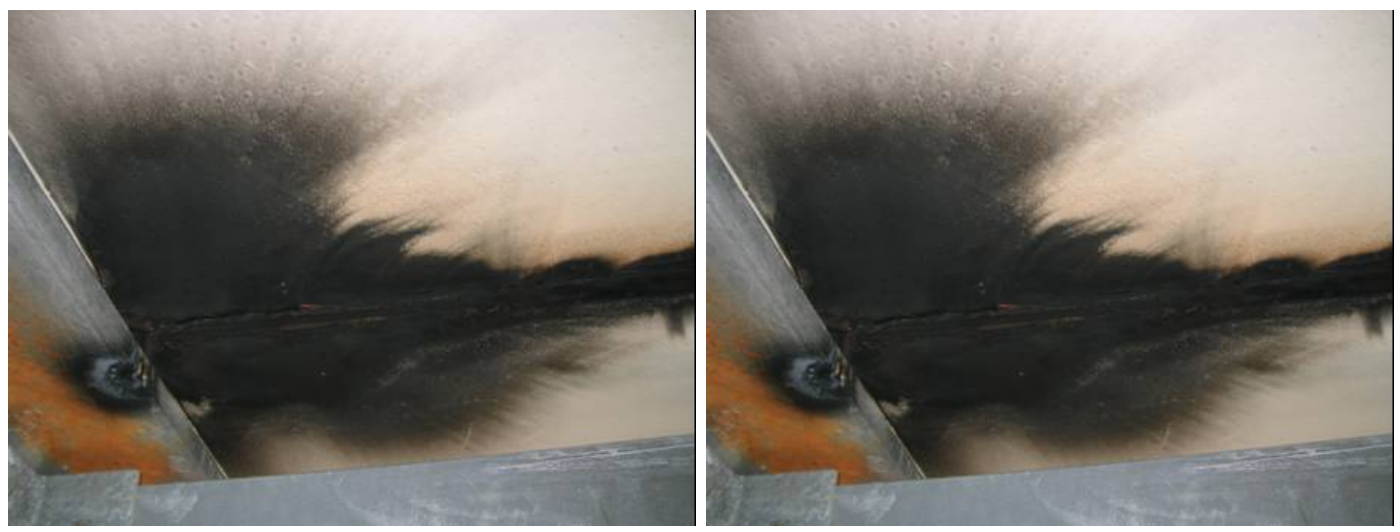

Figure 4-13 Fire damage found in the bottom of panels

- Average service life of Concrete Bridge Deck: 25-30 years

- Expected service life of FRP Composite Bridge Deck: 50-100 years

\subsubsection{Construction cost of FRP bridge deck panels}

- Initial Construction Cost: $\$ 91.40 / \mathrm{sf}$

- Engineering Cost: $\$ 21.51 / \mathrm{sf}$ 


\subsubsection{Defiance County, $\mathrm{OH}$}

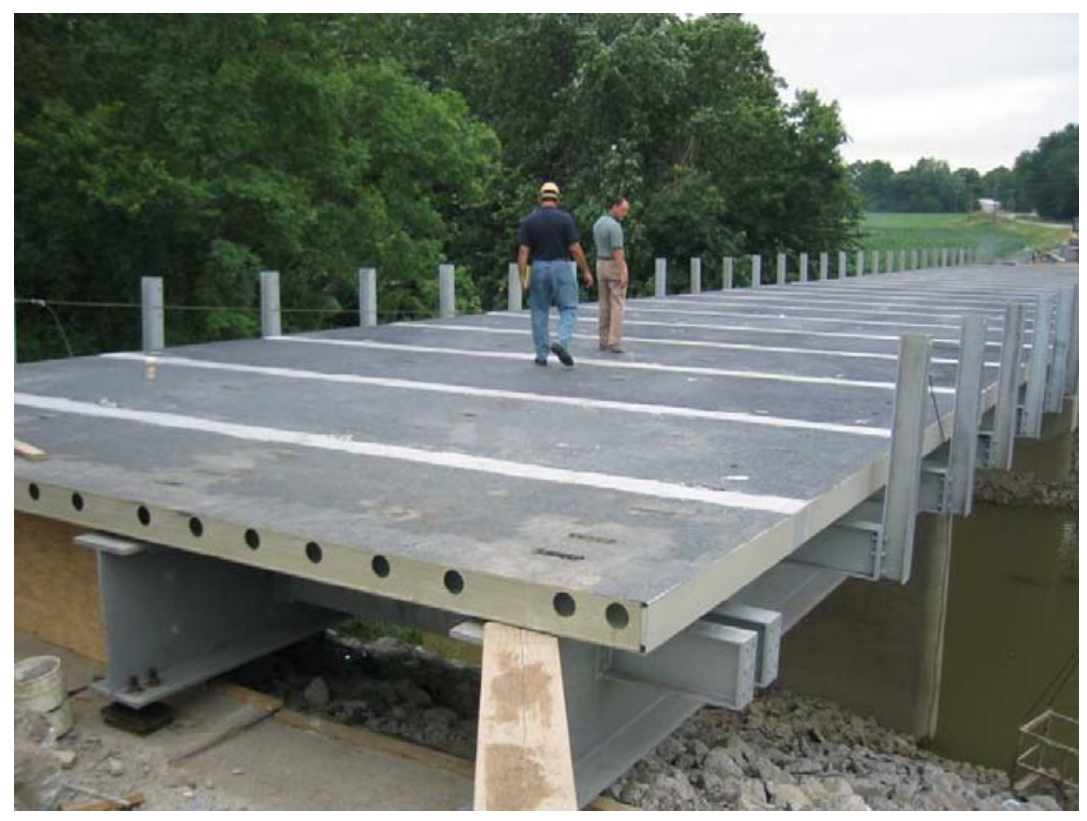

Figure 4-14 County line road over Tiffin River

- Project or bridge name: CR1-Defiance/Wil County Line

- Date installed: July 2003

- Deck dimension: 186 feet 6 inches $* 28$ feet

- Total square footage: 5,222

- Manufacturer: MMC

- Number of span: 3

- Number of FRP bridge deck panels used per span: 8

- Size of FRP bridge deck panels: 8 feet long and 28 feet wide

\subsubsection{Construability issues of FRP bridge deck panels}

- Concrete Cast-in-place deck structure was replaced by FRP bridge deck panels. 
- Epoxy adhesive and Tongue and groove ends are employed for the connection of FRP bridge deck panels.

- Grouted studs are employed for the connection between the FRP bridge deck panels and girder or stringer

- $\underline{\text { Bituminous }}$ is used as the material of the wearing surface applied for FRP bridge deck panels.

- Wearing surface aggregate: N/A

- The manufacturer for wearing surface: N/A

- Manufacturing process: Closed Molding (Pultrusion) : Deck thickness $=8$ in
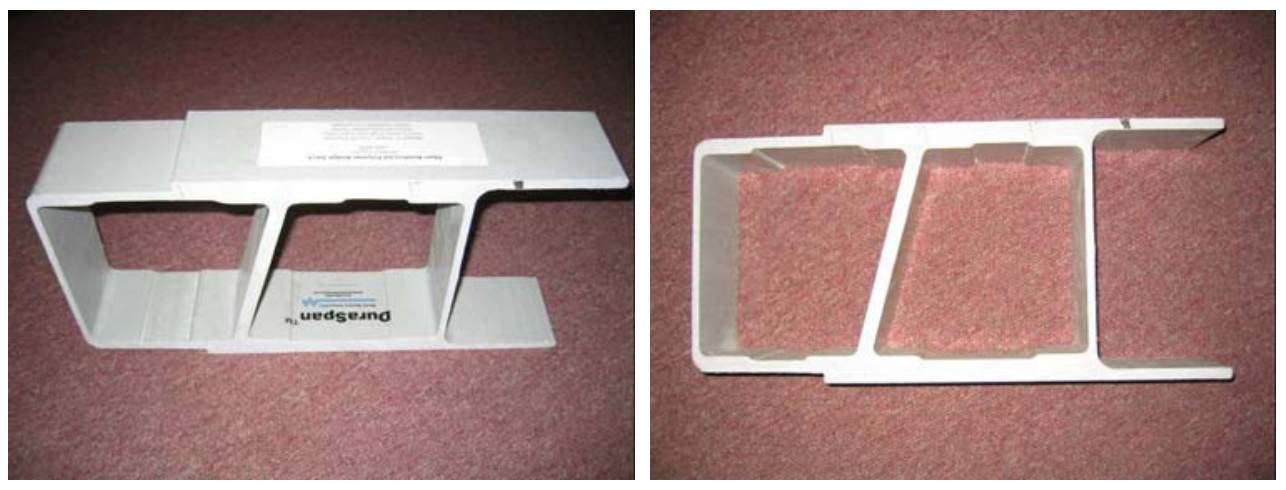

Figure 4-15 Sample of FRP bridge deck panels (Manufacturer: MMC)

- No construction specification of FRP bridge deck panels (Job Specific specifications have been used)

- Warranty from Manufacturer: N/A

- Design Load: HS25

- Deflection limitation: N/A

- Guardrail is connected to the outside beam connection between panels 


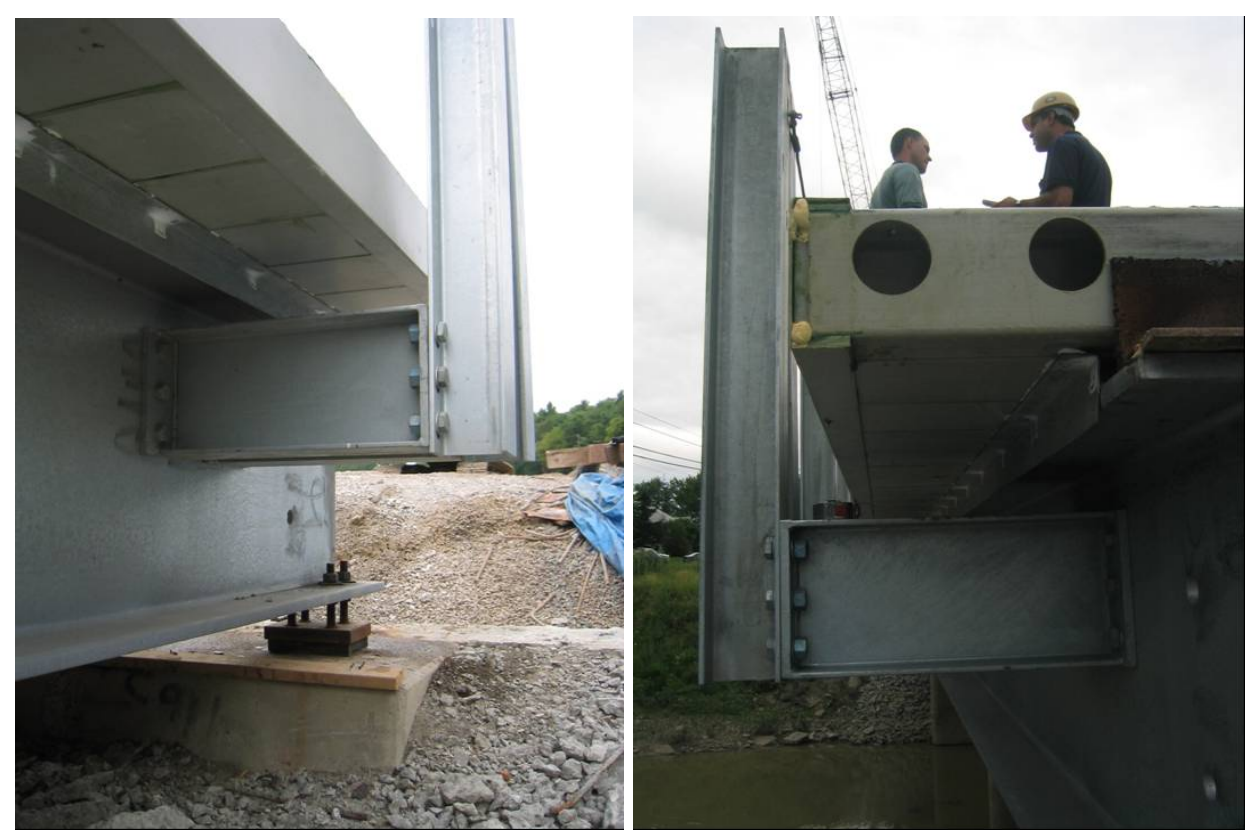

Figure 4-16 Guardrail cantilevered from girders

- Barriers: Design barriers (Manufacturer insisted on using shear studs as connection detail)

- The cross-section type

\section{o Martin-Marietta}

- Flatbed Truck is used for delivery of FRP bridge deck panels from factory to job site.

- The maximum size of FRP bridge deck panels transported: N/A

- Delivery time of FRP bridge deck panels from factory to job site: N/A

\subsubsection{Maintainability and Operability issues of FRP bridge deck panels}

- When the condition rate of bridge decks was 2, FRP bridge deck panels were considered for replacing the deteriorated bridge decks. 
- When the condition rate of the substructure was 7, FRP bridge deck panels were selected.

- No specific analysis procedure or method established in order to inspect, maintain, and repair the FRP bridge deck panels.

- Average service life of Concrete Bridge Deck: 30 years

- Expected service life of FRP Composite Bridge Deck: 75 years

\subsubsection{Construction cost of FRP bridge deck panels}

- Initial Construction Cost: $\$ 93 / \mathrm{SF}$

\subsubsection{Greene County, $\mathrm{OH}$}

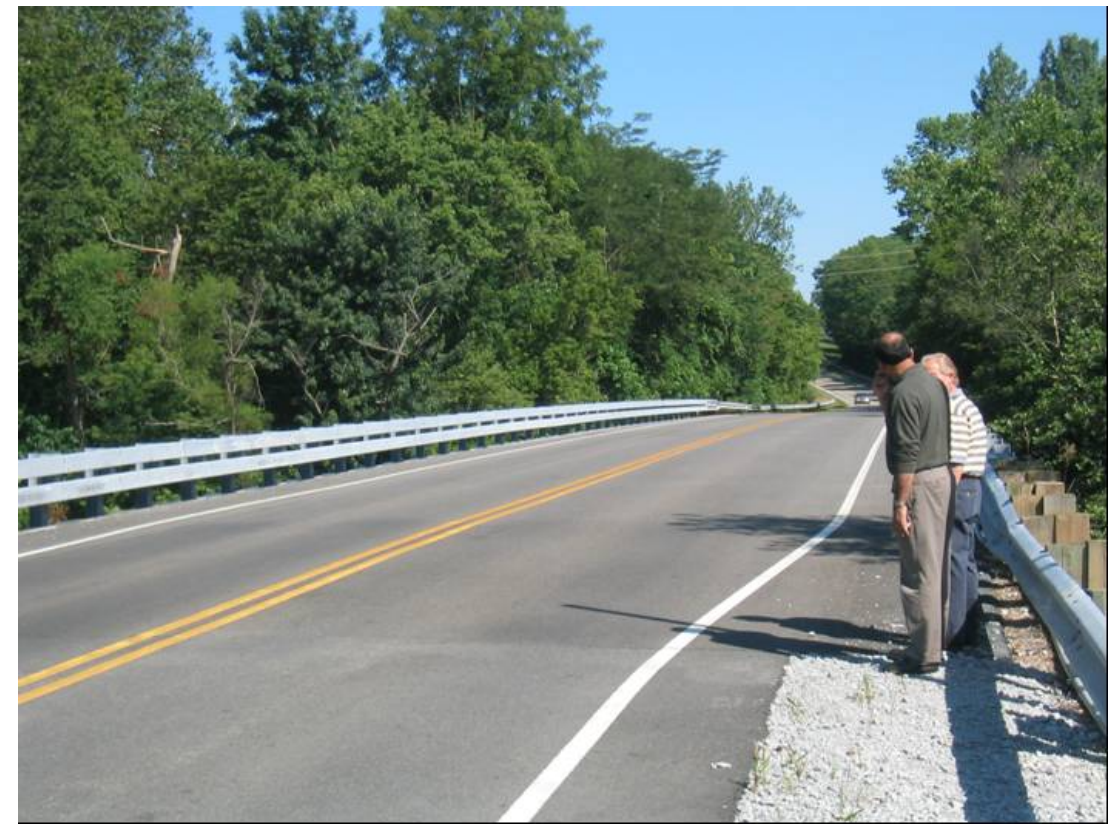

Figure 4- 17 Fairgrounds road bridge

- Project or bridge name: Fairgrounds Road Bridge 
- Date installed: May 2002

- Duration of Installation (Day): 3

- Number of person: 10

- Hours/person: 10

- Deck dimension: 227 feet $* 32$ feet 6 inches

- Total square footage: 7,400

- Manufacturer: MMC

- Contractor: AHERN associate

- Number of span: 3

- Total number of FRP bridge deck panels used: 28

- Size of FRP bridge deck panels: 32 feet long and 8 feet wide

\subsubsection{Construability issues of FRP bridge deck panels}

- Concrete Cast-in-place deck structure types was replaced by FRP bridge deck panels.

- Epoxy adhesive is employed for the connection of FRP bridge deck panels.

o Panels were connected by epoxy and attached to beams with shear studs and grout

- Method employed for the connection between the FRP bridge deck panels and girder or stringer

o Shear studs and grout in pockets

- Polymer modified asphalt is used as the material of the wearing surface applied for FRP bridge deck panels.

- Wearing surface aggregate: Natural aggregate 
- The manufacturer for wearing surface: Barrett paving materials

- Manufacturing process: Closed Molding (Pultrusion) : deck thickness $=8$ in

- No construction specification of FRP bridge deck panels (Job Specific specifications have been used)

- Warranty from Manufacturer: 30 years

- Design Load: HS40

- Deflection limitation: N/A

- Barriers: Cost

- The cross-section type

o Martin-Marietta

- Flatbed Truck is used for delivery of FRP bridge deck panels from factory to job site.

- The maximum size of FRP bridge deck panels transported: $32{ }^{\prime} * 8^{\prime}$

- Guardrail is attached to FRP bridge deck

- Delivery time of FRP bridge deck panels from factory to job site: 1 Day

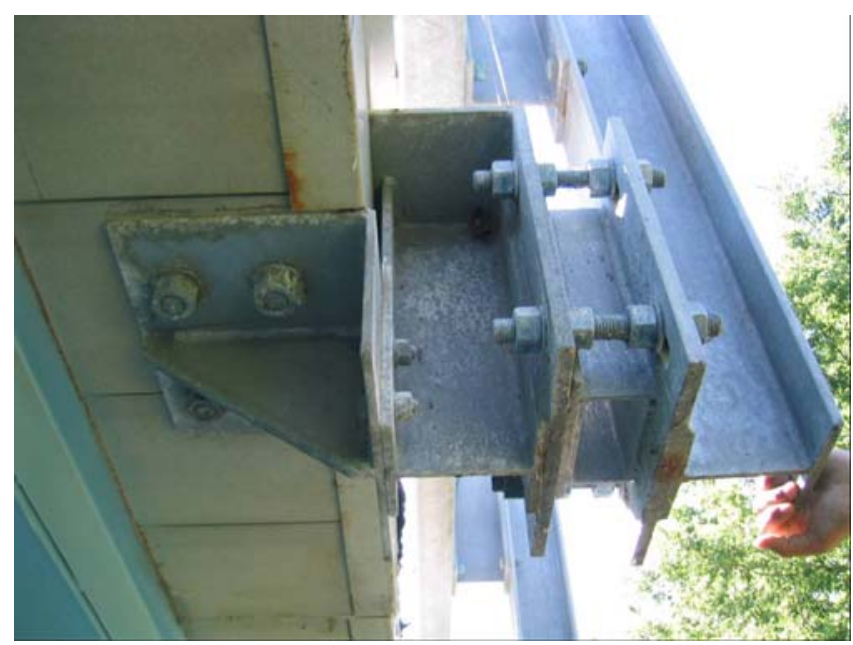

Figure 4-18 Guardrail attached to deck 


\subsubsection{Maintainability and Operability issues of FRP bridge deck panels}

- When the condition rate of bridge decks was 4, FRP bridge deck panels were considered for replacing deteriorated bridge decks.

- When the condition rate of the substructure was 6 , FRP bridge deck panels were selected.

- No specific analysis procedure or method established in order to inspect, maintain, and repair the FRP bridge deck panels.

- Issues/problems with maintenance and operation

o Delamination, debonding, and cracking of wearing surface

o Keeping tolerance around deck edge with guardrail straight

o Some minor gaps between FRP deck bottom and concrete beams
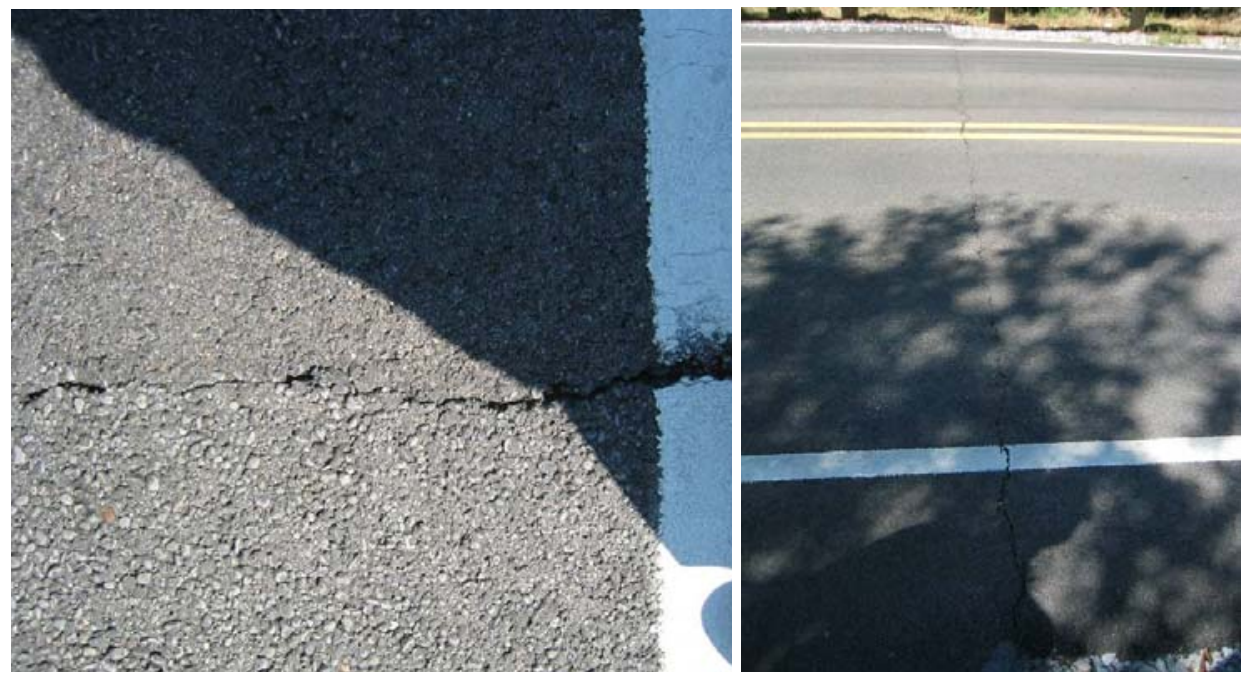

Figure 4-19 De-bonding, and cracking of Wearing surface 

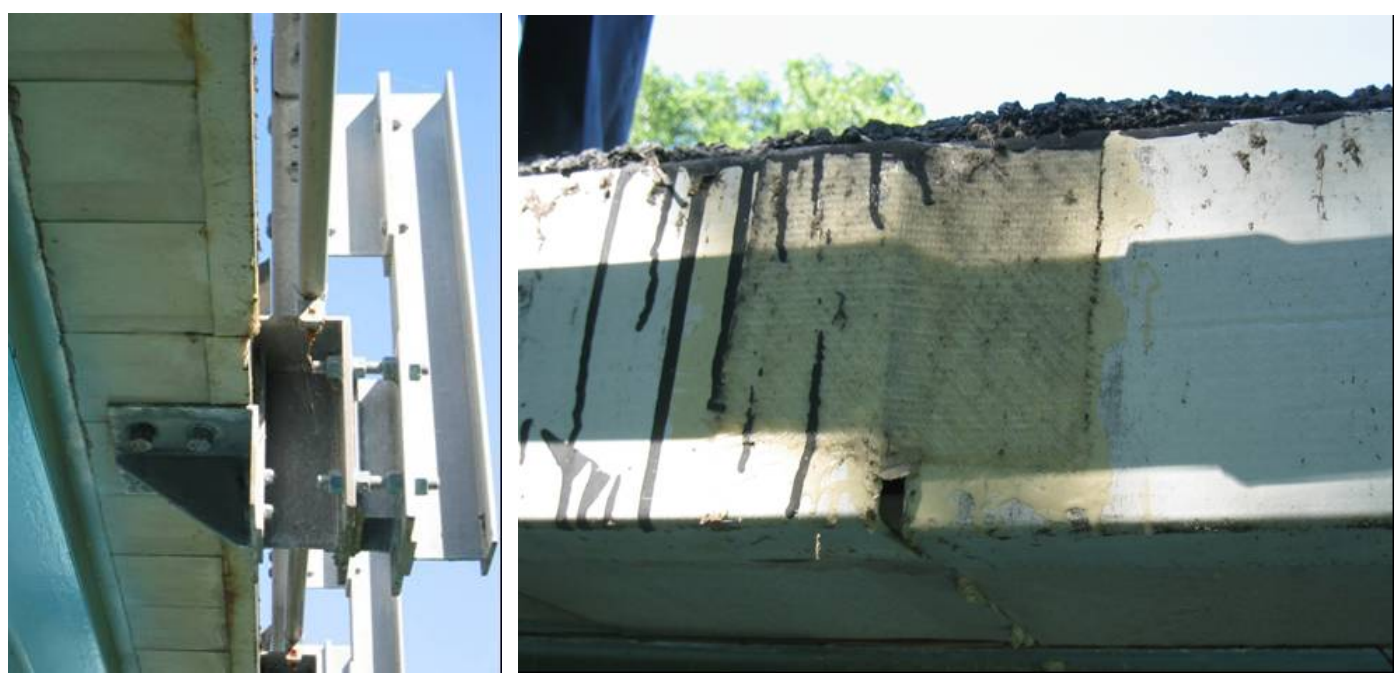

Figure 4- 20 Keeping tolerance around deck edge with guardrail straight

- Average service life of Concrete Bridge Deck: 50 years

- Expected service life of FRP Composite Bridge Deck: N/A

\subsubsection{Construction cost of FRP bridge deck panels}

- Initial Construction Cost: \$90/SF

- Total Cost: $\$ 675,000$

4.3.5 Hamilton County, $\mathrm{OH}$

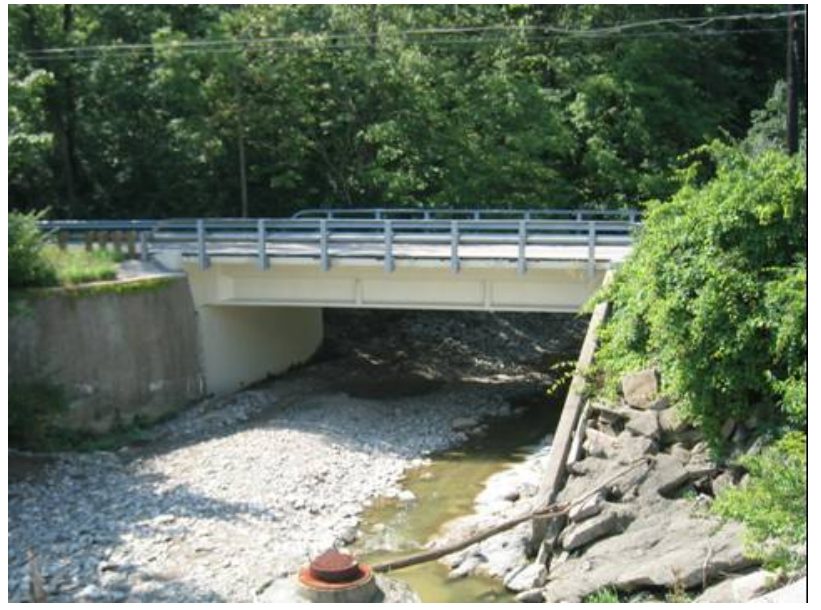

Figure 4-21 Five Mile Road Bridge \# 0171 


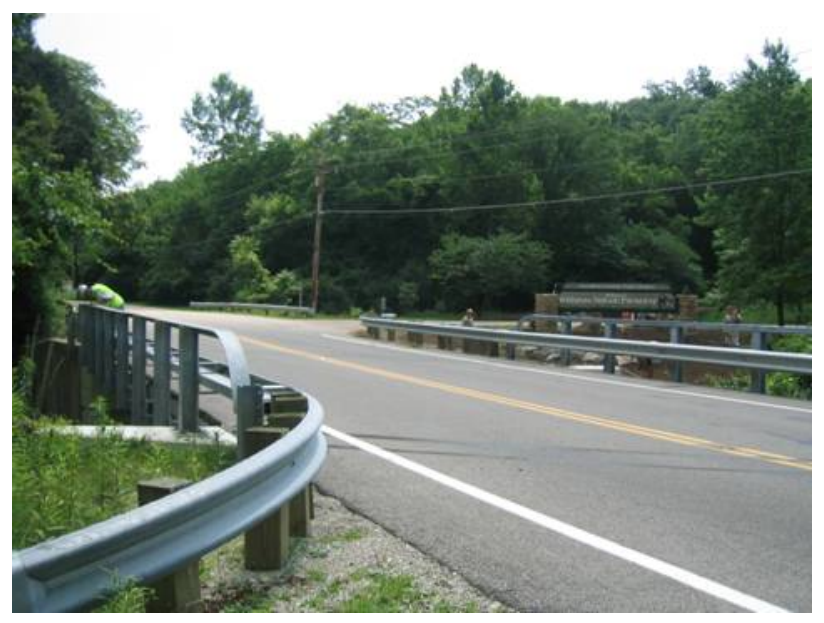

Figure 4-22 Five Mile Road Bridge \#0087

\begin{tabular}{l|c|c|c}
\hline \hline & $\begin{array}{c}\text { Five Mile Road } \\
\text { Bridge \# 0071 }\end{array}$ & $\begin{array}{c}\text { Five Mile Road } \\
\text { Bridge \# 0087 }\end{array}$ & $\begin{array}{c}\text { Five Mile Road } \\
\text { Bridge \#0171 }\end{array}$ \\
\hline \hline Location & Five Mile Road & Five Mile Road & Five Mile Road \\
\hline Date installed & November 30. 2001 & May 26. 2001 & November 30. 2000 \\
\hline Duration (day) & 1 & 1 & 1 \\
\hline Number of person & $5-6$ & $5-6$ & $5-6$ \\
\hline Hours/person & 8 & 8 & 8 \\
\hline Manufacturer & HCI & HCI & HCI \\
\hline Contractor & Ft. defiance Constr. & Ft. defiance Constr. & Ft. defiance Constr. \\
\hline Number of spans & 1 & 1 & 1 \\
\hline $\begin{array}{l}\text { No. of FRP bridge } \\
\text { deck panels used per } \\
\text { span }\end{array}$ & \pm 6 & \pm 6 & \pm 6 \\
\hline $\begin{array}{l}\text { Size of FRP bridge } \\
\text { deck panels (Feet) }\end{array}$ & $\begin{array}{l}\text { Length: } 30 \text { feet } \\
\text { Width: Various }\end{array}$ & $\begin{array}{l}\text { Length: } 30 \text { feet } \\
\text { Width: Various }\end{array}$ & $\begin{array}{l}\text { Length: } 30 \text { feet } \\
\text { Width: Various }\end{array}$ \\
\hline Deck dimension & 44 feet $* 28$ feet & 47 feet *30 feet & 44 feet * 28 feet \\
\hline \hline
\end{tabular}

\section{$\underline{\text { 4.3.5.1 Construability issues of FRP bridge deck panels }}$}

- Concrete Cast-in-place deck structure types was replaced by FRP bridge deck panels.

- Epoxy adhesive and Tongue-and-groove ends are employed for the connection of FRP bridge deck panels. ('Glued' with a product called 'Plexus')

- Method employed for the connection between the FRP bridge deck panels and girder or stringer (Refer to the picture below): 
o Nelson Stud: It is a steel bar about $7 / 8$ " in diameter that is welded to the plate on the top of the beam through a hole that was fabricated in the deck. There is a Nelson Stud gun that does this very quickly as compared to normal welding procedures.

o Mechanically bolted to concrete I-beams

o Void between FRP and concrete flange filled with grout.
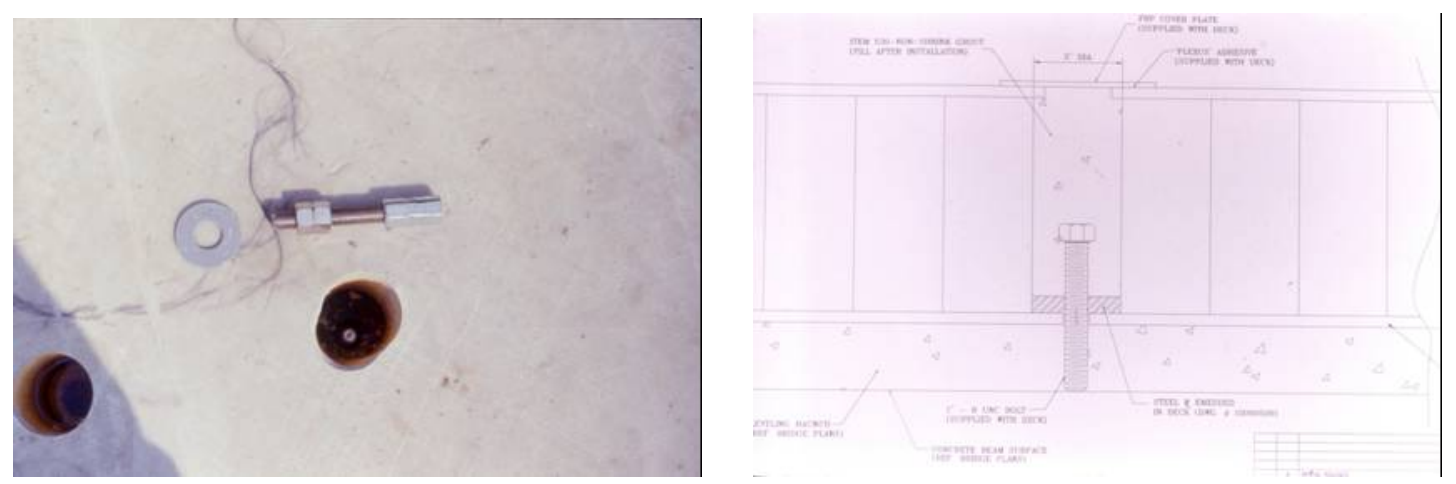

Figure 4-23 Nelson Stud method

- Bituminous (over waterproofing) is used as the material of the wearing surface applied for FRP bridge deck panels.

- Wearing surface aggregate: Coarse + Fine Aggregate in asphalt

- Guard Rail: Attached to deck
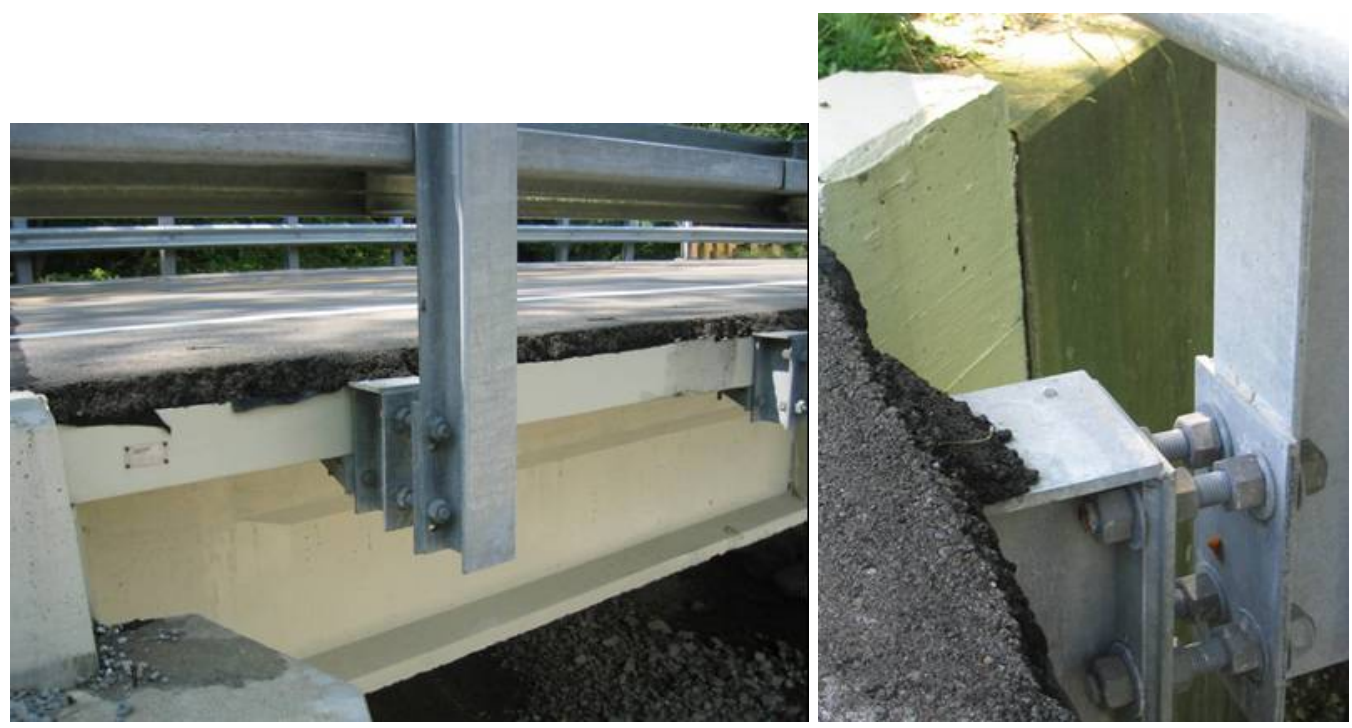

Figure 4- 24 Guardrail attached to deck 
- A manufacturer for wearing surface: N/A, Local plant

- Manufacturing process: Closed Molding (Vacuum Assisted Resin Transfer Molding)

- No construction specification of FRP bridge deck panels (Job Specific specifications have been used)

- No warranty and No experimental Features

- Design Load and deflection limitation: N/A

- Barriers: Design barriers (Guardrail ), Vendor barriers (Located in Delaware)

o Other problem: It was tough to get enough 'Plexus' material in tongue and groove areas before it began to set up.

- The cross-section type

o Hardcore composites: Sandwiched panel

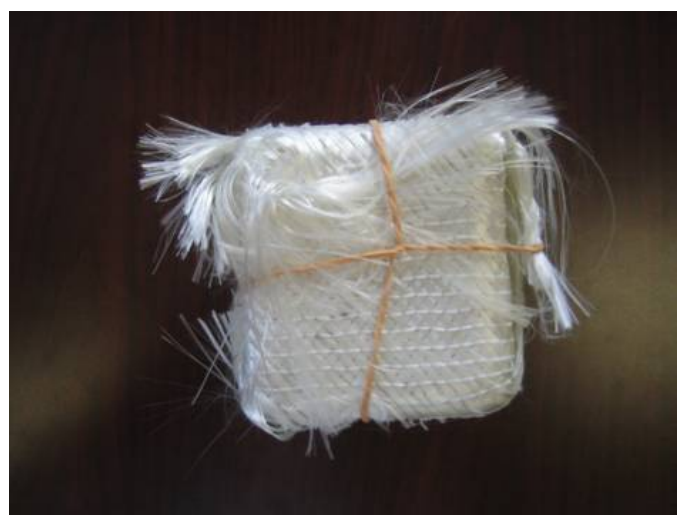

Figure 4-25 Honeycomb cells of sandwiched panels

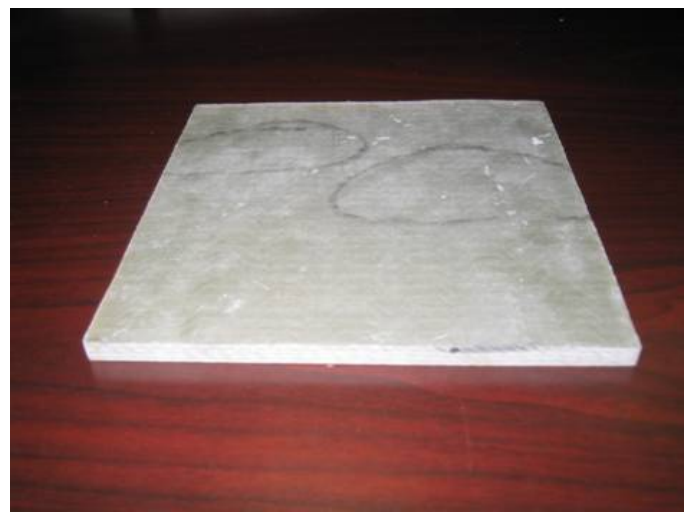

Figure 4-26 Face sheets of sandwiched panels

- How does beam spacing affect the slab thickness in FRP bridge deck panels?

- Needed an 8" panel due to existing beam spacing 
- Flatbed Truck is used for delivery of FRP bridge deck panels from factory to job site.

- The maximum size of FRP bridge deck panels transported: N/A

- Delivery time of FRP bridge deck panels from factory to job site: N/A

\subsubsection{Maintainability issues of FRP bridge deck panels}

- When the condition rate of bridge decks was 3, FRP bridge deck panels were considered for replacing deteriorated bridge decks.

- When the condition rate of the substructure was 7, FRP bridge deck panels were selected.

- No specific analysis procedure or method established in order to inspect, maintain, and repair the FRP bridge deck panels.

- Visual inspection has been performed every one year after FRP bridge deck panels were set up.

- Issues/problems with maintenance and operation after the FRP bridge deck panels were installed:

o Some shims on one deck

o There were some minor gaps between FRP deck bottom and concrete beams

- Average service life of Concrete Bridge Deck: 50 years

- Expected service life of FRP Composite Bridge Deck: 100 years

\subsubsection{Operability issues of FRP bridge deck panels}

(1) B-0071: FRP deck - material + installation: \$ 75/SF,

Total cost: $100,500.00$

(2) B-0087: FRP deck - material + installation: \$75/SF

Total cost: 105,825.00

(3) B-0171: FRP deck - material + installation: \$ 75/SF

Total cost: $98,325.00$ 


\subsection{Result analysis of questionnaire survey}

The following issues on FRP bridge deck panels are analyzed according to the response to the questionnaire survey from four counties (except Montgomery County).

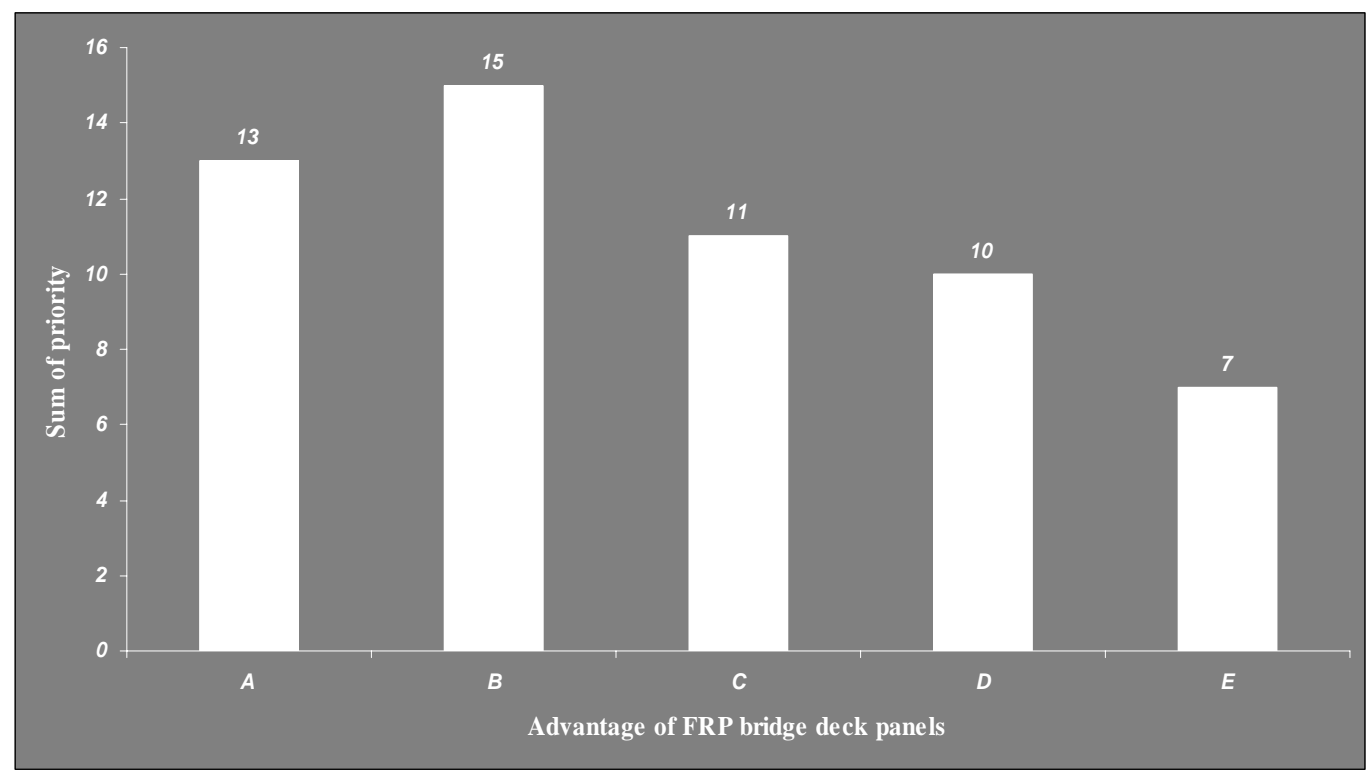

Figure 4-27 Advantage of FRP bridge deck panels

(1) Advantage of FRP bridge deck panels

The county engineers were asked to list the advantages of FRP bridge deck panels using a scale of $1-5$ where $(1=$ least priority and $5=$ top priority $)$. Four county engineers except for Montgomery County engineers answered the question. A-E of horizontal axis in Figure 4-7 represents the advantage of FRP bridge deck panels: A. Increased capacity for live load with possible elimination of weight restrictions, B. Good durability, fatigue resistance, long service life, resistance to de-icing salts, C. Fast installation due to modular, prefabricated nature, and reduced traffic delay, D. Cost saving, less expense for maintenance than total replacement, and E. Less environmental impact and fewer permits required than replacement. 
The opinion of county engineers are same as that of bridge engineers mentioned in Chapter 3 in that they were skeptical that FRP composites bridge decks have less environmental impact and require few permits as compared to conventional decks. Similarly, county engineers somewhat doubted that FRP bridge deck panels could offer cost saving, less expense for maintenance than total replacement.

(2) Road type of application for FRP bridge deck

In low volume rural, four deteriorated conventional bridge decks have been replaced by FRP bridge deck panels. In high volume rural, FRP bridge deck panels were used to replace two deteriorated conventional bridge decks. It is important to note that while the FRP bridge deck panels made by HCI were used in low volume rural, those made by MMC was all used in high volume rural (Refer to Figure 4-28) 


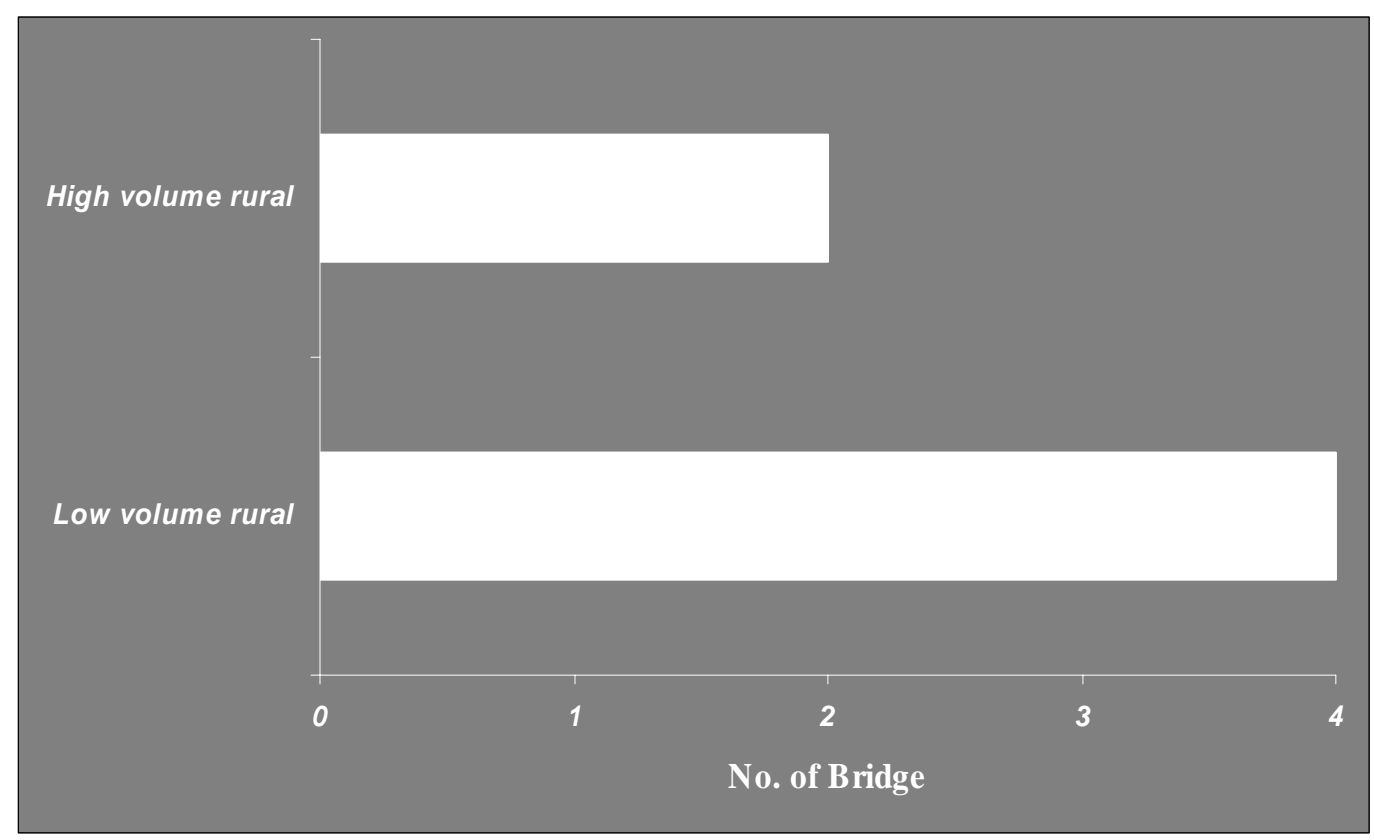

Figure 4-28 Road type of application for FRP bridge deck panels

(2) Deck structure type

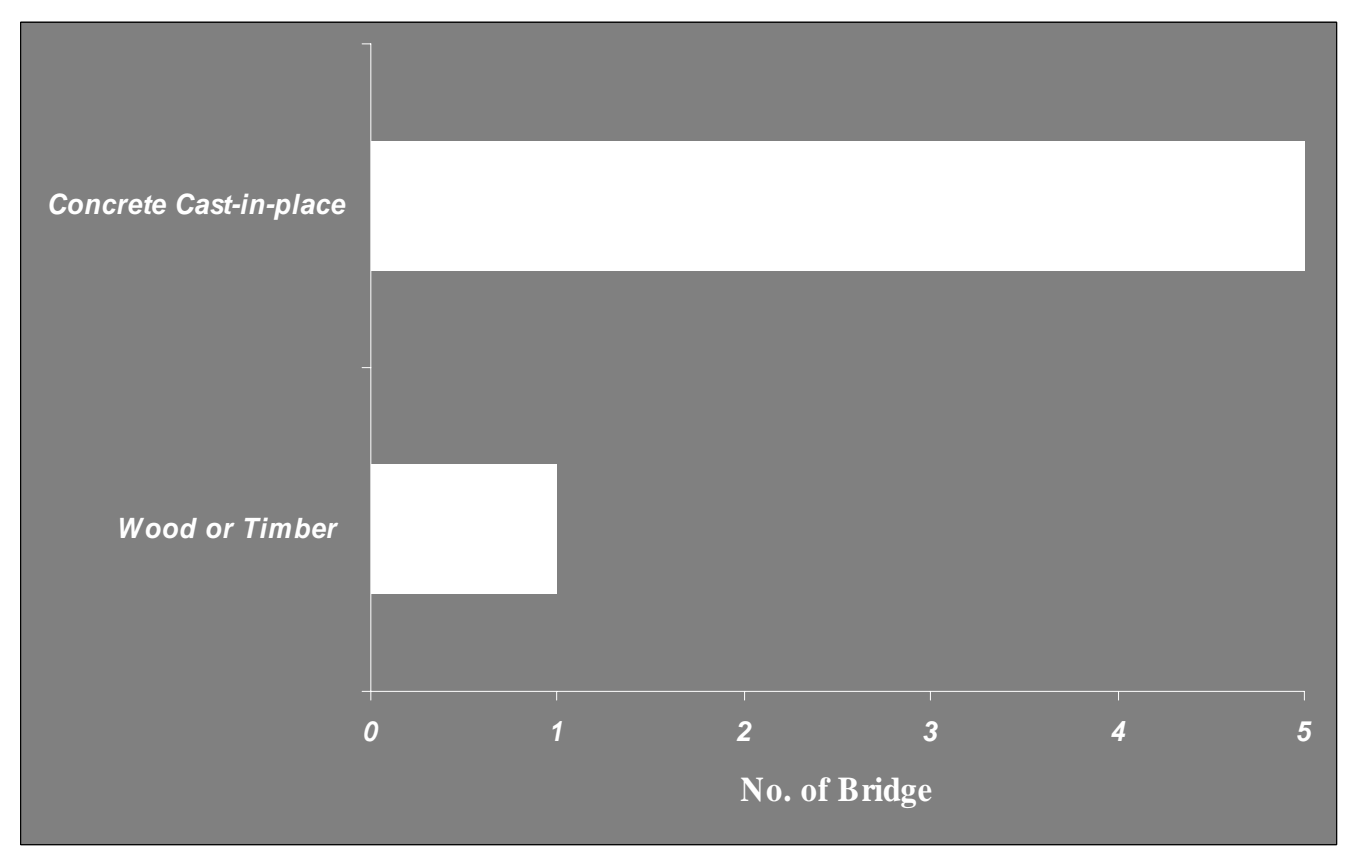

Figure 4-29 Deck structure types 
In the case studies, only two deck structure types - (i) Wood or Timber and (ii) Concrete cast-in-place - were replaced by FRP bridge deck panels (Refer to Figure 4-29). This is somewhat similar to the results obtained from the questionnaire survey sent to DOT bridge engineers in that the FRP bridge deck panels were mostly used in the two deck structure types (Refer to Figure 3-5).

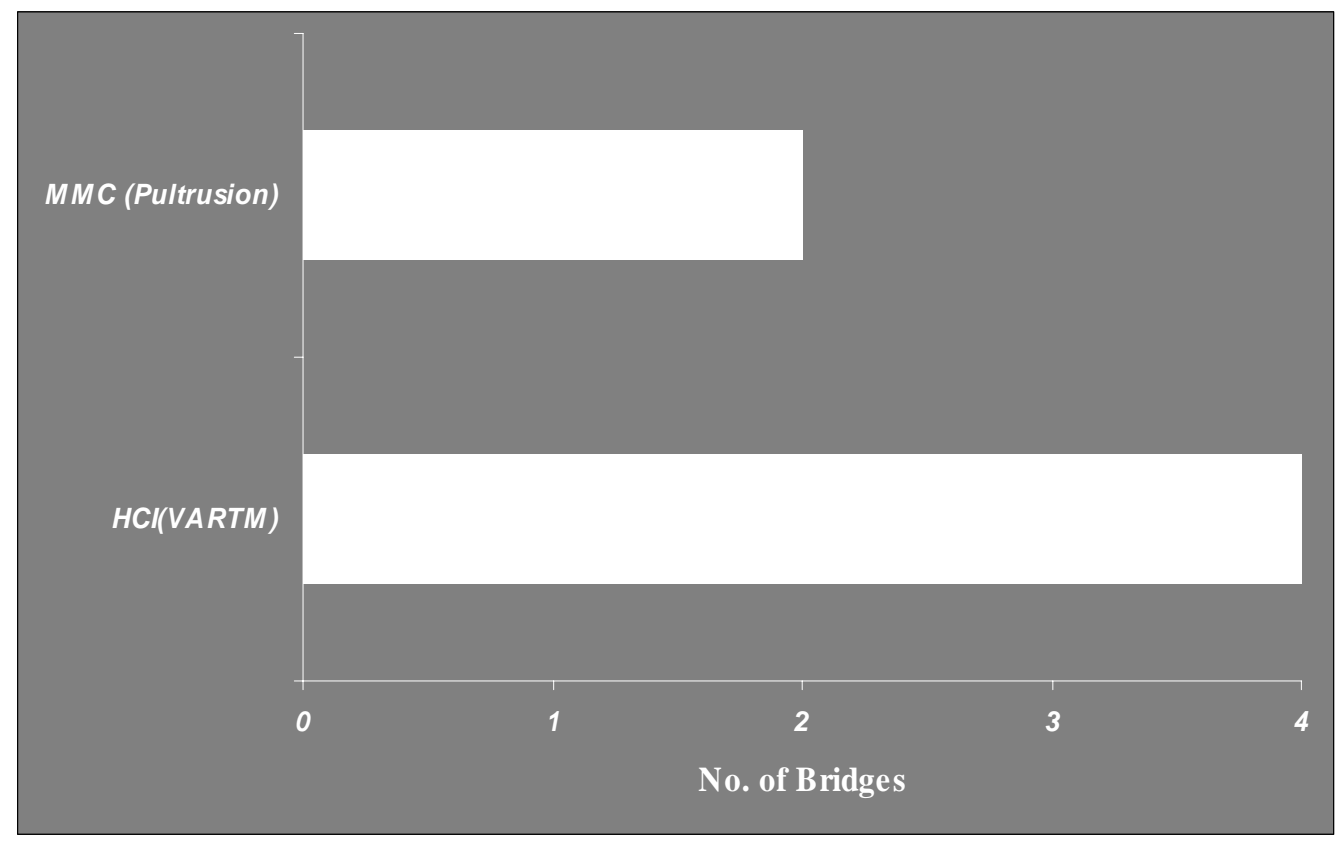

Figure 4-30 Manufacturer and manufacturing method

(3) Manufacturer and manufacturing method

As mentioned in section 4.2, only two manufacturers were involved in Project 100 and C4I. Two bridges used MMC product made by Pultrusion and four bridges used HCI product made by Vacuum Assisted Resin Transfer Molding (VARTM) method (Refer to 4-30). The result is also in accord with that obtained from the questionnaire survey sent to the DOT bridge engineers. The FRP bridge deck panels of HCI and MMC among several manufacturers were used by many DOTs (Refer to Figure 3-10). 


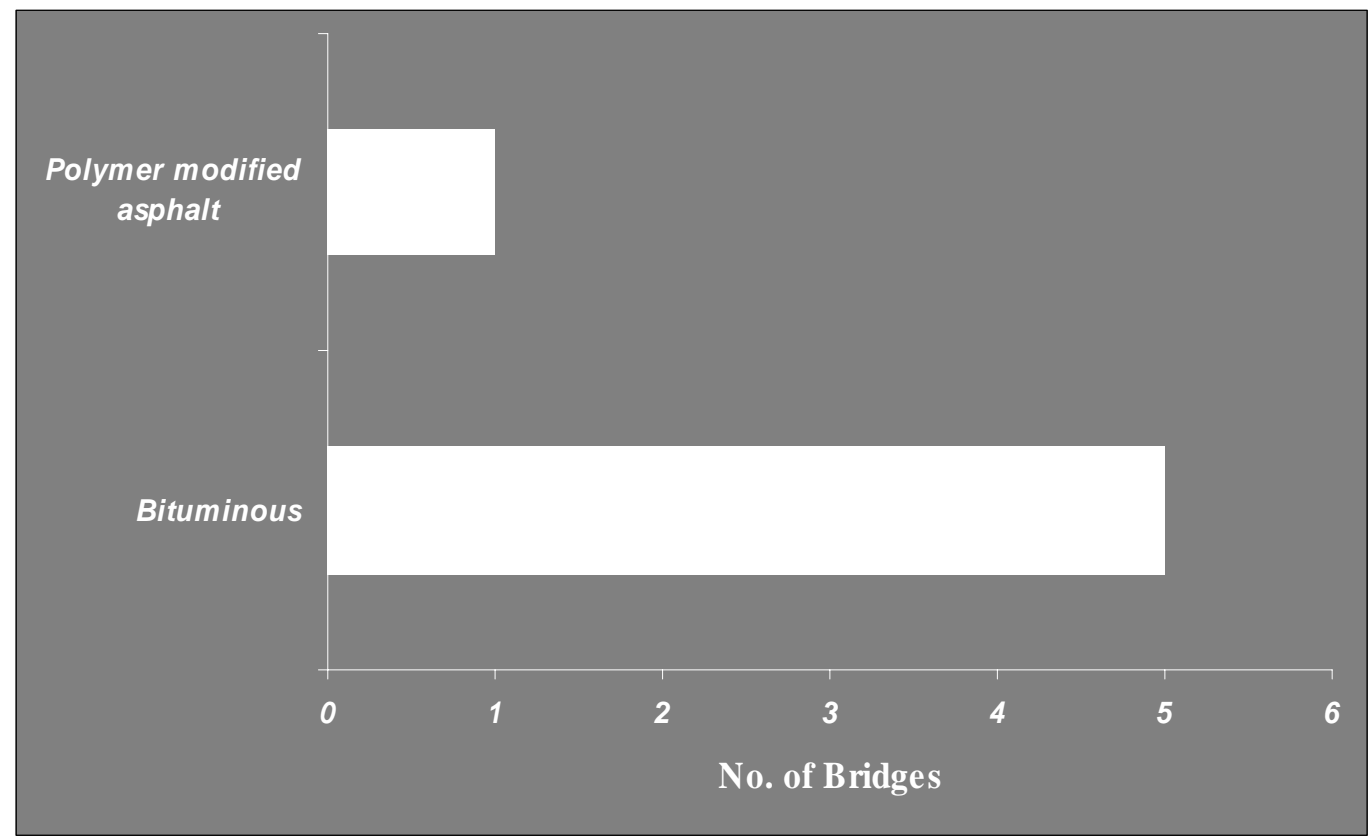

Figure 4-31 Material types of wearing surface

(4) Wearing surface

Most of the bridges used 'Bituminous' as wearing surface and only one bridge used 'Polymer modified asphalt' (Refer to Figure 4-31). In case of DOTs, 'Bituminous' was used by 7 DOTs, followed by Polymer concrete used by 5 DOTs (Refer to Figure 3$15)$.

(5) Installing method of guardrail

There are two methods for installing guardrail: (i) attach concrete barriers or steel guardrail to deck, and (ii) cantilever guardrail from girders. The two methods were used to install guardrail in the identified case studies. It was found that 'Guardrail attached to deck' was a preferable method (Refer to Figure 4-32). 


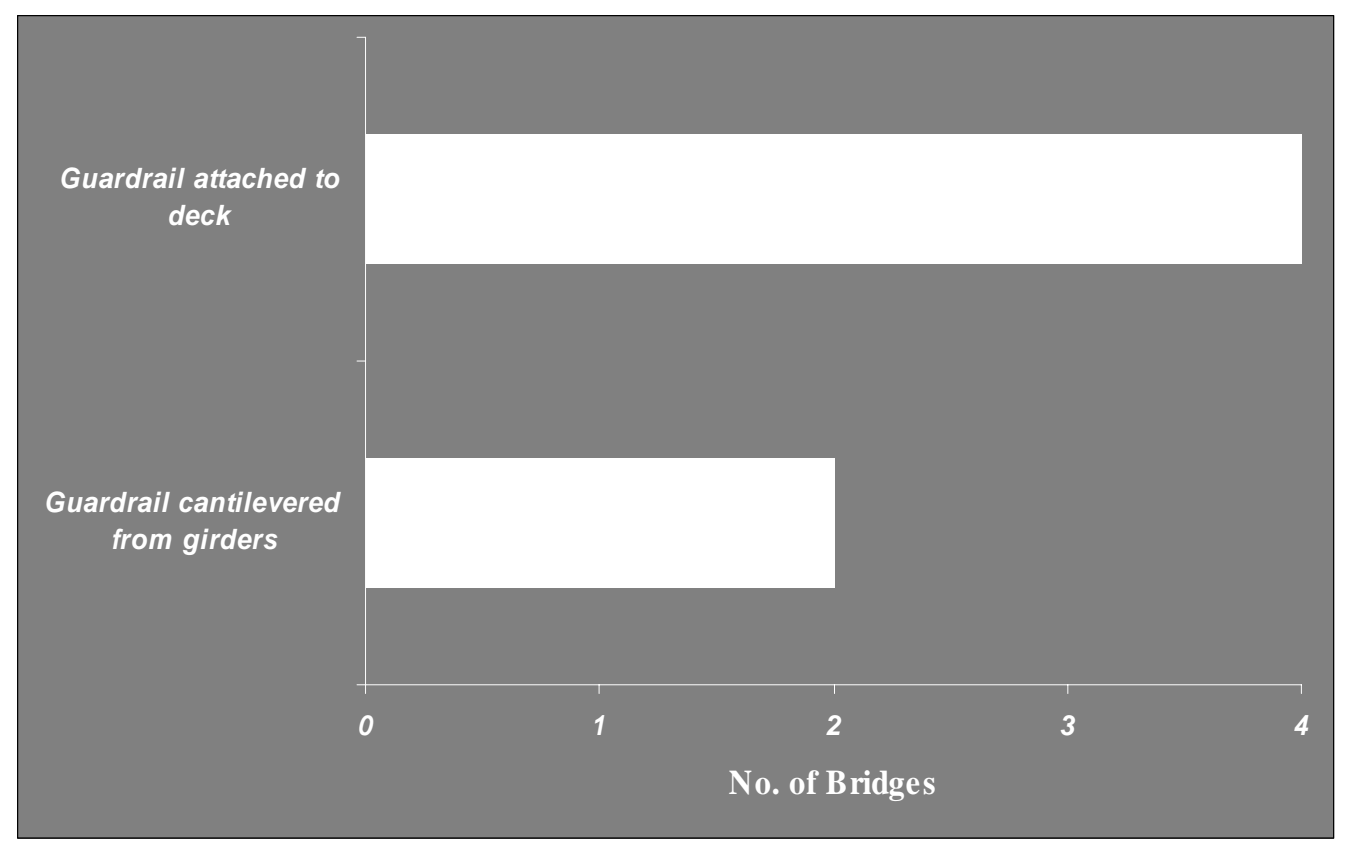

Figure 4-32 Installing method of guardrail

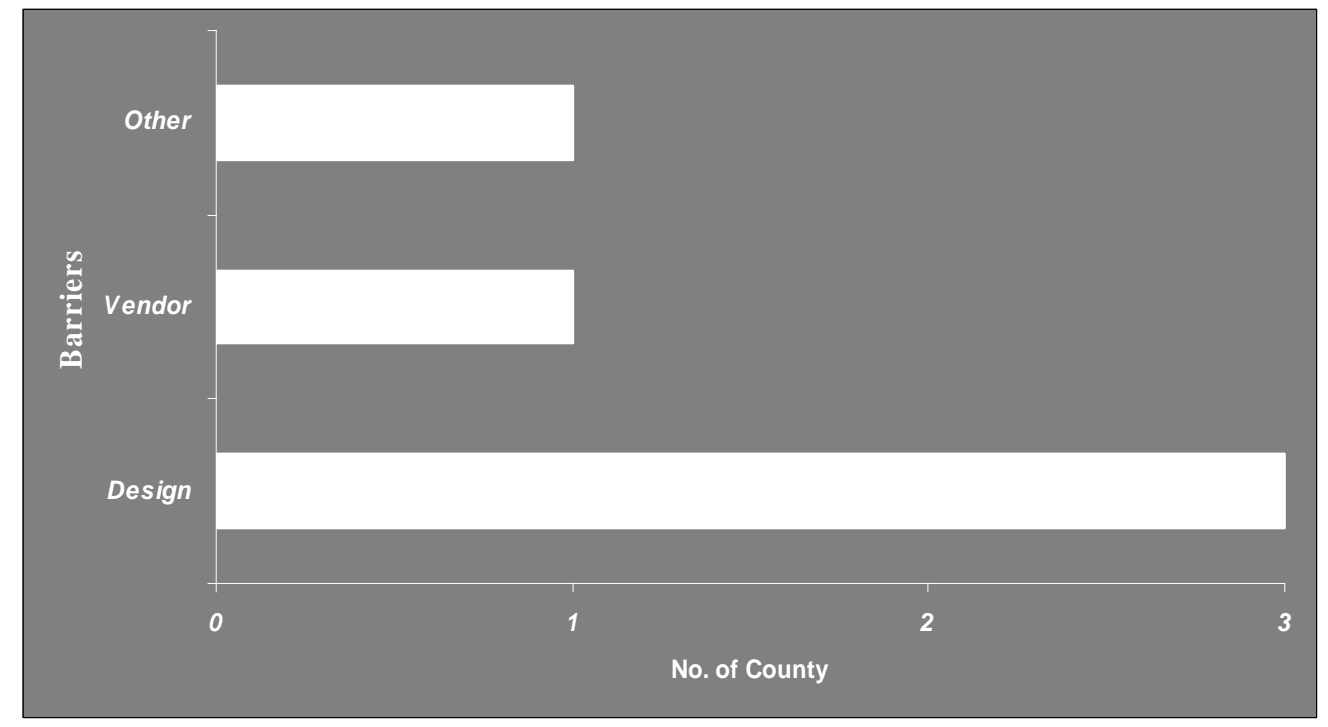

Figure 4-33 Barriers encountered in stalling FRP bride deck panels

(6) Barriers encountered in installing FRP bride deck panels 
County engineers recognized that design barriers were the greatest problem out of barriers encountered in installing FRP bridge deck panels. Their opinion was similar to the opinion of the DOT bridge engineers responding to the questionnaire.

(7) Condition rating of existing bridge structures

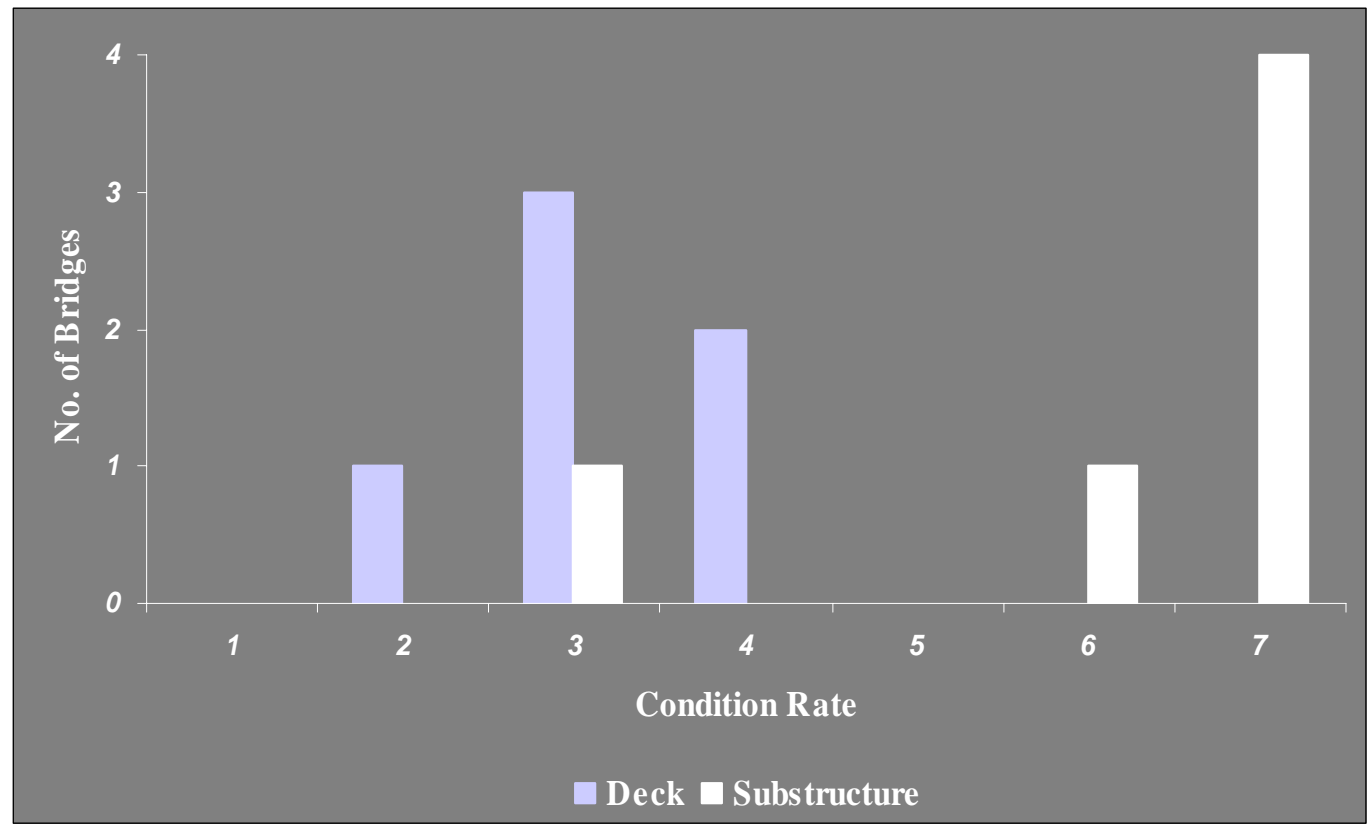

Figure 4-34 Condition rating of existing bridge structures

The condition rate (CR) of existing decks ranged from 2 to 4 when the FRP bridge deck panels were considered to replace the deteriorated conventional decks. A CR of 2-4 implies "structurally deficient", one of two modes of bridge failure defined by the Federal Highway Administration (FHWA). According to FHWA, if one of the three load carrying component (deck, superstructure, and substructure) of a bridge receives a condition rating of less than 5 on a scale of $0-9$, then the bridge is considered to be "structurally deficient". The condition rating of substructure was ranked relatively high unlike the deck. 


\subsection{Manufacturer for FRP bridge deck panels}

The purpose of visiting manufacturer of FRP bridge deck panels was to collect information on the constructability, maintainability, operability, and life cycle cost issues from the perspective of the manufacturers as well as their manufacturing process and to compare them with results obtained through the questionnaire survey-I. The research team visited two manufacturing facilities ( $\mathrm{MMC}$ and $\mathrm{HCI}$ ) and interviewed their engineers on February 25 and 26. 2004. To achieve the purpose, questionnaire-II was used (refer to Appendix B).

4.5.1 Hardcore Composites Inc.

\section{Interview Highlights/Observations and Questionnaire-II}

- Interviewee: Jeff Pote

- Position/Title: Senior Composite Engineer

- Address: 618 Lambsons Lane

- E-mail: jpote@hardcorecomposites.com

(1) General information of FRP bridge deck panels

- Typical size of FRP Panel: 32 feet by 20 feet

- Within the next year, one system has been scheduled and six other projects are in the initial stages of development

- Expected service life of FRP bridge deck panels produced: 75 years

- Information on completed projects 
o A total of 28 projects

o All of the bridges are designed for $\mathrm{L} / 800$ deflection criteria.

o Design loads are variable depending on each project.

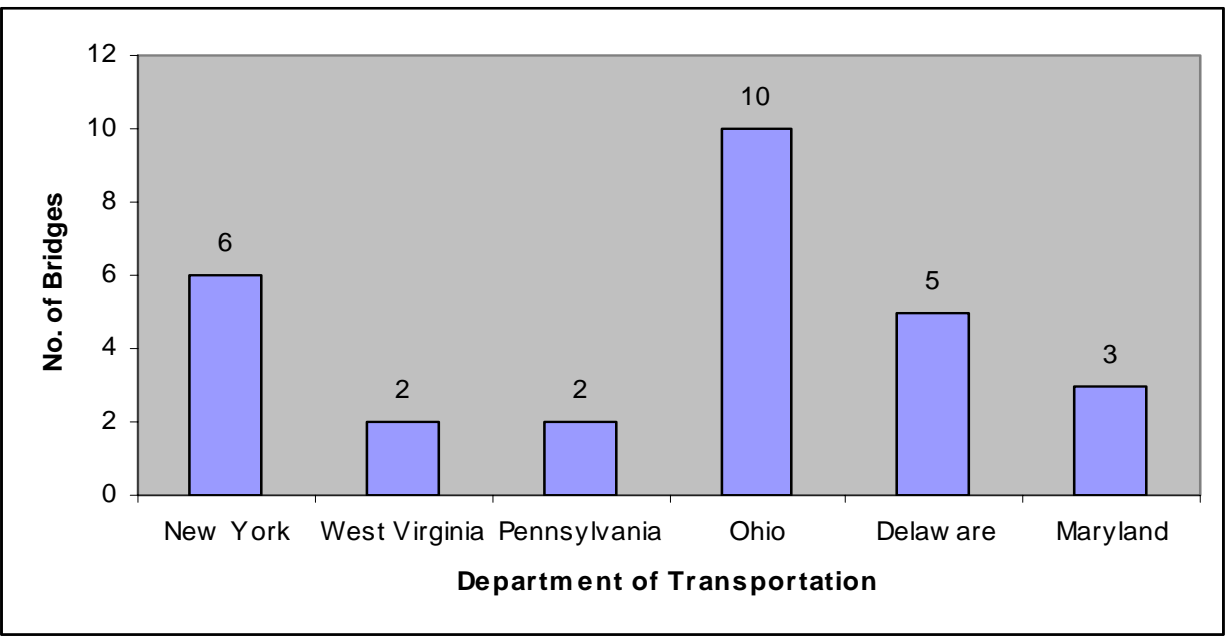

Figure 4-35 Number of bridges for DOTs using HCI's FRP bridge deck panels

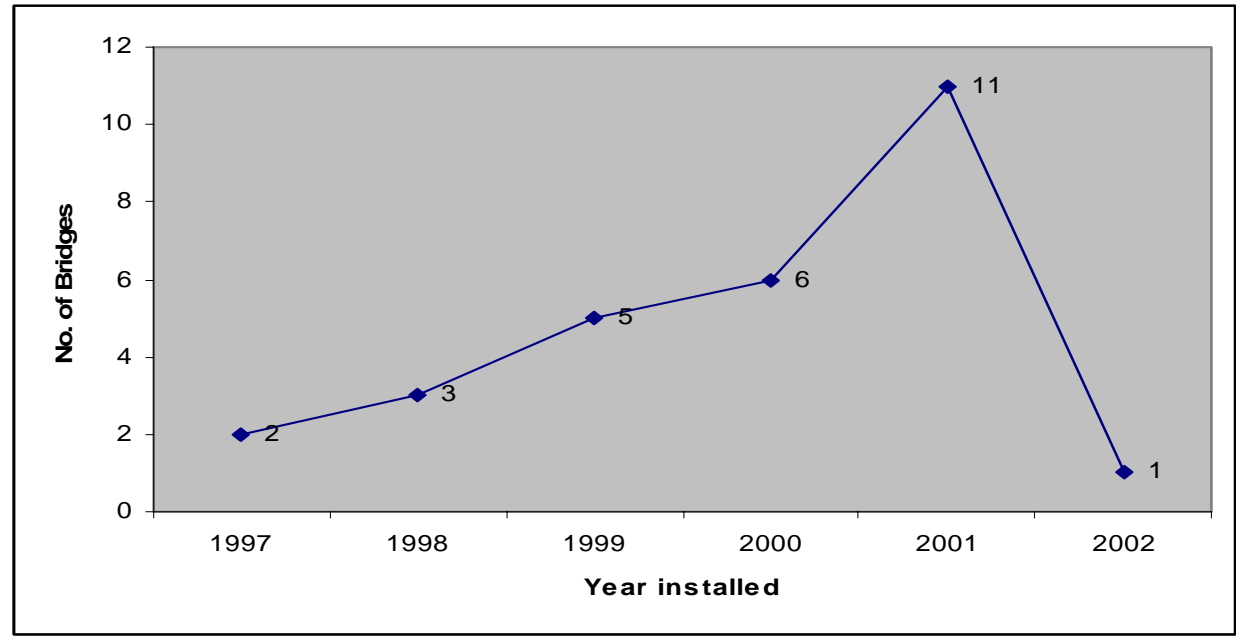

Figure 4-36 Number of bridges versus installed Year of HCI's FRP bridge deck panels 


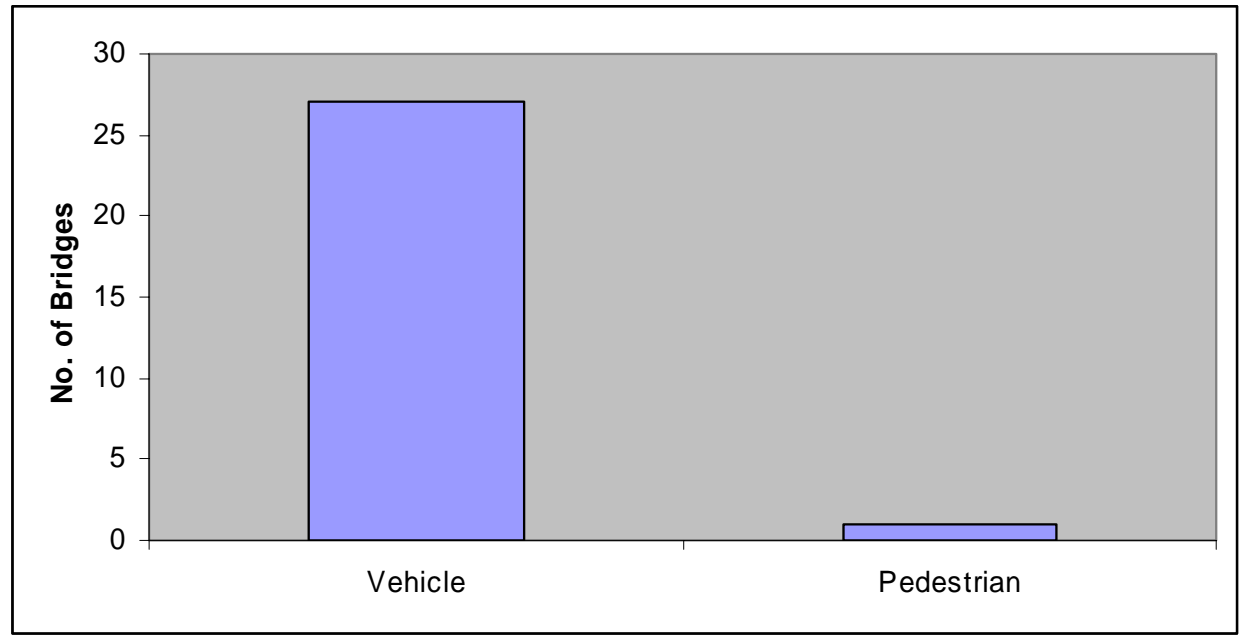

Figure 4-37 Number of vehicle and pedestrian bridges

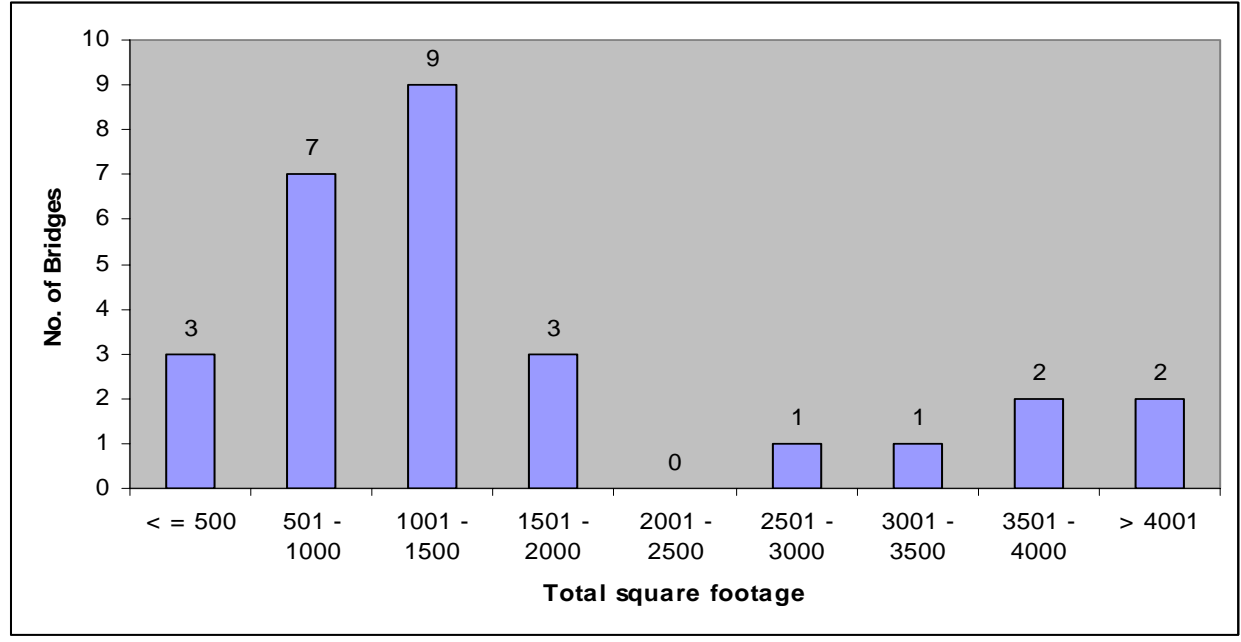

Figure 4-38 Number of bridges based on total square footage

(2) Constructability issues of FRP bridge deck panels

- Wearing surface:

o Asphalt seems to work best for their bridge decks. However, polymer concrete and latex modified concrete have also been successfully applied to their deck systems based on the interview with their senior composite engineer (Refer to Figure 4-39). 


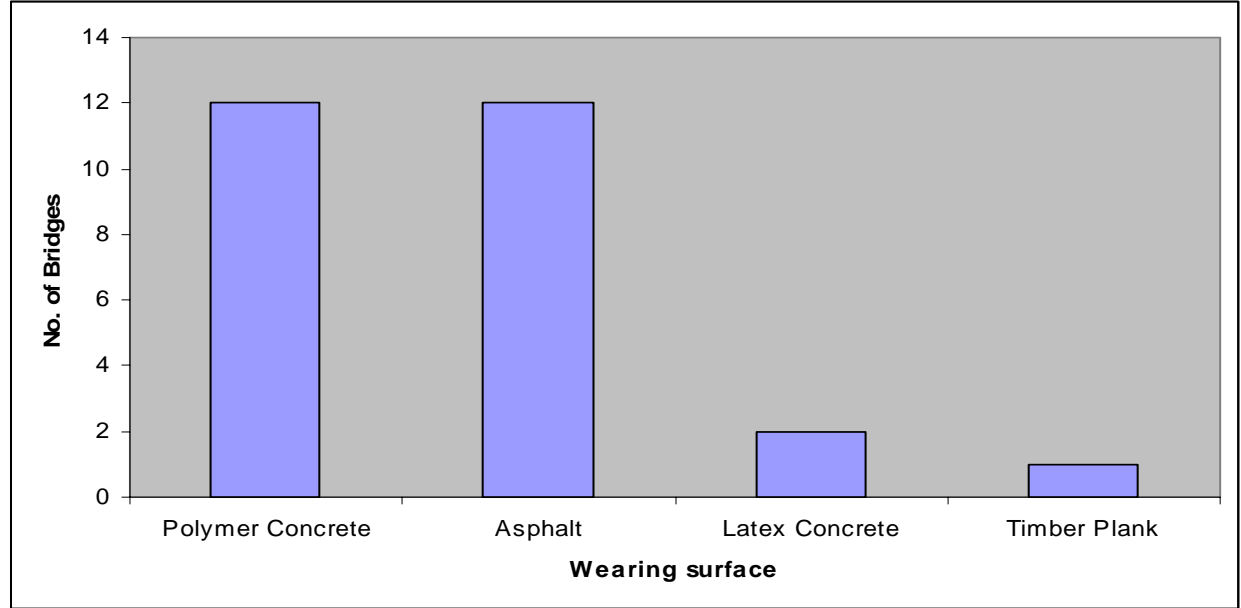

Figure 4-39 Number of bridges according to wearing surface

o Typically recommends the use of polymer concrete or latex modified Portland cement concrete.

o Polymer concrete overlays are comprised of either epoxy or polyester resin mixed with hard, sound aggregate with a particle gradation meeting ASTM C33 specifications.

o For decks accepting polymer concrete, they fabricate the top of the deck with a textured surface that provides mechanical interlock with the polymer concrete.

o So far, they have been using asphalt and they have not encountered any problems.

- Construction specification: They design bridges to meet ASSHTO codes for concrete and steel bridges

- Warranty issue 
o They warranty their decks for 20 years against the following types of damage: (i) delaminations, (ii) UV degradation, (iii) fatigue induced failures, (iv) salt and deicing chemical damage, (v) deflections in excess of the bridge rating, and (vi) excessive stress under rated loads

o They do not warranty their decks against the following items; (i) acts of God, (ii) vandalism, (iii) overloading, (iv) damage from snow plowing, (v) lack of preventive maintenance, (vi) improper installation or modification, and

(v) damage occurred during the placement or shipment of the decks

- Types of thermoset resin of FRP bridge deck panels

o Hardcore Composites uses Vinyl Ester Resin since the resin system has been tested for exposure to chemicals, is very easy to process, and is less expensive than either epoxy or phenolic resins. It is also quite strong when compared with polyester and Phenolic resins (Busel and Lockwood 2000, Rivera and Karbhari 2002, Mouritz and Mathys 1999)

- Types of Fibers

o Fiberglass is used because E-glass is inexpensive as compared to carbon and aramid and it gives the material properties required in the designs.

- Guardrail construction method

o Most of the bridge decks that Hardcore Composites installs with guardrails are either attached to the side of the deck panel or through bolted onto the top of the deck panel. Concrete parapets have been poured onto the deck panels with rebar embedded into the FRP deck panels. 
o The concrete parapets have been tested at Lehigh University to check the failure mechanism and design limits of the embedded rebar. The guardrail systems have been designed with factors of safety and are stamped by a Professional Engineer. Hardcore Composites has performed tests on steel embedment pullout strengths and composite bolt bearing tests, so that these values can be used when calculating the limits of a guardrail system.

- Types of equipment required for installation of FRP bridge deck panels

o Typically a crane (the size of the crane depends on the bridge) and basic construction tools (impact wrench, hand tools) are the only equipment needed.

- Types of crews required for installation of FRP bridge deck panels

o Hardcore Composites sends a crew of 2-3 men for the installation of the bridge deck. Hardcore Composites will supervise the installation and will perform any bonding tasks that are associated with the installation. A standard crew of 2-4 men can install FRP deck. The crew needs to have rigging experience in order to place the panels, but no other formal training beyond basic construction techniques is required.

- Productivity expected from the crew mentioned above

o A normal installation of a Hardcore Composites FRP Bridge will typically take 2-5 days depending on the complexity of the bridge. A basic construction schedule is shown below.

- Day1 - Panels placed, panels attached to stringers or abutment.

- Day 2 - Wearing surface applied. 
- Day 3 - Guardrails attached and other work completed.

- Major obstacles in FRP panels' application

o Factors that influence the use of composite bridges include the high initial cost, low bidding practices, and lack of confidence or acceptance in the market place. Codes that are written for concrete and steel materials and not to maximize the properties of the composite materials are also a hindrance to the use of FRP decks.

(3) Operability issues of FRP bridge deck panels

- Effect of fuel, oil and grease on FRP deck

o The resin system used by Hardcore Composites has been tested for exposure by the resin manufacturer for many different chemicals. These chemicals include gasoline and diesel fuel, for which the resin system is recommended for short-term exposure (24hrs). Hardcore Composites has also performed tests with diesel fuel and saw no significant decline in material properties.

- Procedure of snow removal

o Hardcore Composites' bridges can be plowed just like a normal bridges

- Water drainage installed in FRP bridge deck panels

o Water drainage systems used on Hardcore Composites' bridges include gutters, scuppers, grading the wearing surface, drip edges, and curbs. All of these systems are specified by the county or DOT that is purchasing the bridge. 
(4) Maintainability issues of FRP bridge deck panels

- Generally recommended maintenance practices

o Hardcore Composites typically issues a maintenance manual for their bridge decks. The maintenance manual outlines the procedures for inspecting the deck and for small repairs (refer to Appendix D). They do not provide assistance in maintaining the deck unless a warranty issues arises. They will offer engineering assistance if major damage or repairs are to be completed to the FRP bridge.

- Maintenance problem:

o Delamination and unbonded areas in panel skin

- Delaminations caused during the manufacturing process and injected with an adhesive.

- Poor field connections need to be replaced or altered. Typically this repair is covered by warranty

- Typically repairs are made in the shop at Hardcore Composites and will not appear again in the field

- Hardcore Composites has also changed resin systems and this seems to have eliminated delaminations in the shop.

- Connection issues will continue to arise until all the connection issues are solved (i.e., Salem Avenue Bridge)

o Deck-to-girder connection at haunches: No Problem

o Field and shop joint problem: No Problem, except for wearing surface 
o Polymer wearing surface deficiencies: The reason for this is poor surface preparation, bad lots of material, and poor engineering.

- Typically, the wearing surface is removed either entirely or just the bad sections and a new wearing surface is applied.

- If the surface is not sandblasted properly the wearing surface can peel off. Also, a wearing surface that is partially shop applied and field applied can cause problems if there are too many joints.

- Typically this repair is covered by warranty.

- Usually 1 or 3 trips are required to repair the problem.

o Water intrusions and Fire damage: No Problem

- Procedure or method established to inspect, maintain, and repair

o They provide a maintenance manual with every deck they sell. The manual provides general guidelines for inspection the bridges and some specific techniques that may be employed to verify the structural integrity of the bridge. The manual also includes several repair techniques. Structural repairs that need to be performed to the bridge are always to be approved by an engineer. A copy of a typical maintenance manual is attached to the Appendix D.

- In collecting inspection data on completed projects

o They did not collect the data but the bridge installed over Dubois Creek in Susquehanna County is monitored by Penn State University.

- They have identified problems with regard to maintenance and operation after installation. 
- They have not experienced the replacement of partial section in FRP bridge deck panels.

- They expect that their FRP bridge decks will last with minimal maintenance for 75 years. Environmental tests have been performed on samples of FRP panels that allow them to use environmental knock down factors when designing a bridge.

(5) Life cycle cost issues of FRP bridge deck panels

- Average initial construction cost

o Hardcore Composites FRP bridges can cost $\$ 75 / \mathrm{ft}^{2}$ for an 8 -in deck replacement to $\$ 180 / \mathrm{ft}^{2}$ for a complete self-supporting structure. Hardcore Composites gives a designed and delivered price, but does not include the cost of the installation for the county or contractor

- Steps (as in research or technology) to reduce high initial cost

o Hardcore Composites has performed various tests with different bridge designs, which are patented and proprietary. Ten years of test data have been used in order to lower costs and increase the capacity of the decks.

- Currently best method to reduce high initial cost

o Material costs are too high and standards are not written for composites, which do not allow engineers to utilize the benefits of composite materials. Also qualification of each system for a new state or county is one of the main factors that cause FRP decks to have high initial cost. 
- Major reasons for high initial cost (i.e., manufacturing, delivery, size etc.)

o Manufacturing and the cost to qualify or assure the new customers that an FRP bridge will work.

o Too much time needed before starting a project.

\subsubsection{Martin Marietta Composites}

\section{Interview Highlights/Observations and Questionnaire-II}

- Interviewee: Matthew K. Sams, (PE)

- Position/Title: Senior Engineer

- Address: 2501 Blue Ridge Rd, $5^{\text {th }}$ Floor, Raleigh, NC 27607

- E-mail: matt.sams@martinmarietta.com

(1) General information of FRP bridge deck panels

- Advantage of their product: Light weight, corrosion resistance, rapid installation, easy to fabricate, handle, and install, and high quality manufacturing procedure

- Expected service life of their product: It depends on the installation but 75 years is considered as the expected service life.

- They have 26 bridge decks in service and each is a unique application.

(2) Constructability Issues of FRP bridge deck panels

- Wearing surface: The material for the wearing surface is decided by owner's preference. 
- Construction specification: They provide recommended installation procedures at planning meetings, pre-bid meetings, pre-construction meetings, and they provide on-site technical assistance during installation. They also provide contractors with an installation guide.

- Warranty issues: They stand behind their product. In the beginning, people requested warranties because the material was not tried and true. Now most are comfortable with the backing of their organization. Warranties are not frequently required now, but they are willing to consider if required by owner.

- Problem encountered in installing: Their main barrier is initial concern regarding "new" materials. Once people see, touch, and fell their products, they realize that is quite easy to install

- Types of thermoset resin: Many resins have been used. With their system, polyester resin typically provides best value.

- Types of Fibers: Many fibers have been used. With their system, glass fiber typically provides best value

- Railing construction method: Owner's preference. Railing has been attached a variety of ways

- Types of equipment: Cranes, jacks, etc.

- Types of crew: They typically recommend a minimum of 6 person crew ( 8 10 preferred). No special skills are required

- Productivity expected: It is not uncommon to install each of their panels in 30 minutes or less 
- Major obstacle in the application: High initial cost, current low bidding practice in the US, lack of material and design specification, etc.

(3) Operability of FRP bridge deck panels

- Effect of fuel, oil and grease: Their decks typically are covered by an overlay, which would receive the spills. Detailed information can be provided on a site specific basis

- Procedure of snow removal: Their decks typically are covered by an overlay, which allows snow plows and studded tires.

- Effect by salt and other chemicals: Their decks are resistant to corrosion induced by deicing salts

- Water drainage: All of the following are possible: crowned overlay, crowned deck, scuppers, curbs, super elevations, etc.

(4) Maintainability of FRP bridge deck panels

- The responsibility for the maintenance problem: Like all materials, the owner has responsibility

- General maintenance practices recommended: Nothing very unique. Keeping an eye out for anything that appears out of the ordinary. Most "issues" will be reflected in overlay.

- They provide assistance in the maintenance activities

- They often participate in the first inspection of the bridge

- They have not experienced the replacement of partial section in their products 


\section{$\underline{4.6 \text { Reference }}$}

Busel, J. P. and Lockwood, J. D., eds. (2000). Production selection guide: FRP composite products for bridge applications, Market development Alliance (MDA) of the FRP composites industry, Harrison, NY.

Mouritz, A. P., and Mathys, Z. (1999). "Post-fire mechanical properties of marine polymer composites." Composites Structure, 47(1), 643-653.

Reeve, Scott R. (2000). "FRP Composite Bridge Decks: Barriers to Market Development" National Composites Center, Kettering, Ohio.

River, J., and Karbhar, V. M. (2002). "Cold-temperature and simultaneous aqueous environment related degradation of carbon/vinylester composites." Composites Part B: Engineering, Elsevier Science Ltd., 33(1), 17-24.

Project $100<$ http://www.compositecenter.org/Infra/Project\%20100/Project\%20100.php $>$ (March 22, 2004.) 


\section{CHAPTER 5: PROCESS MODELING AND SIMULATION}

\section{$\underline{5.1 \text { Introduction }}$}

Process modeling and simulation study were used to determine the productivity of installation in both FRP bridge deck panels and conventional bridge deck (precast concrete deck) construction. Installation procedure for the two methods was carefully evaluated to develop the initial process model. Simulation study was conducted using web-based MicroCyclone simulation software (Halpin and Riggs 1992). The data required for the simulation study were collected through questionnaire survey and interview. For simulation study of FRP bridge deck panels, the installation procedure of Martin Marietta Composites (MMC), which was selected in Composites for Infrastructure (C4I) program, among various manufacturers was analyzed to determine their productivity. In order to make a comparative study of the productivity for FRP bridge deck construction, construction method of precast concrete deck panels was used as one of the methods of conventional bridge deck construction. This chapter describes the simulation study by first explaining the background of CYCLONE and WebCYCLONE followed by the construction procedure of the two types of panels (i.e., FRP and precast concrete), as well as the data collection. 


\subsection{Simulation study using WebCYCLONE}

This research used CYCLONE (CYCLic Operations Network) simulation methodology, which simplified the simulation modeling process, and made it accessible to construction practitioners with limited simulation background (Halpin and Riggs 1992). The CYCLONE became the basis for a number of construction simulation systems. The WebCYCLONE is Web based simulation tool which generates CYCLONE formatted simulation code from information collected through its web based interaction with the user. For the modeling of construction processes, the following procedure is required:

1. Define resources which are used to process work task such as equipment, manpower, material, etc.

2. Identify work tasks in the processes. The work tasks mean fundamental field action and work unit focus, intrinsic knowledge and skill at crew member level, and basis of work assignment to labor.

3. Determine the logic of the processing of resources

4. Build a model of the process: Basically, in order to simulate the actual process, resource, work task, and time consumed by processing the resource are required.

The CYCLONE methodology primarily consists of four basic phases (Schaeuble 2001)

1. Identify the flow units in the cycles: The flow units represent the units that are relevant or descriptive for the process to be modeled. These units usually mean resources. 
2. Develop the cycles for each flow unit: For modeling the flow cycle of a unit, all the possible active and passive sates should be considered.

3. Integrate the flow unit cycles: Each flow cycle is integrated into an entire model and it usually is linked together at COMBI nodes.

4. Initialize the flow units: The flow units should be initialized in number and in initial location to analyze the model and are always initialized at waiting positions, QUEUE nodes.

Table 5-1 Basic modeling elements of the CYCLONE

\begin{tabular}{c|c|l}
\hline Name & Symbol & \multicolumn{1}{c}{ Function } \\
\hline \hline Normal Activity & & $\begin{array}{l}\text { This is an activity similar to the COMBI. However, } \\
\text { units arriving at this element begin processing } \\
\text { immediately and are not delayed. }\end{array}$ \\
\hline $\begin{array}{c}\text { Combination } \\
\text { (COMBI) Activity }\end{array}$ & $\begin{array}{l}\text { This element is always preceded by Queue Nodes. } \\
\text { Before it can commence, units must be available at } \\
\text { each of the preceding Queue Nodes. If units are } \\
\text { available, they are combined and processed through } \\
\text { the activity. If units are available at some but not all } \\
\text { of the preceding Queue Nodes, these units are } \\
\text { delayed until the condition for combination is met. }\end{array}$ \\
\hline Function Node & $\begin{array}{l}\text { This element precedes all COMBI activities and } \\
\text { provides a location at which units are delayed } \\
\text { pending combination. Delay statistics are measured } \\
\text { at this element }\end{array}$ \\
\hline Accumulator & $\begin{array}{l}\text { It is inserted into the model to perform special } \\
\text { function such as counting, consolidation, marking, } \\
\text { and statistic collection }\end{array}$ \\
\hline & $\begin{array}{l}\text { It is used to define the number of times the system } \\
\text { cycles }\end{array}$ \\
\hline
\end{tabular}

(Source: Halpin and Riggs 1992)

The actual appearance of the CYCLONE model will depend on the identification and definition of the network elements (i.e., the NORMAL and COMBI) together with 
the associated QUEUE nodes, ARCs, and logical relationships (Halpin and Riggs 1992). These symbols are the basic modeling elements of the CYCLONE modeling systems and are shown in Table 5-1. For the detailed understanding of the CYCLONE, please refer to Halpin and Riggs (1992).

\subsection{Installation Procedure}

As mentioned in the previous section, simulation study using CYCLONE requires an understanding of the construction process of FRP bridge deck panels as well as conventional bridge deck. This section introduces the construction processes for the two types of bridge deck construction.

\subsubsection{FRP bridge deck panels}

The installation procedure for FRP bridge deck panels varies from one manufacturer to another. The installation process used by Martin Marietta Composites (MMC) out of various manufacturers is selected in this research to do simulation study (Busel et al. 2000, Solomon and Sams 2003)

The figures below illustrate the major tasks for installation of MMC FRP bridge deck panels. Installation procedure of $\mathrm{MMC}$ is categorized in two parts: (i) manufacturing procedure and (ii) installation procedure at the job site (Figure 5-1).

(1) From the viewpoint of Manufacturing Procedures:

Step 1: Individual tubes are pultruded at a manufacturing facility. 


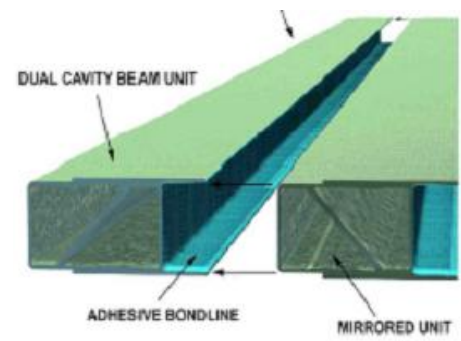

Figure 5-1 Individual tubes pultruded

(Source: Busel and Lockwood 2000)

Step 2: Assembled into panels with a polyurethane adhesive (Panels are typically 8 to $10 \mathrm{ft}$. in width due to highway transport restrictions)

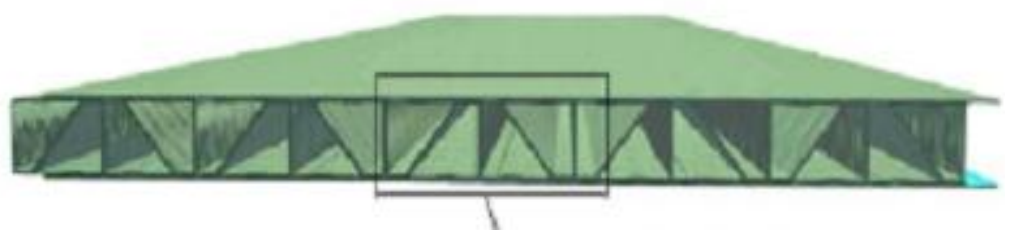

Figure 5-2 Panels assembled with a polyurethane adhesive (Source: Busel and Lockwood 2000)

Step 3: The bonded panels are sent to a finish shop, where all secondary work (hole cutting and sealing, installation of close outs, surface finishing, etc.) is performed. 
Step 4: Finished Panels to be loaded

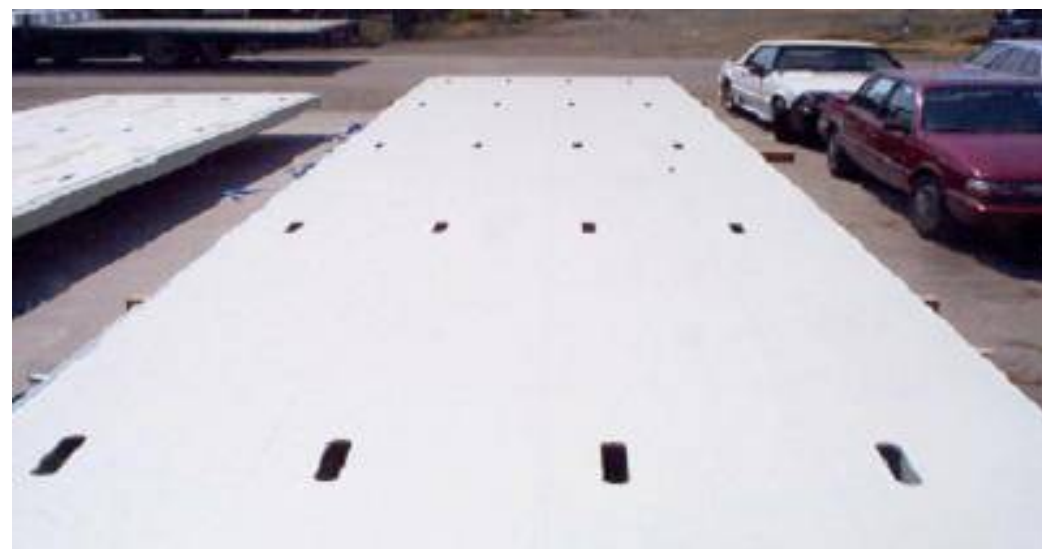

Figure 5-3 Panels finished for loading

(Source: Busel and Lockwood 2000)

Step 5: Panels Transported to Job Site

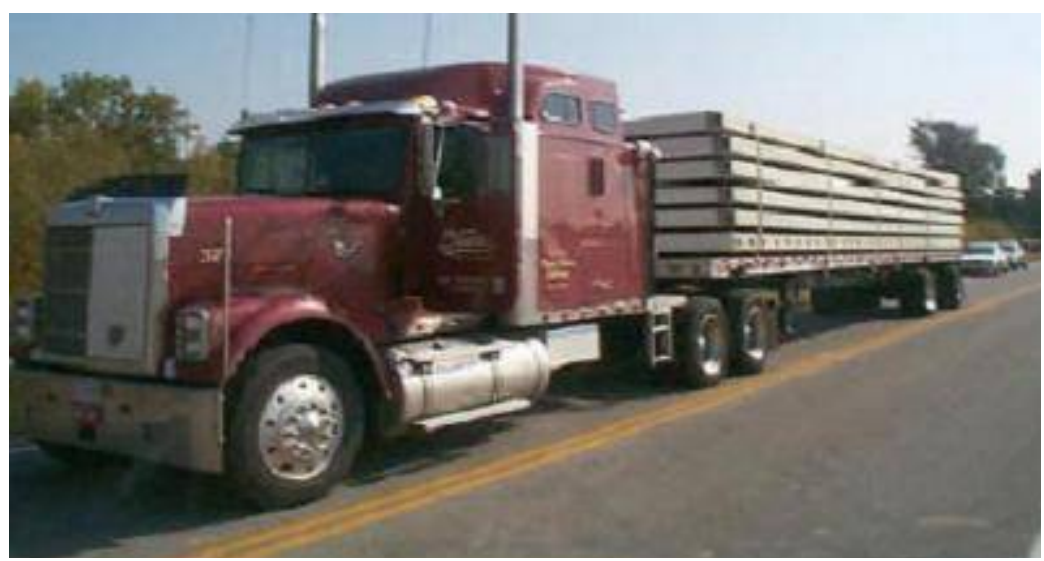

Figure 5-4 Panels Transported to Job Site

(Source: Busel and Lockwood 2000) 
(2) From the viewpoints of Installation Procedures at Job Site

Step 1: Panels being unloaded

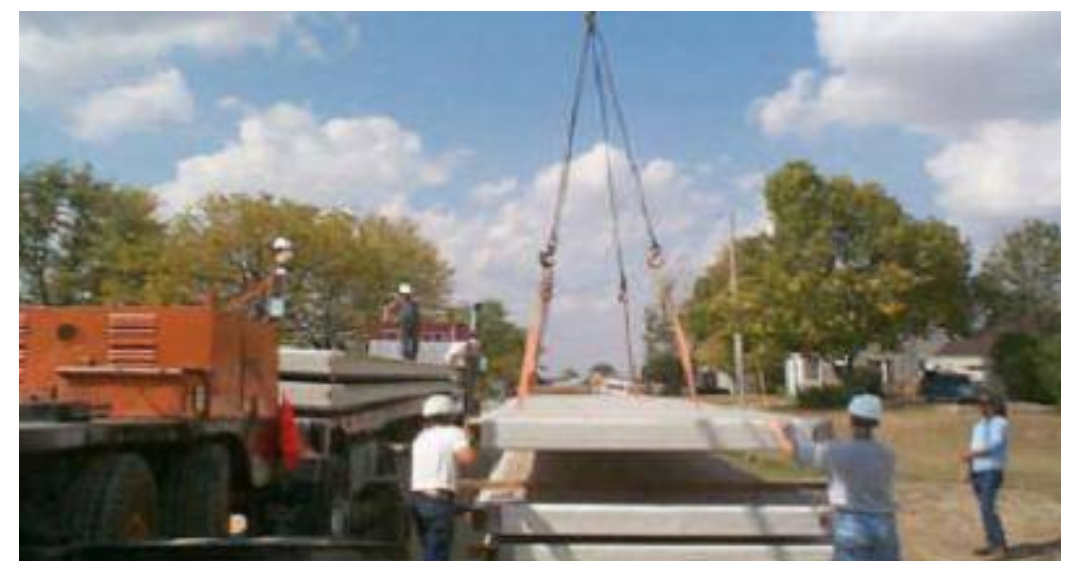

Figure 5-5 Panels being unloaded

(Source: Busel and Lockwood 2000)

Step 2: Installation of First Panels

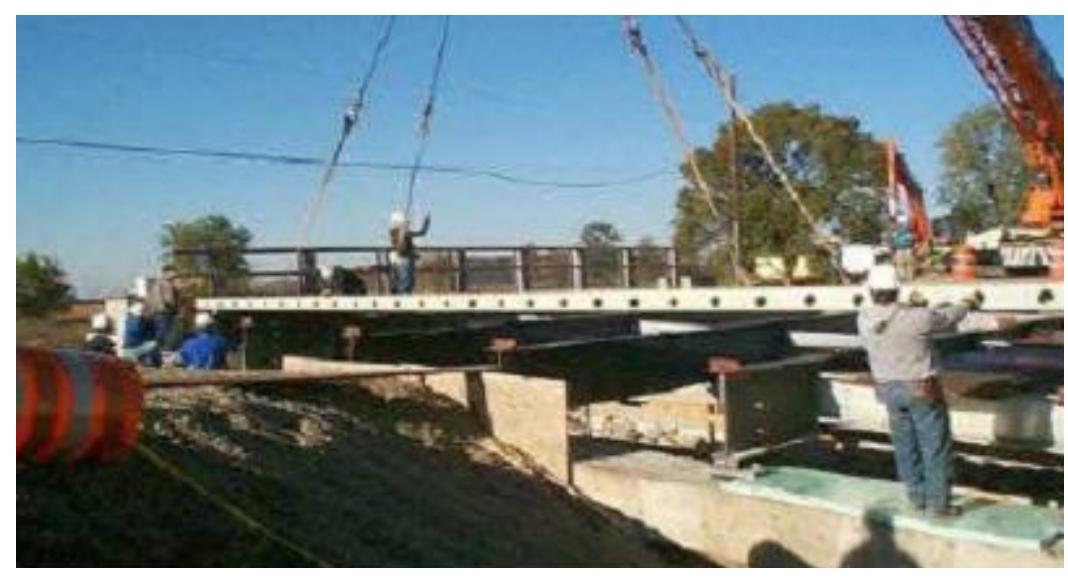

Figure 5-6 Install first panels

(Source: Busel and Lockwood 2000) 
Step 3: First Panel Installation and Alignment

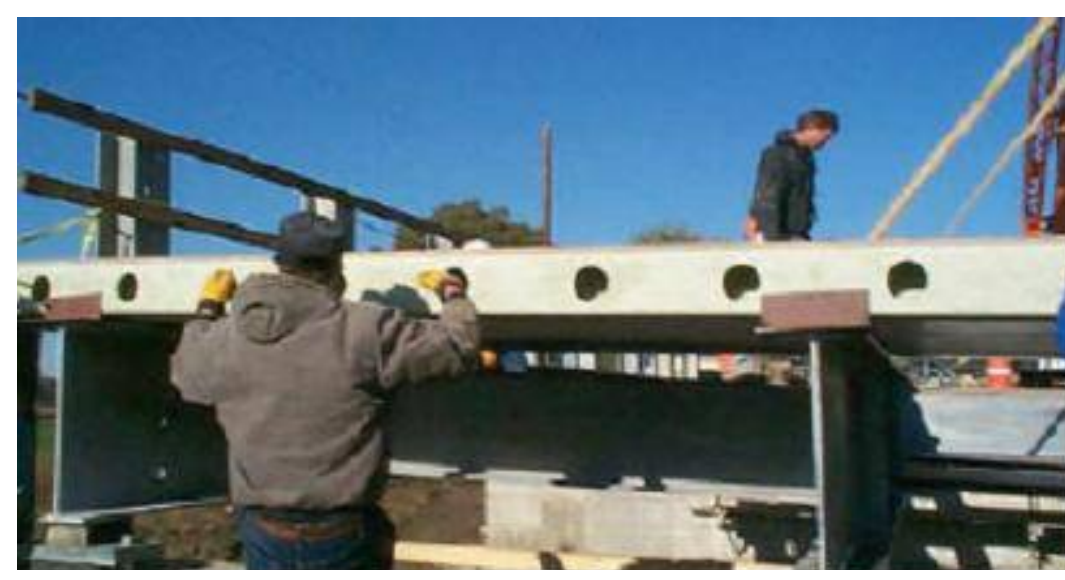

Figure 5-7 Install and align first panel

(Source: Busel and Lockwood 2000)

Step 4: Securing the Deck Utilizing Temporary angles on Top Flanges

The large circular holes in the edge of the deck provides access for placing reinforcing steel and pouring concrete in the last tube in order to accommodate an integral abutment

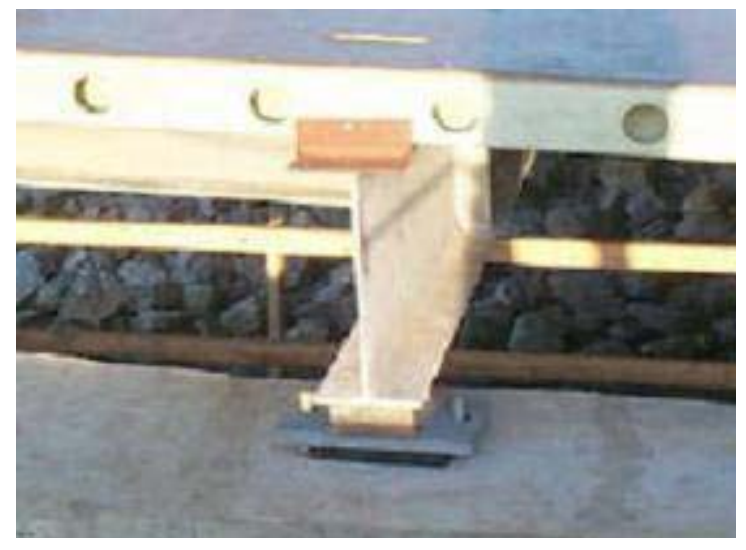

Figure 5-8 Securing of the deck

(Source: Busel and Lockwood 2000) 
Step 5: Liquid Primer and Epoxy Paste Being applied to Field Joints

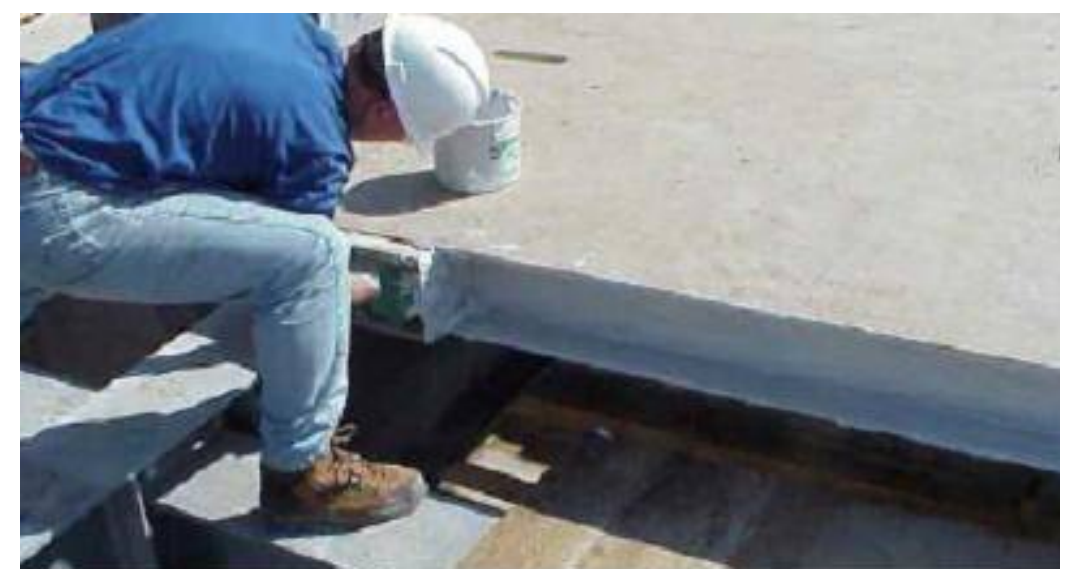

Figure 5-9 Liquid primer and epoxy paste applied to field joints (Source: Busel and Lockwood 2000)

Step 6: Lowering of the Next FRP bridge deck panels

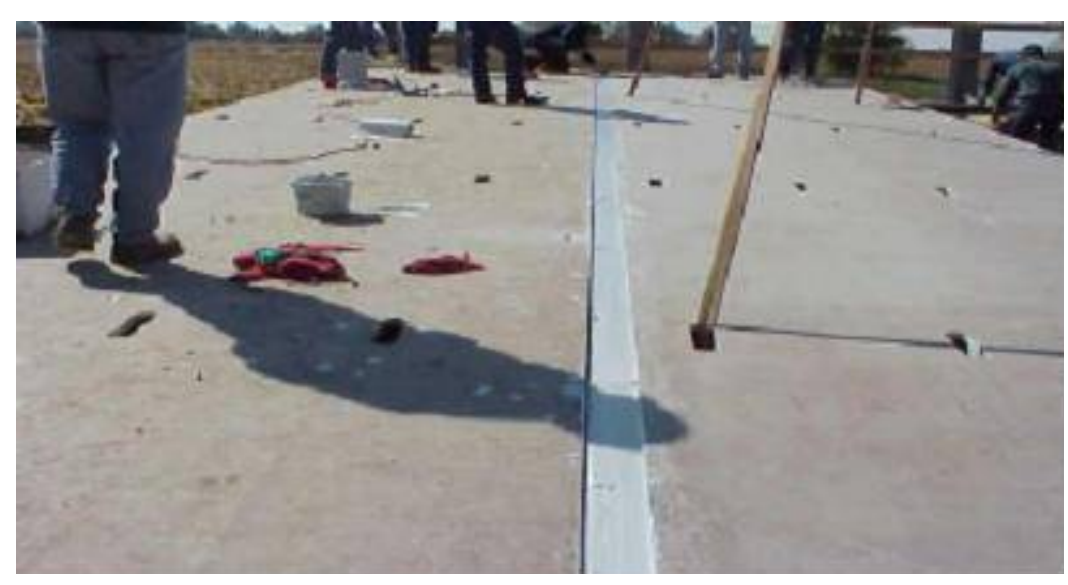

Figure 5-10 Lowering of second panel

(Source: Busel and Lockwood 2000) 
Step 7: A jack is used to align the panels in position

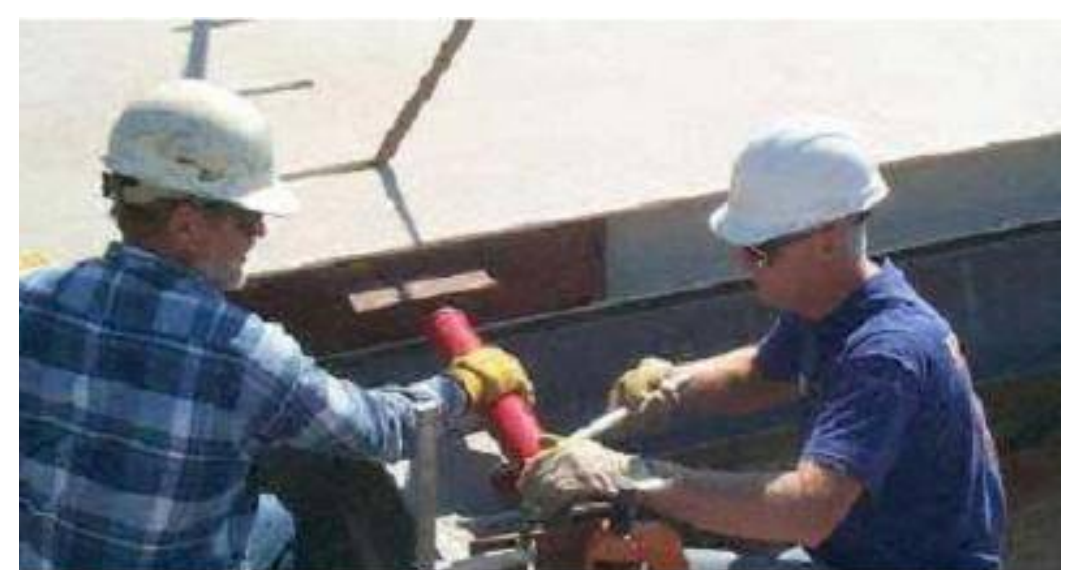

Figure 5-11 Align the panel using a jack

(Source: Busel and Lockwood 2000)

\section{Step 8: FRP Splice Strips Placement Over Field Joints}

The FRP splice strips are installed to ensure a durable and watertight joint.

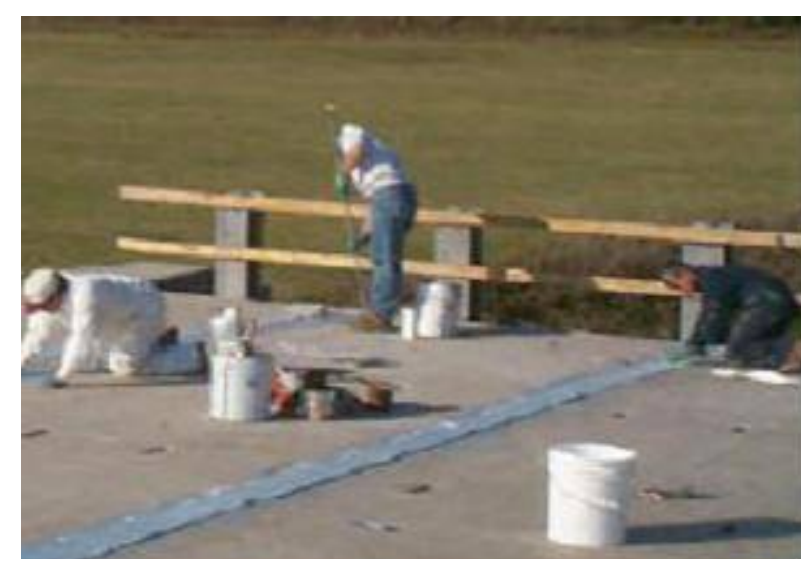

Figure 5-12 Place FRP splice strips over field joints

(Source: Busel and Lockwood 2000) 
Step 9: Finished Panel installation

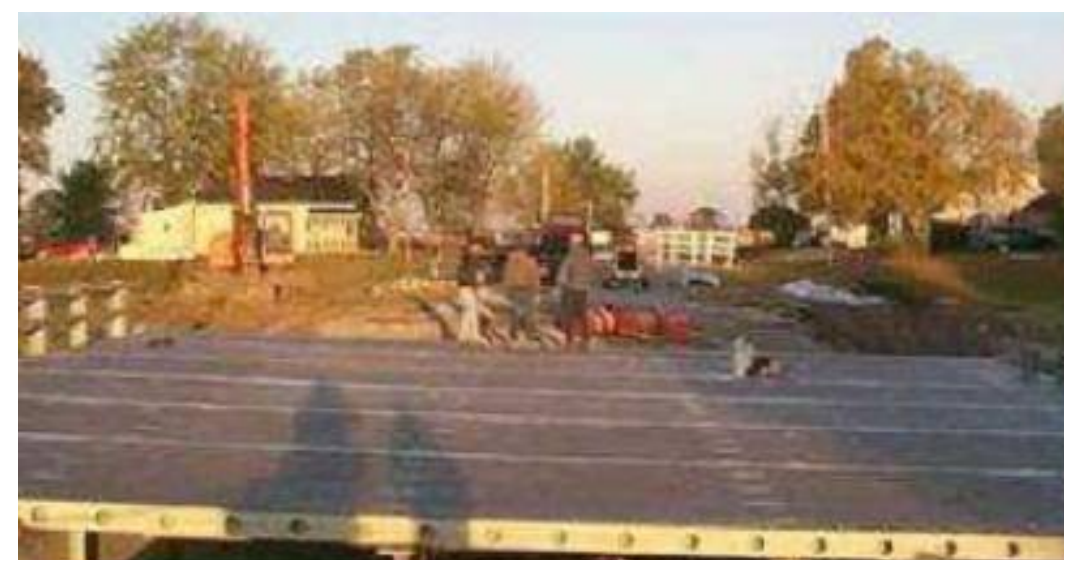

Figure 5-13 Finish panel installation

(Source: Busel and Lockwood 2000)

Step 10: Connections between deck and girder

Shear studs are field welded after the deck panels are in place, and grout is poured in the cavity
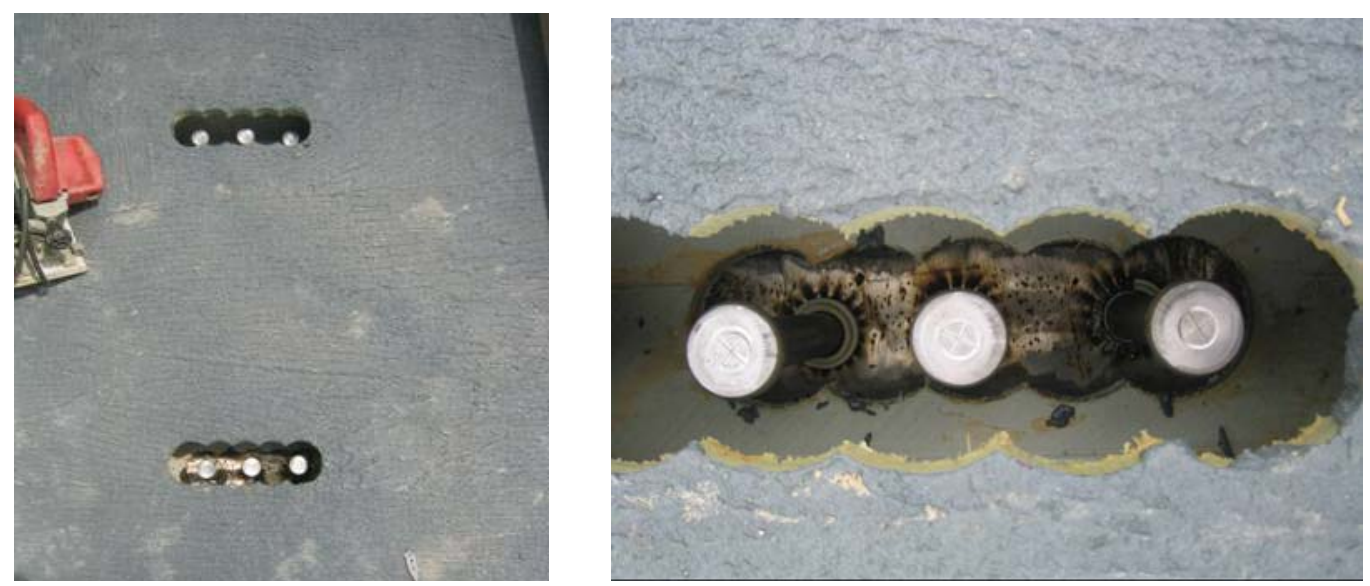

Figure 5-14 Connect decks with girders 
Step 11: Guardrail Installation (Concrete barrier or steel guardrail)

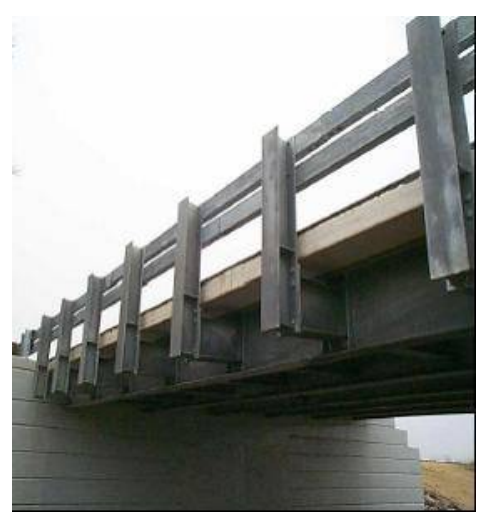

Figure 5-15 Install guardrails 


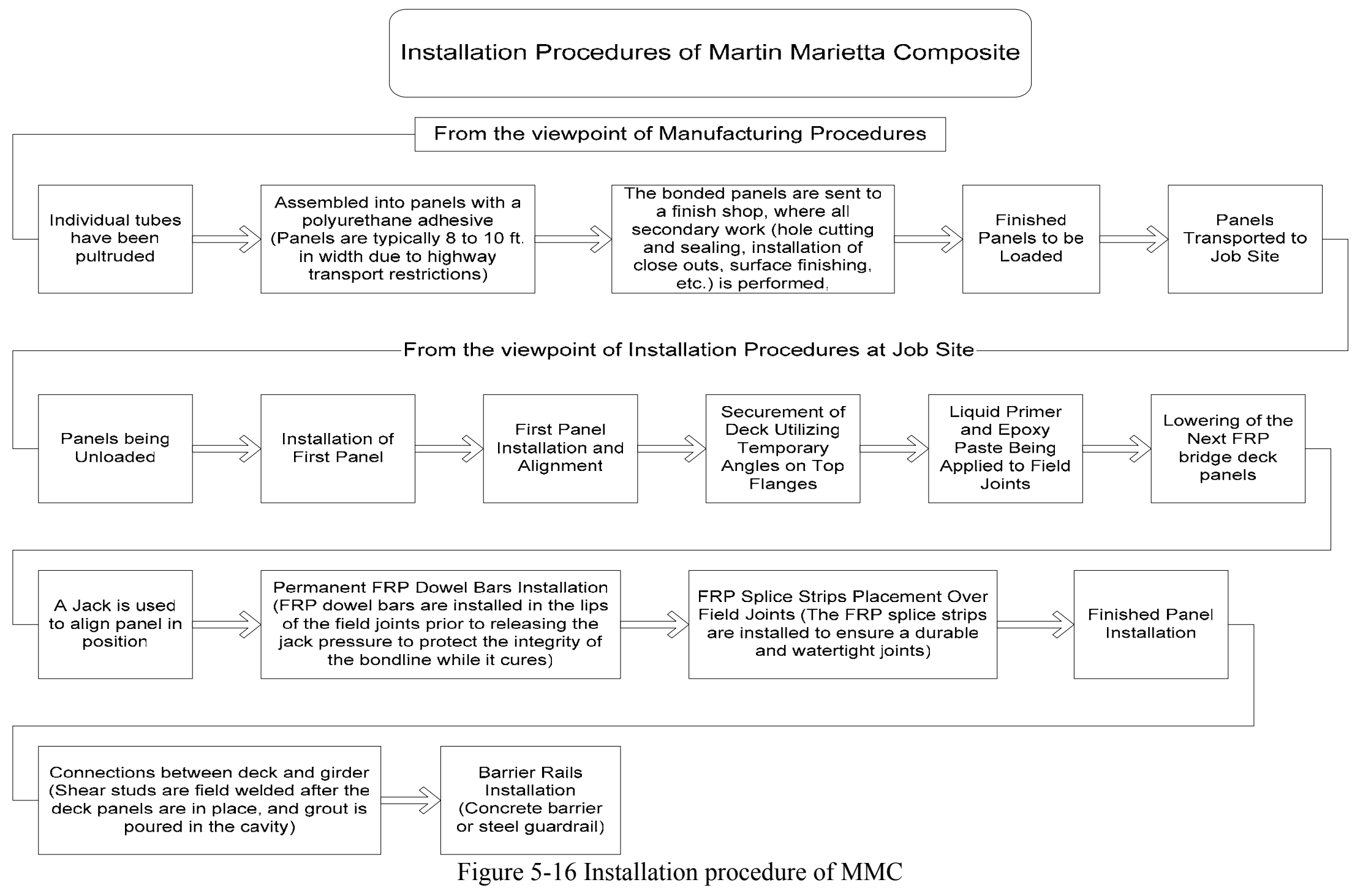




\subsubsection{Precast prestressed concrete deck panels}

The following procedures is used for the installation of precast prestressed concrete deck panels. After the erection of the structural members and the tightening of all bolts, the contractor takes measurements to record the elevations at predetermined grade control points along each girder of each span in the structure. Any falsework of forms should be installed before deck forms are installed. There are two types of deck forms: (i) Removable and (ii) Permanent.

(i) Removable: Most removable forms are made of wood

(ii) Permanent: Permanent forms are usually made of metal or Prestressed concrete. Another type of permanent deck forms is precast, prestressed deck panels. When they are used, the bottom layer of longitudinal deck may be unnecessary because the panels contain their own longitudinal reinforcement.

The construction sequence employed at Cape Girardeau Bridge, Cape Girardeau, Missouri is introduced in this section and used for the construction simulation study of this method.

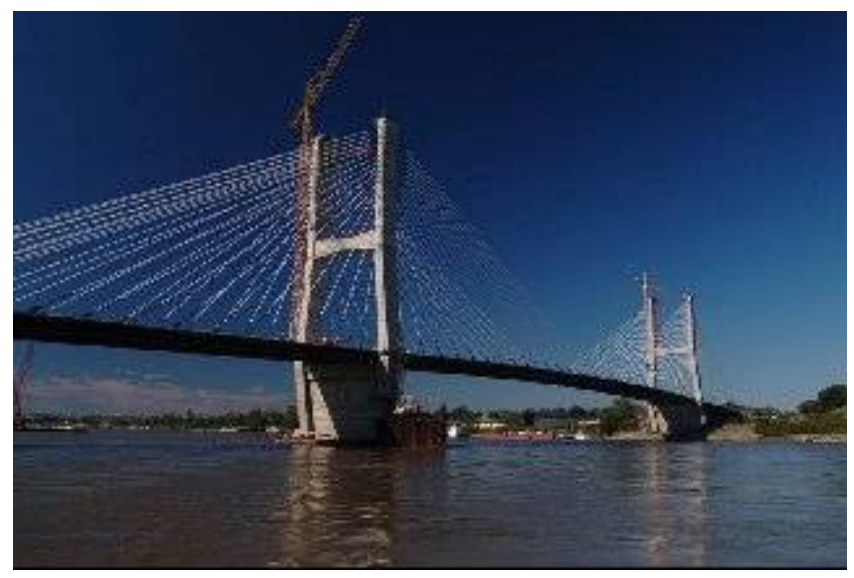

Figure 5- 17 Cape Girardeau Bridge, Cape Girardeau, Missouri 


\section{Project description}

The project was to build cable-stayed bridge over the Mississippi River connecting Cape Girardeau, Missouri, and East Cape Girardeau, Illinois. The bridge is composed of one main span (1,150 feet) and two side spans (468 feet). The width of the bridge is 86 feet and 4 inches (Cape 2004).

- Contractor: Traylor Bros., Inc.

- Project manager: Larry K Owens

- Project engineer: Skylar Lee

- Amount of concrete used: Approximately 50,000 CY.

- Place more than 3,200 tons of rebar, 41,000 tons of structural steel, 12,800 tons of post-tensioned precast concrete deck panels, and 128 stay cables

- Wearing surface: 3 inches silica fume concrete

- Project duration: June 1.2000 - December 13.2003

Cape Girardeau Bridge was composed of two different types of bridges and deck panels ((Larry K. Owens, personal communication, April 2004)

- One type was very large deck panels (approximately 45 feet $\times 15$ feet $\times 1$ foot) and they were used to make the deck of the cable stayed bridge portion of the project

- The other deck panels were more conventional and used in an application that is more similar to the FRP bridge deck panels' situation. Those deck panels were about 4 inches thick. They were made of conventional concrete and prestressed with strand. The top surface was textured to 
facilitate a bond with the poured in place portion of the bridge deck. The panels were also fitted with rebar loops that were used to lift the panels and also to help make them composite with the cast in place concrete. In the conventional deck panel scenario in which the relatively thin deck panels first act as bottom forms for the deck construction and then become composite with the 5 inches of concrete poured on top

\section{Construction procedure}

The construction procedure of Precast prestressed concrete deck panels used on the project is as follows.

(1) Panels transported to job site.

(2) Lay down styrofoam filler strips on the top flanges of the steel plate girders

(3) Panels being unloaded: The panels are delivered to the site and stacked onto the trucks in the proper order so that they can be lifted off of the truck and set directly into position.

(4) Install first panel

(5) Align first panel

(6) Repeat (4) and (5) until all panels are installed

(7) A layer of epoxy-coated rebar is then installed for a 5 inches thick conventionally placed bridge deck

(8) Pour concrete for the 5 inches thick conventionally placed bridge deck (Concrete deck pours were made using conventional truck mounted concrete pumps and Bidwell machines to finish) 
(9) Guardrail is installed after the panel erection is finished

\subsection{Data collection}

5.4.1 Data for simulation of FRP bridge deck panel construction

The data for simulation study using WebCYCLONE were collected through questionnaire-III. The required data include the duration of each task (man-hour requirement), resource inputs such as major equipment, material, etc., and the number of labors. Questionnaire-III is composed of two parts that include:

(1) Part 1: Duration (Minutes) - How much time was needed to finish a certain work (work tasks)?

(2) Part 2: Resource - How many labors were necessary to finish a certain work (work tasks)? What major equipments were required?

The original version of questionnaire-III is attached in Appendix C. The questionnaire was mailed to Defiance and Greene Counties in Ohio. These counties have used FRP bridge deck panels made by MMC called DuraSpan. The cost data of equipment and labor were collected through interview.

(1) Duration and resource data

- Deck dimension for Greene County (Fairgrounds Road Bridge): 227 feet * 32 feet 6 inches

- Total square footage: 7400 '20',

- Deck Depth: 8 inches 
- Number of FRP bridge deck panels used /span: 28

- Panel size: 32'6'' long and 8' wide

In collecting activity duration data for FRP bridge deck panel construction, triangular distributions were used. The main benefit of a triangular distribution is simplicity and it is easy and straightforward to collect data (Moder et al 1983).

The duration and resources data for the activities represented in the simulation model of FRP bridge deck panels were collected from the county engineer of Greene County, $\mathrm{OH}$, as shown in Tables 5-2 and 5-3.

Table 5-2 Duration input data of FRP bridge deck panels

\begin{tabular}{c|l|c|c|c}
\hline \multirow{2}{*}{$\begin{array}{c}\text { Node } \\
\text { No. }\end{array}$} & \multicolumn{1}{|c|}{ Work task } & \multicolumn{3}{c}{ Duration (Minutes) } \\
\cline { 2 - 5 } & \multicolumn{1}{|c}{ Minimum } & Most Likely & Maximum \\
\hline \hline 4 & Unload the panels on the job site & 10 & 15 & 20 \\
\hline 6 & $\begin{array}{l}\text { Life one panel by using a crane } \\
\text { (Panel size: 32'6' 'long 8' wide) }\end{array}$ & 2 & 4 & 6 \\
\hline 9 & $\begin{array}{l}\text { Place one panel into a girder by } \\
\text { using a crane }\end{array}$ & 10 & 15 & 20 \\
\hline 12 & $\begin{array}{l}\text { Align one panel into position by } \\
\text { using a jack }\end{array}$ & 15 & 20 & 25 \\
\hline 16 & $\begin{array}{l}\text { Install the FRP dowel bars in the lips } \\
\text { of the field joints }\end{array}$ & 1 & 2 & 5 \\
\hline 18 & $\begin{array}{l}\text { Install FRP splice strips in the lips of } \\
\text { the field joints }\end{array}$ & 45 & 60 & 90 \\
\hline 21 & $\begin{array}{l}\text { Install shear studs to connect } \\
\text { between decks and girders }\end{array}$ & 30 & 45 & 60 \\
\hline 24 & Pour grout in the cavity & 30 & 45 & 60 \\
\hline 27 & Install guardrail & 900 & 960 & 1020 \\
\hline \hline
\end{tabular}

Table 5-3 Resource input data of FRP bridge deck panels (Labors and equipment)

\begin{tabular}{l|l}
\hline \hline Work tasks & Number of labors \& equipment \\
\hline \hline Finish the placement and alignment of panels & 5 labors, 1 crane and 1 jack \\
\hline Finish the installation of the FRP dowel bars & 1 labors \\
\hline Finish the installation of FRP splice strips & 2 labors \\
\hline Finish the connection between decks and girders & $\begin{array}{l}1 \text { labor for shear studs \& } 5 \\
\text { labors and grout pump for grout }\end{array}$ \\
\hline Finish the installation of the guardrail & 3 labors \\
\hline \hline
\end{tabular}




\section{(2) Cost data}

Hourly equipment costs were derived from the assumption that equipment operates eight hours per day and the total costs of equipment including operation cost were calculated. The hourly rate in 2001 at Midwestern area of USA (75 \$/hr) was considered as the hourly labor cost. The equipment cost data were obtained by interview with a contractor of Fairgrounds Road Bridge project (Table 5-4).

Table 5-4 Equipment costs of FRP bridge deck panels' construction

\begin{tabular}{c|c}
\hline \hline Equipment & Hourly equipment cost (\$) \\
\hline \hline Truck mounted, Crane & $\$ 125 / \mathrm{hr}$ \\
\hline Grout pump & $\$ 175 / \mathrm{hr}$ \\
\hline Shear stud gun & $\$ 175 / \mathrm{hr}$ \\
\hline \hline
\end{tabular}

\subsubsection{Data for simulation of Precast Concrete Panels}

The data required for simulation of Precast Concrete panels were obtained through interview with the project manager and engineer of Cape Girardeau Bridge project.

- Total square footage: 110,500

- Deck Depth: 4 inches

- Number of FRP bridge deck panels Used /span: 1404

- Average Panel size: 10' long and 8' wide

The duration and resource data for the activities represented in the construction simulation model of Precast concrete deck panels were collected from the project manager and engineer on the Cape Girardeau Bridge project shown in Tables 5-5 and 5-6. 
Table 5-5 Duration input data of Precast concrete deck panels

\begin{tabular}{c|l|c|c|c}
\hline \hline \multirow{2}{*}{$\begin{array}{c}\text { Node } \\
\text { No. }\end{array}$} & \multicolumn{1}{|c|}{ Work task } & \multicolumn{3}{c}{ Duration (Hours) } \\
\cline { 2 - 5 } & \multicolumn{1}{|c}{ Minimum } & Most Likely & Maximum \\
\hline 3 & Lay down Styrofoam & 4 & 6 & 8 \\
\hline 7 & Panels being unloaded & 0.25 & 0.5 & 1 \\
\hline 10 & $\begin{array}{l}\text { Install first panel (Panel size: } \\
10 \text { 'long 8' wide) }\end{array}$ & 0.25 & 0.5 & 1 \\
\hline 12 & $\begin{array}{l}\text { Align first panel (Panel size: 10'long } \\
8 \text { ' wide) }\end{array}$ & 5 & 6 & 7 \\
\hline 16 & Install a layer of epoxy-coated rebar & \multicolumn{3}{|c}{} \\
\hline 20 & $\begin{array}{l}\text { Pour concrete along with 5 inches } \\
\text { conventionally placed bridge deck }\end{array}$ & 5 & 2 & 3 \\
\hline 23 & $\begin{array}{l}\text { Pour concrete along with 5 inches } \\
\text { conventionally placed bridge deck }\end{array}$ & 1 & 45 & 60 \\
\hline 27 & $\begin{array}{l}\text { Install barrier rails in Precast } \\
\text { concrete panel }\end{array}$ & 30 & \multicolumn{3}{|c}{} \\
\hline \hline
\end{tabular}

* Constant duration input (for the entire project)

Table 5-6 Resource input data of Precast concrete deck panels (Labors and equipment)

\begin{tabular}{|c|c|c|}
\hline $\begin{array}{l}\text { Node } \\
\text { No. }\end{array}$ & Work task & Number of labors \& equipment \\
\hline 3 & Lay down Styrofoam & 2 Labors \\
\hline 7 & Panels being unloaded & 2 labors and 1 crawler crane \\
\hline 10 & $\begin{array}{l}\text { Install first panel (Panel size: } \\
\text { 10'long 8' wide) }\end{array}$ & 3 labors and 1 crawler crane \\
\hline 12 & $\begin{array}{l}\text { Align first panel (Panel size: 10'long } \\
\text { 8' wide) }\end{array}$ & 3 labors \\
\hline 16 & Install a layer of epoxy-coated rebar & 6 labors (Ironworkers) \\
\hline $\begin{array}{c}20 \& \\
23\end{array}$ & $\begin{array}{l}\text { Pour, cure, and finish concrete along } \\
\text { with } 5 \text { inches conventionally placed } \\
\text { bridge deck }\end{array}$ & $\begin{array}{l}1 \text { pump truck, } 4 \text { finishers, and } 20 \\
\text { labors including operators and } \\
\text { finishers }\end{array}$ \\
\hline 27 & $\begin{array}{l}\text { Install barrier rails in Precast } \\
\text { concrete panel }\end{array}$ & 4 finishers and 2 labors \\
\hline
\end{tabular}

The Styrofoam betting was usually installed by a two man crew. Based on a typical day, workers would unload 6 trucks of 12 panels per truck. Each panel weighs 3500 to 4000 lbs. 130 ton class crane was used to set the deck panels. A typical crew used in setting the deck panels would be 2 men on the truck, 3 men setting the panels, and a 
crane operator. For the node number 16 to 23 of work task, the durations were based on a 43 feet wide deck at 170 feet length with 5 feet $1 / 2$ inches Cast-in-place deck over Precast panels.
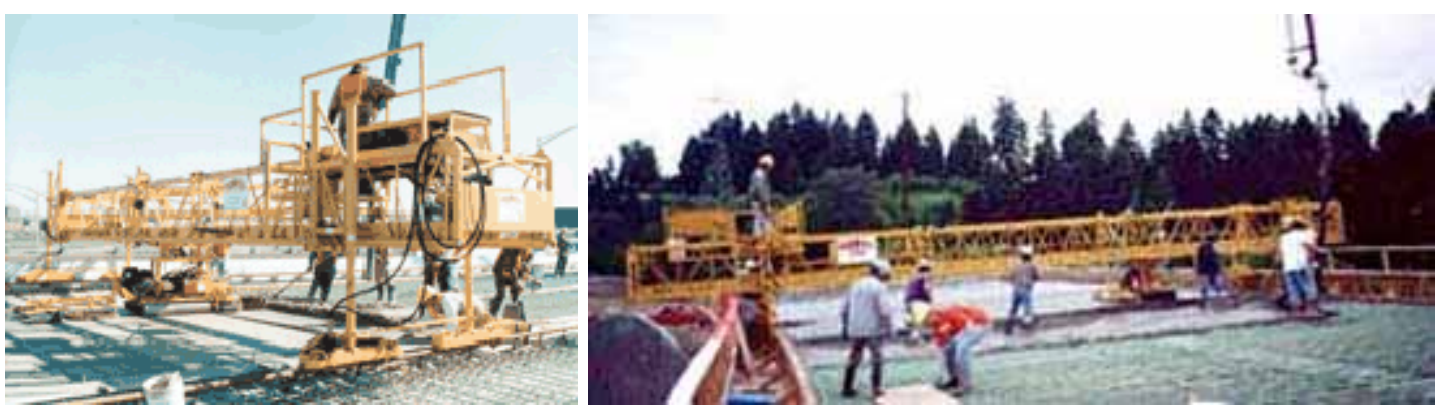

Figure 5-18 Bidwell machine

(Source: http://www.bid-well.com/3600.html)

Bidwell machines were used to finish concrete deck pours. A Bidwell machine is a motorized finishing screed that rides on a truss (Figure 5-18). The truss runs on a rail and self advances as the screed moves across the bridge. Only one crawler crane for 40 hour/week schedule was required in this project.

The equipment cost data were also obtained from the project manger and engineer on the Cape Girardeau Bridge project shown in Tables 5-7. The hourly rate in 2001 at Midwestern area of USA ( $75 \$ / \mathrm{hr}$ ) was considered as the hourly labor cost.

Table 5-7 Equipment costs of Precast concrete deck panels

\begin{tabular}{c|c|c|c}
\hline \hline Equipment & $\begin{array}{c}\text { Hourly operation } \\
\text { cost }(\$)\end{array}$ & $\begin{array}{c}\text { Hourly operator cost } \\
(\$)\end{array}$ & $\begin{array}{c}\text { Total hourly } \\
\text { equipment cost }(\$)\end{array}$ \\
\hline \hline Crawler Crane & $\$ 165 / \mathrm{hr} *$ & $\$ 22 / \mathrm{hr}$ & $\$ 187 / \mathrm{hr}$ \\
\hline Concrete pump truck & $\$ 170 / \mathrm{hr}$ & $\mathrm{N} / \mathrm{A}$ & $\$ 170 / \mathrm{hr}$ \\
\hline Finisher & $\$ 16.50 * *$ & $\$ 22 / \mathrm{hr}$ & $\$ 38.50 \mathrm{hr}$ \\
\hline \hline
\end{tabular}

Note: $* \$ 165=$ Rental rate $(\$ 90 / \mathrm{hr})+$ Operating rate $(\$ 75 / \mathrm{hr}) * * \$ 16.50 / \mathrm{hr}=$ Rental rate $(\$ 11.50 / \mathrm{hr})+$ Operating rate $(\$ 5 / \mathrm{hr})$ 


\subsection{Simulation Model}

Construction simulation models for both FRP bridge deck panels and Precast concrete deck panels were prepared based on construction procedure introduced in 5.3. Figures 5-18 and 5-19 present simulation model of both systems. Input file for FRP bridge deck panels and Precast concrete deck panels are illustrated in Appendix E and Appendix F, respectively.

The Precast concrete deck panels are similar to FRP bridge deck panels in that panels fabricated in the factory are placed in the two systems. The basic difference in both systems is that thin Precast concrete deck panels of 4 inches depth act as bottom forms for the deck construction and then become composite with the 5 " of concrete poured on top. However, FRP bridge deck panels, 8 inches in depth, are directly placed on top of the girders without additional concrete pour on top. 


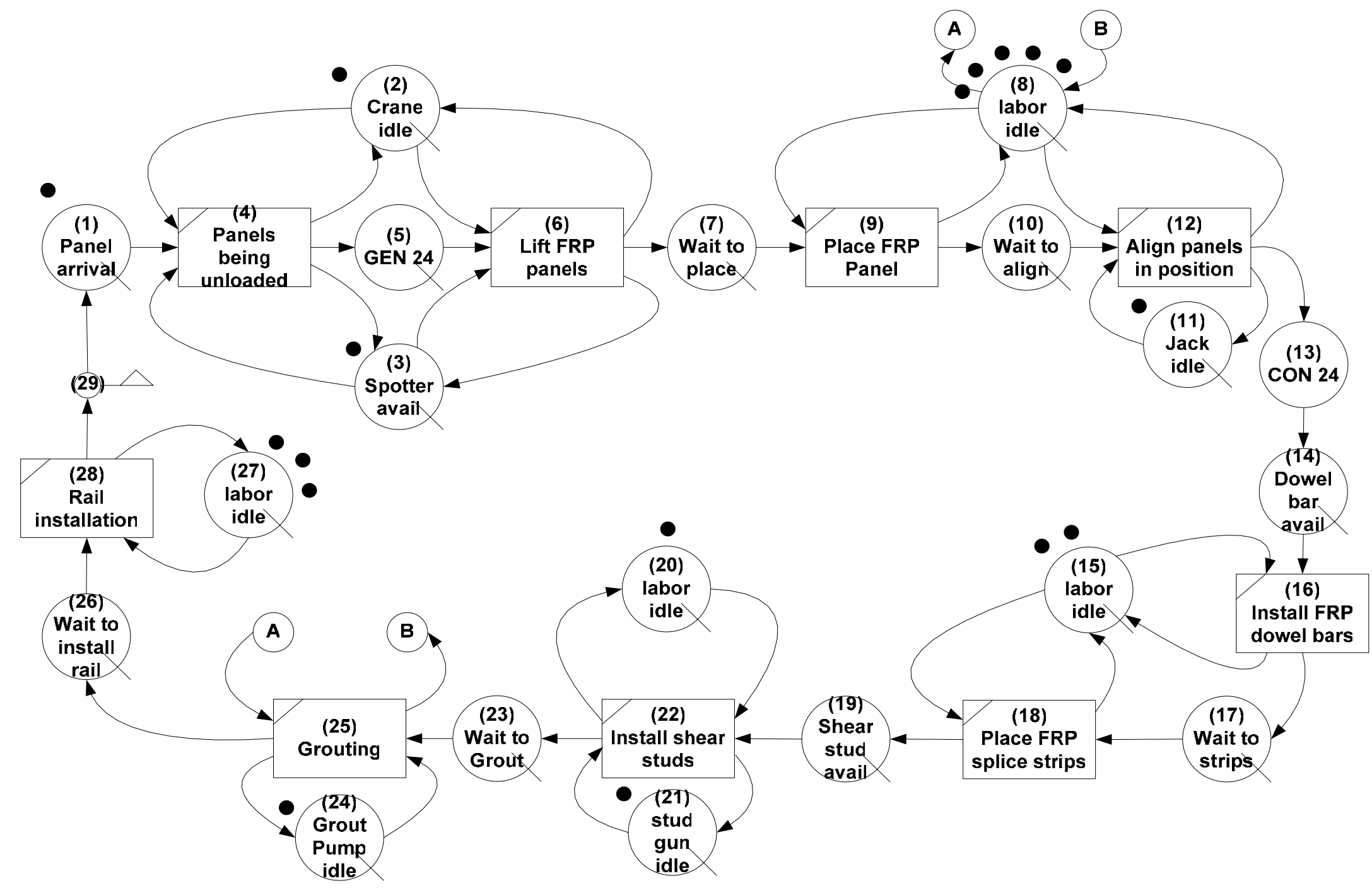

Figure 5-19 Simulation model for FRP bridge deck panels 


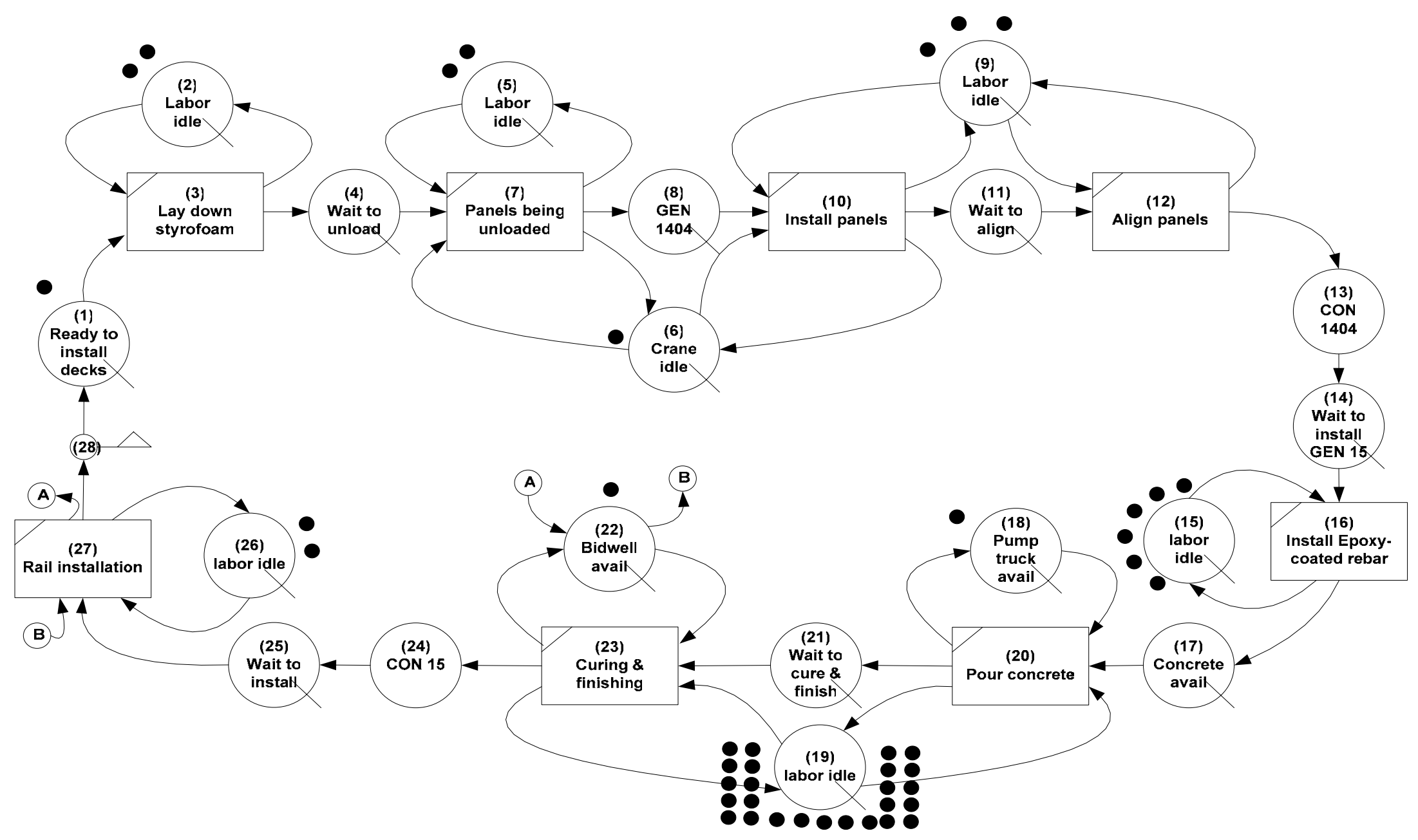

Figure 5-20 Simulation model for Precast concrete deck panels 


\subsection{Simulation results}

Based on WebCYCLONE, the construction simulation result of a repetitive cycle in both projects was presented as the productivity. The productivity was represented as productivity per time unit. For computing productivity of both FRP bridge deck panels and Precast concrete deck panels, 'Hours' was used as the time unit (Table 5-8).

The cycle number in Table 5-8 represents the number of time both systems cycle. For instance, one cycle of FRP bridge deck panels (Refer to Figure 5-19) includes Queue node (1: Panel arrival) to accumulator (29). In case of Precast concrete deck panels (Refer to Figure 5-20), Queue node (1: Ready to install decks) to accumulator (28) is included in the one cycle of the system. It was usually defined by user. Therefore, the productivity of both systems can be calculated through dividing 'Cycle number' by 'Total simulation time (i.e., 300/7946.3 = 0.03775 for FRP bridge deck panels and $20 / 28151.1=0.000710$ for Precast concrete deck)

Table 5-8 Simulated productivity result

\begin{tabular}{c|c|c|c|c|c|}
\hline \hline & $\begin{array}{c}\text { Total } \\
\text { simulation } \\
\text { time (unit) }\end{array}$ & $\begin{array}{c}\text { Cycle } \\
\text { No. }\end{array}$ & $\begin{array}{c}\text { Productivity } \\
\text { (per time unit) }\end{array}$ & $\begin{array}{c}\text { Production/ } \\
\text { cycle }\end{array}$ & $\begin{array}{c}\text { Productivity } \\
\left(\mathrm{ft}^{2} / \mathrm{hr}\right)\end{array}$ \\
\hline $\begin{array}{c}\text { FRP bridge } \\
\text { deck panel }\end{array}$ & $\begin{array}{c}7946.3 \\
\text { (hours) }\end{array}$ & 300 & $\begin{array}{c}0.03775 \\
(\text { cycles } / \mathrm{hr})\end{array}$ & $7400 \mathrm{ft}^{2}$ & $\begin{array}{c}0.03775^{*} 7400= \\
279.375 \mathrm{ft}^{2} / \mathrm{hr}\end{array}$ \\
\hline $\begin{array}{c}\text { Precast } \\
\text { concrete deck }\end{array}$ & $\begin{array}{c}28151.1 \\
\text { (hours) }\end{array}$ & 20 & $\begin{array}{c}0.00071 \\
\text { (cycles } / \mathrm{hr})\end{array}$ & $110,500 \mathrm{ft}^{2}$ & $\begin{array}{c}0.0007 * 110,500 \\
=78.5049 \mathrm{ft}^{2} / \mathrm{hr}\end{array}$ \\
\hline \hline
\end{tabular}

A total square footage of FRP bridge deck panel in the Fairgrounds Road Bridge project was $7,400 \mathrm{ft}^{2}$ while the Cape Girardeau Bridge project placed 110,500 $\mathrm{ft}^{2}$ of post-tensioned precast concrete deck panels. Converting in terms of $\mathrm{ft}^{2} / \mathrm{hr}$, the productivity of 7,400 $\mathrm{ft}^{2}$ of FRP bridge deck panels is $279.375\left(\mathrm{ft}^{2} / \mathrm{hr}\right)$ and that of $110,500 \mathrm{ft}^{2}$ of Precast concrete deck is 78.5049 $\left(\mathrm{ft}^{2} / \mathrm{hr}\right)$. Therefore, it was found that FRP bridge deck panels could produce more than three 
times as much productivity as Precast concrete deck panels $(279.375 / 78.5049=3.55)$. In the next section, sensitivity analysis was introduced to optimize the performance of a given system by changing the resources or other conditions.

\section{$\underline{5.7 \text { Sensitivity analysis }}$}

The objective of sensitivity analysis is to find the optimal performance of a given system by varying the resources. Changing the number of resource units in a model may affect the productivity results. The critical resources can be identified through the sensitivity analysis. The critical resources have a very small amount of idleness time in the systems and generally close to zero. Another possibility to optimize the performance is to keep maintaining the productivity but reducing the resources. This is possible in system where resources have high idleness values (Shuaeuble 2001).

\subsubsection{FRP bridge deck panels}

The sensitivity analysis was performed within the ranges of number of resources illustrated in Table 5-9. Only main 4 resources were considered because the change of their number might affect the productivity of the systems while the rest of resources were fixed as original units. The result of simulated productivity and the unit cost is presented in Table 5-10 and Figure 5-21.

Table 5-9 Units of various resources

\begin{tabular}{c|c|c|c|c}
\hline \hline Systems & Node of no. & Resource & Minimum unit & Maximum unit \\
\hline \hline \multirow{3}{*}{$\begin{array}{c}\text { FRP bridge } \\
\text { deck panel }\end{array}$} & 2 & Crane & 1 & 2 \\
\cline { 2 - 5 } & 8 & Labor & 2 & 5 \\
\cline { 2 - 5 } & 21 & Stud gun & 1 & 2 \\
\cline { 2 - 5 } & 24 & Grout pump & 1 & 2 \\
\hline \hline
\end{tabular}


As shown in Table 5-11, the productivities and costs per unit time (hours) for FRP bridge deck panels are variable depending on the number of resources (i.e., cranes, labors, shear stud gun, and grout pump). Within these ranges, the optimal system was one that was composed of 1 crane, 2 labors at node number 8, 1 shear stud gun, and 1 grout pump, which had the lowest cost per units $(\$ 19.25)$ and the lowest cost per productivity units $(560.640$ units/hour) . The second optimal system required 3 labors at node number 8 and the rest had same composition as the first system. It was found that the number of labors is the first major factor affecting the productivity. On the other hand, the number of other resources did not make much effect on the productivity. 
Table 5-10 Simulation results based on varied resources in FRP bridge deck panels

\begin{tabular}{c|c|c|c|c|c|c|c}
\hline \hline & \multicolumn{3}{|c|}{ Resource information } & \multicolumn{3}{c}{ Productivity information } \\
\hline $\begin{array}{c}\text { Scenarios } \\
\text { Number }\end{array}$ & Crane' & Labor & $\begin{array}{c}\text { Stud } \\
\text { gun }\end{array}$ & $\begin{array}{c}\text { Grout } \\
\text { pump }\end{array}$ & $\begin{array}{c}\text { Productivity } \\
\text { Per Unit Time }\end{array}$ & $\begin{array}{c}\text { Cost Per Unit } \\
\text { Time }\end{array}$ & $\begin{array}{c}\text { Cost Per } \\
\text { Prod. Unit }\end{array}$ \\
\hline \hline $\mathbf{1}$ & $\mathbf{1}$ & $\mathbf{2}$ & $\mathbf{1}$ & $\mathbf{1}$ & $\mathbf{0 . 0 3 4 3}$ & $\mathbf{1 9 . 2 4 6 0}$ & $\mathbf{5 6 0 . 6 4 0}$ \\
\hline 2 & 1 & 2 & 1 & 2 & 0.0342 & 22.2544 & 650.230 \\
\hline 3 & 1 & 2 & 2 & 1 & 0.0344 & 22.1878 & 645.807 \\
\hline 4 & 1 & 2 & 2 & 2 & 0.0344 & 25.1213 & 730.973 \\
\hline 5 & $\mathbf{1}$ & $\mathbf{3}$ & $\mathbf{1}$ & $\mathbf{1}$ & $\mathbf{0 . 0 3 5 6}$ & $2 \mathbf{2 0 . 5 3 1 7}$ & 576.690 \\
\hline 6 & 1 & 3 & 1 & 2 & 0.0355 & 23.3865 & 658.940 \\
\hline 7 & 1 & 3 & 2 & 1 & 0.0356 & 23.4468 & 658.940 \\
\hline 8 & 1 & 3 & 2 & 2 & 0.0354 & 26.4572 & 746.447 \\
\hline 9 & 1 & 4 & 1 & 1 & 0.0369 & 21.7587 & 590.240 \\
\hline 10 & 1 & 4 & 1 & 2 & 0.0370 & 24.7942 & 669.573 \\
\hline 11 & 1 & 4 & 2 & 1 & 0.0369 & 24.7085 & 669.573 \\
\hline 12 & 1 & 4 & 2 & 2 & 0.0368 & 27.5347 & 748.907 \\
\hline 13 & 1 & 5 & 1 & 1 & 0.0376 & 22.9767 & 610.470 \\
\hline 14 & 1 & 5 & 1 & 2 & 0.0377 & 25.9145 & 688.053 \\
\hline 15 & 1 & 5 & 2 & 1 & 0.0376 & 25.8824 & 688.053 \\
\hline 16 & 1 & 5 & 2 & 2 & 0.0376 & 28.9886 & 771.393 \\
\hline 17 & 2 & 2 & 1 & 1 & 0.0343 & 21.3459 & 621.473 \\
\hline 18 & 2 & 2 & 1 & 2 & 0.0343 & 24.2311 & 706.640 \\
\hline 19 & 2 & 2 & 2 & 1 & 0.0343 & 24.2598 & 706.640 \\
\hline 20 & 2 & 2 & 2 & 2 & 0.0343 & 27.1278 & 791.807 \\
\hline 21 & 2 & 3 & 1 & 1 & 0.0356 & 22.6169 & 635.440 \\
\hline 22 & 2 & 3 & 1 & 2 & 0.0355 & 25.5092 & 717.690 \\
\hline 23 & 2 & 3 & 2 & 1 & 0.0356 & 25.5677 & 717.690 \\
\hline 24 & 2 & 3 & 2 & 2 & 0.0356 & 28.5047 & 799.940 \\
\hline 25 & 2 & 4 & 1 & 1 & 0.0369 & 23.8564 & 646.907 \\
\hline 26 & 2 & 4 & 1 & 2 & 0.0369 & 26.7942 & 726.240 \\
\hline 27 & 2 & 4 & 2 & 1 & 0.0368 & 26.7602 & 726.240 \\
\hline 28 & 2 & 4 & 2 & 2 & 0.0369 & 29.7376 & 805.573 \\
\hline 29 & 2 & 5 & 1 & 1 & 0.0377 & 25.1324 & 665.887 \\
\hline 30 & 2 & 5 & 1 & 2 & 0.0377 & 28.0120 & 743.470 \\
\hline 32 & 2 & 5 & 2 & 1 & 0.0378 & 28.0666 & 743.470 \\
\hline & 2 & 5 & 2 & 2 & 0.0377 & 30.9860 & 821.053 \\
\hline
\end{tabular}




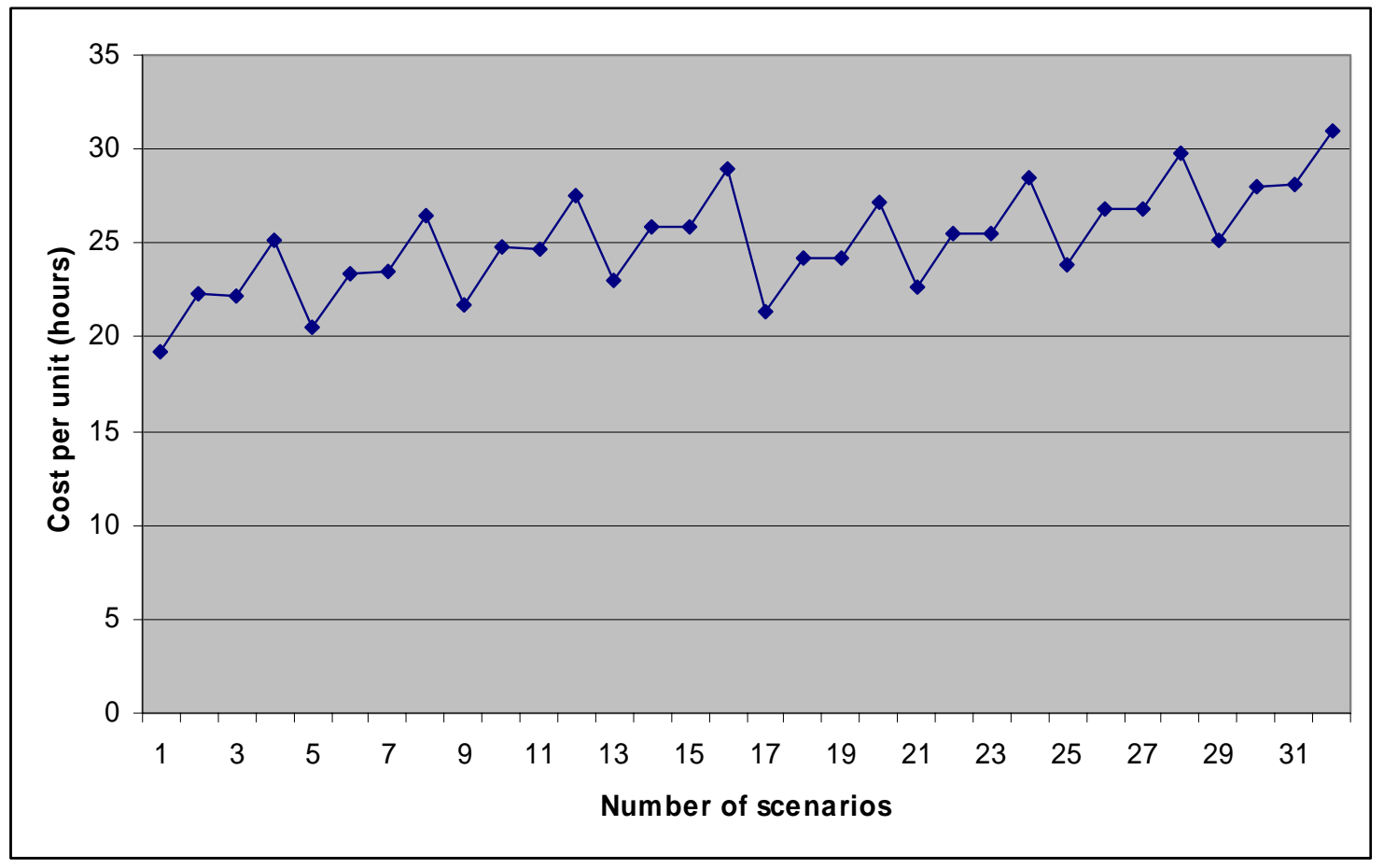

Figure 5-21 Cost per unit (hours) versus scenarios number in FRP bridge decks

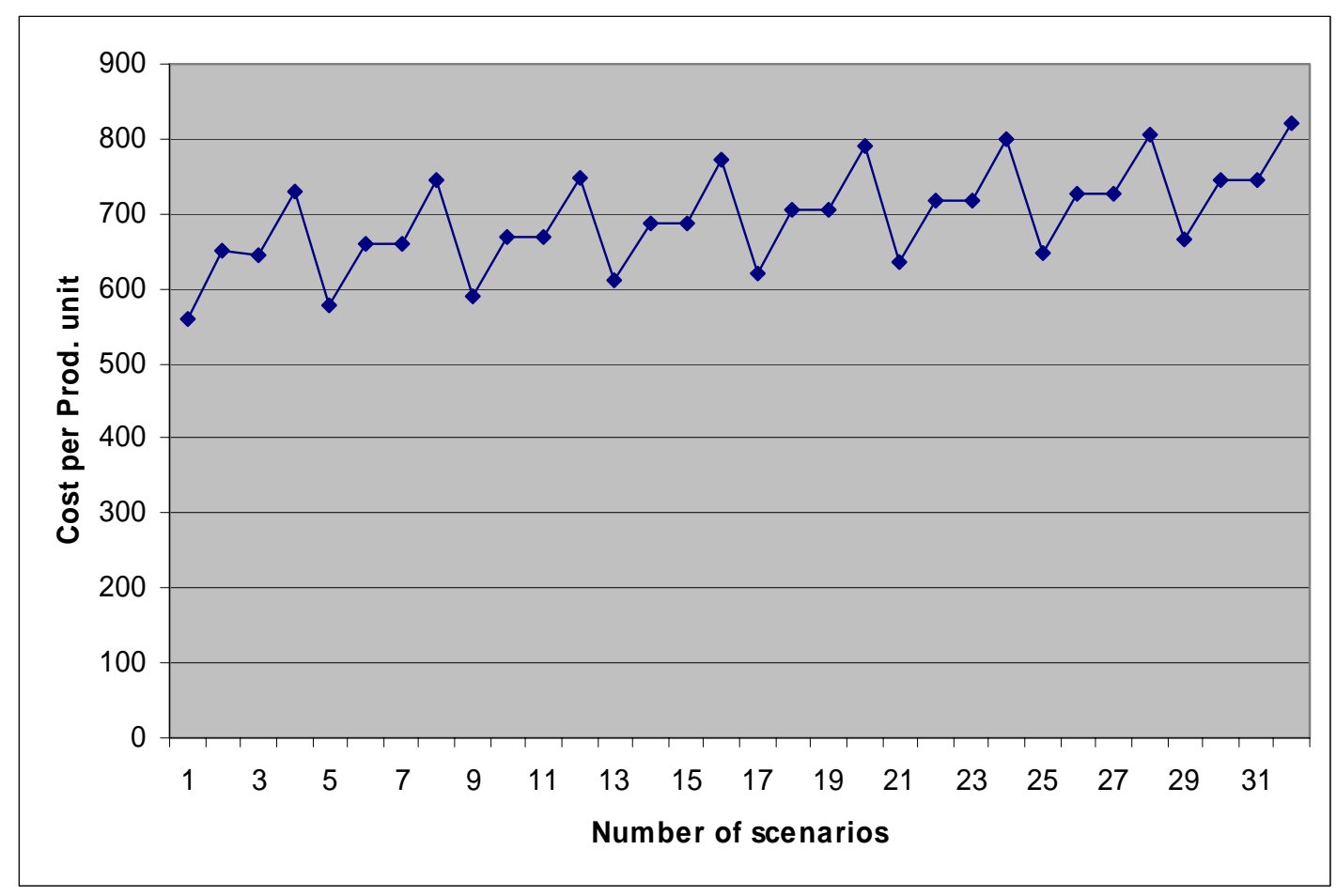

Figure 5-22 Cost per unit (hours) versus scenarios number in FRP bridge decks 


\subsubsection{Precast concrete deck panels}

The sensitivity analysis for Precast concrete deck panels was performed by changing various resources as shown in Table 5-11. A total of 6 out of 9 resources were considered to determine the optimal systems.

Table 5-11 Units of various resources

\begin{tabular}{c|c|c|c|c}
\hline \hline Systems & Node of no. & Resource & Minimum unit & Maximum unit \\
\hline \hline \multirow{4}{*}{$\begin{array}{c}\text { FRP bridge } \\
\text { deck panel }\end{array}$} & 6 & Crane & 1 & 2 \\
\cline { 2 - 5 } & 15 & Labor & 3 & 6 \\
\cline { 2 - 5 } & 18 & Pump truck & 1 & 2 \\
\cline { 2 - 5 } & 19 & Labor & 15 & 2 \\
\cline { 2 - 5 } & 22 & Bidwell & 1 & 4 \\
\hline \hline
\end{tabular}

From the results illustrated in Figure 5-23, the first scenario composed of 1 crane, 3 labors at node number 15, 1 pump truck, 15 labors at node number 19, 1 bidwell, and 2 labors at node number 26 yielded the lowest cost per unit (hours). However, the optimal system was the $361^{\text {st }}$ scenarios that was composed of 2 crane, 4 labors at node number 15,1 pump truck, 15 labors at node number 19, 1 bidwell, and 2 labors at node number 26 which had the highest cost per productivity units $(\$ 53,133.30)$, almost the lowest cost per unit $(\$ 44.80)$, and productivity per time unit $(0.0008 \mathrm{cycles} / \mathrm{hr})$. For entire simulation results based on varied resources in Precast concrete decks please refer to appendix G. As shown in Figure 5-24, the cost per productivity unit decreased rapidly in the scenarios $289(\$ 53,343.83)$ composed of 2 crane, 3 labors at node number 15, 1 pump truck, 15 labors at node number 19,1 bidwell, and 2 labors at node number 26. It was evident that the number of cranes was the major factor affecting the productivity. On the other hand, the number of pump truck and bidwell did not seriously affect the productivity. In addition, the number of labors at node number 15 and 19 was another major factor affecting cost 
per productivity unit. For detailed simulation results of other scenarios please refer to Appendix G.

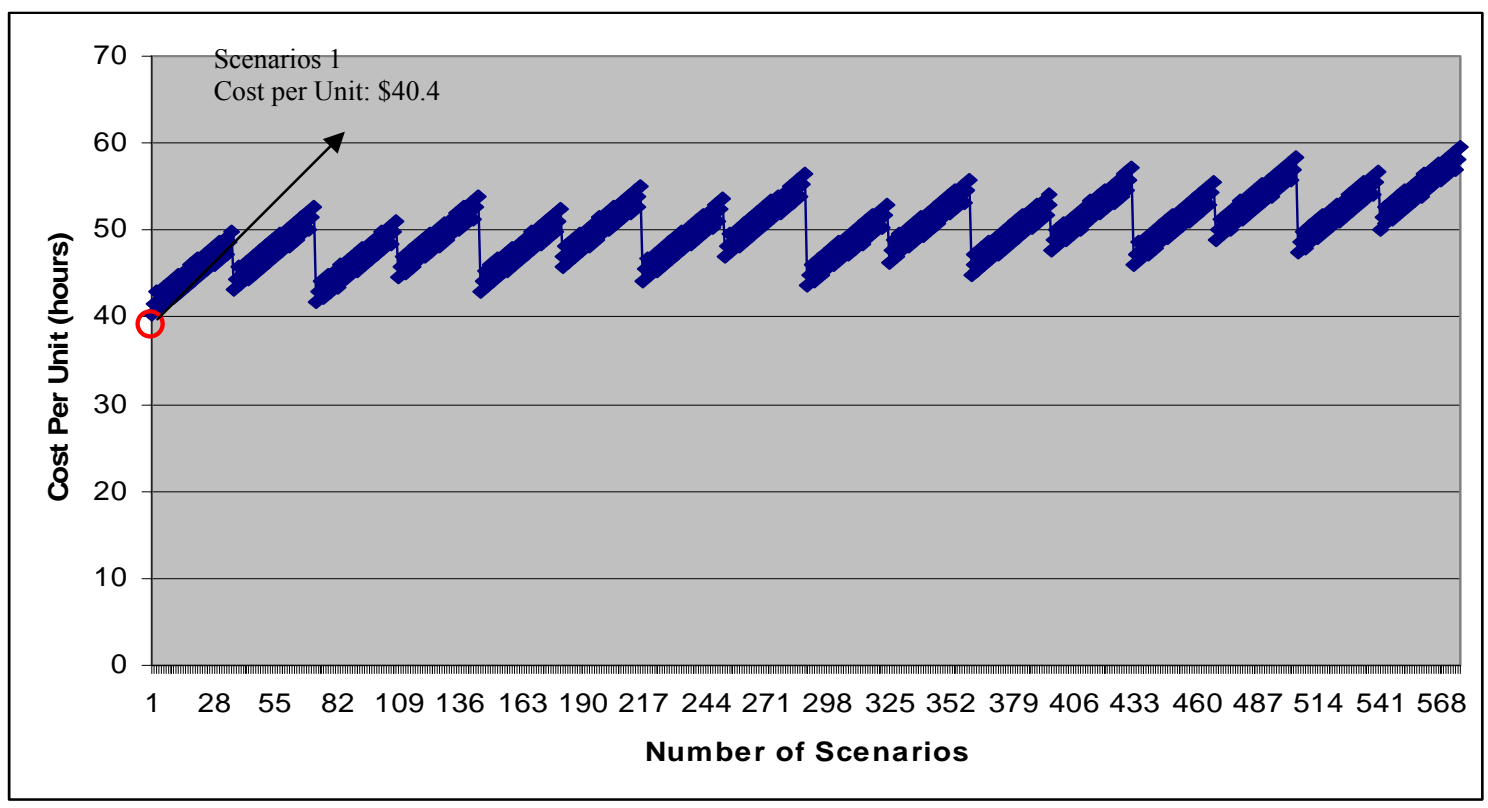

Figure 5-23 Cost per unit versus scenario number in Precast concrete decks

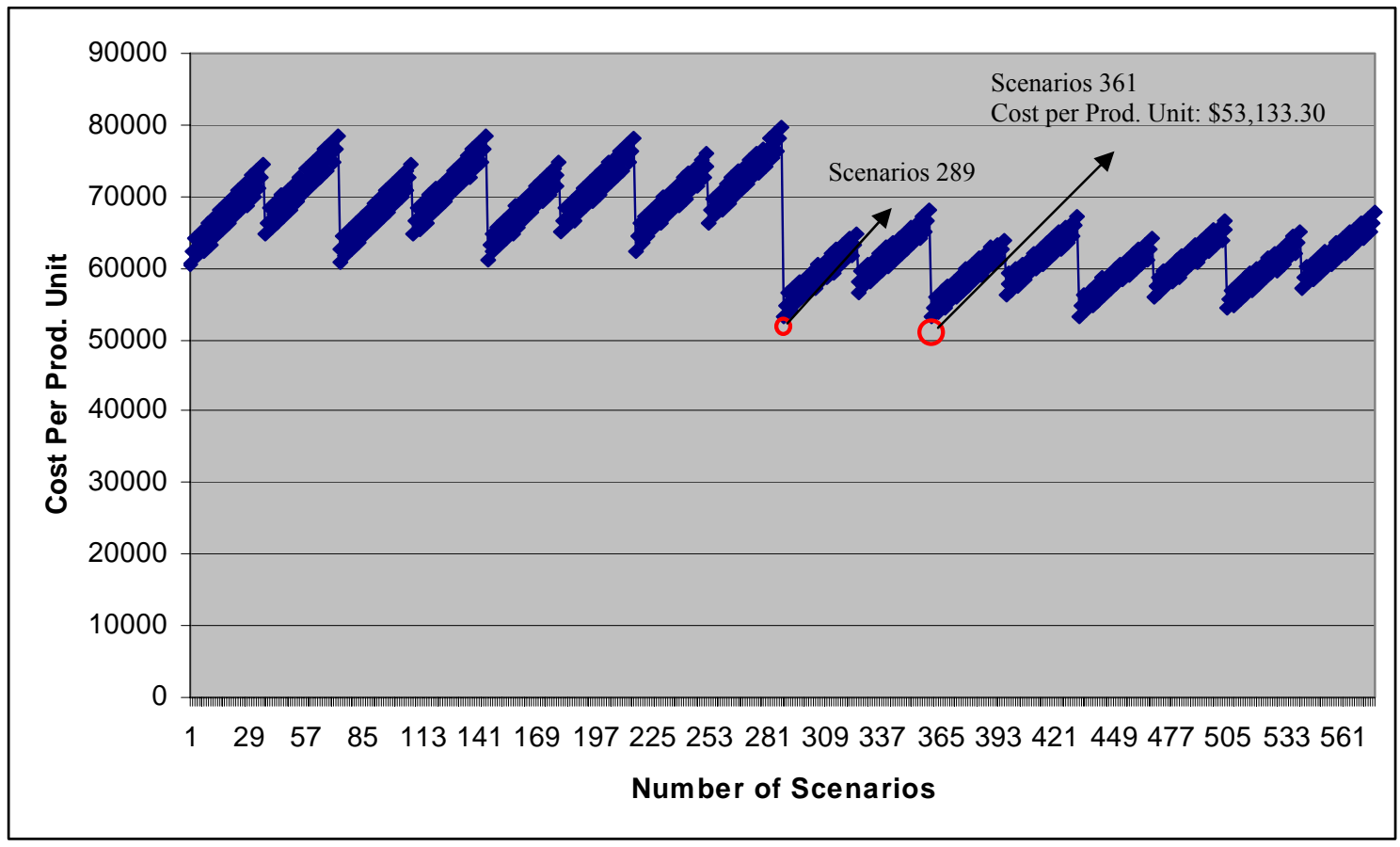

Figure 5-24 Cost per productivity unit versus scenario number in Precast concrete decks 


\section{$\underline{5.8 \text { Comparison of Productivity }}$}

As mentioned before, a total square footage of the FRP bridge deck panel project (Fairgrounds Road Bridge) selected for simulation study in this research was $7,400 \mathrm{ft}^{2}$ while the square footage for the precast concrete deck panel project was $110,500 \mathrm{ft}^{2}$. Converting in terms of $\mathrm{ft}^{2} / \mathrm{hr}$, the productivity of FRP bridge deck panels and Precast concrete decks is $253.82\left(\mathrm{ft}^{2} / \mathrm{hr}\right)$ and $88.4\left(\mathrm{ft}^{2} / \mathrm{hr}\right.$ ), respectively (Refer to Table 5-12) While the productivity of FRP bridge deck panels decreases, that of Precast concrete deck slightly increases. However, the result was almost similar to simulated result before sensitivity analysis illustrated in Table 5-8. The productivity for FRP bridge deck was almost three times than Precast concrete deck $(253.82$ / 88.4 = 2.87). Table 5-13 shows the number of optimized resources in both systems.

In the simulation study, the construction costs except for initial material cost were considered to determine the optimal systems in both FRP bridge deck panels and Precast Concrete deck panels. However, as mentioned in Chapter 2, one of main disadvantage of FRP bridge deck panels was higher initial cost compared to a conventional concrete deck. Therefore, this research did not deal with the comparison of unit cost.

Table 5-12 Comparison of productivity in both systems

\begin{tabular}{c|c|c|c}
\hline \hline $\begin{array}{c}\text { Optimal } \\
\text { Systems }\end{array}$ & $\begin{array}{c}\text { Prod. per unit } \\
\text { time }\end{array}$ & Production/cycle & Productivity $\left(\mathrm{ft}^{2} / \mathrm{hr}\right)$ \\
\hline $\begin{array}{c}\text { FRP bridge } \\
\text { decks }\end{array}$ & $\begin{array}{c}0.0343 \\
\text { (cycles } / \mathrm{hr})\end{array}$ & $7400 \mathrm{ft}^{2}$ & $0.0343 * 7400=253.82 \mathrm{ft}^{2} / \mathrm{hr}$ \\
\hline $\begin{array}{c}\text { Precast concrete } \\
\text { decks }\end{array}$ & $\begin{array}{c}0.0008 \\
\text { (cycles/hr) }\end{array}$ & $110,500 \mathrm{ft}^{2}$ & $0.0008 * 110,500=88.4 \mathrm{ft}^{2} / \mathrm{hr}$ \\
\hline \hline
\end{tabular}


Table 5-13 Optimization of resources in both systems

\begin{tabular}{|c|c|c|}
\hline & $\mathrm{k}$ panels & Precast concrete deck panels \\
\hline $\begin{array}{l}\text { (iii) } \\
\text { (iv) }\end{array}$ & $\begin{array}{l}\text { One crane and spotter to unload and } \\
\text { life panels, } \\
\text { two labors to place and align } \\
\text { panels, } \\
\text { one jack to align panels, } \\
\text { one labor to install FRP dowel bars } \\
\text { and place FRP splice strips, } \\
\text { one labor and stud gun to install } \\
\text { shear studs, } \\
\text { two labors and one group pump for } \\
\text { grouting, } \\
\text { three labors for guardrail } \\
\text { installation. }\end{array}$ & $\begin{array}{l}\text { (i) two labors for laying down Styrofoam } \\
\text { fillers on the top flanges of the steel } \\
\text { plate girders, } \\
\text { (ii) two labors to unload panels, } \\
\text { (iii) two cranes to unload and install panels, } \\
\text { (iv) three labors to install and align panels, } \\
\text { (v) four labors to install epoxy-coated } \\
\text { rebar, } \\
\text { (vi) one pump truck for pouring concrete, } \\
\text { (vii) fifteen labors to pour, cure, and finish } \\
\text { concrete, } \\
\text { (viii) one bidwell for concrete finishing, and } \\
\text { (ix) two labors for guardrail installation. } \\
\end{array}$ \\
\hline
\end{tabular}

\subsection{References}

Busel, J. P. and Lockwood, J. D., eds. (2000). Production selection guide: FRP composite products for bridge applications, Market development Alliance (MDA) of the FRP composites industry, Harrison, NY.

Cape Girardeau Bridge, Cape Girardeau, Missouri. (2004)

$<$ http://traylor.com/pages/map/bridges.html $>$ (April.04.2004)

Halpin, D. W. and Riggs, L. S. (1992). Planning and analysis of construction operations. John Wiley and Sons, Inc., New York, NY.

Moder, J. J., Philips, C. R., and Davis, E. W. (1983). "Project management with CPM, PERT and precedence diagramming." $3^{\text {rd }}$ Ed., Van Nostrand Reinhold Company, New York, NY, 1983.

RS Means book (2003) Building Construction Cost Data, Kingston, MA.

Schaeuble, B. (2001). "Simulation of concrete operations advanced vertical formwork systems." Independent Research Study, Purdue University, W. Lafayette, IN.

Solomon, G. and Sams, M. (2003). "Fiber-Reinforced Polymer (FRP) bridge deck panels DuraSpan $^{\text {TM},, ~ D e p a r t m e n t ~ o f ~ C i v i l ~ E n g i n e e r i n g ~ S e m i n a r, ~ O c t . ~ 2003, ~ P u r d u e ~ U n i v e r s i t y, ~}$ West Lafayette, IN. 
CHAPTER 6 Conclusion and Construction Guidelines

\section{$\underline{6.1 \text { Summary of research }}$}

The results of the research are summarized based on (i) Literature review (ii) Preliminary data collection and identification of candidate projects, and (iii) Detailed data collection, analysis and process modeling.

\subsubsection{Literature review}

The literature review helped in identifying various issues with respect to the construction of FRP composite bridge decks. From the literature review, a fundamental understanding for the FRP composite industry, its unique characteristics, and methodology were summarized in Chapter 2. Their advantages and disadvantages were also summarized in Tables 2-1 and 2-2.

In addition, typical manufacturing processes employed by FRP composite bridge deck manufacturers were introduced; (i) Open molding (Hand lay up process, Chopped laminate process, and Filament winding) and (ii) Closed molding (Resin Transfer Molding (RTM), Resin Infusion Molding, Injection Molding, and Pultrusion). Each of the fabrication processes has its own characteristics that define the type of products to be produced. Several leading FRP composite bridge deck manufacturers were also introduced and their installation procedures were 
identified: (i) Creative Pultrusion, Inc, (ii) Hardcore Composites Inc., (iii) Kansas Structural Composites, Inc., (iv) Strongwell, and (v) Martin Marietta Composites. In terms of the challenges and technical issues with respect to their application, more efficient manufacturing and effective production methods should be explored and developed to enhance application of FRP composite bridge deck panels in civil infrastructure.

\subsubsection{Preliminary Data Collection and Identification of Candidate Projects}

Questionnaire survey-I was developed to identify data with regard to (i) standard techniques and material for FRP deck construction, (ii) man-hour requirement, cost, duration, productivity required for individual projects as well as any barriers encountered in installing FRP decks and (iii) constructability, operability, and maintainability of FRP decks. It was sent to the bridge engineers of each State DOT and the county engineers of five candidate projects identified. Responses obtained from the bridge engineers have been analyzed and compiled in Chapter 3. Also, responses from the county engineers have been analyzed and complied in Chapter 4.

Questionnaire-II assisted research team in collecting information with respect to constructability, maintainability, operability, and life cycle cost issues in terms of manufacturers as well as their manufacturing process. Research team visited two manufacturing facilities (Hardcore Composites and Martin Marietta Composites) and interviewed the senior composite engineers at both locations. 
(1) Summary of responses from the bridge engineers

Among forty-seven State Departments of Transportation (DOTs) responding to the questionnaire survey-I, only 9 State DOTs have currently used FRP bridge deck panels. The main reasons stated for not using FRP bridge deck panels was due to their higher initial cost and unproved durability as compared to a conventional concrete deck. Other stated reasons include:

- Need more reliable performance data

- Need specification for their design or acceptance by AASHTO

- Lack of supplier and installers

- Need inspection criteria and repair procedures

Based on the results of the questionnaire survey-I, it was determined that only eight percent, among the State DOTs that currently do not use FRP bridge deck panels, have a plan to employ them within next five years. Bridge engineers indicated fast installation and good durability as the major advantage of those panels while the minor advantages include cost saving, less environmental impact, and fewer permits required as compared to conventional bridge deck panels (refer to Figure 3-3). The FRP bridge deck panels have been installed mostly on low volume rural roads (refer to Figure 3-4). The various issues on constructability, operability, and maintainability of FRP bridge deck panels were introduced in Chapter 3 and their conclusions are summarized in the next section.

(2) Summary of responses from the county engineers

In addition to questionnaire survey-I mentioned above, research team visited the construction sites where FRP bridge deck panels were used and interviewed the county engineers responsible for the projects to analyze the installation of advanced modular deck systems and 
evaluate benefits due to speed and ease of installation. A total of five candidate projects for FRP bridge deck construction were identified in Ohio for on-site data collection and study. The summary of interview and questionnaire survey-I responses obtained from four of the five counties in Ohio is as follows.

1. Criteria used for selecting a bridge for FRP bridge deck panel application

- Low ADT and ADTT, no skew, and no super-elevation

- Need a grant for construction because of high initial cost

- Good shape of existing substructure and concrete beam

2. Unlike the FRP deck panels of other counties, Sintz Road over Rock Run Bridge located in Clark County used fifty ' $Z$ clips' instead of grout haunch.

3. The installation of additional FRP deck panels has been scheduled in only one among the four counties within the next five years

4. County engineers indicated the most important advantage of FRP decks as good durability such as fatigue resistance, long service life, and resistance to de-icing salts while they mentioned less environmental impact for the least advantage. The results were similar to the opinion expressed by the bridge engineers (refer to Figure 4-27).

5. Similar to the results of questionnaire-I sent to the bridge engineers, Low Volume Rural was ranked as the most preferred road type for FRP bridge deck panel applications. It was also found that thirty percent of FRP decks have been installed in high volume rural roads. This was one of facts supporting the argument that it is possible for them to be used in bridges with high ADT or ADTT (refer to Figure 4-28).

The various issues on constructability, operability, maintainability of FRP bridge deck panels were introduced in Chapter 4 and their conclusions are summarized in the next section. 


\section{(3) Hardcore Composites}

Hardcore Composites has finished a total of 28 projects. All of the bridges are designed for L/800 deflection criteria and design load are variable depending on each project. Ohio State DOT has mostly used their product because of Project 100 in Ohio. New York and Delaware were also identified as important customers for their product (Figure 4-35). According to Hardcore Composites, consistent increase in the installation of their product occurred from 1997 to 2000 which peaked in the year 2001, subsequently, a sudden decrease was noticed in the year 2002 (Figure 4-36). Their products have been mostly used on vehicular bridges and only one pedestrian bridge has used their product (Figure 4-37). The "total square footage" of the bridges installed with their product was in the range of $1001 \mathrm{ft}^{2}$ to $1500 \mathrm{ft}^{2}$. Bridges, whose total square footage ranged from $501 \mathrm{ft}^{2}$ to $1000 \mathrm{ft}^{2}$, were also an important target for their products (Figure 4-38).

The responses to the questionnaire survey indicated that asphalt worked best for the bridge deck wearing surface. However, polymer concrete was also ranked as one of the preferred materials (Figure 4-39). Hardcore Composites has designed their product to satisfy ASSHTO codes for concrete and steel bridges. They have also offered warranty against their deck for 20 years. However, they do not offer warranty against the following items: acts of God, vandalism, overloading, etc. They have used Vinyl Ester as the type of thermoset resin because of ease in processing and cheap price. Fiberglass was used as the type of fiber since it was less expensive than carbon and aramid and it gives the material properties required in the design. Usually two or three member crews were sent to the job sites for the deck installation. The typical equipment required for the installation of their products are a crane and basic construction tools such as impact wrench and hand tools. The standard size of the crew for installation was two to four 
member crews. Usually it takes two to five days for installation depending on the complexity of the bridge.

A senior composite engineer of Hardcore Composites indicated that high initial cost, low bidding practices, and lack of confidence or acceptance in the market place were the major obstacles in the application of FRP bridge deck panels. For maintenance practices, they offer a maintenance manual (refer to Appendix D).

\section{(4) Martin Marietta Composites (MMC)}

They have 26 bridge decks in service and each is a unique application. They have mostly used 'Bituminous' material for the wearing surface that was usually decided based on the owner's preference. They are willing to consider warranty if required by the owner. With their system, polyester resin and glass fiber typically provides best value. Cranes and jacks are the major equipment required for installing their products. MMC typically recommends a minimum of six member crews for installing their products. Special skill is not required for the crews. MMC expects that it is common to install each of their panels in 30 minutes or less. According to the manufacturer, the effect of fuel, oil, and grease would be negligible as the spill would be typically received by the overlay. In terms of effect of salt and other chemicals, their decks are resistant to corrosion induced by deicing salts.

Like all materials, the owner has responsibility for the maintenance problems. MMC often participates in the first inspection of the bridge and provides assistance in the maintenance activities. So far, they have not experienced the replacement of a partial section in their products. 


\subsubsection{Detailed Data Collection, Analysis and Process modeling}

Construction simulation study was performed to determine the productivity, man-hour requirement and system bottlenecks that were important for understanding the construction process in both FRP bridge deck panels and conventional bridge deck panels. The detailed data required for the simulation studies were collected through questionnaire-III and personal interviews. Among various construction procedures developed by each manufacturer of FRP bridge deck panels, MMC construction procedure was selected for the simulation study. In case of conventional bridge deck, the construction procedure for precast concrete deck panels employed at Cape Girardeau Bridge, Cape Girardeau, Missouri was selected.

FRP bridge deck panels could be installed almost three times faster than precast concrete decks (i.e., 279.375/78.5049 $=3.56$ where $279.375 \mathrm{sf}^{2} / \mathrm{hr}$ for FRP bridge deck panels and $78.5049 \mathrm{sf}^{2} / \mathrm{hr}$ represented productivity for precast concrete deck in the sample projects). From the sensitivity analysis (to optimize the performance of a given system by changing the resources or other condition), it was found that the results were almost similar to the above results (i.e., $253.82 / 88.4=2.87$ where $253.82 \mathrm{sf}^{2} / \mathrm{hr}$ was productivity of FRP bridge deck panels and 88.4 $\mathrm{sf}^{2} / \mathrm{hr}$ for the precast concrete deck panels).

The optimal system for FRP bridge deck panels was composed of the following

resources: (i) one crane and spotter to unload and lift panels, (ii) two labors to place and align panels, (iii) one jack to align panels, (iv) one labor to install FRP dowel bars and place FRP splice strips, (v) one labor and stud gun to install shear studs, (vi) two labors and one grout pump for grouting and (vii) three labors for guardrail installation.

The optimal system for precast concrete deck panels required (i) two labors for laying down Styrofoam fillers on the top flanges of the steel plate girders, (ii) two labors to unload 
panels, (iii) two cranes to unload and install panels, (iv) three labors to install and align panels, (v) four labors to install epoxy-coated rebar, (vi) one pump truck for pouring concrete, (vii) fifteen labors to pour, cure, and finish concrete, (viii) one bidwell for concrete finishing, and (ix) two labors for guardrail installation.

\section{$\underline{6.2 \text { Research Conclusions }}$}

\subsubsection{Constructability of FRP bridge deck panels}

The study invstigated the following issues with regard to constructability of FRP bridge deck panels: (i) Deck structure types, (ii) Construction method, (iii) Wearing surface, (iv) Manufacturing processes, (v) FRP bridge deck cross-section types, (vi) construction specification, (vii) Detailed information on complete project, (viii) Barriers encountered in installing and (ix) Delivery issues. The brief conclusions on these issues are as follows.

(1) Conclusion on responses from the bridge engineers

Concrete cast-in-place and wood or timber were ranked as the deck structure types that have been frequently replaced by FRP bridge deck panels (refer to Figure 3-5). Most manufacturers have developed their own technology to provide the connection between decks and between deck and girder. Until now, the FRP bridge deck panels produced by Martin Marietta Composites, called DuraSpan ${ }^{T M}$, have been ranked as the most popular product. The products of Hardcore Composites, Kansas Structural Composites, and Creative Pultrusion have been used by several State DOT (refer to Figure .3-10). 
With respect to the material types for wearing surface, bridge engineers indicated that Bituminous and Polymer concrete have been the most preferred materials. Latex Modified Concrete was the least preferred by the State DOTs (refer to Figure 3-15).

Pultrusion has been ranked as the most used manufacturing process. Hand Lay-up and Vacuums Assisted Resin Transfer Modeling (VARTM) processes are also used by many manufacturers (refer to Figure 3-16). Five respondents indicated construction and design barriers as the barriers encountered while installing FRP bridge deck panels whereas, three indicated vendor as the barrier and one of them mentioned labor barriers (refer to Figure 3-19).

Usually, flat bed trucks were used to delivery the FRP panels from factory to the job site and their maximum deliverable sizes were variable depending on project requirements. It took usually a few days to delivery the panels.

(2) Conclusion on responses from the county engineers

With regard to deck structure types, mostly concrete cast-in-place decks have been replaced by FRP decks. Only one of the candidate projects' deck structure type was wood or timber (refer to Figure 4-30).

With respect to the manufacturers, Hardcore composites' product using VARTM manufacturing process has been installed the most in the projects that were studied while Martin Marietta Composites' product (DuraSpan ${ }^{T M}$ ) was used by two of the candidate projects (refer to Figure 3-30).

Bituminous was ranked as the most important wearing surface material. Only one candidate project employed polymer modified asphalt (refer to Figure 4-31). 
In terms of the method for guardrail installation, 'Guardrail attached to deck' was a preferred method among the methods used for installing guardrail (refer to Figure 4-32). Design barriers encountered in installing FRP decks were the most important problem. (Figure 4-33).

\subsubsection{Operability and Maintainability of FRP bridge deck panels}

(1) Conclusion on responses from the bridge engineers

In terms of maintainability issues, deteriorated conventional bridge decks have been mostly replaced by FRP bridge deck panels when their condition rating reached 4 and condition rating 6 or 7 in case of bridge substructure. The durability of wearing surface particularly delamination was indicated most as the highest maintenance problem. Most respondents expected 75 years as service life of FRP bridge deck panels while they mentioned 25 - 50 years as average service life of a concrete bridge deck.

(2) Conclusion on responses from the county engineers

In terms of condition rating of existing bridge structures, deteriorated conventional bridge decks have been replaced by FRP bridge deck panels when their condition rating reached 2 to 4 and condition rating of bridge substructure was 7 (Figure 4-34).

Two counties have not established a specific analysis procedure or method to inspect, maintain and repair the FRP bridge deck panels. One county has performed visual inspection three to four times per years. The county engineer indicated that any repairs to the panels would be undertaken based on discussion with the manufacture. Another county has performed visual inspection once every year. Three counties did not have any plan to monitor the service of FRP bridge deck panels. One of the counties has performed tap test once every year. 
Clark county engineers indicated that there were no problems with regard to maintenance and operation after FRP bridge deck panels were installed, however, fire damage was found on the bottom of panels as a probable cause of vandalism.

The maintenance problems commonly generated in other counties were delamination, debonding, and cracking of wearing surface and some minor gaps between the bottom of FRP deck and the concrete beams.

\section{$\underline{6.3 \text { Construction guidelines for FRP bridge deck panels }}$}

Indiana Department of Transportation does not have any definition on the terminology of Construction guidelines. For the purpose of this research, the Construction guidelines of FRP bridge deck panels were defined as the construction procedure, installation methods, and material types used in the construction.

\subsubsection{Construction procedure}

As indicated in Chapter 2, the construction procedure of FRP bridge deck panels varies from one manufacturer to another. Unlike conventional bridge deck panels such as concrete and steel decks, there are no uniform standards for their construction and thus the manufacturer's own specifications are used. Chapter 2 introduced the construction procedure used by four different manufacturers. However, due to lack of sufficient performance data it is difficult to analyze which construction procedure is more efficient and productive. As mentioned above, the FRP bridge deck panels produced by MMC have been ranked as the most preferred panels based on the questionnaire survey-I conducted for this research. Accordingly, their construction procedure was selected for the simulation study in Chapter 5. In this chapter, their construction 
procedure including resources required for a certain work task such as equipment and labor were described. The resources required would vary with respect to the project scope. The resources introduced in this section are based on the total square footage of FRP bridge deck panels installed, about 7,500 sf. The construction procedure is as follows:

1. First the panels are unloaded at the job site using a crane.

2. The first panel is installed on the top of girder using a crane and aligned using a jack.

3. The second step is repeated until all panels have been installed. The second and third steps usually require five labors.

4. FRP dowel bars are installed in the lips of the field joints and this step usually requires one labor.

5. FRP splice stripes are installed to ensure a durable and watertight joint, which is usually done by two labors.

6. In order to connect between deck and girder, shear studs are field welded and grout is poured in the cavity. Usually, one labor is required for shear studs and five labors and one grout pump is required for grouting.

7. Finally, guardrail is installed by three labors.

\subsubsection{Installation methods}

There are two important connection methods for installing FRP bridge deck panels: (i) connection between the decks and (ii) connection of the decks to girders. The two connection methods also vary depending on the manufacturer. Due to lack of performance data, it is not easy to say which connection method is more efficient or inefficient. However, it is possible to say that all manufacturers should improve the construction method of the field joints since 
delamination, debonding, and cracking of wearing surface have been reported on the field joints of FRP bridge deck panels for all manufacturers according to the results of the questionnaire survey.

\subsubsection{Connection of deck panels}

(1) Martin Marietta Composites (MMC)

Typical panel-to-panel connections are made by using 'Epoxy adhesive' in the tongueand-groove and then the holes are drilled through both sections and FRP dowel bars are placed in the hole. The reason for installing them is to protect the integrity of the bondline while 'Epoxy adhesive' cures. Finally, the FRP splice strips are installed over the field joints for durability (refer to Figure 6-1).

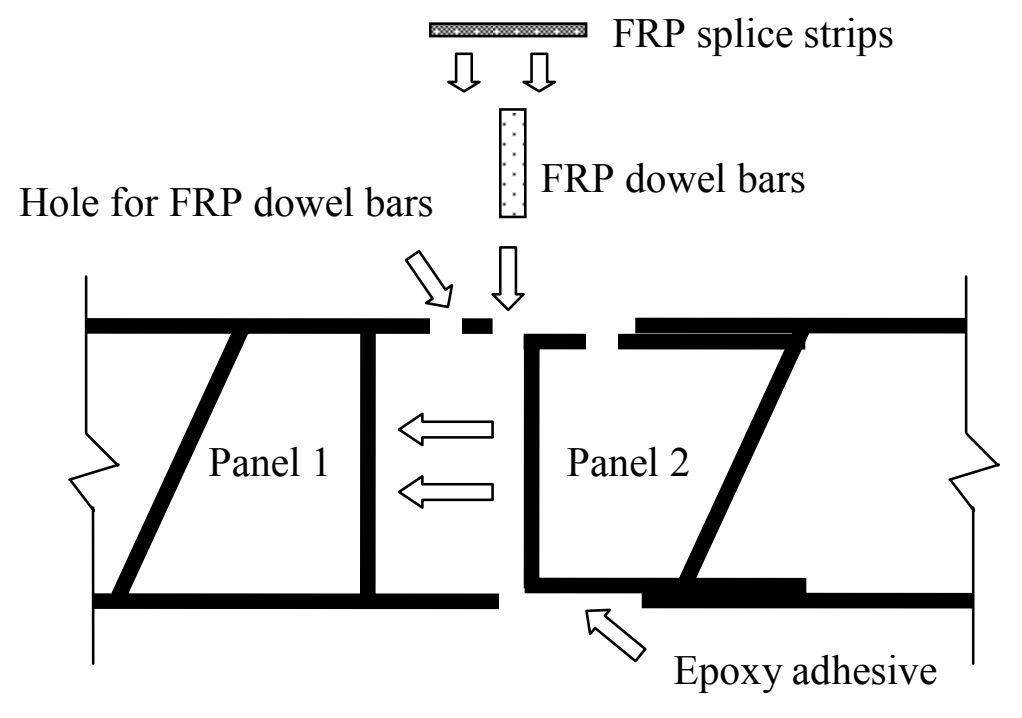

Figure 6-1 MMC joint system 
(2) Hardcore Composite Inc. (HCI)

Typically, panel-to-panel connections are made by using 'Epoxy adhesive' in the tongueand-groove. Finally, FRP splice plates are installed over the field joints for durability (refer to Figure 6-2)

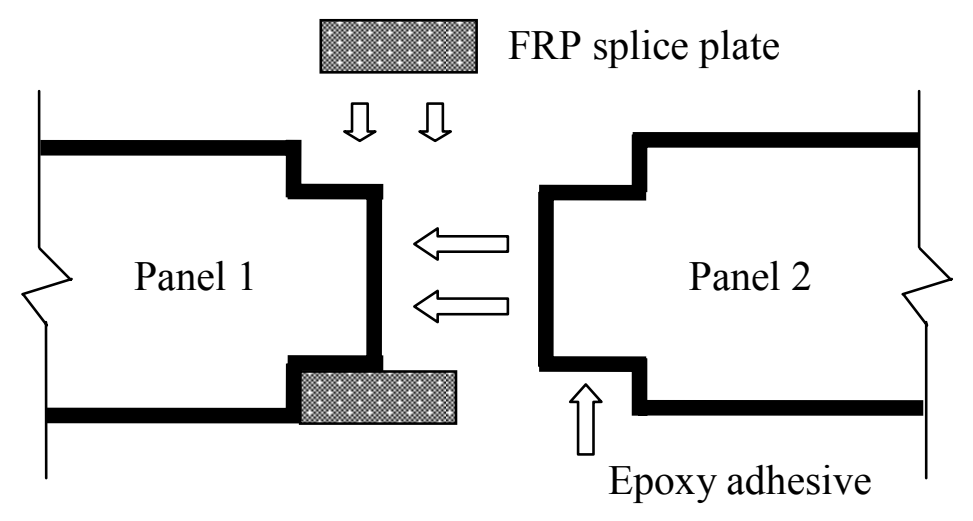

Figure 6-2 HCI joint system

(3) Kansas Structural Composites Inc. (KSCI)

The panel-to-panel connection method is somewhat similar to that of HCI except for using bolts and nuts instead of FRP splice plates.

(4) Creative Pultrusion Inc. (CPI)

The deck modules are connected with polyurethane adhesive in the tongue-and-groove (refer to Figure 6-3). 


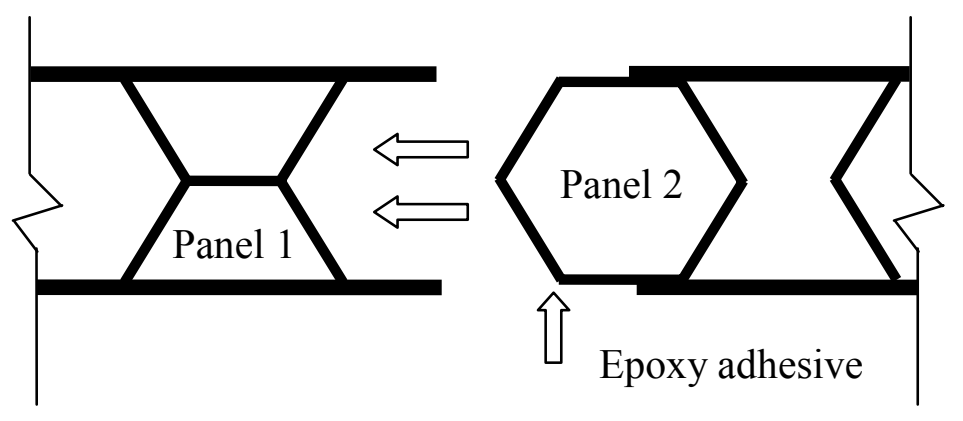

Figure 6-3 CPI joint system

(5) Infrastructure Composites International (ICI)

Pilogrip adhesive is used to connect the male and female ends of adjacent panels together (refer to Figure 6-4)

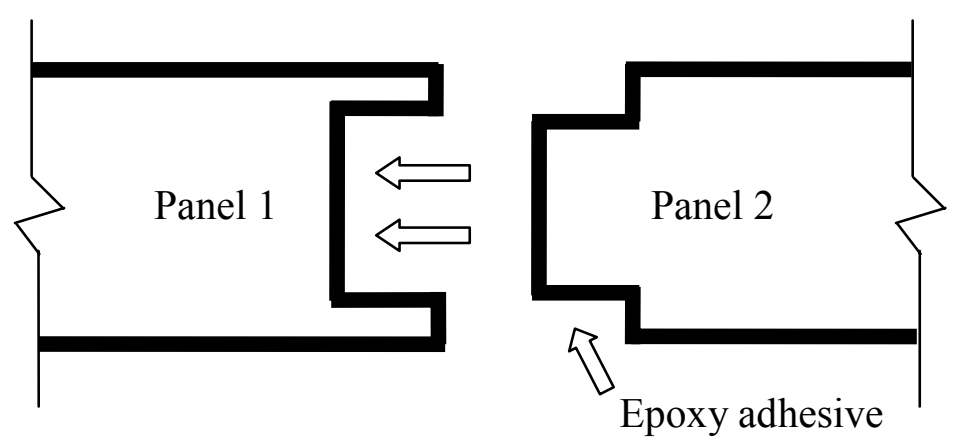

Figure 6-4 ICI joint system

\subsubsection{Connection of deck-to-girder}

(1) Martin Marietta Composites (MMC)

After the decks of MMC are in place, they are connected with the girders by using shear studs (Figure 6-5). As shown in Figure 6-6 (a), holes are cut into the deck at the factory for connection between deck and girder. As shown in Figure 6-6 (c), the shear studs are welded into the girders using a shear stud gun and then non-shrink grout is poured in the cavity as shown in Figure 6-6 (d). 


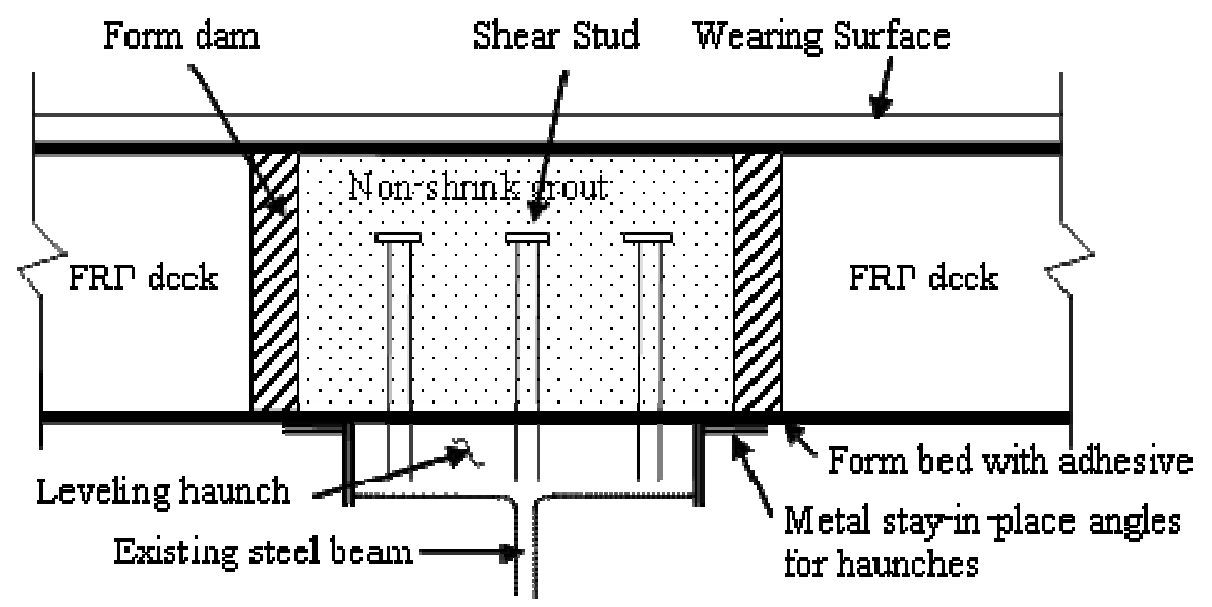

Figure 6-5 MMC deck-to-girder system

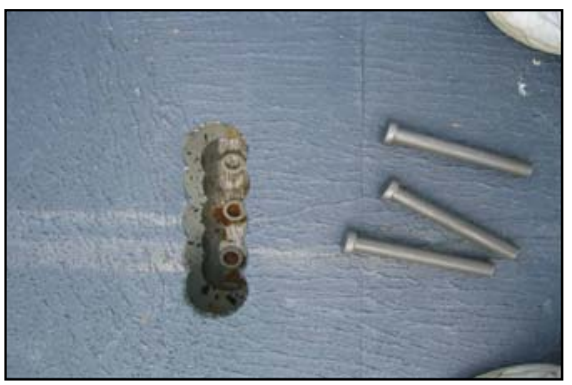

(a) Ready to use shear studs

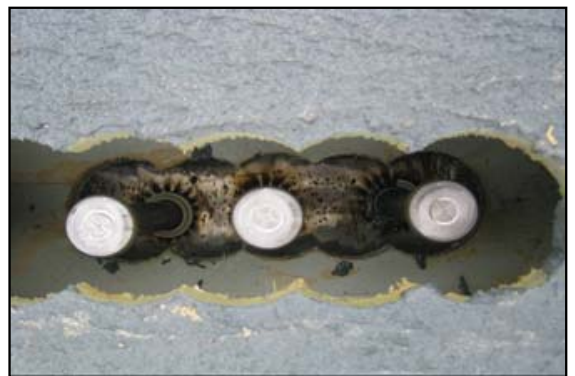

(b) After welding shear studs

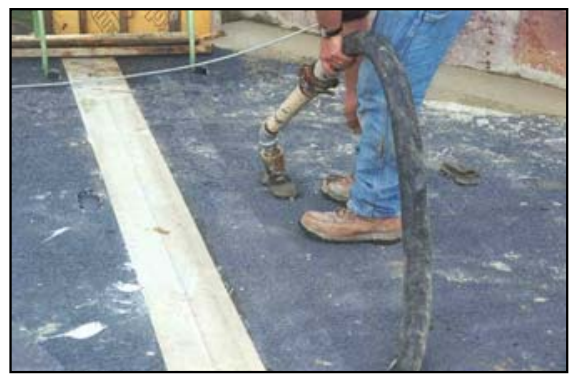

(d) Non-shrink grouting

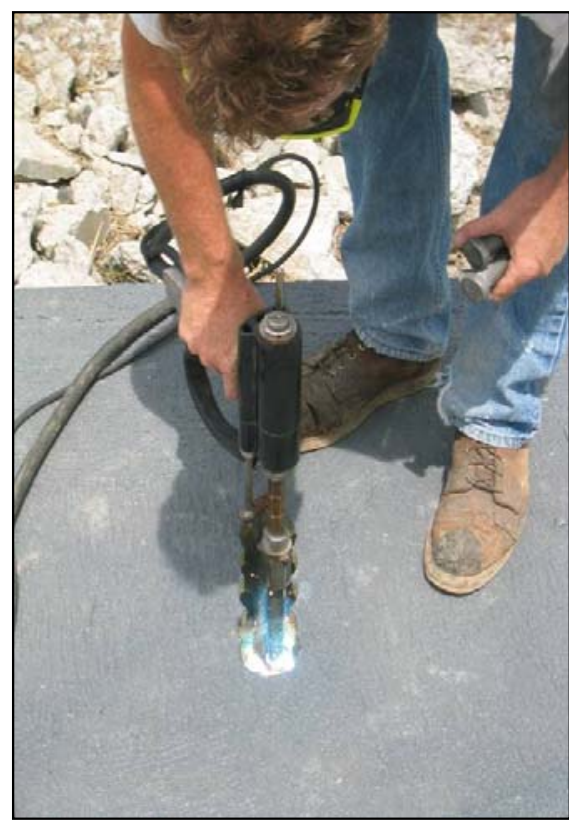

(c) Shear stud gun

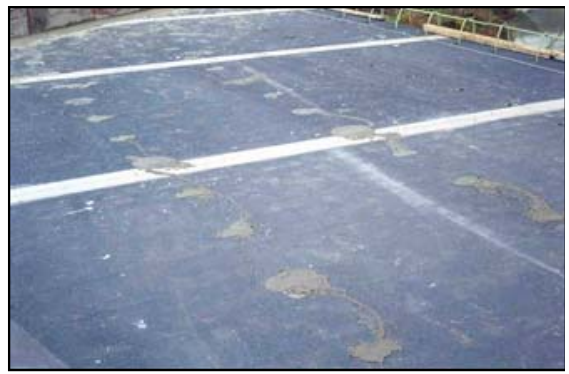

(e) After non-shrink grouting

Figure 6-6 Illustration of MMC deck-to-girder system 
(2) Hardcore Composite Inc. (HCI)

As shown in Figure 6-7, in the deck-to-girder connection, studs are welded into the concrete beams through predrilled stud holes in each of the panels. Finally, the studs are welded to the steel embedded in deck and to steel plates embedded in the concrete beam. Non-shrink grout is poured in the cavity

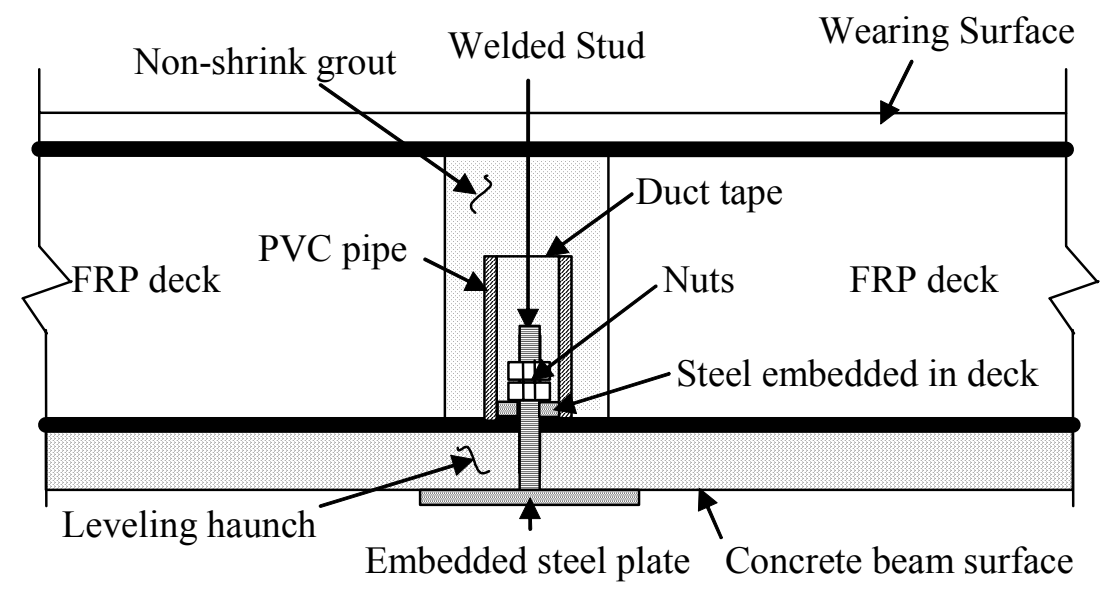

Figure 6-7 HCI deck-to-girder system

(3) Kansas Structural Composites Inc., (KSCI)

To connect deck-to-girder, blind fasteners were used at the joints. 'Blind fasteners' imply that access is needed from only one side of the work piece when they are installed. Polymer concrete is poured to fill the joints.

(4) Creative Pultrusion Inc. (CPI)

Unlike other manufacturers, CPI uses spacer wedges instead of a haunch in order to achieve the desired cross slope. The FRP bridge deck panels are placed on top of the spacer wedges and the shear studs are welded into the existing steel girders through predrilled stud holes in each of the panels. Two cardboard bulkheads are inserted into the deck section in order 
to make cavity for the grout and then non-shrink grout is poured in the cavity (refer to Figure 68)

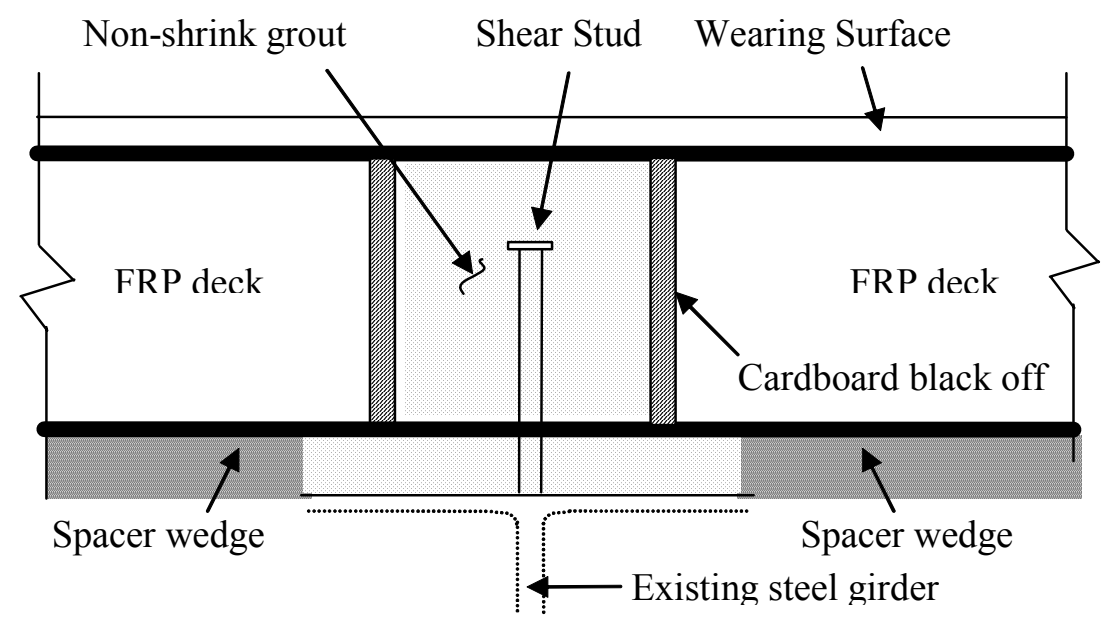

Figure 6-8 CPI deck-to-girder system

(5) Infrastructure Composites International (ICI)

Once the panels are in place, shear studs are welded into the girder flanges through predrilled holes in each of the panels. A plastic cylinder is inserted into the holes in order to make cavity for grout and then non-shrink grout is poured into the cavity.

\subsubsection{Material types}

With regard to material types used in FRP bridge deck panel construction, only material types for wearing surface were identified in this research. As mentioned earlier in this report, 'Bituminous' has been ranked as the most preferred material for wearing surface based on the questionnaire survey-I sent to the bridge engineers and county engineers. In addition, Polymer concrete, epoxy overlay, polymer modified asphalt, and latex modified concrete have been used as materials for the wearing surface. Due to insufficient performance data, it is difficult to say which material type is more efficient or inefficient. Even many State DOTs currently using FRP 
bridge deck panels have had maintenance problems with the wearing surface. This research found that 'Bituminous' material was preferred as wearing surface over other materials including 'Latex modified concrete', 'Epoxy overlay', and 'Polymer concrete.'

\section{$\underline{6.4 \text { Implementation }}$}

This research provides construction guidelines for FRP bridge deck panels that could be effectively used by INDOT. These guidelines identify (i) construction sequence, (ii) constructability issues, (iii) maintainability issues, (iv) operability issues, and (v) construction cost issues. Also this research provides information on the state of the art and manufacturing processes currently in use.

The productivity, man-hour requirement, and system bottlenecks for FRP bridge deck construction are determined by construction simulation study. The results obtained from this study could be used by INDOT to improve the productivity of FRP bridge deck construction in the future.

\section{$\underline{6.5 \text { Recommendations for future research }}$}

This research has identified state of the art (research and development) and state of practice of FRP bridge deck panels both in new bridges and in rehabilitation projects. During this research various issues with regard to constructability, operability, maintainability of FRP bridge deck panels were identified. However, in conducting this research, several limitations were also identified.

It was difficult for the research team to compile and analyze data on maintainability, operability, and life cycle cost of FRP bride decks because the new advanced materials have only 
been applied for highway bridge structures over the last decade in the United States and as such only a few State DOTs have experienced maintenance issues for the FRP bridge deck panels. Thus, it was difficult to prove the advantage of FRP bridge deck panels mentioned in literature review such as cost saving, less expense for maintenance than total replacement and long service life. This is one of the main obstacles in the application of FRP bridge deck panels. In order to enhance their application, the following research should be performed in the future.

1. Innovative modular systems to reduce high initial cost. If the material cost of FRP bridges will not decrease, their application may be limited to bridges of low volume rural types

2. Research on failure of the wearing surface

3. Integration of FRP bridge design, i.e., efficient design and characterization of panelto-panel joints and attachment of deck-to-girder is required

4. Development of design standards and guidelines

5. Benefit-Cost analysis for economical engineering

6. Develop an analytical model to predict the FRP bridge deterioration over time

7. Develop an analytical model to assess life cycle cost of FRP bridge deck panels. 


\section{Joint Transportation Research Program (JTRP)}

in Cooperation with the Indiana Department of Transportation and the Federal Highway Administration

\section{Constructability, Maintainability, and Operability of FIBER REINFORCED POLYMER (FRP) Bridge Deck PANELS}

\section{Questionnaire}
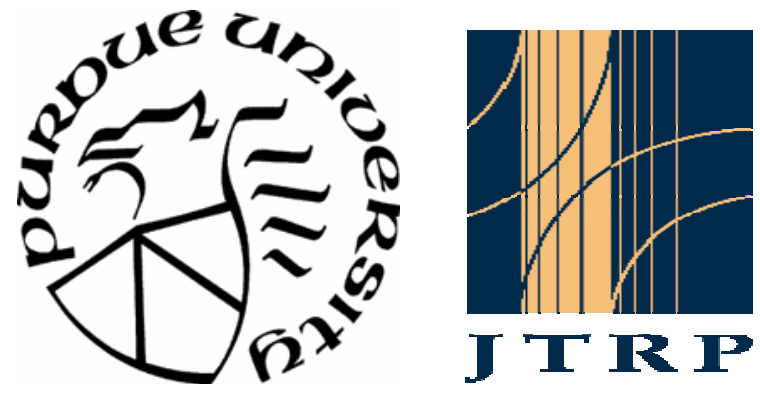

Conducted by:

Purdue University/Joint Transportation Research Program

Project Team

Dr. Makarand Hastak, Assistant Professor

(Div. of Constr. Engr. \& Mgmt. Purdue University) email: hastak@ecn.purdue.edu

Phone: 765-494-2244

Fax: (765) 494-0644

Research Assistant
Dr. Daniel W. Haplin. Professor (Head, Div. of Constr. Engr. \& Mgmt, Purdue University) email: halpin@ecn.purdue.edu Phone: 765-494-0641

Fax: (765) 494-0644

TaeHoon, , Ph. D student (Div. of Constr. Engr. \& Mgmt. Purdue University) email: hong7@purdue.edu

Purdue University, School of Civil Engineering, 550 Stadium Mall Drive, West Lafayette, Indiana 47907-2051 


\section{Purpose of Questionnaire}

This research is sponsored by the Joint Transportation Research Program in cooperation with the Indiana Department of Transportation and the Federal Highway Administration. This research is being conducted by Prof. Makarand(Mark) Hastak, Ph.D., CCE and Prof. Daniel W. Halpin, Ph.D., School of Civil Engineering, Purdue University.

The purpose of this survey is to collect objective and subjective data with regard to constructability, maintainability, operability of FRP (Fiber Reinforced Polymer) bridge deck panels, and the fabrication, construction methods, quality, safety, man-hour requirements, cost and productivity, as well as the skill level required in order to identify issues related to FRP bridge decks and to develop standard construction guidelines for FRP bridge deck construction.

Your input will assist in the development of a detailed report and research summary that will compile the research findings. The final report will address current state of the art, state of practice of fabrication, and use of FRP bridge decks in addition to development of standard construction guildlines for FRP bridge deck. Please, complete the following information as described. Please take a few minutes to complete the survey. Where numerical data is requested, reasonable estimates and/or ranges are acceptable. Please return the survey by e-mail or regular mail at the address provided on the first page.

\section{Direction}

Condition Rate(Table 1) SOURCE: Federal Highway Administration (FHWA). (2002) Recording and Coding Guide for the Structure Inventory and Appraisal of the Nations Bridges.

Table 1 General Bridge condition ratings

\begin{tabular}{c|l}
\hline \hline Code & \multicolumn{1}{c}{ Description } \\
\hline \hline $\mathrm{N}$ & Not Applicable \\
\hline 9 & Excellent Condition \\
\hline 8 & Very Good Condition - no problems noted \\
\hline 7 & Good Condition - some minor problems \\
\hline 6 & Satisfactory condition - structural elements show some minor deterioration \\
\hline 5 & $\begin{array}{l}\text { Fair condition - all primary structural elements are sound but may have minor } \\
\text { selection loss, cracking, spalling or scour. }\end{array}$ \\
\hline 4 & Poor Condition - advanced section loss, deterioration, spalling or scour \\
\hline 3 & $\begin{array}{l}\text { Serious Condition - loss of section, deterioration, spalling or scour have seriously } \\
\text { affected primary structural components. Local failures are possible. Fatigue cracks in } \\
\text { steel or shear cracks in concrete may be present. }\end{array}$ \\
\hline 2 & $\begin{array}{l}\text { Critical Condition - advanced deterioration of primary structural elements. Fatigue } \\
\text { cracks in steel or shear cracks in concrete may be present or scour may have removed } \\
\text { substructure support. Unless closely monitored it may be necessary to close the } \\
\text { bridge until corrective action is taken. }\end{array}$ \\
\hline 1 & $\begin{array}{l}\text { "IMMINENT” Failure Condition - major deterioration or section loss present in } \\
\text { critical structural components or obvious vertical or horizontal movement affecting } \\
\text { structure stability. Bridge is closed to traffic but corrective action may put back in } \\
\text { light service. }\end{array}$ \\
\hline 0 & Failed Condition - out of service -beyond corrective action. \\
\hline \hline
\end{tabular}




\section{General Information}

Organization:

Respondent's name:

Position/Title:

Address:

Tel:

Fax:

E-mail:

\section{Part 1: General information of FRP bridge deck panels}

1. Has your DOT used FRP bridge deck panels?

Yes $\square$ No

(If no, go to question 2. If yes, go to question 3.)

2. If your DOT has not installed any FRP bridge deck panels to date, is there any reason? Please specify:

3. How many FRP bridge deck panels have been scheduled for installation in the near future (within 5 years)?

4. Please indicate the following advantages of FRP bridge deck panels by using a scale of priority from 1-5 where 1 = least priority and 5 = top priority.

\begin{tabular}{l|l}
\hline \hline \multicolumn{1}{c|}{ Advantage } & Priority \\
\hline \hline Increased capacity for live load with possible elimination of weight restrictions & \\
\hline Fast installation due to modular, prefabricated nature, and reduced traffic delay & \\
\hline Cost saving, less expense for maintenance than total replacement & \\
\hline Good durability, fatigue resistance, long service life, resistance to de-icing salts & \\
\hline Less environmental impact and fewer permits required than replacement & \\
\hline \hline
\end{tabular}

5. Where does your DOT most commonly use the FRP composite bridge deck panels? (Check all which apply)

$\square \quad$ All multispan precast bridges
$\square \quad$ Interstates
$\square \quad$ High volume urban
$\square \quad$ Low volume urban
$\square \quad$ High volume rural
$\square \quad$ Low volume rural


6. What were the criteria of your state for selecting a bridge for FRP bridge deck panel application?

Please specify:

7. How many FRP bridge deck panels have been installed by your state?

\begin{tabular}{|c|c|c|c|c|c|c|c|c|}
\hline No. & $\begin{array}{c}\text { Project/Bridge } \\
\text { Name }\end{array}$ & Location & Date Installed & $\begin{array}{c}\text { Duration } \\
\text { (Day) }\end{array}$ & $\begin{array}{l}\text { \# of } \\
\text { person }\end{array}$ & $\begin{array}{l}\text { Hours/ } \\
\text { person }\end{array}$ & $\begin{array}{l}\text { Manufacturer } \\
\text { (Supplier) }\end{array}$ & Contractor \\
\hline (1) & & & 1 & & & & & \\
\hline$(2)$ & & & 1 & & & & & \\
\hline (3) & & & 11 & & & & & \\
\hline (4) & & & 11 & & & & & \\
\hline (5) & & & 11 & & & & & \\
\hline (6) & & & 11 & & & & & \\
\hline (7) & & & 11 & & & & & \\
\hline (8) & & & 11 & & & & & \\
\hline (9) & & & 1 & & & & & \\
\hline (10) & & & 1 & & & & & \\
\hline
\end{tabular}

8. Does your state have any preference in the supplier of FRP bridge deck panels? (Please indicate the reason briefly) 


\section{Part 2: Constructability of FRP bridge deck panels}

9. What deck structure types have been replaced by FRP bridge deck panels? (Check all which apply)

$\begin{array}{ll}\square & \text { Concrete Cast-in-place } \\ \square & \text { Concrete Precast Panels } \\ \square & \text { Open Grating } \\ \square & \text { Closed Grating } \\ \square \quad \text { Steel plate (includes orthotropic) } \\ \square \quad \text { Corrugated steel } \\ \square \quad \text { Aluminum } \\ \square \quad \text { Wood or Timber } \\ \square \quad \text { Other }\end{array}$

Please specify:

10. What type of construction sequence/method is employed for the connection of the FRP bridge deck panels? (Check all which apply)

Epoxy adhesive

Tongue-and-groove ends

Bolts and nuts

Epoxy-bonded Diamond-shaped Douglas-fir Inserts

Other

Please specify:

11. What type of construction sequence/method is employed for the connection between the FRP bridge deck panels and girder or stringer?

$\square \quad$ Epoxy adhesive

$\square \quad$ Blind Fasteners

$\square \quad$ Other

Please specify:

12. What is the material of the wearing surface applied for FRP bridge deck panels in your state?

$\square$ Latex Modified Concrete $\square$ Polymer Concrete $\quad \square \quad$ Bituminous

$\square$ Low Slump Concrete $\quad \square \quad$ Epoxy Overlay

$\square$ Other(specify)

12-1. What wearing surface aggregate is used?

Please specify:

12-2. Who is a manufacturer for the wearing surface?

Please specify: 
13. Does your state have a specific method of FRP bridge deck panel installation? $\square$ Yes $\square$ No If yes, please describe the steps included in your states installation procedure or method?

14. What kind of manufacturing processes were used to produce the FRP bridge deck panels used by your state? (Check all which apply)

\section{Manufacturing process}

\section{Opening Molding}

$\begin{array}{cc}\square & \text { Hand Lay-up } \\ \square & \text { Chopped Laminate Process } \\ & \text { Filament Winding } \\ & \text { Closed Molding } \\ \square & \text { Compression molding } \\ \square & \text { Pultrusion } \\ \square & \text { Reinforced Reaction Injection Molding (RRIM) } \\ \square & \text { Resin Transfer Molding (RTM) } \\ \square & \text { Vacuum Assisted Resin Transfer Molding (VARTM) } \\ \square & \text { Vacuum Bag Molding } \\ \square & \text { Vacuum Infusion Processing } \\ \square & \text { Continuous Lamination } \\ \text { Other (specify) _ }\end{array}$

15. What is the thickness of top, bottom, and diagonal plates of the FRP bridge cross-section type used in your state? (Please refer to below Figure)

Thickness of top $=(\quad)$ in.

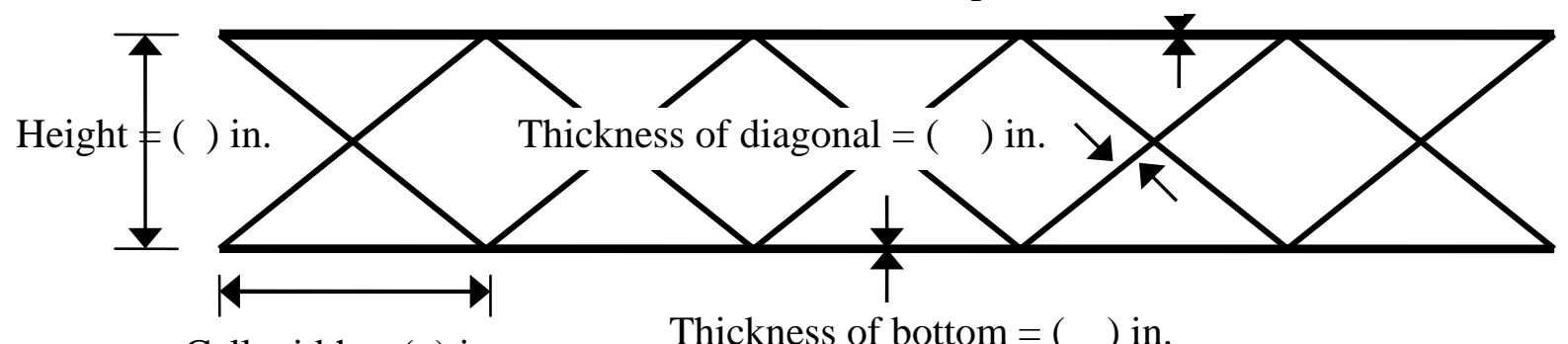

Cell width $=($ ) in.

Thickness of bottom $=(\quad)$ in.

Please specify: 
16. What are the construction specifications of FRP bridge deck panels installed by your DOT? (Please specify)

16-1. Standard Specification:

16-2. Specific provision (Warranty from Manufactures):

16-3. Experimental Features (Warranty from FHWA):

16-4. Deflection limit, design load (HS25, HS 20, etc.) and other:

17. Please indicate the size and the number of FRP bridge deck panels.

\begin{tabular}{c|c|c|c|c|c}
\hline \hline \multirow{2}{*}{ No. } & Project/Bridge & \# of & \multicolumn{2}{|c|}{ Size of FPR bridge deck panels (Feet) } & Used/span \# of FRP \\
& Name & spans & Length of panel & Width of panel & bridge deck panels \\
\hline \hline$(1)$ & & & & & \\
\hline$(2)$ & & & & & \\
\hline$(3)$ & & & & & \\
\hline$(4)$ & & & & & \\
\hline$(5)$ & & & & & \\
\hline$(6)$ & & & & & \\
\hline$(7)$ & & & & & \\
\hline$(8)$ & & & & & \\
\hline$(9)$ & & & & & \\
\hline$(10)$ & & & & \\
\hline
\end{tabular}

18. What kind of barriers were encountered in installing the FRP bridge deck panels? (Check all which apply)

\begin{tabular}{l|l|l}
\hline \hline & \multicolumn{1}{|c|}{ Barriers } & Please specify \\
\hline \hline$\square$ & Design barriers & \\
\hline$\square$ & Construction barriers & \\
\hline$\square$ & Labor barriers & \\
\hline$\square$ & Vendor barriers & \\
\hline$\square$ & Other & \\
\hline
\end{tabular}


19. Please check the cross-section type used in your state. (Check all which apply)

\begin{tabular}{|c|c|c|}
\hline & FRP Bridge deck cross-section type \\
\hline$\square$ & $\begin{array}{c}\text { FHWA-Long Beach State Prototype } \\
\text { [X-type] }\end{array}$ \\
\hline$\square$ & $\begin{array}{c}\text { Martin-Marietta } \\
\text { [Box-type] } \\
\text { WVU-Creative Pultrusions } \\
\text { [Hexagon-type] }\end{array}$ \\
\hline$\square$ & $\begin{array}{c}\text { Georgia Tech-Atlantic Research Navy } \\
\text { Deck LV-type] }\end{array}$ \\
\hline$\square$ & $\begin{array}{c}\text { Georgia Tech-Strongwell } \\
\text { [Double I-Beams type] } \\
\text { Kansas Structural Composites } \\
\text { [Vertical Sine-Wave] }\end{array}$ \\
\hline$\square$ & \begin{tabular}{c} 
Other (Specify): \\
\hline
\end{tabular} \\
\hline
\end{tabular}

20. How does beam spacing affect the slab thickness in FRP bridge deck panels?

Please specify:

21. Please answer the following questions on delivery issues of FRP bridge deck panels.

21-1: What is the method of delivery of FRP bridge deck panels from factory to job site?

Please specify

21-2: What are the maximum size of FRP bridge deck panels transported and the cost of transportation?

Please specify

21-3: How much time is needed to delivery FRP bridge deck panels from factory to job site?

Please specify 
22. Where there any other constructability issues not covered above?

Please specify:

\section{Part 3: Maintainability and Operability of FRP bridge deck panels}

23. What was the condition rate of bridge decks when FRP bridge deck panels were considered for replacing deteriorated bridge decks? (Refer to Table 1)

$\square 9 \square 8 \square 7 \square 6 \square 5 \square 4 \square 3 \square 2 \square 1 \square 0$

22-1. What was the condition rate of the substructure when FRP bridge deck panels were selected? (Refer to Table 1)

\section{$9 \square 8 \square 7 \square 6 \square 5 \square 4 \square 3 \square 2 \square 1 \square 0$}

23. Does your DOT have a specific analysis procedure or method established in order to inspect, maintain, and repair the FPR bridge deck panels after installation? $\quad \square$ Yes $\square$ No

If yes, please describe what are the steps included in your DOT's analysis procedure or method?

24. In terms of inspection and monitoring the service of FRP bridge deck panels, when are the following (or other) actions taken by your DOT?

[FA: age of first application, FT: Frequency thereafter (Years)]

\begin{tabular}{|c|c|c|c|}
\hline \multicolumn{2}{|c|}{ Monitoring } & Actions & Year \\
\hline \multirow{4}{*}{$\begin{array}{l}\text { Regular } \\
\text { inspection }\end{array}$} & $\square$ & Tap test & FA: $\quad F T:$ \\
\hline & $\square$ & Load Tests & FA: $\quad$ FT: \\
\hline & $\square$ & Other(Specify) & FA: $\quad F T:$ \\
\hline & $\square$ & Other(Specify) & FA: $\quad F T:$ \\
\hline
\end{tabular}

25. Has your DOT identified any issues/problems with maintenance and operation after the FRP bridge deck panels were installed? $\square$ Yes $\square$ No

If yes, please describe the issues as well as where and when the issues happened? 
26. Please indicate the type and timing of maintenance undertaken for FRP bridge deck panels since construction.

[FA: age of first application, FT: Frequency thereafter (Years)]

\begin{tabular}{|c|c|c|}
\hline Maintenance & Type of Maintenance & $\begin{array}{l}\text { Timing for Maintenance } \\
\text { (Years) }\end{array}$ \\
\hline \multirow{2}{*}{$\begin{array}{l}\text { Preventive } \\
\text { Maintenance }\end{array}$} & & FA: $\quad$ FT: \\
\hline & & FA: \\
\hline \multirow{2}{*}{$\begin{array}{l}\text { Corrective } \\
\text { Maintenance }\end{array}$} & & FA: $\quad$ FT: \\
\hline & & FT: \\
\hline
\end{tabular}

27. What is the average service life of FRP bridge deck panels compared to concrete bridge decks in your state? (If historical data, with regard to service life of concrete bridge decks or FRP bridge deck panels, is not available, please answer the following questions based on your experience.)

- Average service life of Concrete Bridge Deck:

years

- Expected service life of FRP Composite Bridge Deck: years

\section{Part 4: Life Cycle Cost (LCC) of FRP bridge deck panels}

28. What is the expected unit life cycle cost to date of FRP bridge deck panels installed in your DOT (e.g., dollars per square feet): Initial construction cost, user cost, maintenance cost?

\begin{tabular}{|c|c|c|c|c|}
\hline No. & $\begin{array}{c}\text { Project/ } \\
\text { Bridge Name }\end{array}$ & Life Cycle Cost Items & Unit Cost & Total Cost \\
\hline \multirow{6}{*}{ (1) } & & 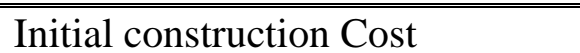 & & \\
\hline & & Engineering and Fabrication Cost & & \\
\hline & & User Cost & & \\
\hline & & Maintenance Cost & & \\
\hline & & Other & & \\
\hline & & Other_- & & \\
\hline \multirow{6}{*}{ (2) } & & $\begin{array}{l}\text { Initial construction Cost } \\
\text {. }\end{array}$ & & \\
\hline & & Engineering and Fabrication Cost & & \\
\hline & & User Cost & & \\
\hline & & Maintenance Cost & & \\
\hline & & Other & & \\
\hline & & Other_ & & \\
\hline \multirow{6}{*}{ (3) } & & $\begin{array}{l}\text { Initial construction Cost } \\
\text { con }\end{array}$ & & \\
\hline & & Engineering and Fabrication Cost & & \\
\hline & & User Cost & & \\
\hline & & Maintenance Cost & & \\
\hline & & Other & & \\
\hline & & Other & & \\
\hline
\end{tabular}




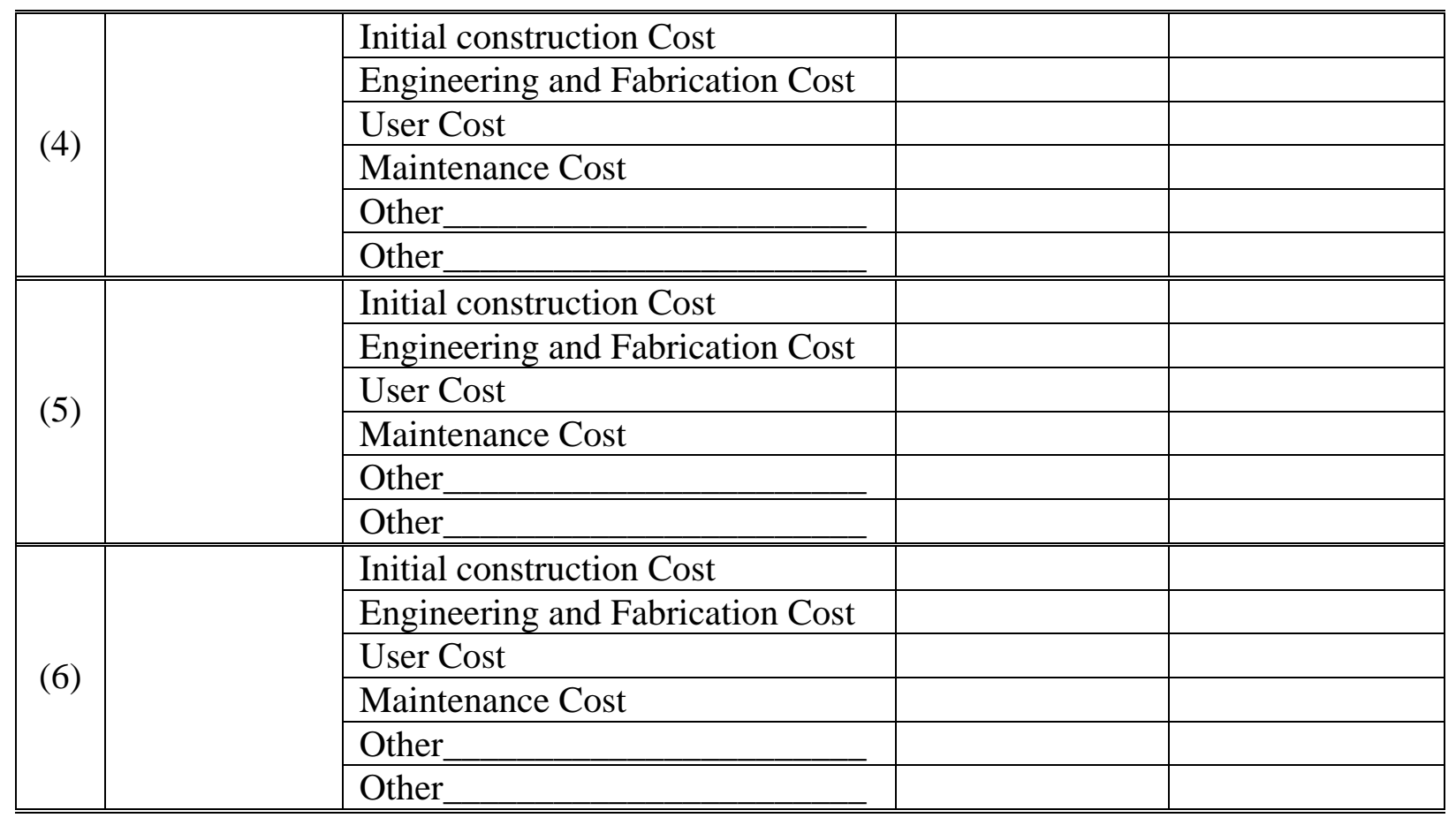

29. Would you be willing to participate in a case study and/or share previous historical data ${ }^{1}$ with regard to FRP bridge deck panels with the JTPR research team? Yes $\square \quad$ No $\square$ If yes, please provide us with the following information:
Contact Name :
E-mail :
Telephone
Fax :

\title{
Thank you for your input
}

Please return the finished questionnaire by to:

\author{
E-mail \\ hong7@purdue.edu, email: \\ hastak@ecn.purdue.edu \\ Dr. Makarand Hastak, Assistant Professor \\ Address \\ (Div. of Constr. Engr. \& Mgmt. Purdue University) \\ Phone: 765-494-2244 \\ Fax: (765) 494-0644
}

\footnotetext{
${ }^{1}$ The historical data may include National Inventory databases on FRP bridge deck panels in your DOT
} 
Appendix B: Questionnaire-II

\section{Joint Transportation Research Program (JTRP)}

in Cooperation with the Indiana Department of Transportation and the Federal Highway Administration

\section{Constructability, Maintainability, and Operability of FIBER REINFORCED POLYMER (FRP) Bridge Deck PANELS}

\section{Questionnaire \# 2}

(Manufacturer)
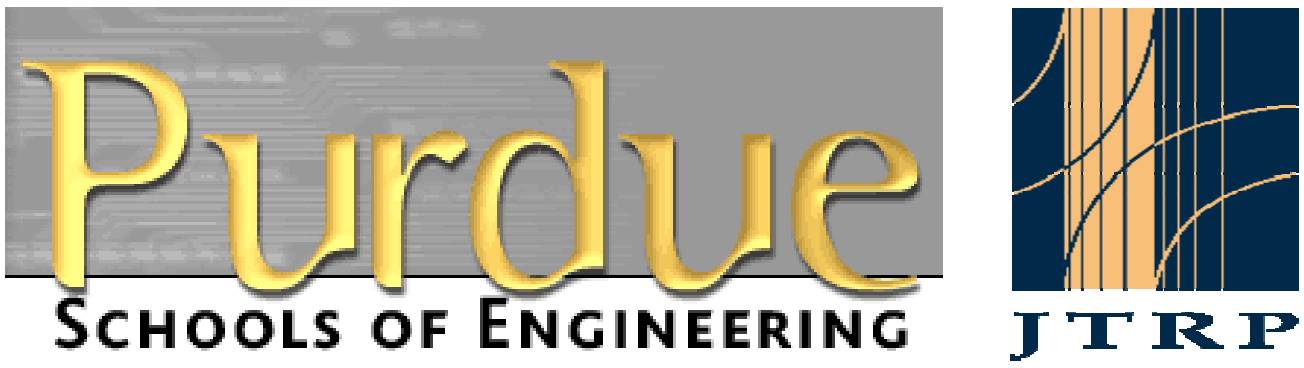

Conducted by:

\section{Purdue University/Joint Transportation Research Program}

Please return the finished questionnaire by March. 31. 2004 to:

Dr. Makarand (Mark) Hastak

Dr. Makarand Hastak, Assistant Professor (Div. of Constr. Engr. \& Mgmt. Purdue University) email: hastak@ecn.purdue.edu

Phone: 765-494-2244

Fax: (765) 494-0644
Project Team

TaeHoon Hong, Research Assistant, Ph.D. Candidate

Phone: 765-496-2046, E-mail: hong7@purdue.edu

Purdue University, School of Civil Engineering, 550 Stadium Mall Drive, West Lafayette, Indiana 47907-2051 


\section{General Information}

Organization:

Respondent's name:

Position/Title:

Address:

Tel: Fax: E-mail:

\section{General Information of FRP bridge deck panels}

1. What are the advantages of FRP bridge deck panels produced by your company?

Advantage

2. What is the expected service life of FRP bridge deck panels produced by your company? ( ) years

3. On what type of bridges are your products being used? (i.e., high volume rural, high volume urban, low volume rural, low volume urban) Please describe the project where your products were used

\begin{tabular}{l|l|l|l|l|l|l}
\hline \hline & Project Name & Location & ADT & $\begin{array}{c}\text { Design } \\
\text { load }\end{array}$ & $\begin{array}{c}\text { Deflection } \\
\text { limit }\end{array}$ & $\begin{array}{c}\text { Bridge types / } \\
\text { Volume }\end{array}$ \\
\hline \hline$(1)$ & & & & & & \\
\hline$(2)$ & & & & & & \\
\hline$(3)$ & & & & & & \\
\hline$(4)$ & & & & & & \\
\hline$(5)$ & & & & & \\
\hline \hline
\end{tabular}

Note: Please use additional sheets as necessary

4. How many FRP bridge deck panels have been scheduled for installation in the near future using your product (within 5 years)? ( )

\section{Constructability Issues of FRP bridge deck panels}

5. What is the best material for wearing surface for the FRP bridge deck panels made out of your product?

(1) Latex modified concrete (2) Polymer Concrete (3) Bituminous (4) Epoxy overlay

(5) Conventional asphalt (6) Polymer modified asphalt (7) Other

6. What are the construction specifications for the FRP bridge deck panels installed by your company? Please specify standard specifications 
7. Do you offer warranty with your product? Please specify

8. What kinds of problems were encountered in installing the FRP bridge deck panels? (i.e., design barriers, construction barriers, labor barriers, vendor barriers, other)

9. What types of thermoset resin have been used in your FRP bridge deck panels?

(1) Polyester (2) Vinly Ester (3) Epoxy (4) Phenolic (5)Polyurthane (6)Other

Please describe why your company prefers to use these products?

10. What kinds of Fibers have been used in your FRP bridge deck panels?

(1) Glass (2) Carbon (3)Aramid (4) Other

Please describe why your company prefers to use these products?

11. Please explain the railing construction method? (i.e., attached to the deck or cantilevered from the beams)

12. What types of safety test have been performed on your guardrail design?

13. What type of equipment is required for the installation of FRP bridge deck panels?

14. What type of crew is required for the installation of FRP bridge deck panels? (Please specify the skill type, number of labors and equipments involved in the crew)

15. What productivity is expected from the crew mentioned above? 
16. Even though FRP composite materials have a lot of advantages over conventional material in construction, the acceptance of their application has been conspicuously slow. What are the major obstacles in their application?

(1) High initial cost (2) Current low bidding practice in the US (3) Lack of material and design specifications (4) other

\section{Operability Issues of FRP bridge deck panels bridge deck panels}

17. What is the effect of fuel, oil and grease on your FRP bridge deck panels?

18. What is the procedure of snow removal for your FRP bridge deck panels?

19. Does it get affected by salt and other chemicals for snow removal?

20. How do you facilitate water drainage from your installed FRP bridge deck panels?

\section{Maintainability Issues of FRP bridge deck panels}

21. Who has the responsibility for the maintenance problems?

22. What general maintenance practices do you recommend for your FRP bridge deck panels?

23. Do you provide assistances in the maintenance activities suggested above?

24. Does your company have a specific procedure or method established in order to inspect, maintain, and repair the FRP bridge deck panels after installation? $\square$ Yes $\square$ No

If yes, please describe the procedure or method

If no, please describe how your company can deal with maintenance problems. 
25. Has your company collected inspection data on completed projects? (i.e., condition rate per year) $\square$ Yes $\square$ No

If yes, please describe what inspection data are collected by your company.

26. Has your company identified any issues/problems with regard to maintenance and operation after FRP bridge deck panels were installed? $\square$ Yes $\square$ No

If so, please describe the issues as well as where and when the issues happened?
(1) Project Name
Location
Type of maintenance
Timing of maintenance
Cost of maintenance
Method of maintenance
Maintained by
(2) Project Name
Location
Type of maintenance
Timing of maintenance
Cost of maintenance
Method of maintenance
Maintained by
(3) Project Name
Location
Type of maintenance
Timing of maintenance
Cost of maintenance
Method of maintenance
Maintained by
(4) Project Name
Location
Type of maintenance
Timing of maintenance
Cost of maintenance
Method of maintenance
Maintained by
(5) Project Name
Location
Type of maintenance
Timing of maintenance
Cost of maintenance 
Method of maintenance

Maintained by

\section{Note: Please use additional sheets as necessary}

27. Has your company experienced the replacement of partial section in FRP bridge deck panels? $\square$ Yes $\square$ No

If yes, please describe the construction procedure for the replacement.

\section{Life Cycle Cost Issues of FRP bridge deck panels}

28. What is average initial construction cost of FRP bridge deck panels produced by your company? (i.e., dollars per square feet) If there are any other costs related to installing FRP bridge decks such as engineering and fabrication cost, please describe the cost and item

Initial construction cost

Engineering and Fabrication Cost Other cost

29. Has your company taken any steps (as in research or technology) to reduce high initial cost? $\square$ Yes $\square$ No

If yes, please describe the research or technology development.

30. What is currently the best method to reduce high initial cost in your company?

31. What are the major reasons for high initial cost (i.e., manufacturing, delivery, size etc.)? Please explain 


\section{Joint Transportation Research Program (JTRP)}

in Cooperation with the Indiana Department of Transportation and the Federal Highway Administration

Constructability, Maintainability, and Operability of FIBER REINFORCED POLYMER (FRP) Bridge Deck PANELS

\section{Questionnaire \# 3}
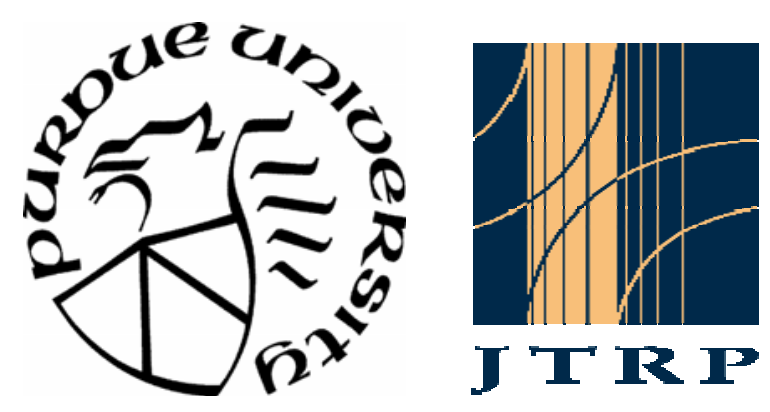

Conducted by:

Purdue University/Joint Transportation Research Program

Please return the finished questionnaire by to:

\section{Project Team}

Dr. Makarand Hastak, Assistant Professor (Div. of Constr. Engr. \& Mgmt. Purdue University) email: hastak@ecn.purdue.edu

Phone: 765-494-2244

Fax: (765) 494-0644
Dr. Daniel W. Haplin. Professor (Head, Div. of Constr. Engr. \& Mgmt, Purdue University) email: halpin@ecn.purdue.edu

Phone: 765-494-0641

Fax: (765) 494-0644

Purdue University, School of Civil Engineering, 550 Stadium Mall Drive, West Lafayette, Indiana 47907-2051 


\section{Question Part 1: Duration (Minutes) -How much time did it need to finish a certain work?}

1. How long would it take to unload the panels on the job site?

Minimum ( ) minutes Most Likely ( ） minutes Maximum ( ) minutes

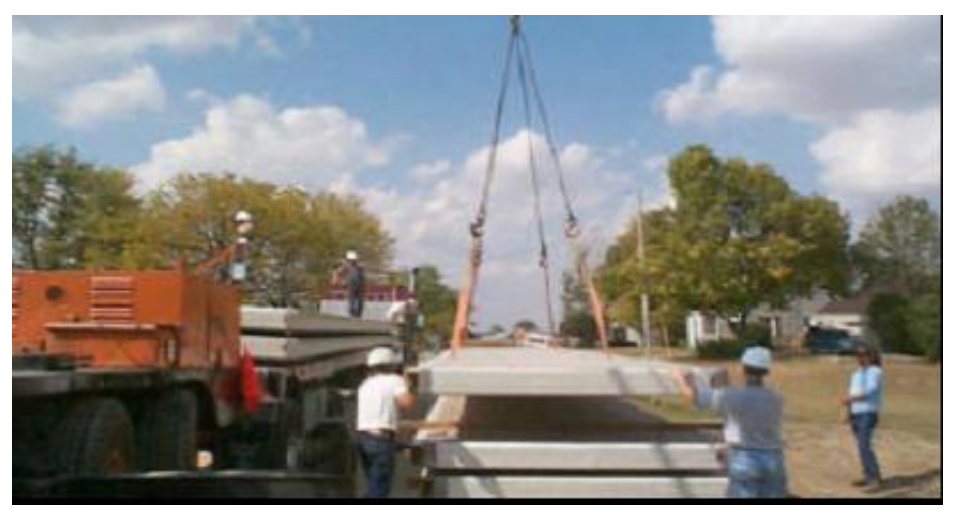

2. How long would it take to lift the FRP bridge deck panel (32.6' long 8' wide) by using a crane? (Time for 1 panel)

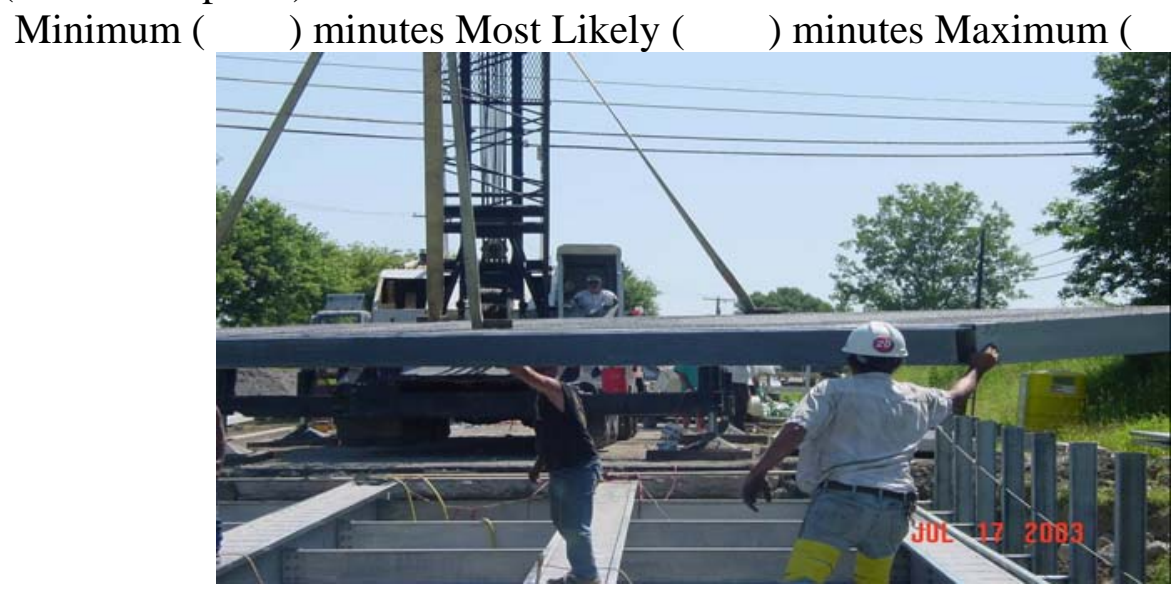

) minutes

3. How long would it take to place the FRP bridge deck panel (32.6' long 8' wide) into a girder or stringer by using a crane? (Time for 1 panel)

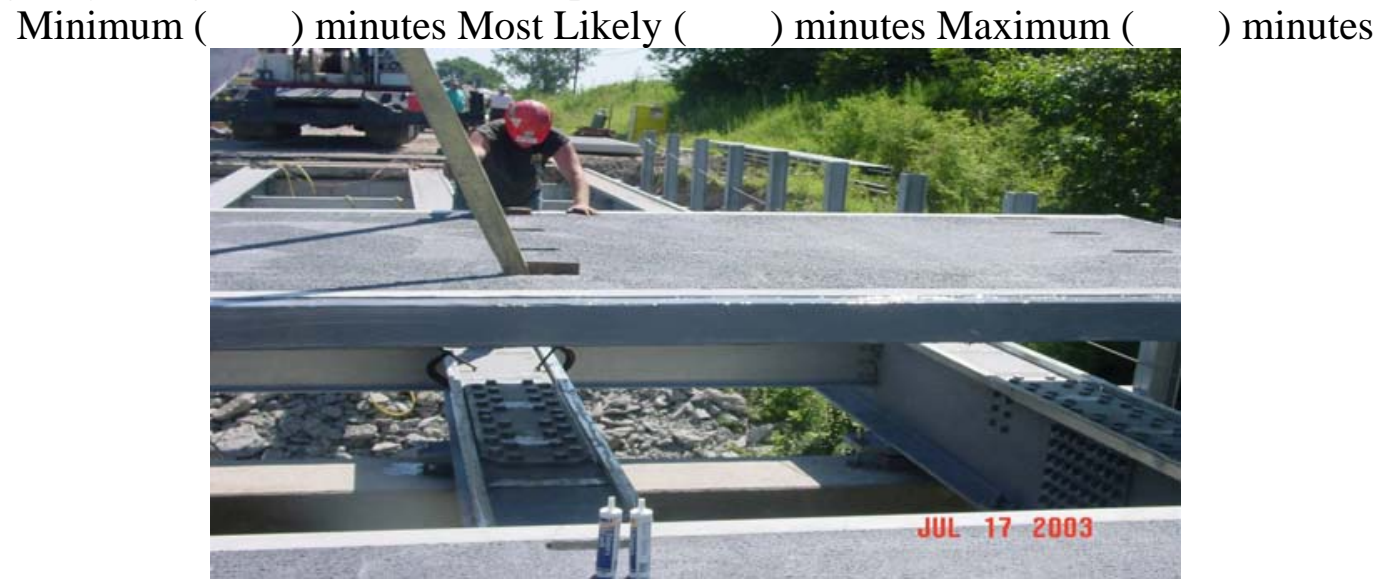


4. How long would it take to align the FRP bridge deck panel (32.6' long 8' wide) into position by using a jack? (Time for 1 panel)

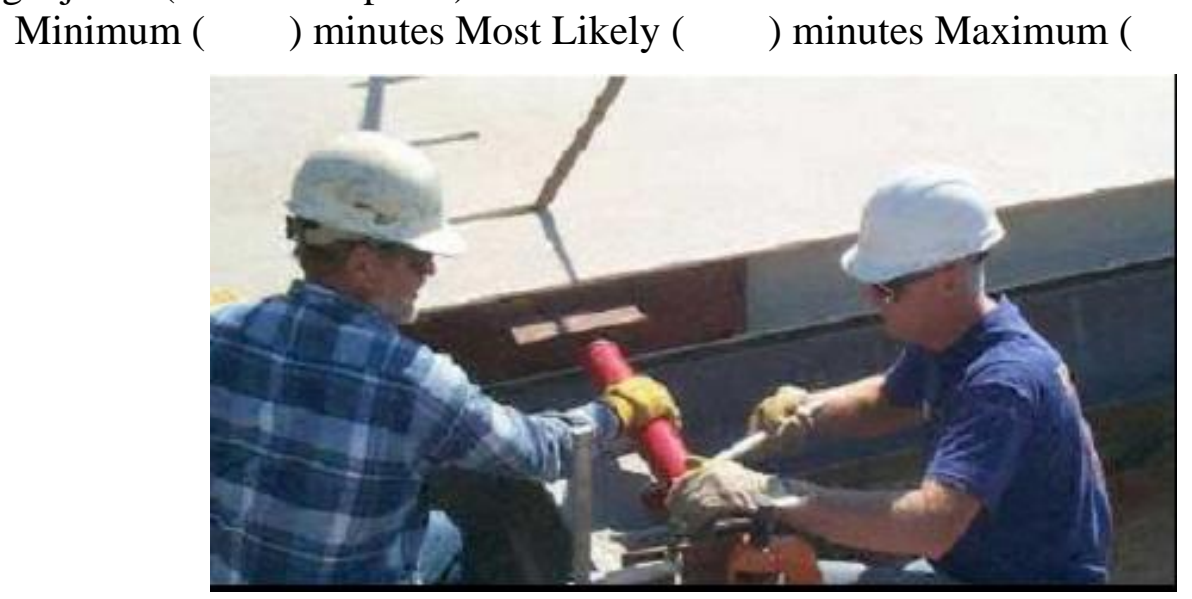

5. How long would it take to install the FRP dowel bars in the lips of the field joints? (Time for entire panels)

Minimum ( ) minutes Most Likely ( ） minutes Maximum ( ） minutes

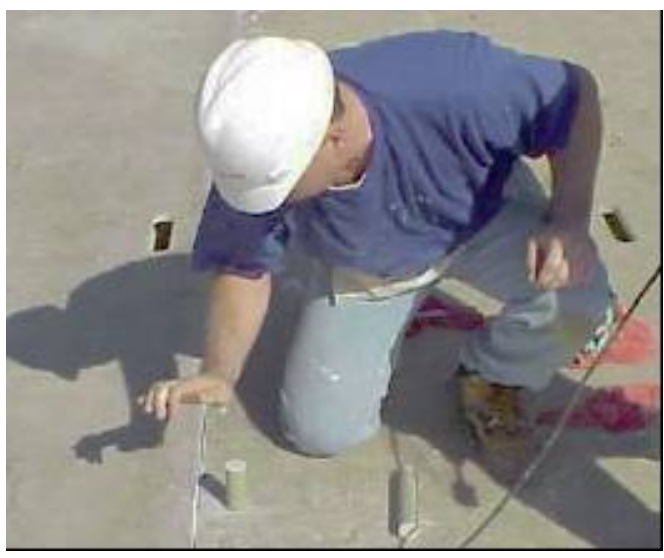

6. How long would it take to install FRP splice strips in the lips of the field joints? (Time for entire panels)

Minimum ( ） minutes Most Likely ( ～） minutes Maximum ( ） minutes

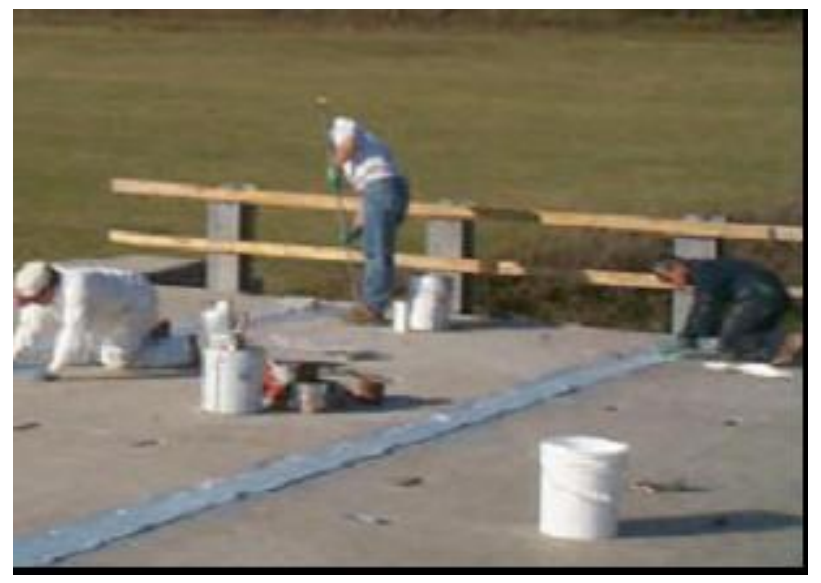


7. How long would it take to install shear studs in order to connect between the deck and girder? (Time for entire panels)

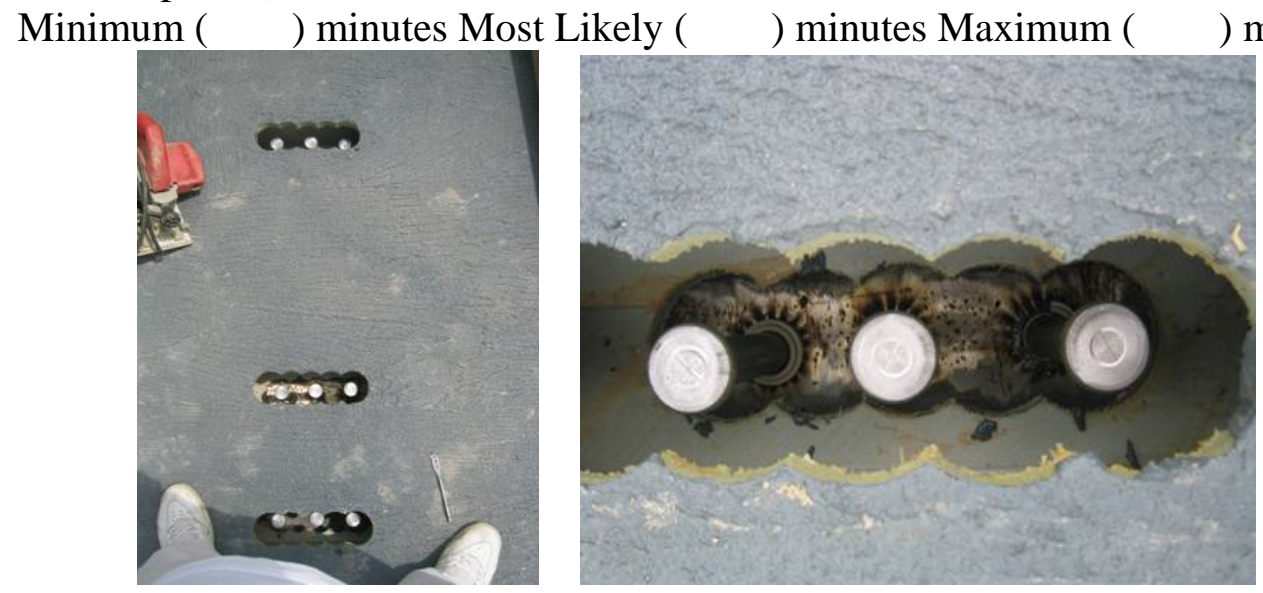

8. How long would it take to pour grout in the cavity (refer to above picture) after shear studs are field welded? (Time for entire panels)

Minimum ( $\quad$ ) minutes Most Likely ( $\quad$ ) minutes Maximum ( ） minutes

9. How long would it take to install barrier rails in FRP bridge deck panels? (Time for entire panels)

Minimum ( $\quad$ ) minutes Most Likely ( $\quad$ ) minutes Maximum ( $\quad$ ) minutes

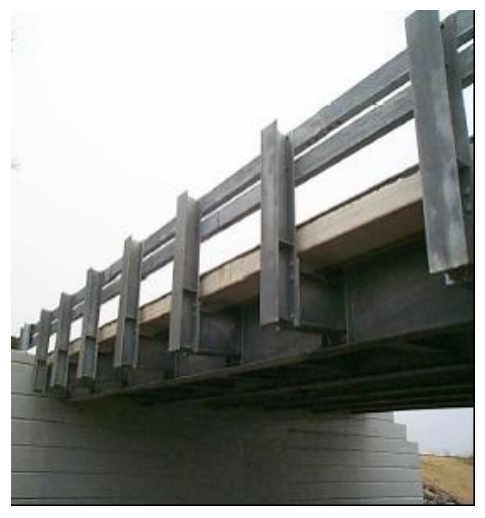

\section{Question Part 2: How many labors were necessary to finish a certain work?}

1. How many labors were necessary to finish the placement and alignment of the FRP panels?

2. How many labors were necessary to finish the installment of the FRP dowel bars?

3. How many labors were necessary to finish the placement of the FRP splice strips? 
4. How many labors were necessary to finish the connecting between deck and girder?

5. How many labors were necessary to finish the installment of the barrier rails?

6. What major equipments were required? 
Appendix D: Hardcore Composites Bridge Inspection and Repair Manual

\section{$\underline{\text { Inspection and Maintenance Guidelines: }}$}

This bridge should be inspected every two years as per normal bridge inspection procedures.

1) Inspect the deck to see if any paint has chipped away and left exposed composite. UV rays from the sun will break down our composites over time. This can be avoided if the deck remains covered with paint.

2) Check the polymer concrete for signs of chipping. Repair with the overlayment that was used for the initial overlayment.

3) Inspect the deck for gouges and degradation that may weaken the properties of the deck.

4) Visual Inspection to see if the Deck has any sagging or other unusual characteristics.

5) The transverse joints in the deck should be inspected every year.

6) The bridge deck should be sounded (tapped with a tap hammer) every inspection. This will detect any delaminations or defects in the deck.

\section{Minor Repairs}

There are two sets of minor repairs. One type will be done without consultation with Hardcore and the other repairs will require consultation with Hardcore. The two types of repairs are listed below along with techniques used to fix the damage.

\section{No Consultation}

\section{1) Paint Flaking or Chipping off}

Problem - paint has been scraped or worn away and left the composite bridge exposed to the outside elements, mainly UV rays from the sun.

\section{Solution}

A) Scrap away all loose paint chips and sand the exposed composite with $80-150$ grit sandpaper to rough up the surface. Do not sand blast the composite as the sand could damage the composite.

B) Clean the area with a solvent.

C) Repaint the area with a Sherwin Williams Tile Clad II Epoxy Paint. Two coats of paint should be applied.

\section{2) Surface Scratches}

Problem - Scratches on the surface of the composite can cause future problems if they are not treated correctly. The scratches that are repairable without consulting Hardcore should be less that 1/16-in in depth and less than 24-in in length.

\section{Solution}

A) Measure the scratch and make sure that it is less than 1/16-in in depth and less than 24-in. in length. 
B) Clean off any dirt or grease that resides in the scratch with a solvent.

C) Fill the crack with a Vinyl Ester Fairing Compound or suitable filler (contact Hardcore for filler recommendation).

D) Sand the VE Compound with medium grit sandpaper.

E) Repaint the portion of the deck with 2 coats of Sherwin Williams Tile Clad II Epoxy Paint.

\section{3) Degradation of the Epoxy Overlayement}

Problem - Portions of the overlayment are worn off or chipped off exposing portions of the composite bridge. This can cause problems with point loading on the deck and can cause UV damage to the composite.

\section{Solution}

A) Lightly sand the bare composite with medium grit sandpaper.

B) Clean off any dirt or grease that resides in the scratch with a solvent.

C) Fill the area with the original polymer concrete that was first laid on the bridge.

\section{Consultation}

\section{1) Blisters}

Problem - Small delaminations occur on the bridge due to wear and impacts. The blisters can compromise the structural integrity of the bridge.

\section{Solution}

Call Hardcore so that we can evaluate the problem and recommend the proper repair.

\section{2) Delaminations}

Problem - Areas of the deck may start to pull apart due to extreme loading conditions. This will weaken the bridge, and immediate repair is necessary.

\section{Solution}

Call Hardcore so that we can evaluate the problem and recommend the proper repair.

\section{3) Surface Gouges}

Problem - Large surface gouges that are deeper than $1 / 16$ ” or longer than 24 ” may cause structural problems in the bridge depending on the location of the gouge. This is due to the fact that the gouge may puncture through one or more face skins.

\section{Solution}

Call Hardcore so that we can evaluate the problem and recommend the proper repair. 


\section{4) Fire Damage}

Problem - If the bridge is exposed to fire for an extended period of time there will be structural damage on the deck. Because the resin burns, some of the bridge will be disintegrated and the bridge structure will be compromised.

\section{Solution}

Call Hardcore so that we can evaluate the problem and recommend the proper repair.

\section{5) Deck Punctures/Holes}

Problem - Holes and punctures depending on the location on the bridge can degrade the mechanical properties in the bridge. Holes and punctures will be caused by severe point loads.

\section{Solution}

Call Hardcore so that we can evaluate the problem and recommend the proper repair.

\section{Major repairs}

Any type of damage that occurs to one of our bridge can usually be repaired. If any large-scale damage occurs to the deck call Hardcore so that the damage can be evaluated. It is impossible to determine what types of defects would require replacement of the bridge until the extent of that damage has been analyzed by Hardcore. 
Appendix E: Input Files for FRP Bridge Deck Panels

NAME FRP BRIDGE DECK PANEL INSTALLATION(GREENE COUNTY) LENGTH 2000000 CYCLE 300

NETWORK INPUT

1 QUE 'PANEL ARRIVAL'

2 QUE 'CRANE IDLE'

3 QUE 'SPOTTER AVAIL'

4 COM 'PANEL BEING UNLOADED' SET 4 PRE 123 FOL 235

5 QUE 'PANEL AVAIL' GEN 24

6 COM 'LIFT' SET 6 PRE 235 FOL 237

7 QUE 'WAIT PLACE'

8 QUE 'LABOR IDLE'

9 COM 'PANEL PLACE' SET 9 PRE 78 FOL 810

10 QUE 'WAIT TO ALIGN'

11 QUE 'JACK IDLE'

12 COM 'ALIGN PANELS IN POSITION' SET 12 PRE 810 11 FOL 81113

13 FUN CON 24 FOL 14

14 QUE 'WAIT TO INSTALL DOWEL BARS'

15 QUE 'LABOR'

16 COM 'FRP DOWEL BARS INSTALLATION' SET 16 PRE 1415 FOL 1517

17 QUE 'WAIT TO STRIP'

18 COM 'FRP SPLICE STRIPS PLACEMENT' SET 18 PRE 1517 FOL 1519

19 QUE 'WAIT SHEAR CONNECTOR'

20 QUE 'LABOR IDLE'

21 QUE 'STUD GUN IDEL'

22 COM 'SHEAR STUDS INSTALLATION' SET 22 PRE 192021 FOL 202123

23 QUE 'WAIT TO GROUT'

24 QUE 'GROUT PUMP IDLE'

25 COM 'GROUTING' SET 25 PRE 82324 FOL 82426

26 QUE 'WAIT RAIL INSTALL'

27 QUE 'LABOR IDLE'

28 COM 'RAIL INSTALL' SET 28 PRE 2627 FOL 2729

29 FUN COU FOL 1 QUA 1

DURATION INPUT

SET 4 TRI 0.170 .250 .3

SET 6 TRI 0.030 .070 .1

SET 9 TRI 0.170 .250 .3

SET 12 TRI 0.170 .330 .42

SET 16 TRI 0.020 .030 .08

SET 18 TRI 0.7511 .5

SET 22 TRI 0.50 .751

SET 25 TRI 0.50 .751

SET 28 TRI 151617

RESOURCE INPUT 
1 'PANEL' AT 1 FIXED 1

1 'CRANE' AT 2 FIXED 125

1 'SPOTTER' AT 3 FIXED 75

5 'LABOR' AT 8 FIXED 75

1 'JACK' AT 11 FIXED 1

2 'LABOR' AT 15 FIXED 75

1 'LABOR' AT 20 FIXED 75

1 'STUD GUN' AT 21 FIXED 175

1 'Grout pump' AT 24 FIXED 175

3 'LABOR' AT 27 FIXED 75

ENDDATA 
Appendix F: Input Files for Precast Concrete Deck Panels

NAME PRECAST Concrete BRIDGE DECK PANEL INSTALLATION LENGTH 9000000 CYCLE 20

NETWORK INPUT

1 QUE 'READY TO INSTALL DECK'

2 QUE 'LABOR IDLE'

3 COM 'LAY DOWN' SET 3 PRE 12 FOL 24

4 QUE 'WAIT TO UNLOAD'

5 QUE 'LABOR IDLE'

6 QUE 'CRANE IDEL'

7 COM 'PANELS BEING UNLOADED' SET 7 PRE 456 FOL 568

8 QUE 'WAIT TO 10' GEN 1404

9 QUE 'LABOR IDLE'

10 COM 'INSTALL PANELS' SET 10 PRE 689 FOL 6911

11 QUE 'WAIT TO ALIGN'

12 COM 'ALIGN PANELS' SET 12 PRE 911 FOL 913

13 FUN CON 1404 FOL 14

14 QUE 'WAIT TO INSTALL' GEN 15

15 QUE 'LABOR IDEL'

16 COM 'INSTALL REBAR' SET 16 PRE 1415 FOL 1517

17 QUE 'CONCRETE AVAIL'

18 QUE 'PUMP TRUCK AVAIL'

19 QUE 'LABOR IDEL'

20 COM 'POUR CONCRETE' SET 20 PRE 171819 FOL 181921

21 QUE 'WAIT TO CURE\&FINISH'

22 QUE 'BIDWELL AVAIL'

23 COM 'FINISHING \& CURING' SET 23 PRE 192122 FOL 192224

24 FUN CON 15 FOL 25

25 QUE 'WAIT TO INSTALL'

26 QUE 'LABOR IDLE'

27 COM 'INSTALL BARRIER RAIL' SET 27 PRE 222526 FOL 222628

28 FUN COU FOL 1 QUA 1

DURATION INPUT

SET 3408

SET 7 TRI 468

SET 10 TRI 0.250 .51

SET 12 TRI 0.250 .51

SET 1640

SET 20 TRI 567

SET 23 TRI 123

SET 27 TRI 304560

RESOURCE INPUT 
1 'READY TO INSTALL DECK' AT 1 FIXED 1

2 'LABOR IDLE' AT 2 FIXED 75

2 'LABOR IDLE' AT 5 FIXED 75

1 'CRANE' AT 6 FIXED 187

3 'LABOR' AT 9 FIXED 75

6 'LABOR' AT 15 FIXED 75

1 'PUMP TRUCK' AT 18 FIXED 170

20 'LABOR' AT 19 FIXED 75

1 'BIDWELL' AT 22 FIXED 38.50

4 'LABOR' AT 26 FIXED 75

ENDDATA 
Appendix G: Simulation Results based on varied resources in Precast Concrete Decks

\begin{tabular}{|c|c|c|c|c|c|c|c|c|c|}
\hline \begin{tabular}{|c|} 
Scenarios \\
Number
\end{tabular} & CRANE & LABOR & \begin{tabular}{|c|} 
PUMP \\
TRUCK
\end{tabular} & LABOR & BIDWELL & LABOR & \begin{tabular}{|l} 
Prod. Per \\
Unit Time
\end{tabular} & \begin{tabular}{|c|} 
Cost Per \\
Unit Time
\end{tabular} & $\begin{array}{l}\text { Cost Per } \\
\text { Prod. Unit }\end{array}$ \\
\hline 1 & 1 & 3 & 1 & 15 & 1 & 2 & 0.0007 & 40.4004 & 60537.50 \\
\hline 2 & 1 & 3 & 1 & 15 & 1 & 3 & 0.0007 & 41.6229 & 62412.50 \\
\hline 3 & 1 & 3 & 1 & 15 & 1 & 4 & 0.0007 & 42.9331 & 64030.35 \\
\hline 4 & 1 & 3 & 1 & 15 & 2 & 2 & 0.0007 & 41.066 & 61623.00 \\
\hline 5 & 1 & 3 & 1 & 15 & 2 & 3 & 0.0007 & 42.2654 & 63375.00 \\
\hline 6 & 1 & 3 & 1 & 15 & 2 & 4 & 0.0007 & 43.5261 & 65119.50 \\
\hline 7 & 1 & 3 & 1 & 16 & 1 & 2 & 0.0007 & 41.6487 & 62412.50 \\
\hline 8 & 1 & 3 & 1 & 16 & 1 & 3 & 0.0007 & 42.9103 & 64287.50 \\
\hline 9 & 1 & 3 & 1 & 16 & 1 & 4 & 0.0007 & 44.1346 & 66162.50 \\
\hline 10 & 1 & 3 & 1 & 16 & 2 & 2 & 0.0007 & 42.2734 & 63248.25 \\
\hline 11 & 1 & 3 & 1 & 16 & 2 & 3 & 0.0007 & 43.5633 & 65250.00 \\
\hline 12 & 1 & 3 & 1 & 16 & 2 & 4 & 0.0007 & 44.7691 & 66856.50 \\
\hline 13 & 1 & 3 & 1 & 17 & 1 & 2 & 0.0007 & 42.8589 & 64416.08 \\
\hline 14 & 1 & 3 & 1 & 17 & 1 & 3 & 0.0007 & 44.1439 & 66162.50 \\
\hline 15 & 1 & 3 & 1 & 17 & 1 & 4 & 0.0007 & 45.419 & 68037.50 \\
\hline 16 & 1 & 3 & 1 & 17 & 2 & 2 & 0.0007 & 43.5831 & 65380.50 \\
\hline 17 & 1 & 3 & 1 & 17 & 2 & 3 & 0.0007 & 44.8172 & 66990.75 \\
\hline 18 & 1 & 3 & 1 & 17 & 2 & 4 & 0.0007 & 46.0338 & 69000.00 \\
\hline 19 & 1 & 3 & 1 & 18 & 1 & 2 & 0.0007 & 44.1372 & 66162.50 \\
\hline 20 & 1 & 3 & 1 & 18 & 1 & 3 & 0.0007 & 45.4371 & 68037.50 \\
\hline 21 & 1 & 3 & 1 & 18 & 1 & 4 & 0.0007 & 46.6919 & 70052.33 \\
\hline 22 & 1 & 3 & 1 & 18 & 2 & 2 & 0.0007 & 44.8158 & 67259.25 \\
\hline 23 & 1 & 3 & 1 & 18 & 2 & 3 & 0.0007 & 46.071 & 69138.00 \\
\hline 24 & 1 & 3 & 1 & 18 & 2 & 4 & 0.0007 & 47.2869 & 70875.00 \\
\hline 25 & 1 & 3 & 1 & 19 & 1 & 2 & 0.0007 & 45.4418 & 68037.50 \\
\hline 26 & 1 & 3 & 1 & 19 & 1 & 3 & 0.0007 & 46.6757 & 70052.33 \\
\hline 27 & 1 & 3 & 1 & 19 & 1 & 4 & 0.0007 & 47.8644 & 71643.93 \\
\hline 28 & 1 & 3 & 1 & 19 & 2 & 2 & 0.0007 & 46.0186 & 68862.00 \\
\hline 29 & 1 & 3 & 1 & 19 & 2 & 3 & 0.0007 & 47.2872 & 70733.25 \\
\hline 30 & 1 & 3 & 1 & 19 & 2 & 4 & 0.0007 & 48.5758 & 72895.50 \\
\hline 31 & 1 & 3 & 1 & 20 & 1 & 2 & 0.0007 & 46.6543 & 69912.50 \\
\hline 32 & 1 & 3 & 1 & 20 & 1 & 3 & 0.0007 & 47.9515 & 71931.08 \\
\hline 33 & 1 & 3 & 1 & 20 & 1 & 4 & 0.0007 & 49.109 & 73515.18 \\
\hline 34 & 1 & 3 & 1 & 20 & 2 & 2 & 0.0007 & 47.2706 & 71016.75 \\
\hline 35 & 1 & 3 & 1 & 20 & 2 & 3 & 0.0007 & 48.588 & 72750.00 \\
\hline 36 & 1 & 3 & 1 & 20 & 2 & 4 & 0.0007 & 49.7554 & 74625.00 \\
\hline 37 & 1 & 3 & 2 & 15 & 1 & 2 & 0.0007 & 43.2733 & 64787.50 \\
\hline 38 & 1 & 3 & 2 & 15 & 1 & 3 & 0.0007 & 44.4838 & 66262.53 \\
\hline 39 & 1 & 3 & 2 & 15 & 1 & 4 & 0.0007 & 45.744 & 68263.35 \\
\hline
\end{tabular}




\begin{tabular}{|c|c|c|c|c|c|c|c|c|c|}
\hline \begin{tabular}{|c|} 
Scenarios \\
Number \\
\end{tabular} & CRANE & LABOR & \begin{tabular}{|c|} 
PUMP \\
TRUCK \\
\end{tabular} & LABOR & BIDWELL & LABOR & \begin{tabular}{|c|} 
Prod. Per \\
Unit Time
\end{tabular} & $\begin{array}{c}\text { Cost Per } \\
\text { Unit Time }\end{array}$ & \begin{tabular}{|c|} 
Cost Per \\
Prod. Unit
\end{tabular} \\
\hline 40 & 1 & 3 & 2 & 15 & 2 & 2 & 0.0007 & 43.8525 & 65618.50 \\
\hline 41 & 1 & 3 & 2 & 15 & 2 & 3 & 0.0007 & 45.095 & 67489.75 \\
\hline 42 & 1 & 3 & 2 & 15 & 2 & 4 & 0.0007 & 46.3764 & 69222.00 \\
\hline 43 & 1 & 3 & 2 & 16 & 1 & 2 & 0.0007 & 44.4905 & 66395.85 \\
\hline 44 & 1 & 3 & 2 & 16 & 1 & 3 & 0.0007 & 45.7092 & 68126.28 \\
\hline 45 & 1 & 3 & 2 & 16 & 1 & 4 & 0.0007 & 46.9896 & 70271.68 \\
\hline 46 & 1 & 3 & 2 & 16 & 2 & 2 & 0.0007 & 45.1402 & 67219.25 \\
\hline 47 & 1 & 3 & 2 & 16 & 2 & 3 & 0.0007 & 46.3923 & 69222.00 \\
\hline 48 & 1 & 3 & 2 & 16 & 2 & 4 & 0.0007 & 47.5993 & 70946.75 \\
\hline 49 & 1 & 3 & 2 & 17 & 1 & 2 & 0.0007 & 45.7006 & 68126.28 \\
\hline 50 & 1 & 3 & 2 & 17 & 1 & 3 & 0.0007 & 47.021 & 70130.85 \\
\hline 51 & 1 & 3 & 2 & 17 & 1 & 4 & 0.0007 & 48.1947 & 71853.78 \\
\hline 52 & 1 & 3 & 2 & 17 & 2 & 2 & 0.0007 & 46.3827 & 69222.00 \\
\hline 53 & 1 & 3 & 2 & 17 & 2 & 3 & 0.0007 & 47.6732 & 71375.00 \\
\hline 54 & 1 & 3 & 2 & 17 & 2 & 4 & 0.0007 & 48.9099 & 72810.50 \\
\hline 55 & 1 & 3 & 2 & 18 & 1 & 2 & 0.0007 & 46.9972 & 70130.85 \\
\hline 56 & 1 & 3 & 2 & 18 & 1 & 3 & 0.0007 & 48.2272 & 72142.93 \\
\hline 57 & 1 & 3 & 2 & 18 & 1 & 4 & 0.0007 & 49.5406 & 73865.85 \\
\hline 58 & 1 & 3 & 2 & 18 & 2 & 2 & 0.0007 & 47.6119 & 71232.25 \\
\hline 59 & 1 & 3 & 2 & 18 & 2 & 3 & 0.0007 & 48.8373 & 72810.50 \\
\hline 60 & 1 & 3 & 2 & 18 & 2 & 4 & 0.0007 & 50.1553 & 74824.50 \\
\hline 61 & 1 & 3 & 2 & 19 & 1 & 2 & 0.0007 & 48.2515 & 71998.35 \\
\hline 62 & 1 & 3 & 2 & 19 & 1 & 3 & 0.0007 & 49.4809 & 73865.85 \\
\hline 63 & 1 & 3 & 2 & 19 & 1 & 4 & 0.0007 & 50.7558 & 75733.35 \\
\hline 64 & 1 & 3 & 2 & 19 & 2 & 2 & 0.0007 & 48.891 & 72810.50 \\
\hline 65 & 1 & 3 & 2 & 19 & 2 & 3 & 0.0007 & 50.1423 & 74974.75 \\
\hline 66 & 1 & 3 & 2 & 19 & 2 & 4 & 0.0007 & 51.4364 & 76692.00 \\
\hline 67 & 1 & 3 & 2 & 20 & 1 & 2 & 0.0007 & 49.4836 & 73569.20 \\
\hline 68 & 1 & 3 & 2 & 20 & 1 & 3 & 0.0007 & 50.7241 & 75733.35 \\
\hline 69 & 1 & 3 & 2 & 20 & 1 & 4 & 0.0007 & 51.9845 & 77445.03 \\
\hline 70 & 1 & 3 & 2 & 20 & 2 & 2 & 0.0007 & 50.088 & 74674.25 \\
\hline 71 & 1 & 3 & 2 & 20 & 2 & 3 & 0.0007 & 51.3744 & 76692.00 \\
\hline 72 & 1 & 3 & 2 & 20 & 2 & 4 & 0.0007 & 52.6464 & 78401.75 \\
\hline 73 & 1 & 4 & 1 & 15 & 1 & 2 & 0.0007 & 41.6749 & 60789.78 \\
\hline 74 & 1 & 4 & 1 & 15 & 1 & 3 & 0.0007 & 42.8827 & 62487.45 \\
\hline 75 & 1 & 4 & 1 & 15 & 1 & 4 & 0.0007 & 44.1412 & 64442.28 \\
\hline 76 & 1 & 4 & 1 & 15 & 2 & 2 & 0.0007 & 42.2731 & 61600.50 \\
\hline 77 & 1 & 4 & 1 & 15 & 2 & 3 & 0.0007 & 43.5035 & 63423.00 \\
\hline 78 & 1 & 4 & 1 & 15 & 2 & 4 & 0.0007 & 44.7926 & 65379.75 \\
\hline 79 & 1 & 4 & 1 & 16 & 1 & 2 & 0.0007 & 42.8813 & 62487.45 \\
\hline 80 & 1 & 4 & 1 & 16 & 1 & 3 & 0.0007 & 44.1411 & 64442.28 \\
\hline 81 & 1 & 4 & 1 & 16 & 1 & 4 & 0.0007 & 45.4183 & 66268.53 \\
\hline 82 & 1 & 4 & 1 & 16 & 2 & 2 & 0.0007 & 43.5395 & 63423.00 \\
\hline 83 & 1 & 4 & 1 & 16 & 2 & 3 & 0.0007 & 44.7539 & 65111.25 \\
\hline 84 & 1 & 4 & 1 & 16 & 2 & 4 & 0.0007 & 46.0661 & 67206.00 \\
\hline
\end{tabular}




\begin{tabular}{|c|c|c|c|c|c|c|c|c|c|}
\hline $\begin{array}{c}\text { Scenarios } \\
\text { Number }\end{array}$ & CRANE & LABOR & \begin{tabular}{|c|} 
PUMP \\
TRUCK \\
\end{tabular} & LABOR & BIDWELL & LABOR & \begin{tabular}{|c|} 
Prod. Per \\
Unit Time
\end{tabular} & $\begin{array}{c}\text { Cost Per } \\
\text { Unit Time }\end{array}$ & \begin{tabular}{|c|} 
Cost Per \\
Prod. Unit
\end{tabular} \\
\hline 85 & 1 & 4 & 1 & 17 & 1 & 2 & 0.0007 & 44.1311 & 64309.95 \\
\hline 86 & 1 & 4 & 1 & 17 & 1 & 3 & 0.0007 & 45.4444 & 66404.60 \\
\hline 87 & 1 & 4 & 1 & 17 & 1 & 4 & 0.0007 & 46.6215 & 67954.95 \\
\hline 88 & 1 & 4 & 1 & 17 & 2 & 2 & 0.0007 & 44.8221 & 65379.75 \\
\hline 89 & 1 & 4 & 1 & 17 & 2 & 3 & 0.0007 & 46.0568 & 67206.00 \\
\hline 90 & 1 & 4 & 1 & 17 & 2 & 4 & 0.0007 & 47.3012 & 69032.25 \\
\hline 91 & 1 & 4 & 1 & 18 & 1 & 2 & 0.0007 & 45.3598 & 66132.45 \\
\hline 92 & 1 & 4 & 1 & 18 & 1 & 3 & 0.0007 & 46.6106 & 67954.95 \\
\hline 93 & 1 & 4 & 1 & 18 & 1 & 4 & 0.0007 & 47.8626 & 69921.03 \\
\hline 94 & 1 & 4 & 1 & 18 & 2 & 2 & 0.0007 & 46.0756 & 67206.00 \\
\hline 95 & 1 & 4 & 1 & 18 & 2 & 3 & 0.0007 & 47.3031 & 69032.25 \\
\hline 96 & 1 & 4 & 1 & 18 & 2 & 4 & 0.0007 & 48.5141 & 70858.50 \\
\hline 97 & 1 & 4 & 1 & 19 & 1 & 2 & 0.0007 & 46.6655 & 67954.95 \\
\hline 98 & 1 & 4 & 1 & 19 & 1 & 3 & 0.0007 & 47.9559 & 70064.60 \\
\hline 99 & 1 & 4 & 1 & 19 & 1 & 4 & 0.0007 & 49.205 & 71894.60 \\
\hline 100 & 1 & 4 & 1 & 19 & 2 & 2 & 0.0007 & 47.2549 & 68890.50 \\
\hline 101 & 1 & 4 & 1 & 19 & 2 & 3 & 0.0007 & 48.5998 & 70858.50 \\
\hline 102 & 1 & 4 & 1 & 19 & 2 & 4 & 0.0007 & 49.8124 & 72684.75 \\
\hline 103 & 1 & 4 & 1 & 20 & 1 & 2 & 0.0007 & 47.9238 & 69921.03 \\
\hline 104 & 1 & 4 & 1 & 20 & 1 & 3 & 0.0007 & 49.1568 & 71599.95 \\
\hline 105 & 1 & 4 & 1 & 20 & 1 & 4 & 0.0007 & 50.4054 & 73573.53 \\
\hline 106 & 1 & 4 & 1 & 20 & 2 & 2 & 0.0007 & 48.5063 & 70858.50 \\
\hline 107 & 1 & 4 & 1 & 20 & 2 & 3 & 0.0007 & 49.835 & 72535.50 \\
\hline 108 & 1 & 4 & 1 & 20 & 2 & 4 & 0.0007 & 51.0662 & 74358.00 \\
\hline 109 & 1 & 4 & 2 & 15 & 1 & 2 & 0.0007 & 44.4959 & 64662.63 \\
\hline 110 & 1 & 4 & 2 & 15 & 1 & 3 & 0.0007 & 45.7527 & 66481.38 \\
\hline 111 & 1 & 4 & 2 & 15 & 1 & 4 & 0.0007 & 47.0329 & 68300.13 \\
\hline 112 & 1 & 4 & 2 & 15 & 2 & 2 & 0.0007 & 45.1231 & 65461.00 \\
\hline 113 & 1 & 4 & 2 & 15 & 2 & 3 & 0.0007 & 46.3712 & 67276.00 \\
\hline 114 & 1 & 4 & 2 & 15 & 2 & 4 & 0.0007 & 47.6805 & 69233.75 \\
\hline 115 & 1 & 4 & 2 & 16 & 1 & 2 & 0.0007 & 45.7246 & 66344.30 \\
\hline 116 & 1 & 4 & 2 & 16 & 1 & 3 & 0.0007 & 46.9504 & 68300.13 \\
\hline 117 & 1 & 4 & 2 & 16 & 1 & 4 & 0.0007 & 48.22 & 70118.88 \\
\hline 118 & 1 & 4 & 2 & 16 & 2 & 2 & 0.0007 & 46.4234 & 67415.00 \\
\hline 119 & 1 & 4 & 2 & 16 & 2 & 3 & 0.0007 & 47.6438 & 69233.75 \\
\hline 120 & 1 & 4 & 2 & 16 & 2 & 4 & 0.0007 & 48.8576 & 71052.50 \\
\hline 121 & 1 & 4 & 2 & 17 & 1 & 2 & 0.0007 & 47.0349 & 68440.95 \\
\hline 122 & 1 & 4 & 2 & 17 & 1 & 3 & 0.0007 & 48.2044 & 70118.88 \\
\hline 123 & 1 & 4 & 2 & 17 & 1 & 4 & 0.0007 & 49.5223 & 71789.30 \\
\hline 124 & 1 & 4 & 2 & 17 & 2 & 2 & 0.0007 & 47.5886 & 69233.75 \\
\hline 125 & 1 & 4 & 2 & 17 & 2 & 3 & 0.0007 & 48.8837 & 71052.50 \\
\hline 126 & 1 & 4 & 2 & 17 & 2 & 4 & 0.0007 & 50.1185 & 72721.00 \\
\hline 127 & 1 & 4 & 2 & 18 & 1 & 2 & 0.0007 & 48.2716 & \begin{tabular}{|l|}
70118.88 \\
\end{tabular} \\
\hline 128 & 1 & 4 & 2 & 18 & 1 & 3 & 0.0007 & 49.54 & 71937.63 \\
\hline
\end{tabular}




\begin{tabular}{|c|c|c|c|c|c|c|c|c|c|}
\hline $\begin{array}{c}\text { Scenarios } \\
\text { Number }\end{array}$ & CRANE & LABOR & \begin{tabular}{|c|} 
PUMP \\
TRUCK \\
\end{tabular} & LABOR & BIDWELL & LABOR & \begin{tabular}{|c|} 
Prod. Per \\
Unit Time
\end{tabular} & $\begin{array}{c}\text { Cost Per } \\
\text { Unit Time }\end{array}$ & \begin{tabular}{|c|} 
Cost Per \\
Prod. Unit
\end{tabular} \\
\hline 129 & 1 & 4 & 2 & 18 & 1 & 4 & 0.0007 & 50.6949 & 73452.23 \\
\hline 130 & 1 & 4 & 2 & 18 & 2 & 2 & 0.0007 & 48.8674 & 71052.50 \\
\hline 131 & 1 & 4 & 2 & 18 & 2 & 3 & 0.0007 & 50.0964 & 72871.25 \\
\hline 132 & 1 & 4 & 2 & 18 & 2 & 4 & 0.0007 & 51.3642 & 74536.00 \\
\hline 133 & 1 & 4 & 2 & 19 & 1 & 2 & 0.0007 & 49.5246 & 72085.95 \\
\hline 134 & 1 & 4 & 2 & 19 & 1 & 3 & 0.0007 & 50.7141 & 73604.30 \\
\hline 135 & 1 & 4 & 2 & 19 & 1 & 4 & 0.0007 & 52.0069 & 75575.13 \\
\hline 136 & 1 & 4 & 2 & 19 & 2 & 2 & 0.0007 & 50.1614 & 72721.00 \\
\hline 137 & 1 & 4 & 2 & 19 & 2 & 3 & 0.0007 & 51.3342 & 74536.00 \\
\hline 138 & 1 & 4 & 2 & 19 & 2 & 4 & 0.0007 & 52.6588 & 76666.50 \\
\hline 139 & 1 & 4 & 2 & 20 & 1 & 2 & 0.0007 & 50.7447 & 73908.45 \\
\hline 140 & 1 & 4 & 2 & 20 & 1 & 3 & 0.0007 & 52.0397 & 75575.13 \\
\hline 141 & 1 & 4 & 2 & 20 & 1 & 4 & 0.0007 & 53.2316 & 77393.88 \\
\hline 142 & 1 & 4 & 2 & 20 & 2 & 2 & 0.0007 & 51.3613 & 74690.00 \\
\hline 143 & 1 & 4 & 2 & 20 & 2 & 3 & 0.0007 & 52.6371 & 76508.75 \\
\hline 144 & 1 & 4 & 2 & 20 & 2 & 4 & 0.0007 & 53.9331 & 78327.50 \\
\hline 145 & 1 & 5 & 1 & 15 & 1 & 2 & 0.0007 & 42.8614 & 61201.70 \\
\hline 146 & 1 & 5 & 1 & 15 & 1 & 3 & 0.0007 & 44.1958 & 63251.35 \\
\hline 147 & 1 & 5 & 1 & 15 & 1 & 4 & 0.0007 & 45.3832 & 64907.78 \\
\hline 148 & 1 & 5 & 1 & 15 & 2 & 2 & 0.0007 & 43.556 & 62248.50 \\
\hline 149 & 1 & 5 & 1 & 15 & 2 & 3 & 0.0007 & 44.7608 & 64171.50 \\
\hline 150 & 1 & 5 & 1 & 15 & 2 & 4 & 0.0007 & 46.0201 & 65826.00 \\
\hline 151 & 1 & 5 & 1 & 16 & 1 & 2 & 0.0007 & 44.1123 & 63119.03 \\
\hline 152 & 1 & 5 & 1 & 16 & 1 & 3 & 0.0007 & 45.4281 & 64907.78 \\
\hline 153 & 1 & 5 & 1 & 16 & 1 & 4 & 0.0007 & 46.6799 & 66696.53 \\
\hline 154 & 1 & 5 & 1 & 16 & 2 & 2 & 0.0007 & 44.7801 & 64305.75 \\
\hline 155 & 1 & 5 & 1 & 16 & 2 & 3 & 0.0007 & 46.0678 & 65688.00 \\
\hline 156 & 1 & 5 & 1 & 16 & 2 & 4 & 0.0007 & 47.2648 & 67614.75 \\
\hline 157 & 1 & 5 & 1 & 17 & 1 & 2 & 0.0007 & 45.4334 & 64907.78 \\
\hline 158 & 1 & 5 & 1 & 17 & 1 & 3 & 0.0007 & 46.6888 & 66696.53 \\
\hline 159 & 1 & 5 & 1 & 17 & 1 & 4 & 0.0007 & 47.8892 & 68628.85 \\
\hline 160 & 1 & 5 & 1 & 17 & 2 & 2 & 0.0007 & 46.0523 & 65826.00 \\
\hline 161 & 1 & 5 & 1 & 17 & 2 & 3 & 0.0007 & 47.2974 & 67614.75 \\
\hline 162 & 1 & 5 & 1 & 17 & 2 & 4 & 0.0007 & 48.5215 & 69403.50 \\
\hline 163 & 1 & 5 & 1 & 18 & 1 & 2 & 0.0007 & 46.7005 & 66836.35 \\
\hline 164 & 1 & 5 & 1 & 18 & 1 & 3 & 0.0007 & 47.8755 & 68341.70 \\
\hline 165 & 1 & 5 & 1 & 18 & 1 & 4 & 0.0007 & 49.1541 & 70274.03 \\
\hline 166 & 1 & 5 & 1 & 18 & 2 & 2 & 0.0007 & 47.3151 & 67756.50 \\
\hline 167 & 1 & 5 & 1 & 18 & 2 & 3 & 0.0007 & 48.5545 & 69403.50 \\
\hline 168 & 1 & 5 & 1 & 18 & 2 & 4 & 0.0007 & 49.7637 & 71341.50 \\
\hline 169 & 1 & 5 & 1 & 19 & 1 & 2 & 0.0007 & 47.8829 & 68628.85 \\
\hline 170 & 1 & 5 & 1 & 19 & 1 & 3 & 0.0007 & 49.1988 & 70421.35 \\
\hline 171 & 1 & 5 & 1 & 19 & 1 & 4 & 0.0007 & 50.3831 & 72062.78 \\
\hline 172 & 1 & 5 & 1 & 19 & 2 & 2 & 0.0007 & 48.511 & 69403.50 \\
\hline
\end{tabular}




\begin{tabular}{|c|c|c|c|c|c|c|c|c|c|}
\hline \begin{tabular}{|c|} 
Scenarios \\
Number \\
\end{tabular} & CRANE & LABOR & \begin{tabular}{|c|} 
PUMP \\
TRUCK \\
\end{tabular} & LABOR & BIDWELL & LABOR & \begin{tabular}{|c|} 
Prod. Per \\
Unit Time
\end{tabular} & $\begin{array}{c}\text { Cost Per } \\
\text { Unit Time }\end{array}$ & \begin{tabular}{|c|} 
Cost Per \\
Prod. Unit
\end{tabular} \\
\hline 173 & 1 & 5 & 1 & 19 & 2 & 3 & 0.0007 & 49.796 & 71341.50 \\
\hline 174 & 1 & 5 & 1 & 19 & 2 & 4 & 0.0007 & 51.0946 & 72981.00 \\
\hline 175 & 1 & 5 & 1 & 20 & 1 & 2 & 0.0007 & 49.198 & 70274.03 \\
\hline 176 & 1 & 5 & 1 & 20 & 1 & 3 & 0.0007 & 50.3974 & 71911.70 \\
\hline 177 & 1 & 5 & 1 & 20 & 1 & 4 & 0.0007 & 51.651 & 73851.53 \\
\hline 178 & 1 & 5 & 1 & 20 & 2 & 2 & 0.0007 & 49.7679 & 71341.50 \\
\hline 179 & 1 & 5 & 1 & 20 & 2 & 3 & 0.0007 & 51.0602 & 72981.00 \\
\hline 180 & 1 & 5 & 1 & 20 & 2 & 4 & 0.0007 & 52.3484 & 74926.50 \\
\hline 181 & 1 & 5 & 2 & 15 & 1 & 2 & 0.0007 & 45.7552 & 64973.55 \\
\hline 182 & 1 & 5 & 2 & 15 & 1 & 3 & 0.0007 & 46.9483 & 66610.23 \\
\hline 183 & 1 & 5 & 2 & 15 & 1 & 4 & 0.0007 & 48.2353 & 68528.55 \\
\hline 184 & 1 & 5 & 2 & 15 & 2 & 2 & 0.0007 & 46.3541 & 65886.00 \\
\hline 185 & 1 & 5 & 2 & 15 & 2 & 3 & 0.0007 & 47.6435 & 67520.75 \\
\hline 186 & 1 & 5 & 2 & 15 & 2 & 4 & 0.0007 & 48.8364 & 69294.50 \\
\hline 187 & 1 & 5 & 2 & 16 & 1 & 2 & 0.0007 & 46.943 & 66469.40 \\
\hline 188 & 1 & 5 & 2 & 16 & 1 & 3 & 0.0007 & 48.2377 & 68383.98 \\
\hline 189 & 1 & 5 & 2 & 16 & 1 & 4 & 0.0007 & 49.4834 & 70306.05 \\
\hline 190 & 1 & 5 & 2 & 16 & 2 & 2 & 0.0007 & 47.6742 & 67663.50 \\
\hline 191 & 1 & 5 & 2 & 16 & 2 & 3 & 0.0007 & 48.8941 & 69441.00 \\
\hline 192 & 1 & 5 & 2 & 16 & 2 & 4 & 0.0007 & 50.1307 & 71218.50 \\
\hline 193 & 1 & 5 & 2 & 17 & 1 & 2 & 0.0007 & 48.2544 & 68673.13 \\
\hline 194 & 1 & 5 & 2 & 17 & 1 & 3 & 0.0007 & 49.5214 & 70306.05 \\
\hline 195 & 1 & 5 & 2 & 17 & 1 & 4 & 0.0007 & 50.7292 & 72083.55 \\
\hline 196 & 1 & 5 & 2 & 17 & 2 & 2 & 0.0007 & 48.8981 & 69441.00 \\
\hline 197 & 1 & 5 & 2 & 17 & 2 & 3 & 0.0007 & 50.0912 & 70918.00 \\
\hline 198 & 1 & 5 & 2 & 17 & 2 & 4 & 0.0007 & 51.4403 & 72996.00 \\
\hline 199 & 1 & 5 & 2 & 18 & 1 & 2 & 0.0007 & 49.5123 & 70157.73 \\
\hline 200 & 1 & 5 & 2 & 18 & 1 & 3 & 0.0007 & 50.7785 & 72083.55 \\
\hline 201 & 1 & 5 & 2 & 18 & 1 & 4 & 0.0007 & 51.9565 & 73705.23 \\
\hline 202 & 1 & 5 & 2 & 18 & 2 & 2 & 0.0007 & 50.1056 & 71068.25 \\
\hline 203 & 1 & 5 & 2 & 18 & 2 & 3 & 0.0007 & 51.3838 & 72996.00 \\
\hline 204 & 1 & 5 & 2 & 18 & 2 & 4 & 0.0007 & 52.622 & 74773.50 \\
\hline 205 & 1 & 5 & 2 & 19 & 1 & 2 & 0.0007 & 50.7325 & 72083.55 \\
\hline 206 & 1 & 5 & 2 & 19 & 1 & 3 & 0.0007 & 52.0022 & 73705.23 \\
\hline 207 & 1 & 5 & 2 & 19 & 1 & 4 & 0.0007 & 53.207 & 75319.40 \\
\hline 208 & 1 & 5 & 2 & 19 & 2 & 2 & 0.0007 & 51.4141 & 72842.00 \\
\hline 209 & 1 & 5 & 2 & 19 & 2 & 3 & 0.0007 & 52.6544 & 74931.25 \\
\hline 210 & 1 & 5 & 2 & 19 & 2 & 4 & 0.0007 & 53.9184 & 76389.50 \\
\hline 211 & 1 & 5 & 2 & 20 & 1 & 2 & 0.0007 & 51.9965 & 73705.23 \\
\hline 212 & 1 & 5 & 2 & 20 & 1 & 3 & 0.0007 & 53.2272 & 75478.98 \\
\hline 213 & 1 & 5 & 2 & 20 & 1 & 4 & 0.0007 & 54.483 & 77252.73 \\
\hline 214 & 1 & 5 & 2 & 20 & 2 & 2 & 0.0007 & 52.6833 & 74773.50 \\
\hline 215 & 1 & 5 & 2 & 20 & 2 & 3 & 0.0007 & 53.8869 & 76389.50 \\
\hline 216 & 1 & 5 & 2 & 20 & 2 & 4 & 0.0007 & 55.0937 & 77998.00 \\
\hline
\end{tabular}




\begin{tabular}{|c|c|c|c|c|c|c|c|c|c|}
\hline \begin{tabular}{|c|} 
Scenarios \\
Number \\
\end{tabular} & CRANE & LABOR & \begin{tabular}{|c|} 
PUMP \\
TRUCK \\
\end{tabular} & LABOR & BIDWELL & LABOR & \begin{tabular}{|c|} 
Prod. Per \\
Unit Time
\end{tabular} & $\begin{array}{c}\text { Cost Per } \\
\text { Unit Time }\end{array}$ & \begin{tabular}{|c|} 
Cost Per \\
Prod. Unit
\end{tabular} \\
\hline 217 & 1 & 6 & 1 & 15 & 1 & 2 & 0.0007 & 44.1236 & 62457.40 \\
\hline 218 & 1 & 6 & 1 & 15 & 1 & 3 & 0.0007 & 45.4414 & 64499.55 \\
\hline 219 & 1 & 6 & 1 & 15 & 1 & 4 & 0.0007 & 46.6953 & 66277.05 \\
\hline 220 & 1 & 6 & 1 & 15 & 2 & 2 & 0.0007 & 44.8067 & 63500.25 \\
\hline 221 & 1 & 6 & 1 & 15 & 2 & 3 & 0.0007 & 46.0544 & 65274.00 \\
\hline 222 & 1 & 6 & 1 & 15 & 2 & 4 & 0.0007 & 47.2524 & 67189.50 \\
\hline 223 & 1 & 6 & 1 & 16 & 1 & 2 & 0.0007 & 45.3637 & 64363.48 \\
\hline 224 & 1 & 6 & 1 & 16 & 1 & 3 & 0.0007 & 46.7046 & 66277.05 \\
\hline 225 & 1 & 6 & 1 & 16 & 1 & 4 & 0.0007 & 47.9104 & 68054.55 \\
\hline 226 & 1 & 6 & 1 & 16 & 2 & 2 & 0.0007 & 46.0904 & 65550.00 \\
\hline 227 & 1 & 6 & 1 & 16 & 2 & 3 & 0.0007 & 47.3166 & 67189.50 \\
\hline 228 & 1 & 6 & 1 & 16 & 2 & 4 & 0.0007 & 48.6013 & 68967.00 \\
\hline 229 & 1 & 6 & 1 & 17 & 1 & 2 & 0.0007 & 46.673 & 66277.05 \\
\hline 230 & 1 & 6 & 1 & 17 & 1 & 3 & 0.0007 & 47.8893 & 67767.40 \\
\hline 231 & 1 & 6 & 1 & 17 & 1 & 4 & 0.0007 & 49.1405 & 69832.05 \\
\hline 232 & 1 & 6 & 1 & 17 & 2 & 2 & 0.0007 & 47.2771 & 67189.50 \\
\hline 233 & 1 & 6 & 1 & 17 & 2 & 3 & 0.0007 & 48.5667 & 68967.00 \\
\hline 234 & 1 & 6 & 1 & 17 & 2 & 4 & 0.0007 & 49.8292 & 70595.25 \\
\hline 235 & 1 & 6 & 1 & 18 & 1 & 2 & 0.0007 & 47.9523 & 68054.55 \\
\hline 236 & 1 & 6 & 1 & 18 & 1 & 3 & 0.0007 & 49.1489 & 69832.05 \\
\hline 237 & 1 & 6 & 1 & 18 & 1 & 4 & 0.0007 & 50.4075 & 71458.48 \\
\hline 238 & 1 & 6 & 1 & 18 & 2 & 2 & 0.0007 & 48.504 & 68821.50 \\
\hline 239 & 1 & 6 & 1 & 18 & 2 & 3 & 0.0007 & 49.8007 & 70595.25 \\
\hline 240 & 1 & 6 & 1 & 18 & 2 & 4 & 0.0007 & 51.1023 & 72675.00 \\
\hline 241 & 1 & 6 & 1 & 19 & 1 & 2 & 0.0007 & 49.1137 & 69684.73 \\
\hline 242 & 1 & 6 & 1 & 19 & 1 & 3 & 0.0007 & 50.3599 & 71458.48 \\
\hline 243 & 1 & 6 & 1 & 19 & 1 & 4 & 0.0007 & 51.7126 & 73387.05 \\
\hline 244 & 1 & 6 & 1 & 19 & 2 & 2 & 0.0007 & 49.8079 & 70893.75 \\
\hline 245 & 1 & 6 & 1 & 19 & 2 & 3 & 0.0007 & 51.0538 & 72369.00 \\
\hline 246 & 1 & 6 & 1 & 19 & 2 & 4 & 0.0007 & 52.2919 & 73986.00 \\
\hline 247 & 1 & 6 & 1 & 20 & 1 & 2 & 0.0007 & 50.3592 & 71458.48 \\
\hline 248 & 1 & 6 & 1 & 20 & 1 & 3 & 0.0007 & 51.6184 & 73232.23 \\
\hline 249 & 1 & 6 & 1 & 20 & 1 & 4 & 0.0007 & 52.9359 & 75164.55 \\
\hline 250 & 1 & 6 & 1 & 20 & 2 & 2 & 0.0007 & 51.053 & 72522.00 \\
\hline 251 & 1 & 6 & 1 & 20 & 2 & 3 & 0.0007 & 52.3406 & 74299.50 \\
\hline 252 & 1 & 6 & 1 & 20 & 2 & 4 & 0.0007 & 53.5203 & 76077.00 \\
\hline 253 & 1 & 6 & 2 & 15 & 1 & 2 & 0.0007 & 47.0215 & 66328.58 \\
\hline 254 & 1 & 6 & 2 & 15 & 1 & 3 & 0.0007 & 48.2483 & 68239.40 \\
\hline 255 & 1 & 6 & 2 & 15 & 1 & 4 & 0.0007 & 49.498 & 69712.75 \\
\hline 256 & 1 & 6 & 2 & 15 & 2 & 2 & 0.0007 & 47.6536 & 67378.00 \\
\hline 257 & 1 & 6 & 2 & 15 & 2 & 3 & 0.0007 & 48.8544 & 68855.00 \\
\hline 258 & 1 & 6 & 2 & 15 & 2 & 4 & 0.0007 & 50.138 & 70617.50 \\
\hline 259 & 1 & 6 & 2 & 16 & 1 & 2 & 0.0007 & 48.2474 & 68094.83 \\
\hline 260 & 1 & 6 & 2 & 16 & 1 & 3 & 0.0007 & 49.5043 & 70009.40 \\
\hline
\end{tabular}




\begin{tabular}{|c|c|c|c|c|c|c|c|c|c|}
\hline $\begin{array}{c}\text { Scenarios } \\
\text { Number }\end{array}$ & CRANE & LABOR & \begin{tabular}{|c|} 
PUMP \\
TRUCK \\
\end{tabular} & LABOR & BIDWELL & LABOR & \begin{tabular}{|c|} 
Prod. Per \\
Unit Time
\end{tabular} & $\begin{array}{c}\text { Cost Per } \\
\text { Unit Time }\end{array}$ & \begin{tabular}{|c|} 
Cost Per \\
Prod. Unit
\end{tabular} \\
\hline 261 & 1 & 6 & 2 & 16 & 1 & 4 & 0.0007 & 50.7317 & 71627.33 \\
\hline 262 & 1 & 6 & 2 & 16 & 2 & 2 & 0.0007 & 48.9265 & 69148.00 \\
\hline 263 & 1 & 6 & 2 & 16 & 2 & 3 & 0.0007 & 50.1775 & 70918.00 \\
\hline 264 & 1 & 6 & 2 & 16 & 2 & 4 & 0.0007 & 51.3486 & 72534.00 \\
\hline 265 & 1 & 6 & 2 & 17 & 1 & 2 & 0.0007 & 49.4568 & 70009.40 \\
\hline 266 & 1 & 6 & 2 & 17 & 1 & 3 & 0.0007 & 50.7505 & 71779.40 \\
\hline 267 & 1 & 6 & 2 & 17 & 1 & 4 & 0.0007 & 51.9771 & 73549.40 \\
\hline 268 & 1 & 6 & 2 & 17 & 2 & 2 & 0.0007 & 50.1279 & 70767.75 \\
\hline 269 & 1 & 6 & 2 & 17 & 2 & 3 & 0.0007 & 51.3987 & 72534.00 \\
\hline 270 & 1 & 6 & 2 & 17 & 2 & 4 & 0.0007 & 52.664 & 74300.25 \\
\hline 271 & 1 & 6 & 2 & 18 & 1 & 2 & 0.0007 & 50.7451 & 71627.33 \\
\hline 272 & 1 & 6 & 2 & 18 & 1 & 3 & 0.0007 & 51.9877 & 73393.58 \\
\hline 273 & 1 & 6 & 2 & 18 & 1 & 4 & 0.0007 & 53.2818 & 75159.83 \\
\hline 274 & 1 & 6 & 2 & 18 & 2 & 2 & 0.0007 & 51.3858 & 72688.00 \\
\hline 275 & 1 & 6 & 2 & 18 & 2 & 3 & 0.0007 & 52.5932 & 74142.50 \\
\hline 276 & 1 & 6 & 2 & 18 & 2 & 4 & 0.0007 & 53.8464 & 76066.50 \\
\hline 277 & 1 & 6 & 2 & 19 & 1 & 2 & 0.0007 & 51.9982 & 73393.58 \\
\hline 278 & 1 & 6 & 2 & 19 & 1 & 3 & 0.0007 & 53.2291 & 75159.83 \\
\hline 279 & 1 & 6 & 2 & 19 & 1 & 4 & 0.0007 & 54.4472 & 76762.75 \\
\hline 280 & 1 & 6 & 2 & 19 & 2 & 2 & 0.0007 & 52.6376 & 74300.25 \\
\hline 281 & 1 & 6 & 2 & 19 & 2 & 3 & 0.0007 & 53.941 & 76066.50 \\
\hline 282 & 1 & 6 & 2 & 19 & 2 & 4 & 0.0007 & 55.1175 & 77998.00 \\
\hline 283 & 1 & 6 & 2 & 20 & 1 & 2 & 0.0007 & 53.2611 & 75319.40 \\
\hline 284 & 1 & 6 & 2 & 20 & 1 & 3 & 0.0007 & 54.5227 & 77089.40 \\
\hline 285 & 1 & 6 & 2 & 20 & 1 & 4 & 0.0007 & 55.7587 & 78692.33 \\
\hline 286 & 1 & 6 & 2 & 20 & 2 & 2 & 0.0007 & 53.9338 & 76228.00 \\
\hline 287 & 1 & 6 & 2 & 20 & 2 & 3 & 0.0007 & 55.1742 & 77998.00 \\
\hline 288 & 1 & 6 & 2 & 20 & 2 & 4 & 0.0007 & 56.421 & \begin{tabular}{|l|}
79768.00 \\
\end{tabular} \\
\hline 289 & 2 & 3 & 1 & 15 & 1 & 2 & 0.0008 & 43.561 & 53343.83 \\
\hline 290 & 2 & 3 & 1 & 15 & 1 & 3 & 0.0008 & 44.7307 & 54743.40 \\
\hline 291 & 2 & 3 & 1 & 15 & 1 & 4 & 0.0008 & 46.07 & 56411.33 \\
\hline 292 & 2 & 3 & 1 & 15 & 2 & 2 & 0.0008 & 44.1797 & 54131.15 \\
\hline 293 & 2 & 3 & 1 & 15 & 2 & 3 & 0.0008 & 45.3827 & 55664.90 \\
\hline 294 & 2 & 3 & 1 & 15 & 2 & 4 & 0.0008 & 46.6905 & 57198.65 \\
\hline 295 & 2 & 3 & 1 & 16 & 1 & 2 & 0.0008 & 44.8256 & 55011.75 \\
\hline 296 & 2 & 3 & 1 & 16 & 1 & 3 & 0.0008 & 46.0591 & 56411.33 \\
\hline 297 & 2 & 3 & 1 & 16 & 1 & 4 & 0.0008 & 47.2605 & 57945.08 \\
\hline 298 & 2 & 3 & 1 & 16 & 2 & 2 & 0.0008 & 45.4415 & 55801.00 \\
\hline 299 & 2 & 3 & 1 & 16 & 2 & 3 & 0.0008 & 46.6707 & 57058.80 \\
\hline 300 & 2 & 3 & 1 & 16 & 2 & 4 & 0.0008 & 47.9141 & 58732.40 \\
\hline 301 & 2 & 3 & 1 & 17 & 1 & 2 & 0.0008 & 46.075 & 56549.25 \\
\hline 302 & 2 & 3 & 1 & 17 & 1 & 3 & 0.0008 & 47.2953 & 57945.08 \\
\hline 303 & 2 & 3 & 1 & 17 & 1 & 4 & 0.0008 & 48.5502 & 59624.25 \\
\hline 304 & 2 & 3 & 1 & 17 & 2 & 2 & 0.0008 & 46.6975 & 57198.65 \\
\hline
\end{tabular}




\begin{tabular}{|c|c|c|c|c|c|c|c|c|c|}
\hline \begin{tabular}{|c|} 
Scenarios \\
Number \\
\end{tabular} & CRANE & LABOR & \begin{tabular}{|c|} 
PUMP \\
TRUCK \\
\end{tabular} & LABOR & BIDWELL & LABOR & \begin{tabular}{|c|} 
Prod. Per \\
Unit Time
\end{tabular} & $\begin{array}{c}\text { Cost Per } \\
\text { Unit Time }\end{array}$ & \begin{tabular}{|c|} 
Cost Per \\
Prod. Unit
\end{tabular} \\
\hline 305 & 2 & 3 & 1 & 17 & 2 & 3 & 0.0008 & 47.9079 & 58732.40 \\
\hline 306 & 2 & 3 & 1 & 17 & 2 & 4 & 0.0008 & 49.1558 & 60413.50 \\
\hline 307 & 2 & 3 & 1 & 18 & 1 & 2 & 0.0008 & 47.3184 & 57945.08 \\
\hline 308 & 2 & 3 & 1 & 18 & 1 & 3 & 0.0008 & 48.5585 & 59478.83 \\
\hline 309 & 2 & 3 & 1 & 18 & 1 & 4 & 0.0008 & 49.7724 & 60863.40 \\
\hline 310 & 2 & 3 & 1 & 18 & 2 & 2 & 0.0008 & 47.9766 & 58732.40 \\
\hline 311 & 2 & 3 & 1 & 18 & 2 & 3 & 0.0008 & 49.1683 & 60413.50 \\
\hline 312 & 2 & 3 & 1 & 18 & 2 & 4 & 0.0008 & 50.4334 & 61951.00 \\
\hline 313 & 2 & 3 & 1 & 19 & 1 & 2 & 0.0008 & 48.5206 & 59333.40 \\
\hline 314 & 2 & 3 & 1 & 19 & 1 & 3 & 0.0008 & 49.7279 & 60863.40 \\
\hline 315 & 2 & 3 & 1 & 19 & 1 & 4 & 0.0008 & 51.094 & 62699.25 \\
\hline 316 & 2 & 3 & 1 & 19 & 2 & 2 & 0.0008 & 49.2275 & 60266.15 \\
\hline 317 & 2 & 3 & 1 & 19 & 2 & 3 & 0.0008 & 50.4204 & 61648.80 \\
\hline 318 & 2 & 3 & 1 & 19 & 2 & 4 & 0.0008 & 51.7356 & 63333.65 \\
\hline 319 & 2 & 3 & 1 & 20 & 1 & 2 & 0.0008 & 49.8449 & 61161.75 \\
\hline 320 & 2 & 3 & 1 & 20 & 1 & 3 & 0.0008 & 51.0549 & 62546.33 \\
\hline 321 & 2 & 3 & 1 & 20 & 1 & 4 & 0.0008 & 52.2984 & 64080.08 \\
\hline 322 & 2 & 3 & 1 & 20 & 2 & 2 & 0.0008 & 50.3688 & 61648.80 \\
\hline 323 & 2 & 3 & 1 & 20 & 2 & 3 & 0.0008 & 51.7257 & 63178.80 \\
\hline 324 & 2 & 3 & 1 & 20 & 2 & 4 & 0.0008 & 52.9757 & 64867.40 \\
\hline 325 & 2 & 3 & 2 & 15 & 1 & 2 & 0.0008 & 46.3294 & 56403.55 \\
\hline 326 & 2 & 3 & 2 & 15 & 1 & 3 & 0.0008 & 47.6381 & 58068.73 \\
\hline 327 & 2 & 3 & 2 & 15 & 1 & 4 & 0.0008 & 48.86 & 59594.98 \\
\hline 328 & 2 & 3 & 2 & 15 & 2 & 2 & 0.0008 & 47.0455 & 57466.80 \\
\hline 329 & 2 & 3 & 2 & 15 & 2 & 3 & 0.0008 & 48.2868 & 58852.20 \\
\hline 330 & 2 & 3 & 2 & 15 & 2 & 4 & 0.0008 & 49.5177 & 60378.45 \\
\hline 331 & 2 & 3 & 2 & 16 & 1 & 2 & 0.0008 & 47.6082 & 58068.73 \\
\hline 332 & 2 & 3 & 2 & 16 & 1 & 3 & 0.0008 & 48.8319 & 59594.98 \\
\hline 333 & 2 & 3 & 2 & 16 & 1 & 4 & 0.0008 & 50.0987 & 61121.23 \\
\hline 334 & 2 & 3 & 2 & 16 & 2 & 2 & 0.0008 & 48.2497 & 58852.20 \\
\hline 335 & 2 & 3 & 2 & 16 & 2 & 3 & 0.0008 & 49.4945 & 60526.80 \\
\hline 336 & 2 & 3 & 2 & 16 & 2 & 4 & 0.0008 & 50.7053 & 61904.70 \\
\hline 337 & 2 & 3 & 2 & 17 & 1 & 2 & 0.0008 & 48.8137 & 59594.98 \\
\hline 338 & 2 & 3 & 2 & 17 & 1 & 3 & 0.0008 & 50.0967 & 60971.05 \\
\hline 339 & 2 & 3 & 2 & 17 & 1 & 4 & 0.0008 & 51.4058 & 62801.40 \\
\hline 340 & 2 & 3 & 2 & 17 & 2 & 2 & 0.0008 & 49.4526 & 60230.10 \\
\hline 341 & 2 & 3 & 2 & 17 & 2 & 3 & 0.0008 & 50.743 & 61752.60 \\
\hline 342 & 2 & 3 & 2 & 17 & 2 & 4 & 0.0008 & 52.0293 & 63430.95 \\
\hline 343 & 2 & 3 & 2 & 18 & 1 & 2 & 0.0008 & 50.1727 & 61121.23 \\
\hline 344 & 2 & 3 & 2 & 18 & 1 & 3 & 0.0008 & 51.3485 & 62493.55 \\
\hline 345 & 2 & 3 & 2 & 18 & 1 & 4 & 0.0008 & 52.5967 & 64016.05 \\
\hline 346 & 2 & 3 & 2 & 18 & 2 & 2 & 0.0008 & 50.7502 & 61904.70 \\
\hline 347 & 2 & 3 & 2 & 18 & 2 & 3 & 0.0008 & 52.0258 & 63275.10 \\
\hline 348 & 2 & 3 & 2 & 18 & 2 & 4 & 0.0008 & 53.211 & 64797.60 \\
\hline
\end{tabular}




\begin{tabular}{|c|c|c|c|c|c|c|c|c|c|}
\hline $\begin{array}{c}\text { Scenarios } \\
\text { Number }\end{array}$ & CRANE & LABOR & \begin{tabular}{|c|} 
PUMP \\
TRUCK \\
\end{tabular} & LABOR & BIDWELL & LABOR & \begin{tabular}{|c|} 
Prod. Per \\
Unit Time
\end{tabular} & $\begin{array}{c}\text { Cost Per } \\
\text { Unit Time }\end{array}$ & \begin{tabular}{|c|} 
Cost Per \\
Prod. Unit
\end{tabular} \\
\hline 349 & 2 & 3 & 2 & 19 & 1 & 2 & 0.0008 & 51.3856 & 62493.55 \\
\hline 350 & 2 & 3 & 2 & 19 & 1 & 3 & 0.0008 & 52.6578 & 64173.73 \\
\hline 351 & 2 & 3 & 2 & 19 & 1 & 4 & 0.0008 & 53.8118 & 65538.55 \\
\hline 352 & 2 & 3 & 2 & 19 & 2 & 2 & 0.0008 & 52.0754 & 63430.95 \\
\hline 353 & 2 & 3 & 2 & 19 & 2 & 3 & 0.0008 & 53.2003 & 64797.60 \\
\hline 354 & 2 & 3 & 2 & 19 & 2 & 4 & 0.0008 & 54.4924 & 66320.10 \\
\hline 355 & 2 & 3 & 2 & 20 & 1 & 2 & 0.0008 & 52.6587 & 64173.73 \\
\hline 356 & 2 & 3 & 2 & 20 & 1 & 3 & 0.0008 & 53.8214 & 65699.98 \\
\hline 357 & 2 & 3 & 2 & 20 & 1 & 4 & 0.0008 & 55.1675 & 67226.23 \\
\hline 358 & 2 & 3 & 2 & 20 & 2 & 2 & 0.0008 & 53.2507 & 64957.20 \\
\hline 359 & 2 & 3 & 2 & 20 & 2 & 3 & 0.0008 & 54.5039 & 66483.45 \\
\hline 360 & 2 & 3 & 2 & 20 & 2 & 4 & 0.0008 & 55.808 & 68009.70 \\
\hline 361 & 2 & 4 & 1 & 15 & 1 & 2 & 0.0008 & 44.795 & 53133.30 \\
\hline 362 & 2 & 4 & 1 & 15 & 1 & 3 & 0.0008 & 45.9831 & 54342.45 \\
\hline 363 & 2 & 4 & 1 & 15 & 1 & 4 & 0.0008 & 47.2851 & 55819.95 \\
\hline 364 & 2 & 4 & 1 & 15 & 2 & 2 & 0.0008 & 45.3852 & 53759.50 \\
\hline 365 & 2 & 4 & 1 & 15 & 2 & 3 & 0.0008 & 46.6711 & 55240.75 \\
\hline 366 & 2 & 4 & 1 & 15 & 2 & 4 & 0.0008 & 47.9359 & 56865.60 \\
\hline 367 & 2 & 4 & 1 & 16 & 1 & 2 & 0.0008 & 46.0451 & 54480.38 \\
\hline 368 & 2 & 4 & 1 & 16 & 1 & 3 & 0.0008 & 47.2416 & 55961.63 \\
\hline 369 & 2 & 4 & 1 & 16 & 1 & 4 & 0.0008 & 48.567 & 57588.30 \\
\hline 370 & 2 & 4 & 1 & 16 & 2 & 2 & 0.0008 & 46.6625 & 55380.60 \\
\hline 371 & 2 & 4 & 1 & 16 & 2 & 3 & 0.0008 & 47.9786 & 57009.20 \\
\hline 372 & 2 & 4 & 1 & 16 & 2 & 4 & 0.0008 & 49.1951 & 58203.25 \\
\hline 373 & 2 & 4 & 1 & 17 & 1 & 2 & 0.0008 & 47.2687 & 55961.63 \\
\hline 374 & 2 & 4 & 1 & 17 & 1 & 3 & 0.0008 & 48.572 & 57588.30 \\
\hline 375 & 2 & 4 & 1 & 17 & 1 & 4 & 0.0008 & 49.7334 & 59073.30 \\
\hline 376 & 2 & 4 & 1 & 17 & 2 & 2 & 0.0008 & 47.9728 & 56722.00 \\
\hline 377 & 2 & 4 & 1 & 17 & 2 & 3 & 0.0008 & 49.14 & 58203.25 \\
\hline 378 & 2 & 4 & 1 & 17 & 2 & 4 & 0.0008 & 50.4934 & 59835.60 \\
\hline 379 & 2 & 4 & 1 & 18 & 1 & 2 & 0.0008 & 48.5556 & 57442.88 \\
\hline 380 & 2 & 4 & 1 & 18 & 1 & 3 & 0.0008 & 49.7873 & 59073.30 \\
\hline 381 & 2 & 4 & 1 & 18 & 1 & 4 & 0.0008 & 51.0077 & 60558.30 \\
\hline 382 & 2 & 4 & 1 & 18 & 2 & 2 & 0.0008 & 49.2293 & 58350.60 \\
\hline 383 & 2 & 4 & 1 & 18 & 2 & 3 & 0.0008 & 50.3685 & 59684.50 \\
\hline 384 & 2 & 4 & 1 & 18 & 2 & 4 & 0.0008 & 51.7198 & 61320.60 \\
\hline 385 & 2 & 4 & 1 & 19 & 1 & 2 & 0.0008 & 49.8435 & 59073.30 \\
\hline 386 & 2 & 4 & 1 & 19 & 1 & 3 & 0.0008 & 50.9993 & 60405.38 \\
\hline 387 & 2 & 4 & 1 & 19 & 1 & 4 & 0.0008 & 52.243 & 62043.30 \\
\hline 388 & 2 & 4 & 1 & 19 & 2 & 2 & 0.0008 & 50.4099 & 59835.60 \\
\hline 389 & 2 & 4 & 1 & 19 & 2 & 3 & 0.0008 & 51.67 & 61320.60 \\
\hline 390 & 2 & 4 & 1 & 19 & 2 & 4 & 0.0008 & 52.9958 & 62805.60 \\
\hline 391 & 2 & 4 & 1 & 20 & 1 & 2 & 0.0008 & 51.031 & 60405.38 \\
\hline 392 & 2 & 4 & 1 & 20 & 1 & 3 & 0.0008 & 52.306 & 62043.30 \\
\hline
\end{tabular}




\begin{tabular}{|c|c|c|c|c|c|c|c|c|c|}
\hline \begin{tabular}{c|} 
Scenarios \\
Number
\end{tabular} & CRANE & LABOR & \begin{tabular}{c|} 
PUMP \\
TRUCK
\end{tabular} & LABOR & BIDWELL & LABOR & $\begin{array}{l}\text { Prod. Per } \\
\text { Unit Time }\end{array}$ & \begin{tabular}{|c|} 
Cost Per \\
Unit Time \\
\end{tabular} & $\begin{array}{l}\text { Cost Per } \\
\text { Prod. Unit }\end{array}$ \\
\hline 393 & 2 & 4 & 1 & 20 & 1 & 4 & 0.0008 & \begin{tabular}{|l|}
53.4949 \\
\end{tabular} & 63367.88 \\
\hline 394 & 2 & 4 & 1 & 20 & 2 & 2 & 0.0008 & 51.6254 & 61165.75 \\
\hline 395 & 2 & 4 & 1 & 20 & 2 & 3 & 0.0008 & 52.8773 & 62647.00 \\
\hline 396 & 2 & 4 & 1 & 20 & 2 & 4 & 0.0008 & 54.1408 & 63965.90 \\
\hline 397 & 2 & 4 & 2 & 15 & 1 & 2 & 0.0008 & 477.6418 & 56213.95 \\
\hline 398 & 2 & 4 & 2 & 15 & 1 & 3 & 0.0008 & 48.8715 & 57691.45 \\
\hline 399 & 2 & 4 & 2 & 15 & 1 & 4 & 0.0008 & 50.0676 & 59168.95 \\
\hline 400 & 2 & 4 & 2 & 15 & 2 & 2 & 0.0008 & 48.2897 & 56972.40 \\
\hline 401 & 2 & 4 & 2 & 15 & 2 & 3 & 0.0008 & 49.4822 & 58301.55 \\
\hline 402 & 2 & 4 & 2 & 15 & 2 & 4 & 0.0008 & 50.746 & 59927.40 \\
\hline 403 & 2 & 4 & 2 & 16 & 1 & 2 & 0.0008 & 48.8483 & 57545.03 \\
\hline 404 & 2 & 4 & 2 & 16 & 1 & 3 & 0.0008 & 50.1495 & 59168.95 \\
\hline 405 & 2 & 4 & 2 & 16 & 1 & 4 & 0.0008 & 51.3727 & 60492.53 \\
\hline 406 & 2 & 4 & 2 & 16 & 2 & 2 & 0.0008 & 49.5238 & 58301.55 \\
\hline 407 & 2 & 4 & 2 & 16 & 2 & 3 & 0.0008 & 50.737 & 59775.30 \\
\hline 408 & 2 & 4 & 2 & 16 & 2 & 4 & 0.0008 & 52.0254 & 61249.05 \\
\hline 409 & 2 & 4 & 2 & 17 & 1 & 2 & 0.0008 & 50.145 & 59168.95 \\
\hline 410 & 2 & 4 & 2 & 17 & 1 & 3 & 0.0008 & 51.4261 & 60800.38 \\
\hline 411 & 2 & 4 & 2 & 17 & 1 & 4 & 0.0008 & 52.6175 & 62123.95 \\
\hline 412 & 2 & 4 & 2 & 17 & 2 & 2 & 0.0008 & 50.7879 & 59927.40 \\
\hline 413 & 2 & 4 & 2 & 17 & 2 & 3 & 0.0008 & 52.0542 & 61404.90 \\
\hline 414 & 2 & 4 & 2 & 17 & 2 & 4 & 0.0008 & 53.303 & 62722.80 \\
\hline 415 & 2 & 4 & 2 & 18 & 1 & 2 & 0.0008 & 51.3754 & 60646.45 \\
\hline 416 & 2 & 4 & 2 & 18 & 1 & 3 & 0.0008 & 52.6608 & 62123.95 \\
\hline 417 & 2 & 4 & 2 & 18 & 1 & 4 & 0.0008 & 53.8088 & 63440.03 \\
\hline 418 & 2 & 4 & 2 & 18 & 2 & 2 & 0.0008 & 51.9583 & 61404.90 \\
\hline 419 & 2 & 4 & 2 & 18 & 2 & 3 & 0.0008 & 53.2861 & 62882.40 \\
\hline 420 & 2 & 4 & 2 & 18 & 2 & 4 & 0.0008 & 54.4727 & 64196.55 \\
\hline 421 & 2 & 4 & 2 & 19 & 1 & 2 & 0.0008 & 52.6453 & 61966.28 \\
\hline 422 & 2 & 4 & 2 & 19 & 1 & 3 & 0.0008 & 53.883 & 63440.03 \\
\hline 423 & 2 & 4 & 2 & 19 & 1 & 4 & 0.0008 & 55.1429 & 65078.95 \\
\hline 424 & 2 & 4 & 2 & 19 & 2 & 2 & 0.0008 & 53.2077 & 62722.80 \\
\hline 425 & 2 & 4 & 2 & 19 & 2 & 3 & 0.0008 & 54.5212 & 64359.90 \\
\hline 426 & 2 & 4 & 2 & 19 & 2 & 4 & 0.0008 & 55.7235 & 65670.30 \\
\hline 427 & 2 & 4 & 2 & 20 & 1 & 2 & 0.0008 & 53.8104 & 63440.03 \\
\hline 428 & 2 & 4 & 2 & 20 & 1 & 3 & 0.0008 & 55.1746 & 65078.95 \\
\hline 429 & 2 & 4 & 2 & 20 & 1 & 4 & 0.0008 & 56.3887 & 66387.53 \\
\hline 430 & 2 & 4 & 2 & 20 & 2 & 2 & 0.0008 & 54.5596 & 64359.90 \\
\hline 431 & 2 & 4 & 2 & 20 & 2 & 3 & 0.0008 & 55.8202 & 65837.40 \\
\hline 432 & 2 & 4 & 2 & 20 & 2 & 4 & 0.0008 & 57.0687 & 67144.05 \\
\hline 433 & 2 & 5 & 1 & 15 & 1 & 2 & 0.0009 & 46.0638 & 53239.05 \\
\hline 434 & 2 & 5 & 1 & 15 & 1 & 3 & 0.0009 & 47.3389 & 54828.23 \\
\hline 435 & 2 & 5 & 1 & 15 & 1 & 4 & 0.0009 & 48.5447 & 56134.05 \\
\hline 436 & 2 & 5 & 1 & 15 & 2 & 2 & 0.0009 & 46.6953 & 53982.10 \\
\hline
\end{tabular}




\begin{tabular}{|c|c|c|c|c|c|c|c|c|c|}
\hline \begin{tabular}{c|} 
Scenarios \\
Number
\end{tabular} & CRANE & LABOR & \begin{tabular}{c|} 
PUMP \\
TRUCK
\end{tabular} & LABOR & BIDWELL & LABOR & $\begin{array}{l}\text { Prod. Per } \\
\text { Unit Time }\end{array}$ & \begin{tabular}{|c|} 
Cost Per \\
Unit Time \\
\end{tabular} & $\begin{array}{l}\text { Cost Per } \\
\text { Prod. Unit }\end{array}$ \\
\hline 437 & 2 & 5 & 1 & 15 & 2 & 3 & 0.0009 & \begin{tabular}{|l|}
47.9195 \\
\end{tabular} & 55429.60 \\
\hline 438 & 2 & 5 & 1 & 15 & 2 & 4 & 0.0009 & 49.1209 & 56877.10 \\
\hline 439 & 2 & 5 & 1 & 16 & 1 & 2 & 0.0009 & 47.3295 & 54828.23 \\
\hline 440 & 2 & 5 & 1 & 16 & 1 & 3 & 0.0009 & 48.5029 & 56134.05 \\
\hline 441 & 2 & 5 & 1 & 16 & 1 & 4 & 0.0009 & 49.7382 & 57581.55 \\
\hline 442 & 2 & 5 & 1 & 16 & 2 & 2 & 0.0009 & 47.9771 & 55429.60 \\
\hline 443 & 2 & 5 & 1 & 16 & 2 & 3 & 0.0009 & 49.1417 & 56729.75 \\
\hline 444 & 2 & 5 & 1 & 16 & 2 & 4 & 0.0009 & 50.4917 & 58626.80 \\
\hline 445 & 2 & 5 & 1 & 17 & 1 & 2 & 0.0009 & 48.5781 & 56279.48 \\
\hline 446 & 2 & 5 & 1 & 17 & 1 & 3 & 0.0009 & 49.7474 & 57581.55 \\
\hline 447 & 2 & 5 & 1 & 17 & 1 & 4 & 0.0009 & 51.0972 & 58876.13 \\
\hline 448 & 2 & 5 & 1 & 17 & 2 & 2 & 0.0009 & 49.179 & 57024.45 \\
\hline 449 & 2 & 5 & 1 & 17 & 2 & 3 & 0.0009 & 50.4293 & 58324.60 \\
\hline 450 & 2 & 5 & 1 & 17 & 2 & 4 & 0.0009 & 51.6448 & 59772.10 \\
\hline 451 & 2 & 5 & 1 & 18 & 1 & 2 & 0.0009 & \begin{tabular}{|l|}
49.7861 \\
\end{tabular} & 57730.73 \\
\hline 452 & 2 & 5 & 1 & 18 & 1 & 3 & 0.0009 & 51.0169 & 59029.05 \\
\hline 453 & 2 & 5 & 1 & 18 & 1 & 4 & 0.0009 & 52.2521 & 60476.55 \\
\hline 454 & 2 & 5 & 1 & 18 & 2 & 2 & 0.0009 & 50.4403 & 58475.70 \\
\hline 455 & 2 & 5 & 1 & 18 & 2 & 3 & 0.0009 & 51.6549 & 59772.10 \\
\hline 456 & 2 & 5 & 1 & 18 & 2 & 4 & 0.0009 & 52.8999 & 61061.00 \\
\hline 457 & 2 & 5 & 1 & 19 & 1 & 2 & 0.0009 & 51.0227 & 59029.05 \\
\hline 458 & 2 & 5 & 1 & 19 & 1 & 3 & 0.0009 & 52.3125 & 60476.55 \\
\hline 459 & 2 & 5 & 1 & 19 & 1 & 4 & 0.0009 & 53.5873 & 62084.48 \\
\hline 460 & 2 & 5 & 1 & 19 & 2 & 2 & 0.0009 & 51.747 & 59926.95 \\
\hline 461 & 2 & 5 & 1 & 19 & 2 & 3 & 0.0009 & 52.9197 & 61219.60 \\
\hline 462 & 2 & 5 & 1 & 19 & 2 & 4 & 0.0009 & 54.1959 & 62667.10 \\
\hline 463 & 2 & 5 & 1 & 20 & 1 & 2 & 0.0009 & 52.3083 & 60476.55 \\
\hline 464 & 2 & 5 & 1 & 20 & 1 & 3 & 0.0009 & 53.5696 & 62084.48 \\
\hline 465 & 2 & 5 & 1 & 20 & 1 & 4 & 0.0009 & 54.756 & 63207.38 \\
\hline 466 & 2 & 5 & 1 & 20 & 2 & 2 & 0.0009 & 52.8732 & 61061.00 \\
\hline 467 & 2 & 5 & 1 & 20 & 2 & 3 & 0.0009 & 54.2245 & 62667.10 \\
\hline 468 & 2 & 5 & 1 & 20 & 2 & 4 & 0.0009 & 55.4767 & 64114.60 \\
\hline 469 & 2 & 5 & 2 & 15 & 1 & 2 & 0.0009 & 48.9053 & 56080.78 \\
\hline 470 & 2 & 5 & 2 & 15 & 1 & 3 & 0.0009 & 50.068 & 57366.85 \\
\hline 471 & 2 & 5 & 2 & 15 & 1 & 4 & 0.0009 & 51.3278 & 58799.35 \\
\hline 472 & 2 & 5 & 2 & 15 & 2 & 2 & 0.0009 & 49.4952 & 56521.35 \\
\hline 473 & 2 & 5 & 2 & 15 & 2 & 3 & 0.0009 & 50.7948 & 58254.30 \\
\hline 474 & 2 & 5 & 2 & 15 & 2 & 4 & 0.0009 & 51.9524 & 59534.70 \\
\hline 475 & 2 & 5 & 2 & 16 & 1 & 2 & 0.0009 & 50.1486 & 57366.85 \\
\hline 476 & 2 & 5 & 2 & 16 & 1 & 3 & 0.0009 & 51.4261 & 58953.28 \\
\hline 477 & 2 & 5 & 2 & 16 & 1 & 4 & 0.0009 & 52.5885 & 60074.18 \\
\hline 478 & 2 & 5 & 2 & 16 & 2 & 2 & 0.0009 & 50.7976 & 58102.20 \\
\hline 479 & 2 & 5 & 2 & 16 & 2 & 3 & 0.0009 & 52.0606 & 59534.70 \\
\hline 480 & 2 & 5 & 2 & 16 & 2 & 4 & 0.0009 & 53.2959 & 60967.20 \\
\hline
\end{tabular}




\begin{tabular}{|c|c|c|c|c|c|c|c|c|c|}
\hline $\begin{array}{c}\text { Scenarios } \\
\text { Number }\end{array}$ & CRANE & LABOR & \begin{tabular}{c|} 
PUMP \\
TRUCK
\end{tabular} & LABOR & BIDWELL & LABOR & $\begin{array}{l}\text { Prod. Per } \\
\text { Unit Time }\end{array}$ & \begin{tabular}{|c|} 
Cost Per \\
Unit Time \\
\end{tabular} & $\begin{array}{l}\text { Cost Per } \\
\text { Prod. Unit }\end{array}$ \\
\hline 481 & 2 & 5 & 2 & 17 & 1 & 2 & 0.0009 & \begin{tabular}{|l|}
51.3337 \\
\end{tabular} & 58799.35 \\
\hline 482 & 2 & 5 & 2 & 17 & 1 & 3 & 0.0009 & 52.6069 & 60231.85 \\
\hline 483 & 2 & 5 & 2 & 17 & 1 & 4 & 0.0009 & 53.8849 & 61664.35 \\
\hline 484 & 2 & 5 & 2 & 17 & 2 & 2 & 0.0009 & 52.0027 & 59690.55 \\
\hline 485 & 2 & 5 & 2 & 17 & 2 & 3 & 0.0009 & 53.2008 & 60967.20 \\
\hline 486 & 2 & 5 & 2 & 17 & 2 & 4 & 0.0009 & 54.5446 & 62399.70 \\
\hline 487 & 2 & 5 & 2 & 18 & 1 & 2 & 0.0009 & 52.6841 & 60389.53 \\
\hline 488 & 2 & 5 & 2 & 18 & 1 & 3 & 0.0009 & 53.891 & 61664.35 \\
\hline 489 & 2 & 5 & 2 & 18 & 1 & 4 & 0.0009 & 55.2011 & 63096.85 \\
\hline 490 & 2 & 5 & 2 & 18 & 2 & 2 & 0.0009 & 53.2958 & 60807.60 \\
\hline 491 & 2 & 5 & 2 & 18 & 2 & 3 & 0.0009 & 54.4774 & 62399.70 \\
\hline 492 & 2 & 5 & 2 & 18 & 2 & 4 & 0.0009 & 55.8306 & 63832.20 \\
\hline 493 & 2 & 5 & 2 & 19 & 1 & 2 & 0.0009 & 53.9297 & 61664.35 \\
\hline 494 & 2 & 5 & 2 & 19 & 1 & 3 & 0.0009 & 55.0693 & 62931.68 \\
\hline 495 & 2 & 5 & 2 & 19 & 1 & 4 & 0.0009 & 56.338 & 64529.35 \\
\hline 496 & 2 & 5 & 2 & 19 & 2 & 2 & 0.0009 & 54.485 & 62399.70 \\
\hline 497 & 2 & 5 & 2 & 19 & 2 & 3 & 0.0009 & 55.7842 & 63999.30 \\
\hline 498 & 2 & 5 & 2 & 19 & 2 & 4 & 0.0009 & 57.0506 & 65264.70 \\
\hline 499 & 2 & 5 & 2 & 20 & 1 & 2 & 0.0009 & 55.1968 & 63262.03 \\
\hline 500 & 2 & 5 & 2 & 20 & 1 & 3 & 0.0009 & 56.3918 & 64529.35 \\
\hline 501 & 2 & 5 & 2 & 20 & 1 & 4 & 0.0009 & 57.5879 & 65789.18 \\
\hline 502 & 2 & 5 & 2 & 20 & 2 & 2 & 0.0009 & 55.7463 & 63832.20 \\
\hline 503 & 2 & 5 & 2 & 20 & 2 & 3 & 0.0009 & 57.0359 & 65264.70 \\
\hline 504 & 2 & 5 & 2 & 20 & 2 & 4 & 0.0009 & 58.2957 & 66522.60 \\
\hline 505 & 2 & 6 & 1 & 15 & 1 & 2 & 0.0009 & 47.3431 & 54403.20 \\
\hline 506 & 2 & 6 & 1 & 15 & 1 & 3 & 0.0009 & 48.5797 & 55697.78 \\
\hline 507 & 2 & 6 & 1 & 15 & 1 & 4 & 0.0009 & \begin{tabular}{|l|}
49.7471 \\
\end{tabular} & 56835.68 \\
\hline 508 & 2 & 6 & 1 & 15 & 2 & 2 & 0.0009 & 47.9458 & 54855.20 \\
\hline 509 & 2 & 6 & 1 & 15 & 2 & 3 & 0.0009 & 49.2154 & 56287.70 \\
\hline 510 & 2 & 6 & 1 & 15 & 2 & 4 & 0.0009 & \begin{tabular}{|l|}
50.4548 \\
\end{tabular} & 57720.20 \\
\hline 511 & 2 & 6 & 1 & 16 & 1 & 2 & 0.0009 & 48.5647 & 55552.35 \\
\hline 512 & 2 & 6 & 1 & 16 & 1 & 3 & 0.0009 & 49.8363 & 57134.03 \\
\hline 513 & 2 & 6 & 1 & 16 & 1 & 4 & 0.0009 & 51.0656 & 58570.28 \\
\hline 514 & 2 & 6 & 1 & 16 & 2 & 2 & 0.0009 & 49.1196 & 56140.35 \\
\hline 515 & 2 & 6 & 1 & 16 & 2 & 3 & 0.0009 & 50.4045 & 57720.20 \\
\hline 516 & 2 & 6 & 1 & 16 & 2 & 4 & 0.0009 & 51.6764 & 59307.55 \\
\hline 517 & 2 & 6 & 1 & 17 & 1 & 2 & 0.0009 & 49.7819 & 56984.85 \\
\hline 518 & 2 & 6 & 1 & 17 & 1 & 3 & 0.0009 & 50.9937 & 58570.28 \\
\hline 519 & 2 & 6 & 1 & 17 & 1 & 4 & 0.0009 & 52.2548 & 59849.85 \\
\hline 520 & 2 & 6 & 1 & 17 & 2 & 2 & 0.0009 & \begin{tabular}{|l|}
50.4626 \\
\end{tabular} & 57720.20 \\
\hline 521 & 2 & 6 & 1 & 17 & 2 & 3 & 0.0009 & 51.6311 & 58997.85 \\
\hline 522 & 2 & 6 & 1 & 17 & 2 & 4 & 0.0009 & 52.952 & 60585.20 \\
\hline 523 & 2 & 6 & 1 & 18 & 1 & 2 & 0.0009 & 51.0642 & 58570.28 \\
\hline 524 & 2 & 6 & 1 & 18 & 1 & 3 & 0.0009 & 52.2378 & 59849.85 \\
\hline
\end{tabular}




\begin{tabular}{|c|c|c|c|c|c|c|c|c|c|}
\hline \begin{tabular}{c|} 
Scenarios \\
Number
\end{tabular} & CRANE & LABOR & \begin{tabular}{c|} 
PUMP \\
TRUCK \\
\end{tabular} & LABOR & BIDWELL & LABOR & $\begin{array}{l}\text { Prod. Per } \\
\text { Unit Time } \\
\end{array}$ & \begin{tabular}{|c|} 
Cost Per \\
Unit Time \\
\end{tabular} & $\begin{array}{c}\text { Cost Per } \\
\text { Prod. Unit }\end{array}$ \\
\hline 525 & 2 & 6 & 1 & 18 & 1 & 4 & 0.0009 & 53.4799 & 61442.78 \\
\hline 526 & 2 & 6 & 1 & 18 & 2 & 2 & 0.0009 & 51.726 & 59307.55 \\
\hline 527 & 2 & 6 & 1 & 18 & 2 & 3 & 0.0009 & 52.8928 & 60585.20 \\
\hline 528 & 2 & 6 & 1 & 18 & 2 & 4 & 0.0009 & 54.1478 & 62017.70 \\
\hline 529 & 2 & 6 & 1 & 19 & 1 & 2 & 0.0009 & 52.2438 & 59693.18 \\
\hline 530 & 2 & 6 & 1 & 19 & 1 & 3 & 0.0009 & 53.5756 & 61282.35 \\
\hline 531 & 2 & 6 & 1 & 19 & 1 & 4 & 0.0009 & 54.7813 & 62714.85 \\
\hline 532 & 2 & 6 & 1 & 19 & 2 & 2 & 0.0009 & 52.9117 & 60426.60 \\
\hline 533 & 2 & 6 & 1 & 19 & 2 & 3 & 0.0009 & 54.2267 & 62180.05 \\
\hline 534 & 2 & 6 & 1 & 19 & 2 & 4 & 0.0009 & 55.4166 & 63450.20 \\
\hline 535 & 2 & 6 & 1 & 20 & 1 & 2 & 0.0009 & 53.5682 & 61442.78 \\
\hline 536 & 2 & 6 & 1 & 20 & 1 & 3 & 0.0009 & 54.7746 & 62714.85 \\
\hline 537 & 2 & 6 & 1 & 20 & 1 & 4 & 0.0009 & 56.1171 & 64315.28 \\
\hline 538 & 2 & 6 & 1 & 20 & 2 & 2 & 0.0009 & 54.2135 & 62017.70 \\
\hline 539 & 2 & 6 & 1 & 20 & 2 & 3 & 0.0009 & 55.4902 & 63450.20 \\
\hline 540 & 2 & 6 & 1 & 20 & 2 & 4 & 0.0009 & 56.6805 & 65052.55 \\
\hline 541 & 2 & 6 & 2 & 15 & 1 & 2 & 0.0009 & 50.1693 & 57216.68 \\
\hline 542 & 2 & 6 & 2 & 15 & 1 & 3 & 0.0009 & 51.4195 & 58645.43 \\
\hline 543 & 2 & 6 & 2 & 15 & 1 & 4 & 0.0009 & 52.6649 & 60074.18 \\
\hline 544 & 2 & 6 & 2 & 15 & 2 & 2 & 0.0009 & 50.7375 & 57950.10 \\
\hline 545 & 2 & 6 & 2 & 15 & 2 & 3 & 0.0009 & \begin{tabular}{|l|}
52.0098 \\
\end{tabular} & 59223.00 \\
\hline 546 & 2 & 6 & 2 & 15 & 2 & 4 & 0.0009 & 53.2515 & 60488.40 \\
\hline 547 & 2 & 6 & 2 & 16 & 1 & 2 & 0.0009 & 51.3158 & 58491.50 \\
\hline 548 & 2 & 6 & 2 & 16 & 1 & 3 & 0.0009 & \begin{tabular}{|l|}
52.6067 \\
\end{tabular} & 60074.18 \\
\hline 549 & 2 & 6 & 2 & 16 & 1 & 4 & 0.0009 & 53.908 & 61502.93 \\
\hline 550 & 2 & 6 & 2 & 16 & 2 & 2 & 0.0009 & \begin{tabular}{|l|}
52.0738 \\
\end{tabular} & 59223.00 \\
\hline 551 & 2 & 6 & 2 & 16 & 2 & 3 & 0.0009 & 53.3081 & 60807.60 \\
\hline 552 & 2 & 6 & 2 & 16 & 2 & 4 & 0.0009 & 54.5924 & 62236.35 \\
\hline 553 & 2 & 6 & 2 & 17 & 1 & 2 & 0.0009 & 52.6284 & 60074.18 \\
\hline 554 & 2 & 6 & 2 & 17 & 1 & 3 & 0.0009 & 53.8146 & 61341.50 \\
\hline 555 & 2 & 6 & 2 & 17 & 1 & 4 & 0.0009 & 55.0953 & 62766.50 \\
\hline 556 & 2 & 6 & 2 & 17 & 2 & 2 & 0.0009 & 53.3067 & 60648.00 \\
\hline 557 & 2 & 6 & 2 & 17 & 2 & 3 & 0.0009 & 54.4564 & 62236.35 \\
\hline 558 & 2 & 6 & 2 & 17 & 2 & 4 & 0.0009 & \begin{tabular}{|l|}
55.7677 \\
\end{tabular} & 63498.00 \\
\hline 559 & 2 & 6 & 2 & 18 & 1 & 2 & 0.0009 & 53.8231 & 61341.50 \\
\hline 560 & 2 & 6 & 2 & 18 & 1 & 3 & 0.0009 & 55.1808 & 62766.50 \\
\hline 561 & 2 & 6 & 2 & 18 & 1 & 4 & 0.0009 & 56.4188 & 64191.50 \\
\hline 562 & 2 & 6 & 2 & 18 & 2 & 2 & 0.0009 & 54.5441 & 62073.00 \\
\hline 563 & 2 & 6 & 2 & 18 & 2 & 3 & 0.0009 & 55.7832 & 63498.00 \\
\hline 564 & 2 & 6 & 2 & 18 & 2 & 4 & 0.0009 & \begin{tabular}{|l|}
57.0566 \\
\end{tabular} & 64923.00 \\
\hline 565 & 2 & 6 & 2 & 19 & 1 & 2 & 0.0009 & 55.1836 & 62931.68 \\
\hline 566 & 2 & 6 & 2 & 19 & 1 & 3 & 0.0009 & 56.3413 & 64360.43 \\
\hline 567 & 2 & 6 & 2 & 19 & 1 & 4 & 0.0009 & 57.5855 & 65443.83 \\
\hline 568 & 2 & 6 & 2 & 19 & 2 & 2 & 0.0009 & 55.8124 & 63498.00 \\
\hline
\end{tabular}




\begin{tabular}{|c|c|c|c|c|c|c|c|c|c|}
\hline $\begin{array}{c}\text { Scenarios } \\
\text { Number }\end{array}$ & CRANE & LABOR & $\begin{array}{c}\text { PUMP } \\
\text { TRUCK }\end{array}$ & LABOR & BIDWELL & LABOR & $\begin{array}{c}\text { Prod. Per } \\
\text { Unit Time }\end{array}$ & $\begin{array}{c}\text { Cost Per } \\
\text { Unit Time }\end{array}$ & $\begin{array}{c}\text { Cost Per } \\
\text { Prod. Unit }\end{array}$ \\
\hline 569 & 2 & 6 & 2 & 19 & 2 & 3 & 0.0009 & 57.0589 & 64923.00 \\
\hline 570 & 2 & 6 & 2 & 19 & 2 & 4 & 0.0009 & 58.2359 & 66348.00 \\
\hline 571 & 2 & 6 & 2 & 20 & 1 & 2 & 0.0009 & 56.4141 & 64191.50 \\
\hline 572 & 2 & 6 & 2 & 20 & 1 & 3 & 0.0009 & 57.6219 & 65443.83 \\
\hline 573 & 2 & 6 & 2 & 20 & 1 & 4 & 0.0009 & 58.8683 & 66865.08 \\
\hline 574 & 2 & 6 & 2 & 20 & 2 & 2 & 0.0009 & 57.0533 & 64923.00 \\
\hline 575 & 2 & 6 & 2 & 20 & 2 & 3 & 0.0009 & 58.205 & 66348.00 \\
\hline 576 & 2 & 6 & 2 & 20 & 2 & 4 & 0.0009 & 59.5487 & 67773.00 \\
\hline
\end{tabular}




\section{REFERENCES}

Alampalli, S., O’Connor, J., Yannotti, A. P., and Luu, K. T. (1999). “Fiber-reinforced plastics for bridge construction and rehabilitation in New York." Materials and Construction:

Exploring the connection, Proc., $5^{\text {th }}$ Materials Engineering Congress, L. C. Bank, ed., ASCE, Reston, Va., 344-350.

Busel, P. John and Lockwood, D. James (2002). "Product selection guide: FRP composite products for Bridge applications.” The Market Development Alliance of the FRP Composites Industry, Harrison, NY.

Cape Girardeau Bridge, Cape Girardeau, Missouri. (2004)

$<$ http://traylor.com/pages/map/bridges.html> (April.04.2004)

Composite World (2003). “Composite Industry Overview.” Ray Publishing Inc., <http://www.compositesworld.com/sb/ov-introduction> (Nov. 6, 2003).

Creative Pultrusions (CP) (2003). “Corporate Information.” Creative Pultrusions, Inc., $<$ http://www.creativepultrusions.com/corporate.html> (Nov. 12, 2003).

Current Practices in FRP Composites Technology FRP Bridge Decks and Superstructures. (2003). <http://www.fhwa.dot.gov/bridge/frp/deckproj.htm> (Oct.04.2003)

Ehlen, Mark A. (1999). “Life Cycle Costs of Fiber-Reinforced-Polymer Bridge Decks.” Journal of Materials in Civil Engineering, ASCE, 11(3), 224-230

Ehlen, Mark A. (1997). “Life Cycle Costs of New Construction Materials.” Journal of Infrastructure Systems, ASCE, Vol. 3, No. 4, pp. 129-133.

European Pultrusion Technology Association (EPTA) (2003). “What is pultrusion?” $<$ http://www.pultruders.com> (Oct. 5, 2003).

Gall, T. L. (1986). Engineers’ Guide to Composite Materials. American Society for Metals.

Goldstein, H. (1996). “Catching up on Composites.” Civil Engineering, ASCE, March, pp. 47-49.

Halpin, D. W. and Riggs, L. S. (1992). Planning and analysis of construction operations. John Wiley \& Sons, Inc., New York, NY.

Hardcore Composites (2003). “About Hardcore.” Hardcore Comopsites Inc., <http://www.hardcorecomposites.com/about.html> (Jul. 23, 2003). 
Henry, J.A. (1985). "Deck girders system for highway bridges using fiber reinforced plastics.” M.S. Thesis, North Carolina State University, NC.

Infrastructure Composites International (ICI) (2003). "Who are we.” Infrastructure Composites International Inc., < http://www.infracomp.com/index.html> (Jul.22, 2003).

Kansas Structural Composites Inc. (KSCI) (2003). “Company profile.” Kansas Structural Composites, Inc. <http://www.ksci.com/> (Jun. 12, 2003).

Kelly, A. (Ed.). (1989). Concise Encyclopedia of Composite Materials, Pergamon Press plc, Oxford, England.

Kelton, W. D., Sadowski, R. P., and Sadowski, D. A. (2002). "Simulation with ARENA," $2^{\text {nd }}$ edition, McGraw-Hill, New York, NY., 3-15.

Martin Marietta Composites (MMC). (2003). “Composite Materials Overview.” Martin Marietta Composites Inc., <http://www.martinmarietta.com/Products/composites. asp> (Oct. 12, 2003).

Mirmiran, A. (1995). “Concrete Composite Construction for Durability and Strength.” Proceedings of the Symposium on Extending Life Span of Structures, International Association for Bridge and Structural Engineering, San Francisco, CA, pp. 1155-1160.

Moder, J. J., Philips, C. R., and Davis, E. W. (1983). "Project management with CPM, PERT and precedence diagramming.” $3^{\text {rd }}$ Ed., Van Nostrand Reinhold Company, New York, NY, 1983.

Mouritz, A. P., and Mathys, Z. (1999). "Post-fire mechanical properties of marine polymer composites.” Composites Structure, 47(1), 643-653.

Nystrom, H. E., Watkins, S. E., Nanni, A., and Murray, S. (2003). "Financial viability of fiberreinforced polymer (FRP) bridges.” Journal of Management Engineering, 19(1), 2-8.

O'Connor, Jerry (2003). “FRP Decks and Superstructures: Current Practice.” FHA, < http://www.fhwa.dot.gov/bridge/frp/deckprac.htm> (Dec.4, 2003).

Plecnik, J. M., and Azar, W. A. (1991). "Structural components, highway bridge deck applications.” International Encyclopedia of composites, I. Lee and M. Stuart (eds), Vol. 6, pp.430-445.

RS Means book (2003) Building Construction Cost Data, Kingston, MA.

Tang, Benjamin and Podolny, Walter Jr. (1998). “A Successful Beginning for Fiber Reinforced Polymer (FRP) Composite Materials in Bridge Applications.” Proc., Int. Conf. on Corrosion and Rehabilitation of Reinforced Concrete Structures, December 7-11, 1998, Orlando, FL. 
Reeve, Scott R. (2000). “FRP Composite Bridge Decks: Barriers to Market Development” National Composites Center, Kettering, Ohio.

River, J., and Karbhar, V. M. (2002). “Cold-temperature and simultaneous aqueous environment related degradation of carbon/vinylester composites.” Composites Part B: Engineering, Elsevier Science Ltd., 33(1), 17-24.

Project $100<$ http://www.compositecenter.org/Infra/Project\%20100/Project\%20100.php> (March 22, 2004.)

Schaeuble, B. (2001). "Simulation of concrete operations advanced vertical formwork systems." Independent Research Study, Purdue University, W. Lafayette, IN.

Sieble, F. and Karbhari, V. (1996). “Advanced Composites for Civil Engineering Applications in the United States.” University of California, San Diego, CA.

Seible, F. and Karbhari, V. (1996). "Advanced Composites Build on Success," Civil Engineering, ASCE, August, Vol.66, No. 8, pp. 44-47.

Smith, S.A., Emmanwori, L.L., Sadler, R.L., and Shivakumar, K.N. (2000). "Evaluation of Composite sandwich panels fabricated using vacuum assisted resin transfer molding." Center for Composite Materials Research, North Carolina A\&T State University, Greensboro, NC.

Solomon, G. and Sams, M. (2003). "Fiber-Reinforced Polymer (FRP) bridge deck panels DuraSpan $^{\text {TM } ”, ~ D e p a r t m e n t ~ o f ~ C i v i l ~ E n g i n e e r i n g ~ S e m i n a r, ~ O c t . ~ 2003, ~ P u r d u e ~ U n i v e r s i t y, ~}$ West Lafayette, IN.

SPI Composites Institute (1998). "A Look at the World's FRP Composites Bridges." A publication of the Market Development Alliance, New York, 1998.

Strongwell (2003). "Bridge supersturure and deck system components and applications.” Strongwell, Inc., <http://www.strongwell.com/specialproducts/bridgesdecks.htm \#decks> (Oct.13, 2003).

Tang, B. and Podolny, W. (1998). “A successful beginning for fiber reinforced polymer (FRP) composite materials in bridge applications.” FHWA Proceeding, International Conference on corrosion and rehabilitation of reinforced concrete structures, Orlando, FL.

Yost, J. R. and Schmeckpeper, E. R. (2001). "Strength and serviceability of FRP grid reinforced bridge decks.” Journal of Bridge Engineering, ASCE, Vol. 6, No. 6, pp. 605-612.

Zhou, A., Lesko, J. J., and Davalos, J. F. (2001). "Fiber reinforced polymer decks for bridge systems.” COMPOSITES 2001, Convention and Trade Show, Composite Fabrications Association (CFS), Tampa, FL, Oct. 2001. 
Zureick, A, Shin, B., and Munley, E. (1995). "Fiber-reinforced polymeric bridge decks.” Structural Engineering Review, 7(3), Aug. 1995, pp. 257-266. 